\title{
A macro-econometric model for Lithuania LITMOD
}

\author{
Celov, D.; Vilkas, E.; Grinderslev, D.; Møller Andersen, F.
}

Publication date:

2004

Document Version

Publisher's PDF, also known as Version of record

Link back to DTU Orbit

Citation (APA):

Celov, D., Vilkas, E., Grinderslev, D., \& Møller Andersen, F. (2004). A macro-econometric model for Lithuania LITMOD. LMA Ekonomikos Institutas.

\section{General rights}

Copyright and moral rights for the publications made accessible in the public portal are retained by the authors and/or other copyright owners and it is a condition of accessing publications that users recognise and abide by the legal requirements associated with these rights.

- Users may download and print one copy of any publication from the public portal for the purpose of private study or research.

- You may not further distribute the material or use it for any profit-making activity or commercial gain

- You may freely distribute the URL identifying the publication in the public portal

If you believe that this document breaches copyright please contact us providing details, and we will remove access to the work immediately and investigate your claim. 
$\square \square$

LMA Ekonomikos Institutas

Dmitry Celov

Eduardas Vilkas
Risø National Laboratory

Dorte Grinderslev

Frits Møller Andersen

\section{A Macro-Econometric Model for Lithuania LITMOD}

December 2003 


\section{Preface}

This report presents theoretical considerations and analyses of past developments related to the formulation of a macro-econometric model of the Lithuanian economy called LITMOD. In addition, a few analyses using the model for simulation of scenarios are included.

The purpose of the model is to describe the structure and the short to medium-term development in Lithuanian economy, to secure internal consistency in economic analyses and to assist a structured thinking on economical development and policy issues.

The work presented in the report is part of a Danish/British Energy Pre-Accession Project for the Lithuanian Ministry of Economy supported by the Danish Energy Authority and the British Department of Trade and Industry. A focus in the overall project is the development of the energy consumption. However, to obtain reliable forecasts of energy demand, reliable forecasts of the economical development in sectors are needed. The present model is a further development of the LITMOD developed within the Ministry of Economy and the Authors are very grateful for the support and kind assistance from State Secretary Gediminas Miškinis and Head of Economy Development Policy Division Arvydas Kazlauskas. The Ministry of Economy has the authority to use and distribute the present model to potential users.

To be useful, economic models and especially econometric models need regular revisions, updating, and re-estimations. The present version of LITMOD may be seen as one step in developing applicable macro-economic models for Lithuania. The present model is useful for general analyses of the Lithuanian economy. However, for more detailed analyses, a further disaggregation of parts of the model is required as well as the inclusion of additional submodels. In addition, as further data becomes available, the basis for the description of individual model parts and equations may be changed to become more realistic, thus making the modelling more reliable. Growing interest to mathematical modelling of the Lithuanian economy, to which LITMOD makes a positive input, recently led to the formation of the LEMM project at Vilnius University. The LEMM project is carried out in collaboration between the Institute of Economics and the Institute of Mathematics and Informatics and will during the next three years, aim to develop a multipurpose set of models for detailed analysis and forecasting of the Lithuanian economy. LITMOD may serve as a starting point in the development of at least some components of the LEMM project. 


\section{Table of Contents}

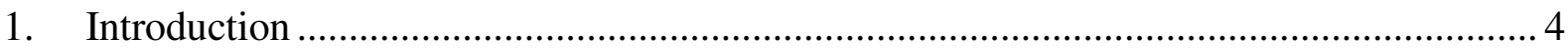

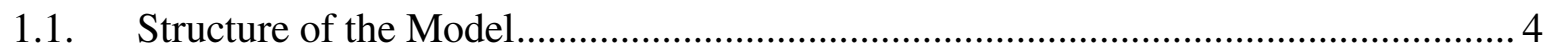

1.2. Specification of Equations ................................................................................ 5

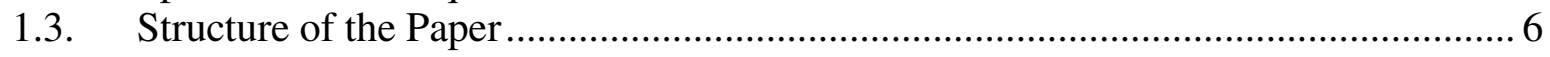

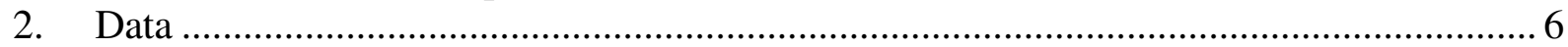

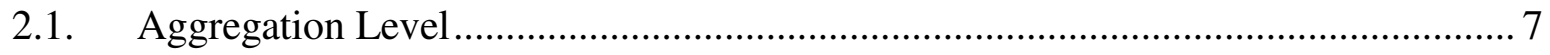

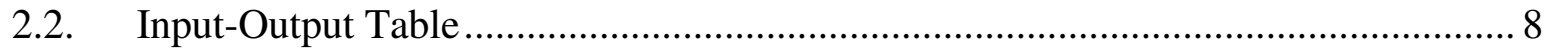

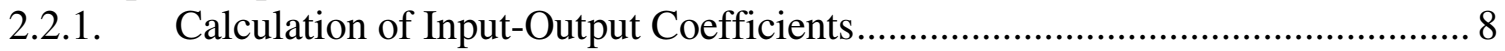

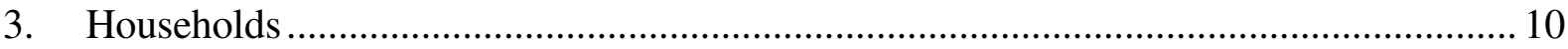

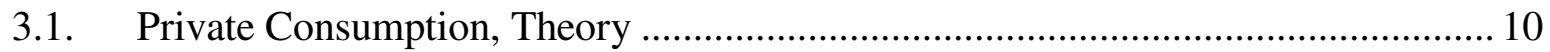

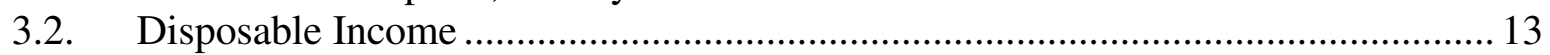

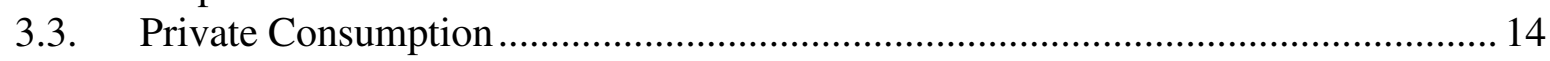

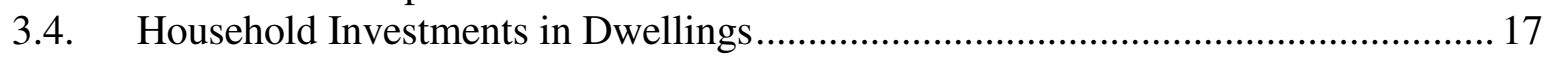

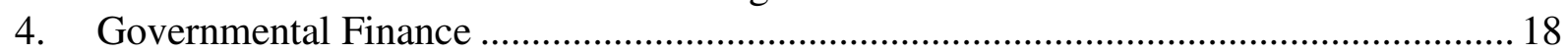

4.1. Government Consumption .............................................................................. 19

4.2. Government Revenue and Balance ................................................................. 19

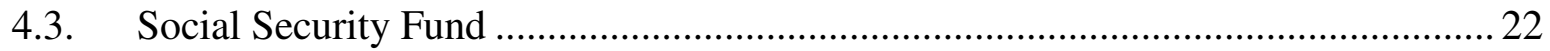

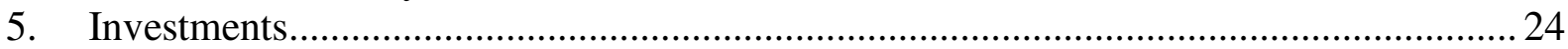

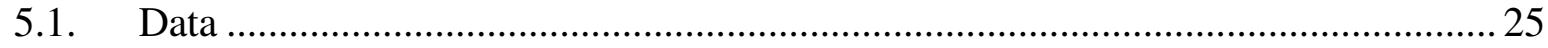

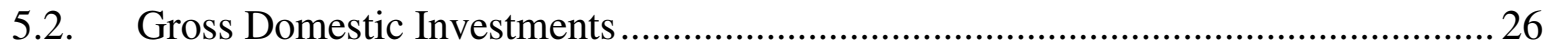

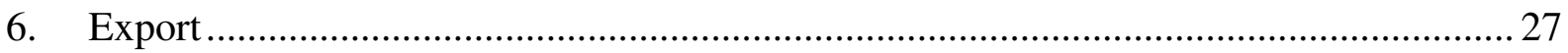

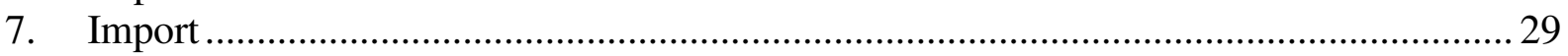

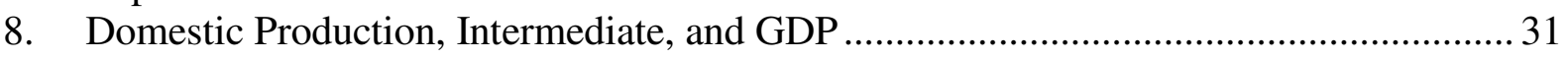

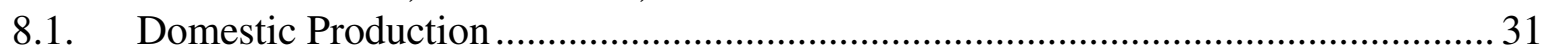

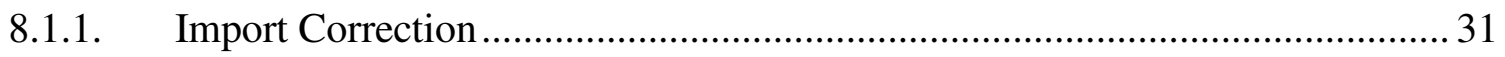

8.1.2. Corrections between Sectors and Quarters................................................ 31

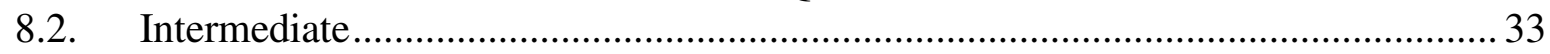

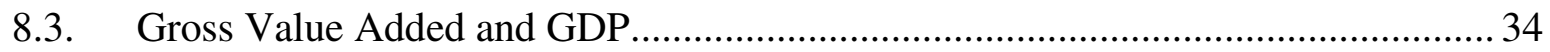

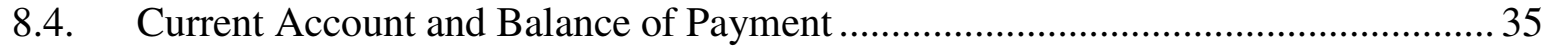

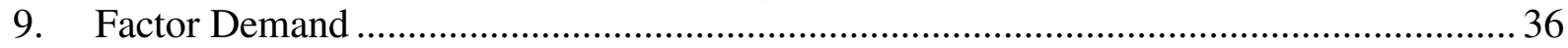

9.1. Production Function and Factor Demand Equations............................................. 36

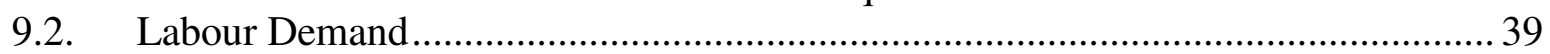

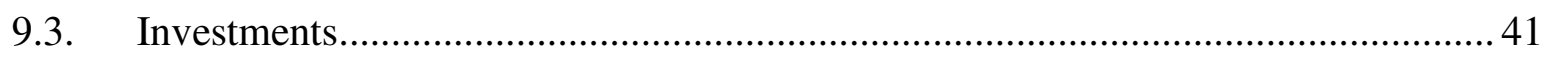

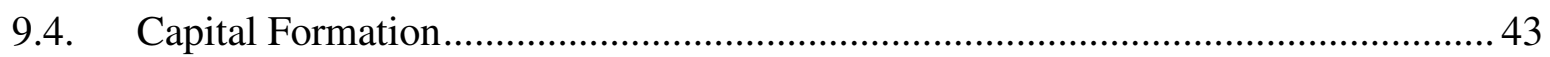

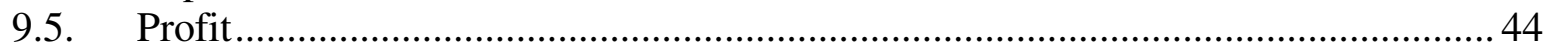

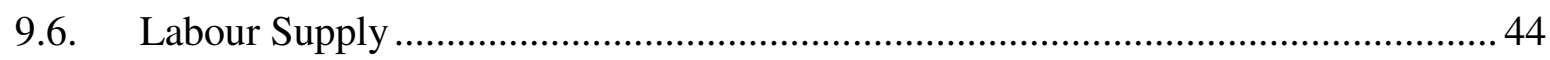

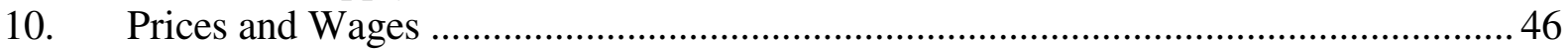

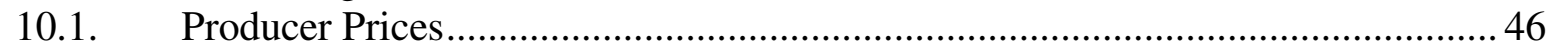

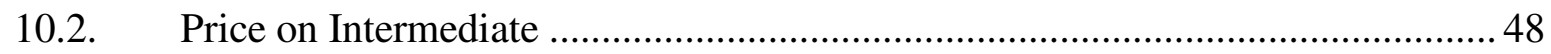

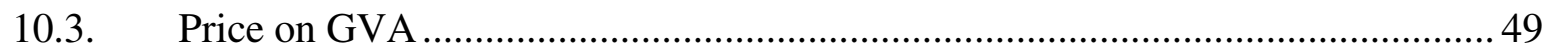

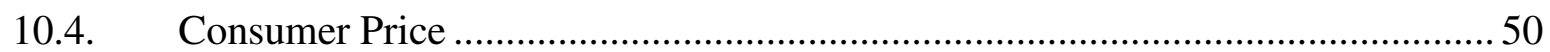

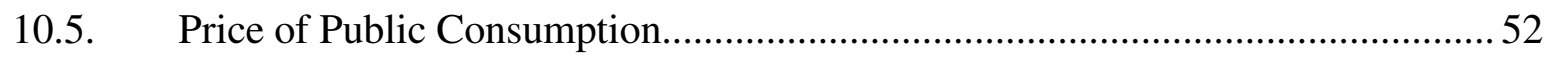

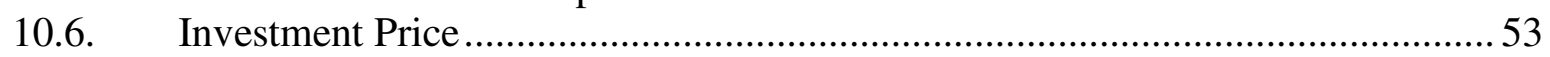

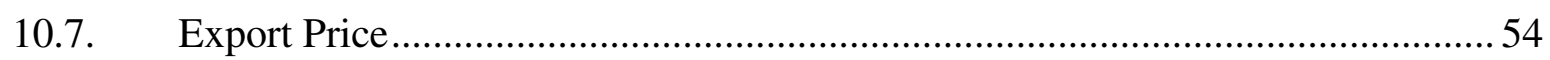

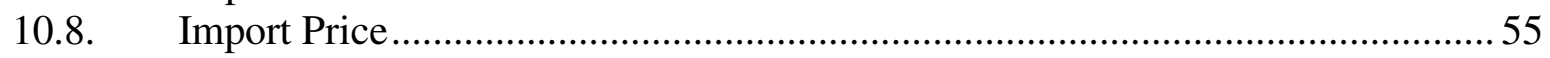

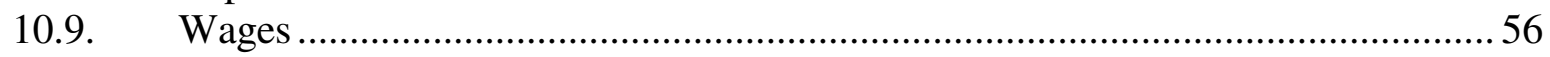

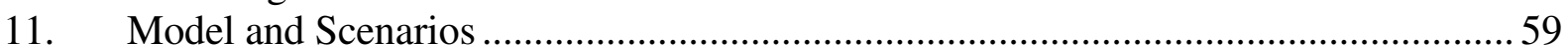

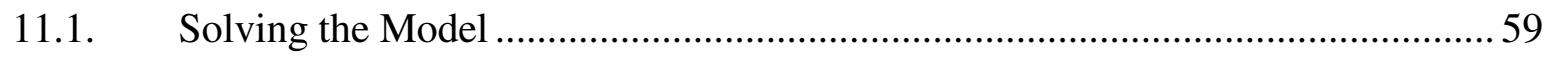

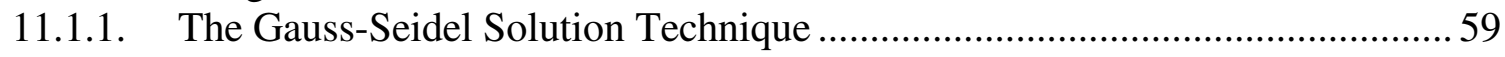

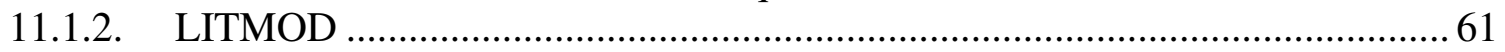




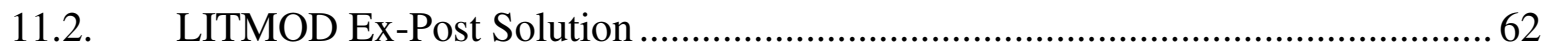

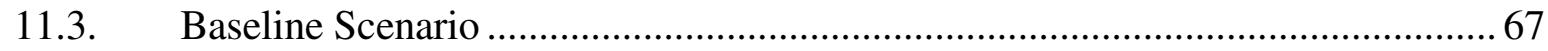

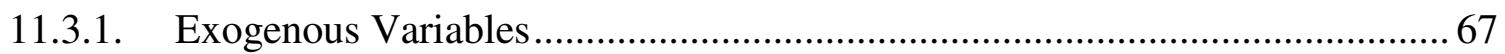

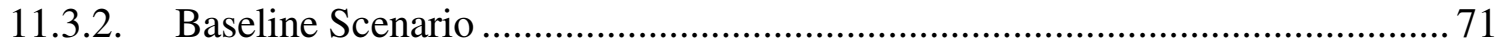

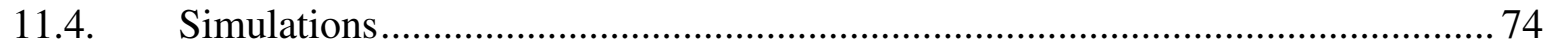

11.4.1. Price on Import Increased by $1 \%$.............................................................. 74

11.4.2. Public Consumption Increased by $1 \%$.......................................................... 77

11.4.3. Export Market Increased by 1\% ………………………………………..... 79

11.4.4. Interest Rate Decreased by 1\%-point ................................................................ 80

11.4.5. VAT Rate Decreased by 1\%-point.............................................................. 82

11.4.6. Population is Increased by $1 \%$................................................................. 83

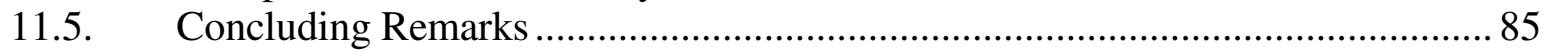

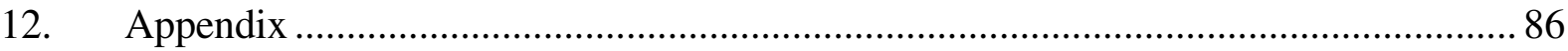

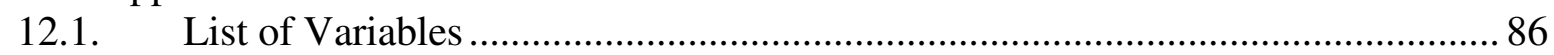

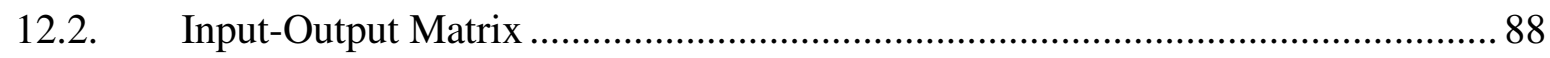

12.3. Private Consumption, Alternative Estimations ............................................... 90

12.4. Calculation of World Market Variables ............................................................ 93

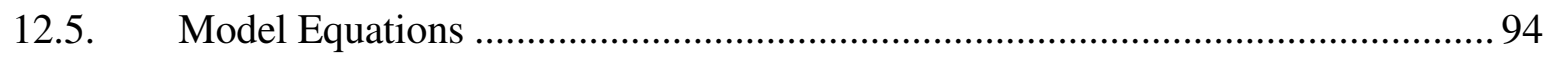

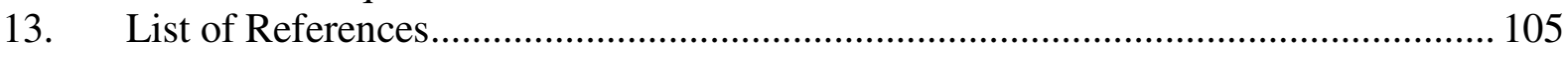




\section{Introduction}

LITMOD is a small medium-term demand-driven Keynisian macro-economic model of the Lithuanian economy, including elements of supply-side modelling. The model is estimated on quarterly national account data. A first version of the model was developed within the Lithuanian Ministry of Economy in a Phare Twinning project by Arvydas Kazlauskas and August Leppä. ${ }^{1}$ The model mainly determines the real flows of the Lithuanian economy with a 12-sector input-output table as a central element. The purpose of the model is to describe the general development and structure of the Lithuanian economy. The first version of LITMOD included a small monetary block that is excluded from the present model. Given the size of the model, monetary flows and the income and expenditure of the general government is also modelled at a relatively aggregated level, which is not fully adequate for evaluations of national fiscal policies.

\subsection{Structure of the Model}

The minimum that is needed to describe the real flows of the economy are equations determining categories of total final consumption (including import) and factor inputs by sectors. Equations explaining real flows of the economy include a number of variables such as prices and income flows that determine the real flows. Most of these variables are endogenous in the model. In addition, the model includes a number of equations describing interesting balances in current prices, e.g., the public sector deficit and the balance of payment.

A summary flow chart of LITMOD is given in Figure 1, where shaded boxes are exogenous variables. Total final demand, split into private consumption, investments, governmental consumption and export, determines domestic production and import. Production by branches is determined from demand from other branches and deliveries to categories of final consumptions using constant input-output coefficients. Domestic production determines factor demand and income. Prices are determined from production costs and the wagedetermination is described by productivity and a Philips-curve relation.

Important exogenous variables to the model are the population, various taxes/tax-rates, governmental consumption, interest rate, foreign prices and demand.

\footnotetext{
${ }^{1}$ Arvydas Kazlauskas and August Leppä: Two Models for the Lithuanian Economy, SEIL project working paper, 03.10.2000.
} 


\section{Figure 1 A Flow Chart of LITMOD}

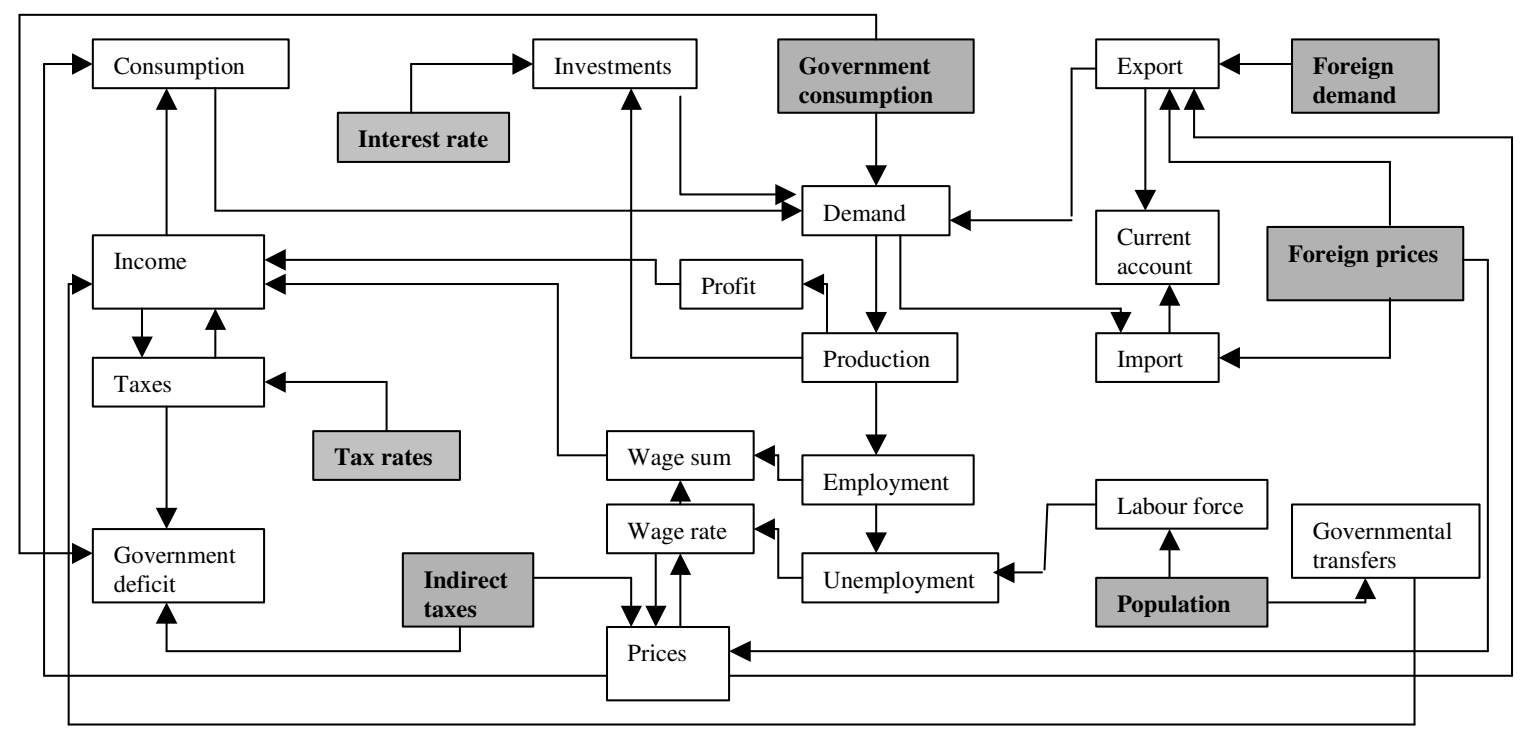

\subsection{Specification of Equations}

Concerning the specification of equations, an error-correction specification is generally used, implying that we estimate a long-term equilibrium equation and an adjustment mechanism. Due to few observations, a number of the parameters are restricted in estimations. In the ultimate case, long-term equilibrium parameters are determined from theoretical considerations and conventional judgments as in general equilibrium models, and adjustment parameters are estimated from observations, i.e., equations may be estimated conditioned on restrictions on long-term parameters and evaluations of reasonable adjustment parameters.

The general idea in the error-correction model is that economic theory states that in equilibrium, a variable $Y^{*}$ is a function of some other variables, i.e., $Y^{*}=f\left(X_{1}, X_{2}\right)$. However, it is, in general, not reasonable to assume that the economy is in equilibrium. Therefore, we formulate an adjustment mechanism. If the actual level of $Y$ in one period is less than the equilibrium level $Y^{*}$, the change in $Y$ should be positive - this is the errorcorrection. Besides this, the change in $Y$ is also determined by the changes in the long-term level of $Y$. Finally, $\varepsilon$ is the error term, i.e., we have:

$$
\Delta \log (Y)=\beta \cdot \Delta \log \left(Y^{*}\right)-\gamma \cdot\left(\log \left(Y_{-1}\right)-\log \left(Y_{-1}^{*}\right)\right)+\varepsilon
$$

Greek letters are parameters throughout. The error correction parameter $\gamma$ measures how much of the adjustment towards the equilibrium is done each period (each quarter in this model). If, for example, $\gamma=0.20,20 \%$ of the adjustment is done each quarter.

This is the general formulation we use, but we allow, in some cases, changes in the different explanatory variables (the $X$ 's) to have different adjustment effects on changes in $Y$, and we include additional explanatory variables in the short-run determination of $Y$.

In order to estimate the relationship, we need to specify an analytical expression of the relationship, for instance, a log-linear relation. When choosing a log-linear formulation, the 
parameters (the $\alpha$ 's) are interpreted as elasticities; if $X_{1}$ is increased with $1 \%, Y$ is in the longrun increased with $\alpha_{1} \%$.

$$
\log \left(Y^{*}\right)=\alpha_{0}+\alpha_{1} \cdot \log \left(X_{1}\right)+\alpha_{2} \cdot \log \left(X_{2}\right)
$$

We assume in the estimation that the error term $\left\{\varepsilon_{t}\right\}_{t=1, \ldots, \mathrm{T}}$ is independent, with mean zero, and with a constant variance $\sigma^{2}$. Furthermore, we assume that the error term follows a normal distribution. The last assumption is only needed when we look at test statistics after the estimation.

\subsection{Structure of the Paper}

The paper is structured in the following way:

Firstly, we describe the current data in Chapter 2. Secondly, we describe the different parts of the model with estimated equations and identities in Chapter 3-10. Finally, we construct a baseline scenario and show simulations with the model in Chapter 11. The list of references (p. 105) covers literature used as inspiration during the process.

\section{Data}

For most of the variables, quarterly data is collected for the period $1995 \mathrm{q} 1$ to $2002 \mathrm{q} 2$. A list of variables in LITMOD is included in Appendix 12.1.

The following categories cover most of the variables used in the model:

- $\quad$ Sectorial data (gross production, GDP, input, investment, labour);

- $\quad$ Government finance (expenditure, revenue, debt, budget surplus);

- $\quad$ Population (population, employed, labour force, unemployment rate);

- $\quad$ Earnings (average monthly earnings in the private and public sectors);

- Balance of payments (current account, import and export, foreign direct investment);

- $\quad$ Components of gross value added (taxes and subsidies on products);

- Monetary data (exchange rates, interest rates).

The time series are mainly from Statistics Lithuania and Bank of Lithuania. Statistics Lithuania also uses the data sources of other institutions such as the Ministry of Finance (government finance and taxation), Board of the State Social Security (SSSF revenue and expenditure), Labour Exchange (labour market), Ministry of Interior and Customs Department (export and import). The Bank of Lithuania supports the data on the balance of payments and monetary data. All other time series were provided by Statistics Lithuania bearing in mind pointed co-operation with other institutions.

In the following sections - documenting the different parts of the model - there will be a short description of the variables used.

In the first LITMOD, most variables were seasonally adjusted. In order to easily compare data from LITMOD with official statistics, we prefer to leave the variables unadjusted and instead 
- when it is needed - use quarterly dummies in the estimations. Other arguments for not seasonally adjust the data is that it may cause auto-correlation in the time series. As stated in Greene, "the adjustment is done to smooth out unusual movements in the data and, as such, makes the current observation dependent on what was typical in the past". 2

A fundamental part of the model is the input-output system based on an input-output table from 1997. The input-output table is described in Section 2.2.1.

\subsection{Aggregation Level}

In LITMOD version 1, there were 5 sectors:
A Agriculture
M Manufacturing
C Construction
S Services
G Public Service

We have chosen a more disaggregated level with the following 12 sectors. This is the same aggregation level as in the MAED model used for energy planning (LEI 2004):
A Agriculture
MN Mining and Quarrying
E Energy
M1 Manufacturing in Basic Materials
M2 Manufacturing in Machinery and Equipment
M3 Manufacturing in Non-Durable Goods
M4 Manufacturing, Miscellaneous
C Construction
S1 Trade, Hotels and Restaurants
S2 Transport, Storage and Communication
S3 Finance, Insurance, Real Estate and Business Services
S4 Community, Social and Personal Service

The energy sector (E) is oil refineries and energy conversion (electricity, heating, natural gas, and water supply). This sector and the mining sector (MN) are difficult to forecast, but are important due to expected future changes in the Lithuanian energy sector. Therefore, it is preferred to have these as separate sectors.

Also, the manufacturing sector is disaggregated into 4 sectors (M1-M4), and the service sector is disaggregated into 3 sectors (S1-S3) in order to have a more detailed forecast and facilitate analysis of structural changes.

\footnotetext{
${ }^{2}$ William Greene (1997): "Econometric Analysis".
} 


\subsection{Input-Output Table}

A central element in the model is an input-output table shown schematically in Table 1 . The A-matrix gives intermediate deliveries from sector $i$ to individual sectors. To the right of the A-matrix, we have deliveries from sectors to categories of final consumption. As in the inputoutput table, we have for Lithuania deliveries from sectors to intermediate - and final consumption includes deliveries of goods from similar sectors abroad. In order to obtain output (or production) by domestic sectors, import is subtracted. The matrix below the Amatrix shows payments to factor inputs and indirect taxes. Totalling columns for the sectors gives total input (also equal to output) by sectors. Totalling columns for categories of final consumption gives total private consumption, total governmental consumption, investments, export, and import. Dividing the input-output table by column sums gives input-output coefficients adding to one. We assume these coefficients to be constant.

Table 1 A Schematic Input-Output Table

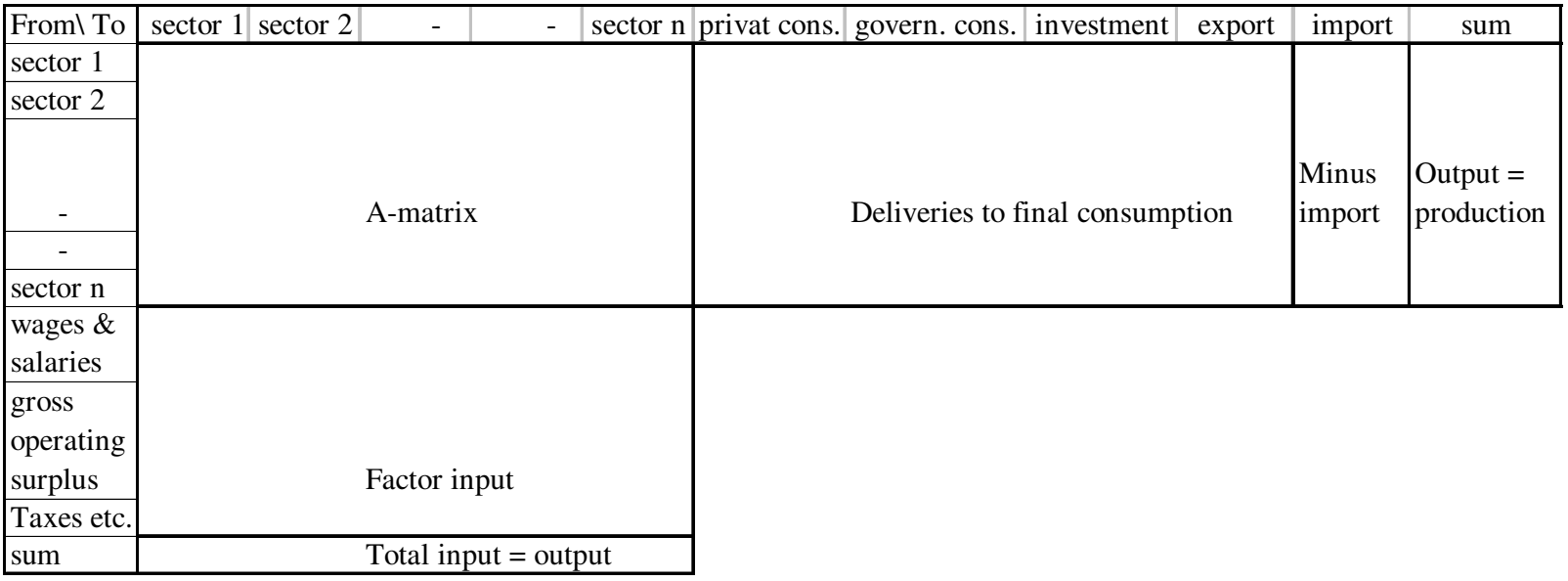

The original Input-Output table from Bank of Lithuania has 28 sectors and 4 components of final consumption (private consumption, public consumption, investment, and export). The data is from 1997 and in basis prices.

\subsubsection{Calculation of Input-Output Coefficients}

We have in the Input-Output table rows with deliveries of total supply (import and domestic production) to sectors and to final consumption. The supply of type $j$ ( $j$ is index for the 12 sectors: A, MN, E, M1, M2, M3, M4, C, S1, S2, S3, S4) consists of domestic production in sector $j\left(Q_{j}\right)$ and import from similar sectors abroad $\left(M_{j}\right)$. The supply is delivered to other sectors $i$ and to the categories of final consumption $\left(X_{k}\right)$ and equals the total use of type $j$. We have four components of final consumption (private consumption, public consumption, investments, and export).

In (3), the $a$ 's are input-output coefficients calculated as the corresponding table entries in the input-output table divided by the column sum. For example, $a_{A, M 3} \cdot Q_{M 3}$ is agricultural products 
(A) delivered to food manufacturing (M3), and $a_{A, C} C$ is agricultural products (A) delivered to private consumption $(\mathrm{C}){ }^{3}$

$$
\text { Supply }_{j}=M_{j}+Q_{j}=\sum_{i} a_{j i} \cdot Q_{i}+\sum_{k} a_{j k} \cdot X_{k}=U s e_{j}
$$

In the model, we use these relations to determine domestic production in the 12 sectors $\left(Q_{j}\right)$. The input-output coefficients are calculated from the total supply including import, and we calculate domestic production from the input-output deliveries by subtracting the import, as seen in equation (4). The modelling of domestic production is described in detail in Section 8.1.

$$
Q_{j}=\sum_{i} a_{j i} \cdot Q_{i}+\sum_{k} a_{j k} \cdot X_{k}-M_{j}
$$

However, we do not have time series of import of 12 types (the $M_{j}$ 's), but only total import of goods $(M)$. Therefore, we assume that the composition of the import is constant (e.g., the amount of imported agricultural products is a constant proportion of the total import), i.e, we have:

$$
Q_{j}=\sum_{i} a_{j i} \cdot Q_{i}+\sum_{k} a_{j k} \cdot X_{k}-m_{j} \cdot M
$$

The coefficients $m_{j}$ are assumed constant and calculated as $M_{j} / M$. The import coefficients fulfil the restrictions $\sum_{j} m_{j}=1$.

The Input-Output table includes a row with Primary Energy Input. This is import, only (no domestic production), and most of it is used in the sectors (not as final consumption). In the Input-Output table, the sum "Total Intermediate" differs from "Intermediate Official" with the exact supply of Primary Energy Input. For all other goods and services, import and domestic production are columns, and the total supply is divided into the different deliveries. Therefore, we have chosen to add the row Primary Energy Items to the column with import and subtract it from the column with production.

The Input-Output matrix aggregated to 12 sectors and the matrix with the calculated InputOutput coefficients is included as Table 28 and Table 29 in Appendix 12.2.

The Input-Output coefficients are calculated with yearly data from 1997, and we assume in the model that these coefficients are constant. In a forecast, the user is able to change the value of the coefficients due to specific knowledge about the sectors, but the user has to make sure that the restrictions on the coefficients are not violated.

Table 2 shows that the service sectors (S1-S4) have 47\% of the total domestic production in 1997 whereas the public sector (S4) alone accounts for 14\%. Manufacturing accounts for $27 \%$ of total domestic production, and the M3-sector (manufacturing of non-durable goods) is the largest sector with $18 \%$ of total domestic production.

\footnotetext{
${ }^{3}$ There is in an Input-Output table often a row (or more) with import deliveries to sectors and final consumption. In the above example, this means that it would have been possible to divide the delivery of agricultural products to private consumption into deliveries from domestic production and from import.
} 
Table 2 Size of Sectors as Share of Total Domestic Production in 1997

\begin{tabular}{lcccccccccccc}
\hline Sector & A & MN & E & M1 & M2 & M3 & M4 & C & S1 & S2 & S3 & S4 \\
\hline Output & & & & & & & & & & & & \\
Share in \% & 12 & 1 & 7 & 4 & 4 & 18 & 1 & 8 & 15 & 9 & 7 & 14 \\
\hline
\end{tabular}

The five largest deliveries to sectors (more than 1 bill. Litas in 1997) are deliveries of agricultural products (imported and domestically produced) to sector M3 (manufacturing of non-durable goods, including foods), deliveries from S1 (trade, etc.) to A (agriculture) and M3 (manufacturing of non-durable goods), deliveries from S3 (finance, insurance, renting, business service, etc.) to $\mathrm{S} 4$ (public sector) and deliveries from M1 (manufacturing in basic materials including building materials) to sector $\mathrm{C}$ (construction).

Table 3 shows the I-O coefficients for deliveries from sectors to the components of final consumption. The final consumption components are $C p$ private consumption (demand described in Section 3.3), Cg public consumption (Section 4.1), I investments (Section 5.2), and $X$ export (Section 6). ${ }^{4}$

Table 3 I-O Coefficients for Deliveries from Sectors to Final Consumption

\begin{tabular}{lrrrrrrrrrrrr}
\hline Sector & $\mathrm{A}$ & $\mathrm{MN}$ & $\mathrm{E}$ & $\mathrm{M} 1$ & $\mathrm{M} 2$ & $\mathrm{M} 3$ & $\mathrm{M} 4$ & $\mathrm{C}$ & $\mathrm{S} 1$ & $\mathrm{~S} 2$ & $\mathrm{~S} 3$ & $\mathrm{~S} 4$ \\
\hline $\mathrm{a}_{j, C p}$ & 0.13 & 0.00 & 0.07 & 0.03 & 0.04 & 0.45 & 0.03 & 0.02 & 0.14 & 0.03 & 0.00 & 0.05 \\
$\mathrm{a}_{j, C g}$ & 0.00 & 0.00 & 0.00 & 0.00 & 0.00 & 0.00 & 0.00 & 0.00 & 0.00 & 0.00 & 0.00 & 1.00 \\
$\mathrm{a}_{j, I}$ & 0.00 & 0.00 & 0.00 & 0.08 & 0.34 & 0.02 & 0.00 & 0.33 & 0.03 & 0.14 & 0.05 & 0.01 \\
$\mathrm{a}_{j, X}$ & 0.11 & 0.00 & 0.12 & 0.16 & 0.11 & 0.23 & 0.02 & 0.02 & 0.11 & 0.10 & 0.02 & 0.00 \\
\hline
\end{tabular}

If we look at the composition of the private consumption $(C p), 13 \%$ is delivered from agriculture (food), $7 \%$ is energy use, $55 \%$ is goods, and $36 \%$ is services. All public consumption $(C g)$ is delivered from the public service sector (S4).

The investments from sectors and households $(I)$ are buildings (delivered from sector $\mathrm{C}$ ) and machinery (sector M2). Manufacturing accounts for 52\% of the export, service sectors for $23 \%$, agricultural products is $11 \%$ of the export, and energy products is $12 \%$ of the total export.

\section{Households}

We begin this section by going through some theories on private consumption in 3.1. In 3.2, we discuss how to construct a variable for disposable income. Afterwards, we estimate an equation for private consumption in 3.3 and an equation for household investment in dwellings in 3.4.

\subsection{Private Consumption, Theory}

The determination of total private consumption is a crucial variable in macro-economic models and the specification of this relation has been the subject of numerous studies. In all studies, the fundamental link is that private consumption will in the long run depend on some

\footnotetext{
${ }^{4}$ The table is transposed from the table in the Appendix.
} 
income or wealth measure, but the specification of the link varies between studies. In the short run, several other variables may be included:

- $\quad$ Changes in the unemployment rate as a proxy for uncertainties with respect to future income;

- Consumer prices or inflation - increased inflation will in the medium-term dampen consumption due to efforts to keep real savings unchanged;

- Changes in real interest rates; changes income from capital/savings and is a proxy for capital gains/loses;

- Changes in the composition of income - the propensity to consume out of wage, profit income or social transfers are not necessarily identical.

One way to specify the link between consumption and income/wealth is that total private consumption is a constant share of some income measure. Thus

$$
C_{t}=a_{0} \cdot Y_{t}^{*}
$$

where $C_{t}$ is total private consumption in period $t, Y_{t}^{*}$ is income in period $t$, and $a_{0}$ is the constant share of income that is consumed.

Taking logarithms of (6), we have

$$
\log \left(C_{t}\right)=\alpha_{0}+\log \left(Y_{t}^{*}\right)
$$

If we assume that the marginal propensity to consume differs from unity, (7) may include a constant to the income term, i.e.,

$$
\log \left(C_{t}\right)=\alpha_{0}+\alpha_{1} \cdot \log \left(Y_{t}^{*}\right)
$$

where $\alpha_{1}$ is the marginal propensity to consume. This is the standard Keynesian formulation of private consumption using current disposable income as $Y_{t}^{*}$.

The Modiglani life cycle theory of consumption states that the consumers prefer to smooth consumption over lifetime, so consumption depends not only on current income, but is subject to an intertemporal budget constraint. The Friedman permanent income hypothesis states that transitory changes in income mainly lead to temporary changes in consumption, whereas current consumption will depend on the consumers' permanent income, i.e., their expected long-run average income.

The permanent income level is somehow related to the present and previous income. One way to calculate the permanent income is to assume this to be a geometric average of present and previous incomes, i.e.,

$$
\log \left(Y_{t}^{*}\right)=(1-\lambda) \sum_{i=0}^{\infty} \lambda^{i} \cdot \log \left(Y_{t-i}\right)
$$

Inserting this into (8), we have 


$$
\log \left(C_{t}\right)=\alpha_{0}+\alpha_{1}(1-\lambda) \sum_{i=0}^{\infty} \lambda^{i} \cdot \log \left(Y_{t-i}\right)
$$

Now, subtracting $\lambda \cdot \log \left(C_{t-1}\right)$ from (10), we have (11) that may be estimated,

$$
\log \left(C_{t}\right)=(1-\lambda) \alpha_{0}+(1-\lambda) \alpha_{1} \log \left(Y_{t}\right)+\lambda \log \left(C_{t-1}\right)
$$

Normally, $C_{t}$ and $Y_{t}$, the real private consumption and real disposable income, are defined per capita. In addition, to cope with short-term changes, a number of proxy variables for the effects mentioned in the bullet points may be included. For instance, including changes in the unemployment rate to mirror uncertainties with respect to future income in (10), changes (11) to

$$
\log \left(C_{t}\right)=(1-\lambda) \alpha_{0}+(1-\lambda) \alpha_{1} \log \left(Y_{t}\right)+\alpha_{2}\left(\Delta U_{t}-\lambda \cdot \Delta U_{t-1}\right)+\lambda \log \left(C_{t-1}\right)
$$

where $\Delta U_{t}$ is the change in the unemployment rate from period $t-1$ to $t$.

Looking at private consumption in a slightly different way, consumers may during their lifetime tend to optimise utility depending on consumption and the wealth they leave. When simplifying assumptions, optimisation of budget restrictions implies that the aggregated consumption function may be written as a linear homogenous function in income and capital. Using logarithmic transformations, we may write the long-term consumption function as

$$
\log \left(C_{t}^{*}\right)=\beta_{0}+\beta_{1}\left(\theta \cdot \log \left(Y_{t}\right)+(1-\theta) \cdot \log \left(W_{t}\right)\right)
$$

The parameter $\beta_{1}$ is the marginal propensity to consume, and if we assume a constant share of income and capital used for consumption, $\beta_{1}$ is restricted to 1 . If we have no data for capital, $\theta$ is implicitly restricted to 1 , implying that only current income affects consumption.

Modelling the adjustment to the long-run relation by an error correction model, including variables describing short-term variations in consumption, we have

$$
\operatorname{Dlog}\left(C_{t}\right)=b_{1} \cdot \operatorname{Dlog}\left(Y_{t}\right)+b_{2} \cdot \operatorname{Dlog}\left(X_{t}\right)-\gamma\left[\log \left(C_{t-1}\right)-\log \left(C_{t-1}^{*}\right)\right]
$$

where $X$ represents additional short-term explanatory variables, and $b_{1}$ is the short-run marginal propensity to consume out of current income.

Under certain restrictions, the two approaches give the same equation. First of all, (11) can be rewritten as

$$
\operatorname{Dlog}\left(C_{t}\right)=(1-\lambda) \alpha_{0}+(1-\lambda) \alpha_{1} \log \left(Y_{t}\right)-(1-\lambda) \log \left(C_{t-1}\right)
$$

Since we have no data for household capital in the model, the parameter $\theta$ is restricted to one in (13) and the equation states that

$$
\log \left(C_{t}^{*}\right)=\beta_{0}+\beta_{1} \cdot \log \left(Y_{t}\right)
$$

The error correction towards this long run optimal consumption level can be rewritten (here without additional explanatory variables) as 


$$
\begin{aligned}
\operatorname{Dlog}\left(C_{t}\right) & =b_{1} \operatorname{D} \log \left(Y_{t}\right)-\gamma\left[\log \left(C_{t-1}\right)-\log \left(C_{t-1}^{*}\right)\right] \\
& =b_{1} \operatorname{Dlog}\left(Y_{t}\right)-\gamma \log \left(C_{t-1}\right)+\gamma \beta_{0}+\gamma \beta_{1} \log \left(Y_{t-1}\right) \\
& =\gamma \beta_{0}+b_{1} \log \left(Y_{t}\right)-\gamma \log \left(C_{t-1}\right)+\left(\gamma \beta_{1}-b_{1}\right) \log \left(Y_{t-1}\right)
\end{aligned}
$$

This equals (15) if, and only if, $b_{1}=\gamma \cdot \beta_{1}$ (with $\alpha_{0}=\beta_{0}, \alpha_{1}=\beta_{1}$, and $\gamma=1-\lambda$ ), i.e., we estimate one additional parameter in the second approach instead of assuming that the shortrun marginal propensity to consume $\left(b_{1}\right)$ is given by the long-run marginal propensity to consume $\left(\beta_{1}\right)$ and the adjustment speed $(\gamma)$.

\subsection{Disposable Income}

The disposable income is an important variable in macroeconomic models and in LITMOD. Disposable income is the main explanatory variable for the development of private consumption. At present, its definition is not a trivial task and we try in this section to explain why.

Lithuanian Statistics defines disposable income as the sum of the following income flows: total income in cash and kind ${ }^{5}$ received as earnings from employment, income from farming, business, handicrafts and free professional activity as well as pensions, benefits, scholarships, income from property, and rent. However, we do not have "official" data on a reasonable disposable income. Alternatively, we construct an instrumental variable (18), which we call "disposable income". This variable consists of three main parts: after-tax income from employment, net profit from business and farming activities and payments from State Social Security Fund (SSSF).

$$
\begin{aligned}
Y_{t} & =0.001 \cdot 3 \cdot\left(\left(n t_{\min }+\left(w_{P R I}-n t_{\min }\right) \cdot\left(1-t_{L}\right)\right) \cdot L_{P R I}+\left(n t_{\min }+\left(w_{P U B}-n t_{\min }\right) \cdot\left(1-t_{L}\right)\right) \cdot L_{P U B}\right) \\
& + \text { Prof } \cdot\left(1-t_{C} \cdot \text { tcbase }\right)+0.001 \cdot 0.96 \cdot C_{G S S}
\end{aligned}
$$

Where,

$Y_{t} \quad$ Disposable income (DI, mill. Litas current prices)

$L_{P R I} \quad$ Labour demand in the private sector (LNpri, 1000 fulltime workers)

$L_{P U B} \quad$ Labour demand in the public sector (LNS4, 1000 fulltime workers)

$w_{P R I} \quad$ Average monthly gross earning in private sector (Wpri, Litas current prices)

$w_{P U B} \quad$ Average monthly gross earning in public sector (Wpub, Litas current prices)

$n t_{\min } \quad$ Non-taxable monthly wage (ntmin, Litas current prices)

Prof Profit from firms (PROF, mill. Litas current prices)

$C_{G S S} \quad$ Expenditure of SSSF (CGSEV, 1000 Litas current prices)

$t_{L} \quad$ Consolidated tax on labour

$t_{C} \cdot$ tcbase Consolidated tax on profits

\footnotetext{
${ }^{5}$ Due to the nature of these non-cash earnings, it is difficult to estimate its level and we should consider it as additional benefits from employment and income from non-business activities: income in kind from hunting, fishing, gathering mushrooms, berries, etc.
} 
In (18), different income flows are converted from monthly data to quarterly data and time series in thousands of Litas into millions of Litas.

There are two average constructed tax rates in (18). Most of the employees pay 33\% labour tax from the wage sum subtracted by minimum non-taxable monthly wage ( $214 \mathrm{Lt}$. before 01.01.2002, 290 Lt., after 01.01.2003 and 250 Lt. in-between) and 3\% tax to the social security fund. In addition, $15 \%$ labour tax is levied on seamen's income, income from sporting, artistic activities, royalties, etc. Besides this, a number of employees pay a fixed tax into the national budget. We have over the estimation period exercised different combinations of the mentioned tax concluding that the consolidated tax rate on income is $25-30 \%$. It is assumed in the model that the income tax rate $\left(t_{L}\right)$ is equal to $27 \%$. Concerning taxes on profit, an appropriate assumption for the level of the tax rate $\left(t_{C}\right)$ is $22 \%$ and a correction factor (tcbase) of 0.188 , which is an average tax rate on profit of $4.1 \%$.

Finally, we assume that all SSSF expenditure, except for administrative costs (4\%), is transferred into household disposable income.

Figure 2 illustrates that the estimated disposable income is very close to the amount of private consumption and investments in dwellings. It even exceeds this expenditure over the last two years. It is seen from the graph that disposable income reaches maximum during the second and third quarter of the year, while consumption increases during the year (and then decreases in the beginning of the next year).

Figure 2 Disposable Income $(Y d)$ and Expenditure $(C p+I h)$

mill. Litas Current Prices

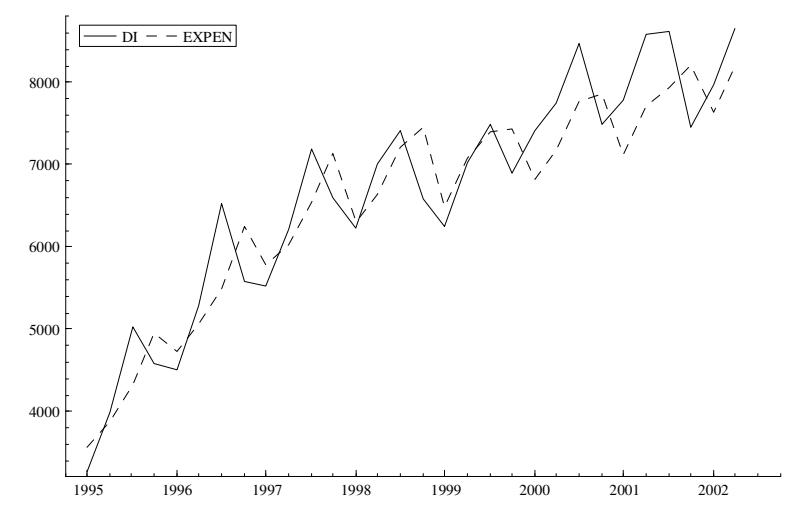

Seasonally Adjusted

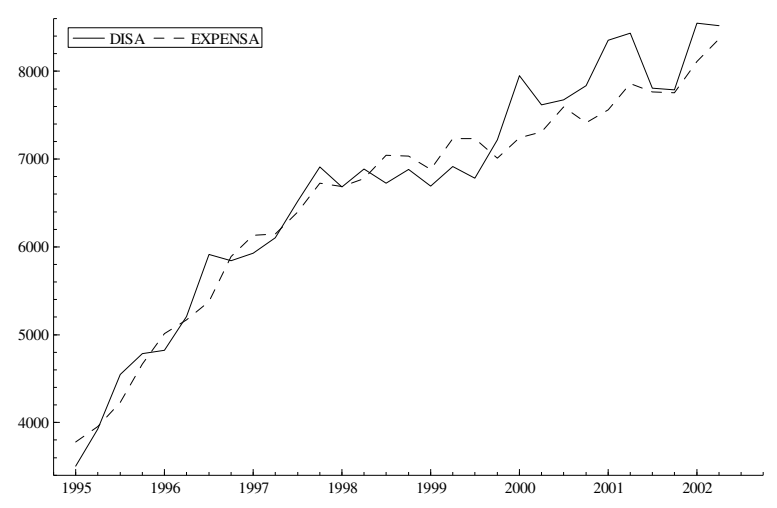

\subsection{Private Consumption}

According to the Lithuanian Statistical Yearbook, consumption expenditure includes expenditure in cash and kind for household consumption needs, i.e., food, clothes, footwear, dwelling, health care, culture, and recreation. Consumption expenditure is grouped by the COICOP classification (Classification of Individual Consumption by Purpose prepared by OECD). However, at present, we look at relations in the model between aggregated private consumption and disposable income. At a later stage, the structure of private consumption may be modelled by a consumer demand system. 
We use the second approach from Section 3.1 to model private consumption in the model. Since we have no data for the household capital, we use the formulation in (16) as the longrun consumption function. Quarterly dummies are added to allow for seasonal differences in income and consumption.

$$
\log \left(C p^{*}\right)=\alpha_{0}+\alpha_{1} \cdot \log \left(Y / P_{C}\right)+\lambda_{2} \cdot Q_{2}+\lambda_{3} \cdot Q_{3}+\lambda_{4} \cdot Q_{4}
$$

The adjustment to the long-run relation is an error correction model, and the short-run marginal propensity to consume $\left(\beta_{1}\right)$ is allowed to differ from the long-run propensity $\left(\alpha_{1}\right)$. Consumption is in the short-run allowed to depend on changes in consumption price $\left(P_{C}\right)$, changes in interest rate $(i)$, and changes in the unemployment rate $(U){ }^{6}$

$$
\begin{aligned}
\operatorname{Dlog}(C p) & =\beta_{1} \mathrm{D} \log \left(Y / P_{C}\right)+\beta_{2} \mathrm{D}(i)+\beta_{3} \mathrm{D}(U)+\beta_{4} \mathrm{Dlog}\left(P_{C}\right) \\
& +\beta_{0}\left[\log \left(C p_{-1}^{*}\right)-\log \left(C p_{-1}\right)\right]
\end{aligned}
$$

Where

$$
\begin{array}{ll}
C p & \text { Private consumption }(C R N, \text { mill. Litas constant prices) } \\
C p^{*} & \text { Private consumption, equilibrium level } \\
Y & \text { Disposal income in household sector }(D I, \text { mill. Litas current prices) } \\
P_{C} & \text { Price deflator on private consumption }(p c, 1995=1) \\
i & \text { Interest rate ( } r a \text { is average annual interest rate in } \%) \\
U & \text { Unemployment rate }(U, \text { rate }) \\
Q_{2}-Q_{4} & \text { Quarterly dummies; } \mathrm{Q}_{2} \text { is equal to one in second quarters and else zero. }
\end{array}
$$

In Appendix 12.3, we show three different estimations of equation (19) and (20), describing private consumption almost identically, but with very different results when used in the model. This demonstrates some of the considerations we have before choosing an estimation to use in the model - not just in this case, but with all the equations.

As explained in the Appendix, we choose to estimate the long-run marginal propensity to consume $\left(\alpha_{1}\right)$ in the long-term equation (19) and then estimate the dynamic adjustment (20) with this parameter fixed. Parameter estimates and t-statistics as well as $\mathrm{R}^{2}$ are shown in Table 4.

Table 4 Parameter Estimates, Private Consumption

\begin{tabular}{rrrrrrrrrrr}
\hline Param & $\alpha_{0}$ & $\alpha_{1}$ & $\lambda_{2}$ & $\lambda_{3}$ & $\lambda_{4}$ & $\beta_{0}$ & $\beta_{1}$ & $\beta_{2}$ & $\beta_{3}$ & $\beta_{4}$ \\
\hline 1.726 & 0.806 & -0.012 & 0.069 & -0.268 & 0.351 & 0.232 & -0.010 & 0 & -0.666 \\
& $\left.{ }^{*}-20\right]$ & & {$[-0.36]$} & {$[1.07]$} & {$[2.68]$} & {$[2.97]$} & {$[2.68]$} & {$[-2.58]$} & $*$ & {$[-3.55]$} \\
\hline
\end{tabular}

Estimation period 1995q2-2002q2. t-values in [ ]. $R^{2}=0.949805$

${ }^{*}$ Restricted parameter. ${ }^{1} \mathrm{t}$-value in estimation of long-run equation is 12.94 .

\footnotetext{
${ }^{6}$ Instead of changes in the logs of unemployment rate and interest rate, we use the changes (i.e., $\left.\mathrm{D}\left(U_{t}\right)=U_{t}-U_{t-1}\right)$ since the variables are in \%. Then, the parameter measures how many \% consumption will change if the unemployment rate is changed by $1 \%$ point.
} 
The marginal propensity to consume is $23 \%$ in the short-run $\left(\beta_{1}\right)$ and $81 \%$ in the long-run $\left(\alpha_{1}\right)$. There was no significant effect of changes in the unemployment rate $\left(\beta_{3}=0\right)$. Increased interest rate decreases consumption moderately in the short-run (an increase in the interest rate of 1 percentage point decreases the private consumption with $1 \%\left(\beta_{2}=0.01\right)$ in the first quarter, but the private consumption remains unchanged in the long-run); money deposit is more valuable now so consumption is pending until later. Additionally, it is important to mention that the whole system adapts rather quickly to the equilibrium state $\left(\beta_{0}=0.35\right)$.

The quarterly dummies are included in the long-term equation. ${ }^{7}$ We can see that if we should have the simple long-term equilibrium relationship between consumption and disposable income, then consumption should be lower in the fourth quarter $\left(\lambda_{4}<0\right)$. As mentioned in Section 3.2, disposable income is highest in the second and third quarter while consumption reaches the yearly maximum in the fourth quarter.

To illustrate the estimation, Figure 3 shows the actual value and the estimated value of private consumption. The left graph shows the fitting of the growth rate where the straight line DLCRN is the actual value of $\operatorname{Dlog}(C)$ and the dotted line with label $\mathrm{E}$ is the estimated value. The right graph shows the actual and estimated level of private consumption. The residuals from the estimations are less than $4 \%$ as seen in Figure 4.

Figure 3 Private Consumption: Actual and Estimated Values in Growth Rate (left) and Level (right)
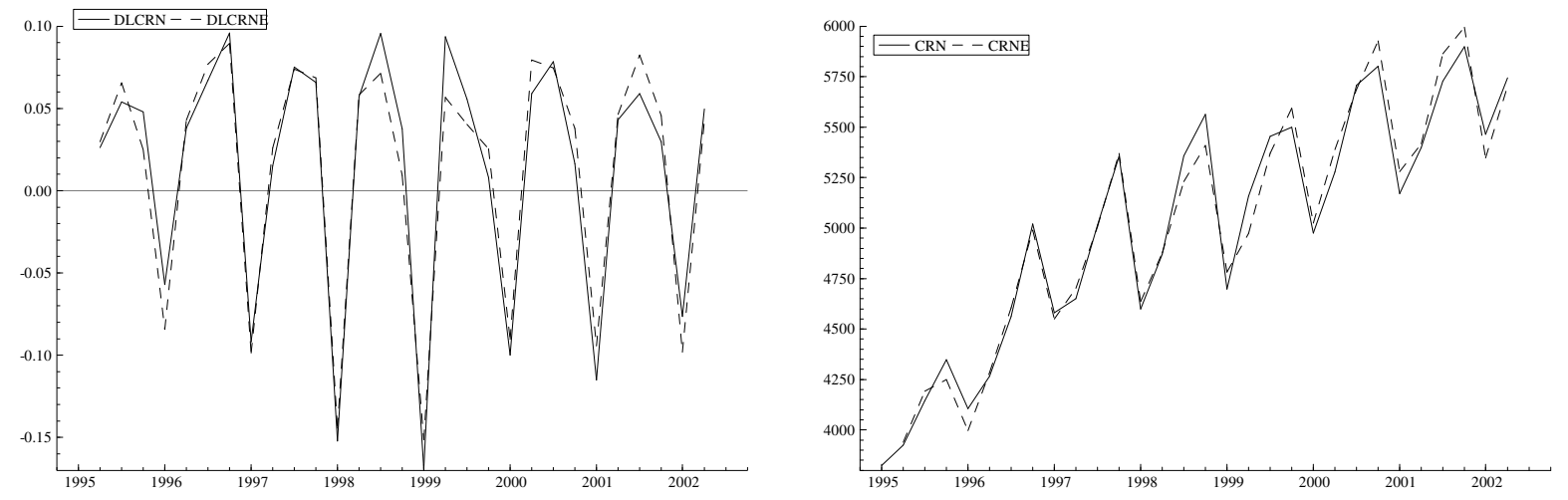

\footnotetext{
${ }^{7}$ The three quarterly dummies are included in the estimation if one or more of the dummies improve the explanation (increases the adjusted $\mathrm{R}^{2}$ ); as a rule of thumb, this is the case if the numerical $t$-value is above 1 .
} 


\section{Figure 4 Private Consumption, Residuals in \%}

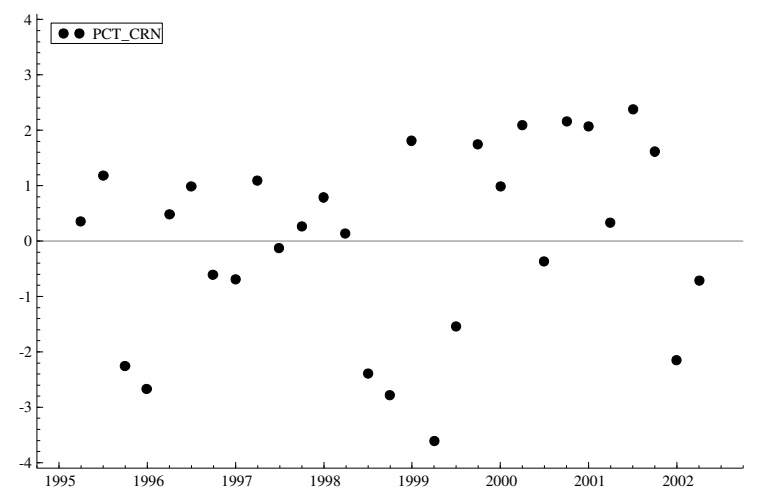

\subsection{Household Investments in Dwellings}

Investments in dwellings are, compared with private consumption, approximately $2.5 \%$. This is a relatively small part, but investment in dwellings is an important macro-economic indicator. Increasing investments are caused either by increased real income or improved financial intermediation (more loans and credits to households). On the other hand, economical depressions caused by internal and/or external factors (e.g., Russian crisis, high inflation rate, EU entrance, etc.) will immediately influence the dynamics of household investments in dwellings.

The most important determinants for investments in dwellings are the real disposable income, producer price on construction, long-term loans on dwellings or interest rate on these loans. The "external" factors mentioned above are included in the model in the form of dummies. For example, Figure 5 (left) shows an increase each $4^{\text {th }}$ quarter in investments excluding the two-year period of the Russian crisis. Therefore, the model includes a modified dummy for the $4^{\text {th }}$ quarter as well as a dummy for the relatively rapid decrease in 1998q2. The long-run relationship is specified as $(21){ }^{8}$

$$
\log \left(I_{H}\right)=\alpha_{0}+\alpha_{1} \log \left(Y_{-1} / P_{C,-1}\right)+\alpha_{2} \log \left(P_{Q_{C}}\right)+\alpha_{3} i+\alpha_{4} D 98 q 2+\lambda_{4} Q_{4 I H}
$$

Where

$I_{H} \quad$ Investments in dwellings ( $I R H$, mill Litas constant prices)

$Y \quad$ Disposable income (DI, mill Litas current prices)

$P_{C} \quad$ Consumer price index $(p c, 1995=1)$

$P_{Q_{C}} \quad$ Producer price in construction sector $(p q c, 1995=1)$

$i \quad$ Interest rate ( $r a$ is average annual interest rate in \%)

D98q2 Dummy (1 in 1998q2, else 0)

$Q_{4 I H} \quad$ Modified quarterly dummy for $4^{\text {th }}$ quarter

\footnotetext{
${ }^{8}$ We only have data for investments in dwellings in current prices (IVH) and calculate investments in constant prices using the overall investment deflator $(p i=I V / I R N)$.
} 
Estimated parameters and t-statistics are shown in Table 5, and the fit of the equation is shown in Figure 5. We could not estimate a significant effect of price on construction or interest rate ( $\alpha_{2}$ and $\alpha_{3}$ are restricted to zero). When real disposable income increases, households invest more in dwellings. However, the income elasticity is below one $\left(\alpha_{1}=0.56\right)$.

Table 5 Investments in Dwellings, Parameter Estimates

\begin{tabular}{lccccrr}
\hline Parameter & $\alpha_{0}$ & $\alpha_{1}$ & $\alpha_{2}$ & $\alpha_{3}$ & $\alpha_{4}$ & $\lambda_{4}$ \\
\hline 0 & 0.561 & 0 & 0 & -0.479 & 0.350 \\
& $*$ & {$[245.41]$} & $*$ & $*$ & {$[-5.03]$} & {$[7.60]$} \\
\hline Estimation period 1995q1-2002q2; t-values in [ ]; ${ }^{*}$ restricted parameter; R $^{2}$ 0.845565 &
\end{tabular}

Figure 5 Household Investments in Dwellings, Fit and Residuals
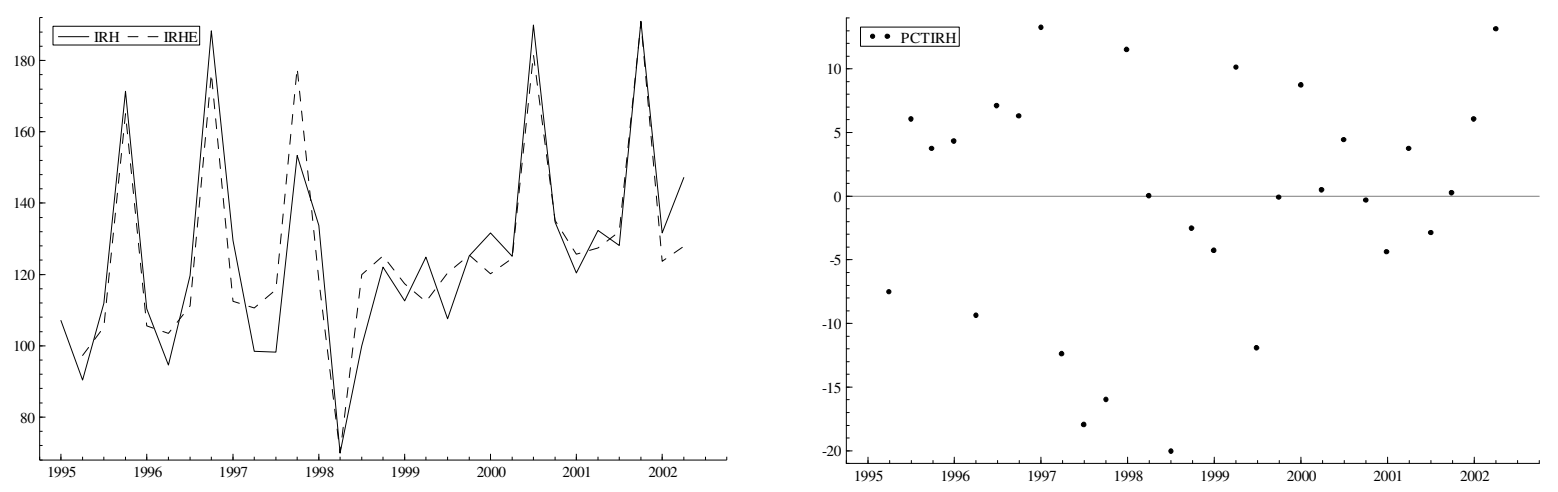

\section{Governmental Finance}

In any economic model, the description of the governmental finance is very important, as governmental consumption is a large part of final demand and because the financing of governmental consumption has considerable implications for the economical development. The Government primarily maintains the following two functions:

- $\quad$ The provision of public goods and services to households and companies; ${ }^{9}$

- $\quad$ Redistribution of income and wealth.

The financial resources accumulated in the Lithuanian state budget are used to finance general public needs. Together with municipal budgets, the state budget forms the national budget, the management of which is based on the laws of the Republic of Lithuania.

The Government affects the economy mainly through governmental expenditures, taxation, regulation, and publically owned enterprises. These aspects of governmental influence are briefly discussed in the sections below.

\footnotetext{
${ }^{9}$ Examples of public goods and services are national defence, law enforcement, public health, transportation, and education.
} 
We should also pay attention to methodological difficulties. Up to the present year, the Ministry of Finance used a quite old methodology presented in the IMF Government Finance Statistics Manual 1986 (GFSM 1986) for the calculations of general government finance. Today, the Ministry uses the ESA'95 methodology harmonised with the new IMF GFSM 2001. As the two methodologies are incomparable, one should be careful when the model is updated with new data on public finance.

Additionally, this chapter covers equations for the State Social Security Fund budget in Section 4.3. The social insurance system in Lithuania comprises social insurance contributions (compulsory and voluntary) paid by the employer and social insurance benefits.

\subsection{Government Consumption}

The Government consumption, $C g$, is one of the final demand components in the input-output system. All the demand for government consumption is delivered from the public sector (S4).

As mentioned above, the state and municipal budgets make up the national budget, and is used for education, culture, science, health care, social welfare, environmental protection, economy development, general government and national defence.

The Government's consumption in Lithuania consists of three main parts: expenditures on economy (infrastructure, housing, agriculture, forestry, manufacture, fuel and energy, etc.), social issues (health and education, social care and recreation) and other government expenditures (army, police, general government services, etc.). The last two parts are joined into current expenditures; the first forms the capital expenditure, which varies from $7 \%$ to $17 \%$ of the total government budget.

We assume in the model that the governmental consumption is exogenous - a very important policy variable.

\subsection{Government Revenue and Balance}

First of all, we would like to investigate the general structure of government revenue.

Budget revenue consists legally of taxes and other receipts established by the laws of the Republic of Lithuania. According to the GFSM 1986, government revenue is divided into two parts: taxes and other revenue.

In the model, the governmental revenue $(R)$ consists of four parts: tax on wage income $\left(R_{w}\right)$, tax on profit $\left(R_{p}\right)$, revenue from VAT paid by households $\left(R_{v}\right)$, and taxes minus subsidies paid by the production sectors $\left(R_{s}\right)$.

$$
R=1000 \cdot\left(R_{w}+R_{p}+R_{v}+R_{s}\right)
$$

The calculation of the four revenues in the model is shown in (23). 


$$
\begin{aligned}
& R_{w}=0.001 \cdot 3 \cdot\left(\left(w_{P R I}-n t_{\min }\right) \cdot t_{L} \cdot L_{P R I}+\left(w_{P U B}-n t_{\min }\right) \cdot t_{L} \cdot L_{P U B}\right) \\
& R_{p}=\text { Prof } \cdot t_{C} \cdot \text { tcbase } \\
& R_{v}=C \cdot P_{C} \cdot t_{v a t} /\left(1+t_{v a t}\right) \\
& R_{s}=t_{p} \cdot C_{T}
\end{aligned}
$$

Where

$\begin{array}{ll}R & \text { Governmental revenue (CGREV, } 1000 \text { Litas current prices) } \\ R_{w} & \text { Revenue from tax on wage (CGREVW, mill. Litas current prices) } \\ R_{p} & \text { Revenue from tax on profit (CGREVP, mill. Litas current prices) } \\ R_{v} & \text { Revenue from VAT paid by households (CGREVV, mill. Litas current prices) } \\ R_{S} & \text { Revenue from net taxes paid by sectors (CGREVS, mill. Litas current prices) } \\ L_{P R I} & \text { Labour demand in private sector ( } L N p r i, 1000 \text { full time workers) } \\ L_{P U B} & \text { Labour demand in public sector ( } L N S 4,1000 \text { full time workers) } \\ w_{P R I} & \text { Average monthly gross earning in private sector (Wpri, Litas current prices) } \\ w_{P U B} & \text { Average monthly gross earning in public sector (Wpub, Litas current prices) } \\ n t_{m i n} & \text { Non-taxable monthly wage ( } n t m i n, \text { Litas current prices) } \\ P r o f & \text { Profit from firms (PROF, mill. Litas current prices) } \\ t_{L} & \text { Consolidated tax on labour ( } t l) \\ t_{C} \cdot t c b a s e & \text { Consolidated tax on profits }(t c, t c b a s e) \\ C & \text { Private consumption }(C R N, \text { mill. Litas constant prices) } \\ P_{C} & \text { Price on private consumption ( } p c, 1995=1) \\ t_{v a t} & \text { VAT rate ( } v a t) \\ t_{p} & \text { Net tax rate on products }(t p) \\ C_{T} & \text { Inputs in sectors (INVT, mill. Litas current prices) }\end{array}$

There is a taxation of two types of income, namely wage and profit. Tax on wage income is discussed in Section 3.2 and, in the model, we use a constant tax rate on wage income $\left(t_{L}=\right.$ 0.27 ) in the estimation period. As tax rate on profit from sectors, we use the tax rate on capital income $\left(t_{C}=0.22\right)$. However, this generates larger revenue than the officially published data. Therefore, we use a correction factor (tcbase $=0.188$ ) correcting for income levels as done in Leppä's version of LITMOD.

The second part of government revenue is taxes on products and other revenue. First of all, households pay VAT on goods and services. In the model, we use an average VAT rate of $18 \%\left(t_{v a t}=0.18\right)$. The revenue is close to the official VAT revenue. The VAT base is private consumption in current prices $\left(C \cdot P_{C}\right)$. As this includes VAT, we correct for this by multiplying by $1 /\left(1+t_{\text {vat }}\right)$. The remaining part of the revenue is assumed in the model to be paid by the production sectors. We use a calculated average net tax rate in the model on products of $4.5 \%\left(t_{p}=0.045\right) .^{10}$

\footnotetext{
${ }^{10}$ The rate is calculated from the official revenue from taxes on products and other non-product taxes minus subsidies minus the calculated revenue from VAT paid by households.
} 
Figure 6 (left) shows that the calculated level of government revenue (CgrevE) is close to the official government revenue (Cgrev). From the structural analysis of government revenue, it is seen that ((23) and Figure 6 (right)) approximately $47 \%$ of the revenue derives from VAT. Taxes on labour income contribute $26 \%$; the rest is obtained from other taxes on products and taxes on profits. The smallest share comes from taxes on profits, i.e., the largest part of profits goes into disposable income of households and indirectly joins the national budget through private consumption and VAT. Within a black market economy, VAT has the advantage of tax consumption and not income in order to collect desirable tax revenue.

\section{Figure 6 Government Revenue, Fit and Structure}
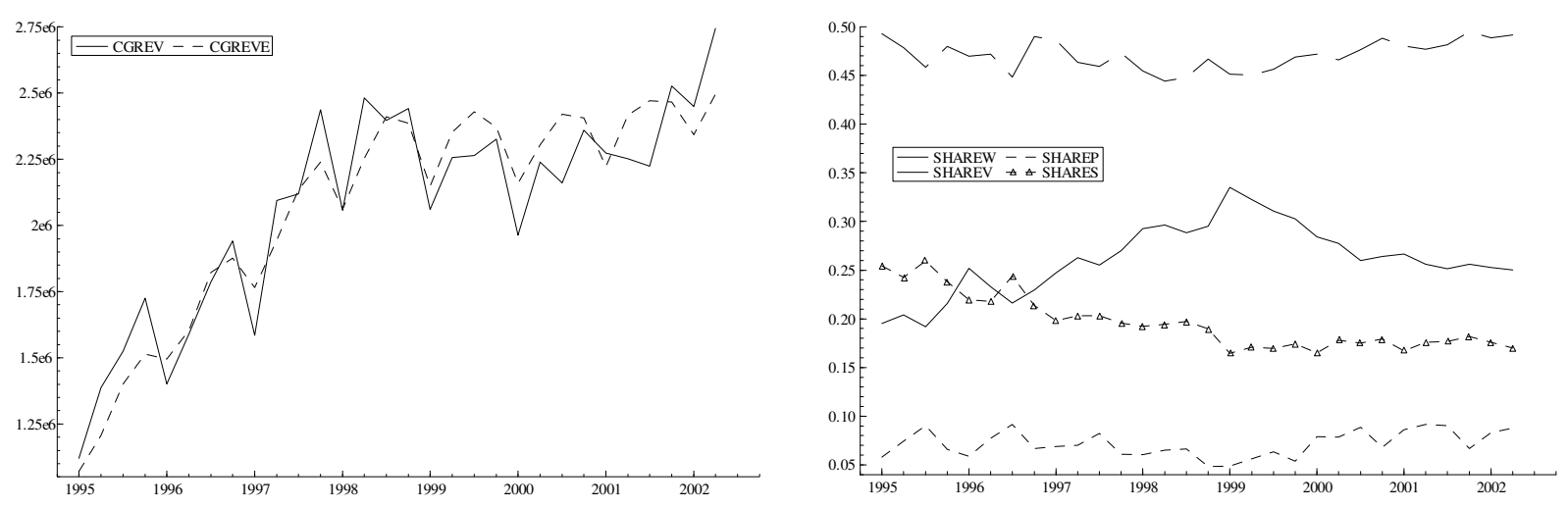

The governmental balance (deficit) is defined as government expenditure ${ }^{11}$ subtracted by government revenue.

$$
G_{D E F}=R-1000 \cdot C_{g} \cdot P_{C_{g}}
$$

Where

$\begin{array}{ll}G_{D E F} & \text { government deficit }(G D E F, 1000 \text { Litas current prices }) \\ C_{g} & \text { government consumption, national accounts }(C G R N, \text { mill. Litas constant prices }) \\ P_{C g} & \text { price index on government consumption }(p c g, 1995=1) \\ R & \text { government revenue }(C G R E V, 1000 \text { Litas current prices })\end{array}$

As seen in Figure 7 (right), the estimated revenue is higher than real expenditure, mostly at the beginning of the estimation period. This is the part where CGV mostly differs from CGEXV, but as the CGEXV and estimated government revenue are getting closer to CGEXV and CGREV, respectively, the difference between estimated and real government deficit becomes smaller. This convergence allows us to include (24) into the model. This inclusion is very useful when analysing scenarios. It is important to consider whether or not the government deficit is constantly increasing.

\footnotetext{
${ }^{11}$ There are two different sources for data on government expenditure: the part from GDP calculated by expenditure approach on the basis of national accounts (CGV), another from the Ministry of Finance as discussed above (CGEXV). The principles of their calculus are very close, so the theory showed above also works in the case of CGV. Though CGV is a bit lower, we prefer to use CGV in the model as it does not include non-budgetary funds and some other parts of national budget.
} 
Figure 7 Governmental Expenditure (left) and Governmental Balance (right)
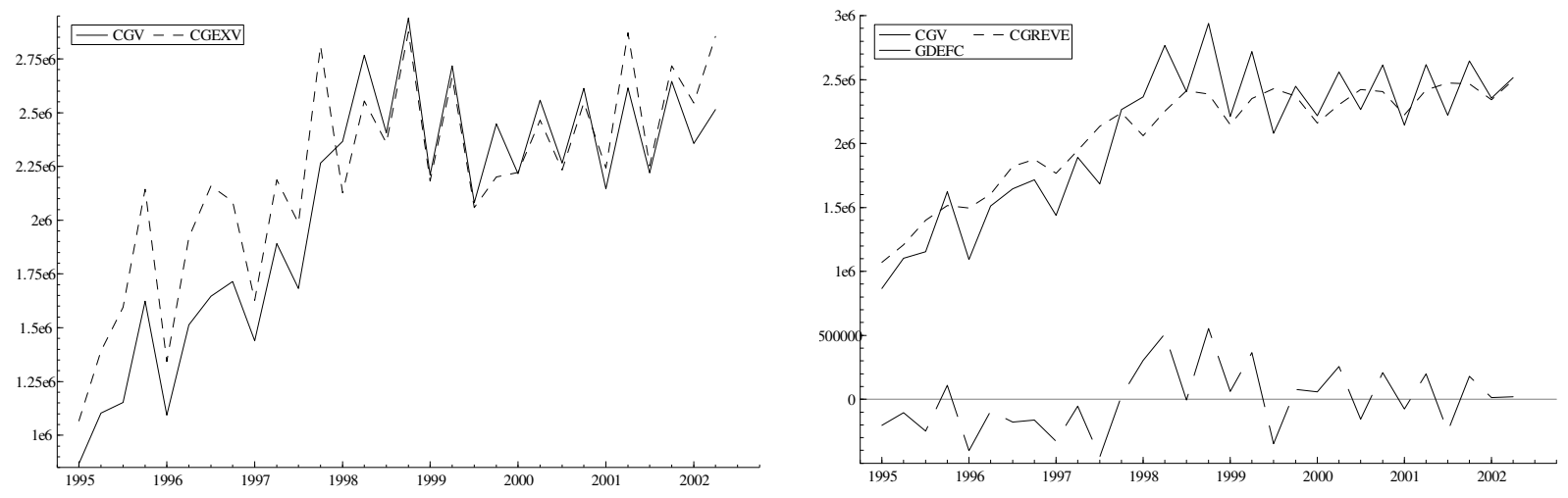

\subsection{Social Security Fund}

The State Social Insurance system covers nearly all Lithuanian residents: either as the insurers, the insured, or the beneficiaries. The system is based on the principle of solidarity of generations: employed population support pensioners, disabled and unemployed persons by paying social insurance contributions.

The employer (the sectors) pays a fixed rate of the wage payments to the Social Security Fund (34\%), and the revenue of social security fund is, therefore, calculated as a share of total domestic wages:

$$
R_{S S F}=t_{s s f} \cdot W
$$

Where

$R_{S S F} \quad$ Revenue of SSF (SSCIN, mill. Litas current prices)

$t_{s s f} \quad$ SSF rate (ssc)

W Wage sum (Wsum, mill. Litas current prices)

The social fund expenditure is paid to households (CGSEV is included in the disposal income $D I$, see Section 3.2). Figure 8 (left) shows that expenditure is since 1998 much greater than revenue. However, according to the latest report form the SSSF, the deficit decreased and became minimal.

State Social Security Fund expenditure structurally consists of the following parts:

$$
C_{G S S}=\text { Pension }+ \text { Health }+ \text { Benefits }+ \text { Unem }+F C+\text { Other }
$$

Where

$C_{G S S} \quad$ Expenditure of SSSF (CGSEV, 1000 Litas current prices);

Pension Retirement benefits, disability pensions, deferred pay

Health Sickness benefit

Benefits Special benefits: child benefit, widowhood benefit and scientist benefit

Unem Unemployment compensation 
Other Other expenditures

According to statistical information for the period 1995 to 2001 , an average of $72.4 \%$ was spent on pensions, $9.3 \%$ on special benefits, and $9 \%$ on health insurance; $4 \%$ was fixed cost, unemployment compensations and other benefits took the remainder of approximately $5 \%$. In the calculation of disposable income of households, we should pay attention to the estimated fixed cost. In the identity for household disposable income CGSEV is included, using a 0.96 correction factor.

We should notice that retirement benefit is the largest part of SSSF's expenditure. In the model, we included exogenous variables for the number of pensioners and for the other part of SSSF's expenditure. It is intuitively clear that the wage-rate is an import determinant for pensions and possibly for the other expenditure, i.e., we specify the following equation for an average monthly pension:

$$
\log (\text { Pens })=\alpha_{0}+\alpha_{1} \log \left(P_{C}\right)+\alpha_{2} \log \left(W_{P R I}\right)+\lambda_{2} Q_{2}+\lambda_{3} Q_{3}+\lambda_{4} Q_{4}
$$

Where

Pens $\quad$ Average pension (monthly in Litas)

$P_{C} \quad$ Consumer price index

$W_{P R I} \quad$ Average wage in private sector (monthly in Litas)

$Q_{2}-Q_{4} \quad$ Quarter dummies

Table 6 Monthly Pension, Parameter Estimates

\begin{tabular}{lllllll}
\hline Parameter & $\alpha_{0}$ & $\alpha_{1}$ & $\alpha_{2}$ & $\lambda_{2}$ & $\lambda_{3}$ & $\lambda_{4}$ \\
\hline .640576 & 0 & .703500 & -.038229 & -.053483 & -.091575 \\
& {$[3.82758]$} & $*$ & {$[28.4816]$} & {$[-2.01378]$} & {$[-2.72407]$} & {$[-4.63528]$} \\
\hline Estimation period 1995q1-2001q4; t-values in [ ]; ${ }^{*}$ restricted parameter; $\mathrm{R}^{2}=0.970$ \\
\hline
\end{tabular}

We see that the value of pension is positively related to the average monthly wage, but the elasticity is below one. This implies that pensions do not keep up with changes in average wage within the private sector. There was unfortunately no significant influence of the consumer prices (parameter restricted to zero). The final equation for SSSF expenditure is specified as:

$$
C_{G S S}=3 \cdot \text { Pens } \cdot \text { Pensnr }+C_{G S S, \text { other }}
$$


Figure 8 SSF Revenue and Expenditure (left). Pension (right)
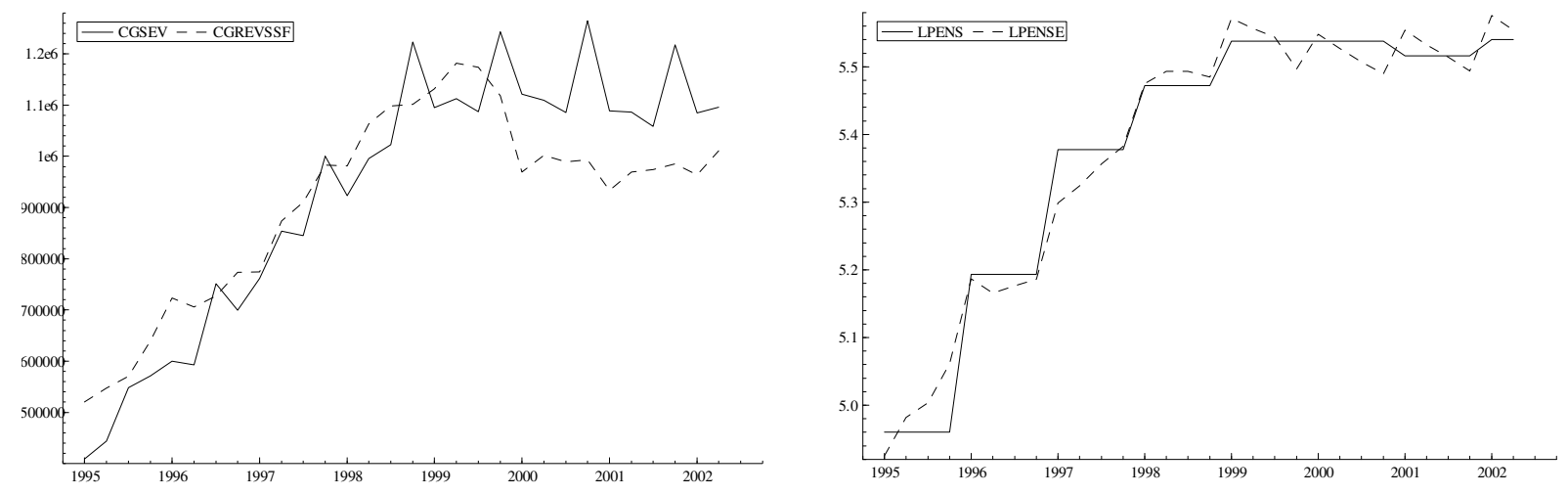

\section{Investments}

The gross domestic investment (IRN1 in our notation) is a very important part of GDP. Its dynamics represent the country's ability to satisfy the population's increasing need for goods and services. The creation and accumulation of capital is intended to increase the level of productivity and thus allow for an increase in the production of goods and services at a future date.

Traditionally, economists distinguish between capital, non-capital and financial (portfolio) investments. This model primarily concentrates on capital investments and partly investigates financial investments since foreign direct investments (FDI $)^{12}$ are used as one of the determinant of gross investment. Besides capital investment, gross domestic investments also include the value of investment in non-capital assets (information, human capital, technology, etc.) not directly measured within this model, but not less important.

According to the Statistical Yearbook, the capital investment could be defined as the investment in tangible fixed assets covering cost of buildings, equipment, machinery, vehicles, construction and alteration of existing fixed assets (current maintenance costs are excluded). Total capital investment consists of capital investments in sectors $\left(I_{j}\right)$ and household investments in dwellings $\left(I_{H}\right)$ :

$$
I_{C}=\sum_{j} I_{j}+I_{H}
$$

Foreign direct investment could be characterised as investment forming the basis for longterm relations between a direct foreign investor and an enterprise of direct investment. $10 \%$ of votes are considered to be the lowest level, allowing a direct foreign investor to participate in the management of a direct investment enterprise. Foreign investment that allows less than $10 \%$ of votes is defined as portfolio investment and not as direct investment.

In summarising the discussion, we define gross domestic investments as:

\footnotetext{
${ }^{12}$ In fact, there are two ways to calculate the foreign direct investments: from the stock of foreign direct investments and from the balance of payment. However, the Bank of Lithuania and Statistical Department use different bond prices (nominal and market) approaches for these calculations, so that the data becomes incomparable. It could even bring a paradoxical situation when $f d i$ is growing by one approach and decreases by another. In our work, we use data from the balance of payment. We use $f d i$ as an exogenous variable.
} 


$$
I_{D}=I_{C}+I_{f}+I_{n c}
$$

Where

$I_{D} \quad$ Gross domestic investments (IRN1, mill. Litas constant prices)

$I_{C} \quad$ Total capital investments $(I R T H)$

$I_{f} \quad$ Investments in financial assets (portfolio investments)

$I_{n c} \quad$ Non-capital investments ${ }^{13}$

Other aspects of the modelling of investments are described: investments in sectors (Section 9.3) and investments in dwellings (Section 3.4). The equation in the model for gross domestic investment will be specified in the section below.

\subsection{Data}

We have data for capital investments in sectors and dwellings in current prices $(I V j)$ and gross fixed capital formation in current and constant prices (IV and IRN). However, we are modelling the demand for investments in constant prices. We calculate an aggregated investment price $(P I=I V / I R N)$ from total investments and use this to calculate investments in sectors in constant prices $(I R j=I V j / P I)$. We implicitly make the assumption that the aggregated investment price is highly correlated with the investment price in each sector.

From Figure 9 (right), it is seen that the calculated total capital investments have a seasonal pattern and a growing trend. The share of total capital investment in the gross investments makes on average $63 \%$, and there is an increasing tendency.

Figure 9 Total Capital Investments relative to the Gross Domestic Investment (left). Gross Investment, Gross Fixed Capital Formation, Total Capital Investment and Foreign Direct Investments in Current Prices (right)
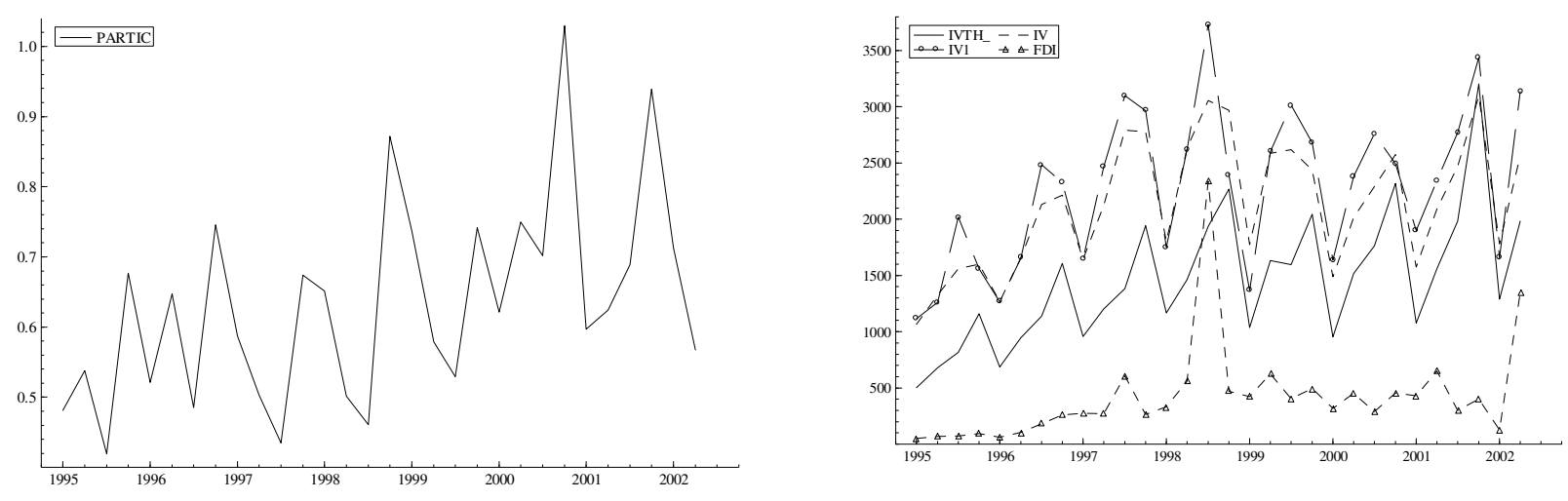

A rapid growth in foreign direct investments in 1998q3 is explained by the privatisation of "Lietuvos telekomas". The influence of the consequent privatisation process in Lithuania is also seen from steadily positive changes in foreign direct investment stock.

${ }^{13} I_{f}$ and $I_{n c}$ are not estimated in the model. 


\subsection{Gross Domestic Investments}

As important determinants for gross domestic investments $\left(I_{D}\right)$, we use total capital investments $\left(I_{C}\right)$, GDP $(Y)$, and real foreign direct investments $\left(I_{f d}\right)$. In equation (31), we restrict $\alpha_{1}$ to one, because total capital investments make a certain observed part of gross domestic investments (see (30)). An unobserved residual (non-material and portfolio investments) could be determined by the other included variables. Capital investments fluctuate more rapidly than gross domestic investments, and seasonal adjustments are included due to this. There is also a statistically significant effect on the Russian crisis and thus a static (long-term) equation for gross domestic investments is:

$$
I_{D}=\alpha_{0}+\alpha_{1} I_{C}+\alpha_{2} I_{f d}+\alpha_{3} Y+\alpha_{4} D_{R C,-1}+\lambda_{2} Q_{2}+\lambda_{3} Q_{3}+\lambda_{4} Q_{4}
$$

Where

$I_{D} \quad$ Gross domestic investment (IRN1, mill. Litas constant prices)

$Y \quad$ Gross value added (GDPT, mill. Litas constant prices)

$I_{f d} \quad$ Foreign direct investment (FDI/PI, mill. Litas constant prices)

$I_{C} \quad$ Total capital investment (IRTH, mill. Litas constant prices)

$D_{R C} \quad$ Dummy for Russian crisis in $1998 \mathrm{q} 3$

$Q_{2}-Q_{4} \quad$ Quarter dummies

Table 7 Gross Domestic Investments, Parameter Estimates

\begin{tabular}{rrrrrrrrr}
\hline Parameter & $\alpha_{0}$ & $\alpha_{1}$ & $\alpha_{2}$ & $\alpha_{3}$ & $\alpha_{4}$ & $\lambda_{2}$ & $\lambda_{3}$ & $\lambda_{4}$ \\
\hline 540.978 & 1 & .553061 & 0 & -245.018 & 217.328 & 467.107 & -162.977 \\
{$[5.57540]$} & ${ }^{*}$ & {$[4.77034]$} & ${ }^{*}$ & {$[-2.95464]$} & {$[1.87749]$} & {$[3.85344]$} & {$[-1.39687]$} \\
\hline Estimation period 1995q1-2002q2; t-values in [ ]; ${ }^{*}$ restricted parameter; $R^{2}=0.893986$ & & \\
\hline
\end{tabular}

Figure 10 shows plot of residuals and fitted versus actual values.

\section{Figure 10 Gross Domestic Investments, Fit and Residuals}
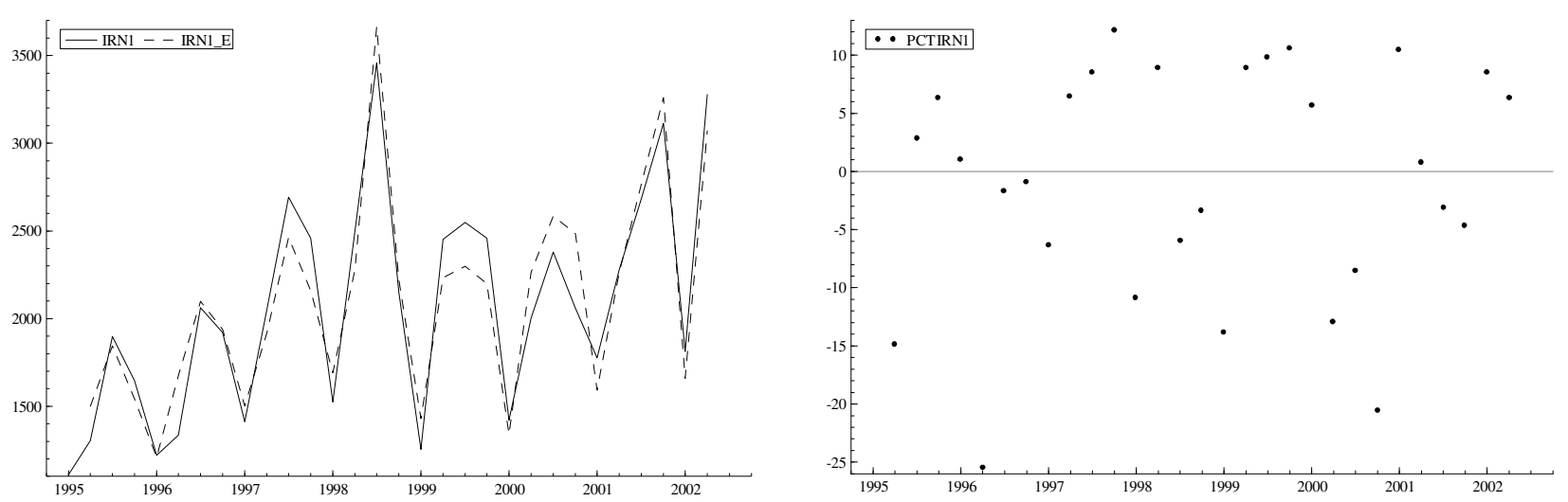


\section{6. $\quad$ Export}

The basic set-up in the export and import modelling is an Armington model. ${ }^{14}$ Regarding import, the model idea can be described in the following way: A given Lithuanian demand for a product can either be fulfilled by domestic production or by import. Both types of supply adjust according to demand, but the composition of domestic and foreign produced goods depends on the prices of domestic production and import since the consumers prefer the cheapest. So the import share of the market is a function of relative prices. Even though the domestic and foreign produced product is essentially the same, the consumer distinguishes between them according to the country of origin; therefore, domestic and foreign produced goods are not perfect substitutes, and the same products can have different prices. The same type of model is used for exporting, since export is import from Lithuania seen from abroad.

We do not have data for the size of the export market so we use instead a weighted average of the GDP growth in the countries to which Lithuania export. As weights, we use the export shares in 2001 of Lithuania's 14 main foreign trade partners, (the calculation of $Y_{W o r l d}$ is shown in Appendix 12.4). It is normally assumed that the export market increases faster than GDP due to an increased internationalisation. So, if we assume that the export share (export/size of export market) is in the long-run constant (usually in the Armington model), we expect export elasticity with respect to the GDP-index to be larger than one $\left(\alpha_{1}>1\right.$ in (32)).

We use as price on the export market a 'World Market Price' where market prices in the three export markets (EU, Central Europe, and CIS) are weighted according to their share of export during 2001 (the calculation of the World Market Price is shown in Appendix 12.4).

If the export market competition was monopolistic, ${ }^{15}$ we would estimate a negative relationship between the export and the relative export price $\left(\alpha_{2}<0\right.$ in Equation (32)). If there was perfect competition instead, the World Market Price determines the export price and the relative price is constant and cannot be used as an explanatory variable. In this case, we will see a positive relationship between export and World Market Price $\left(\alpha_{4}>0\right.$ in Equation (32)). The determination of the export price in the model is described in Section 10.8.

$$
\begin{aligned}
\log \left(X^{*}\right)= & \alpha_{0}+\alpha_{1} \log \left(Y_{\text {World }}\right)+\alpha_{2} \log \left(p_{X} / p_{\text {World }}\right)+\alpha_{4} \log \left(p_{\text {World }}\right) \\
& +\kappa \cdot D_{R C}+\lambda_{2} \cdot Q_{2}+\lambda_{3} \cdot Q_{3}+\lambda_{4} \cdot Q_{4}
\end{aligned}
$$

Where
$X \quad$ Export $(X R N$, mill. Litas constant prices)
$X^{*} \quad$ Export, equilibrium level
$Y_{\text {World }} \quad$ GDP in export market, weighed index of GDP in the primary export countries (GDPwr, 1995=1).
$p_{X} \quad$ Export price $(p x, 1995=1)$
$p_{\text {World }} \quad$ World Market Price $(w m p, 1995=1)$

\footnotetext{
${ }^{14}$ Paul Armington (1969): A Theory of Demand for Products Distinguished by Place of Production. IMF staff Papers, 26 (p. 159-178).

${ }^{15}$ It is often assumed that manufacturing export is monopolistic. In Lithuania, the export of goods is much greater than export of services. Therefore, we expect to see a monopolistic competition in the aggregated export.
} 
The dynamic adjustment to the long-term relation is formulated as an error correction model.

$$
\begin{aligned}
\operatorname{Dlog}(X) & =\beta_{1} \operatorname{Dlog}\left(Y_{\text {World }}\right)+\beta_{2} \operatorname{Dlog}\left(p_{X} / p_{\text {World }}\right)+\beta_{3} \operatorname{Dlog}\left(p_{X}\right)+\beta_{4} \operatorname{Dlog}\left(p_{\text {World }}\right) \\
& +\kappa \cdot \mathrm{D}\left(D_{R C}\right)+\beta_{0}\left[\log \left(X_{-1}\right)-\log \left(X_{-1}^{*}\right)\right]
\end{aligned}
$$

We see in Figure 11 (left) that export grows faster than GDP in the export market expected for the drastic decrease in the export during 1998 and the following years. The decrease is due to the Russian crisis (in the figure, XRN1 is total export in constant prices equal to one in 1995q1, and GDP_w1 is the World GDP index with 1995q1=1). We use a dummy in the estimation $\left(D_{R C}\right)$ to explain the downward shift in the export following the Russian crisis. Previously, a large share of the Lithuanian export was to the CIS countries whereas by the end of the estimation period, half of the export was to the EU. The shift in export markets was due to the Russian crisis, but we were not able to formulate an equation explaining the shift, for example, by including the growth rate in the Russian GDP. Therefore, we use a dummy in the estimation. $^{16}$

We see in Figure 11 (right) that the World Market Price in the last part of the estimation period grows more rapidly than the export price ( $p x 1$ is the export price with $1995 \mathrm{q} 1=1$, and wmp is the World Market Price index with 1995q1=1).

\section{Figure 11 Export, Foreign Market and Relative Export Price}
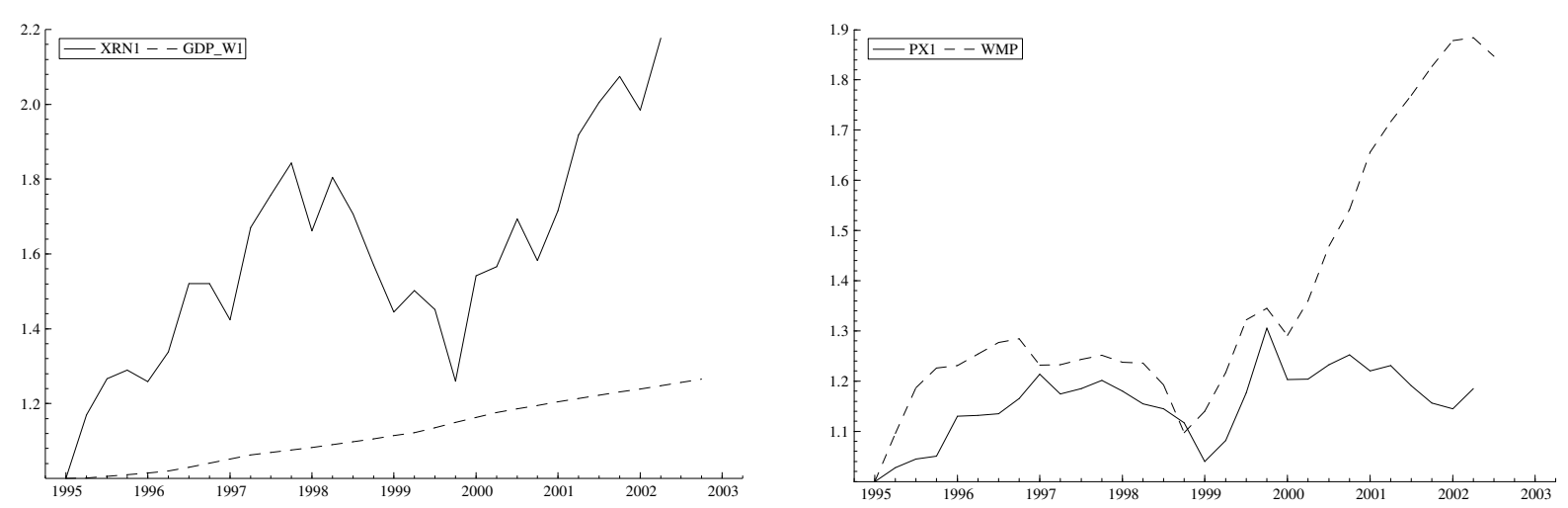

The parameter estimates from the chosen estimation are shown in Table 8, and the historical fit of the estimated equation is shown in Figure 12.

\begin{tabular}{|c|c|c|c|c|c|c|c|c|c|c|c|c|}
\hline$\alpha_{0}$ & $\alpha_{1}$ & $\alpha_{2}$ & $\alpha_{4}$ & $\kappa$ & $\lambda_{2}$ & $\lambda_{3}$ & $\lambda_{4}$ & $\beta_{0}$ & $\beta_{1}$ & $\beta_{2}$ & $\beta_{3}$ & $\beta_{4}$ \\
\hline $\begin{array}{l}8.355 \\
{[90.9]}\end{array}$ & $\begin{array}{l}1.571 \\
{[2.08]}\end{array}$ & $\begin{array}{c}-0.514 \\
{[-1.73]}\end{array}$ & $\begin{array}{l}0 \\
*\end{array}$ & $\begin{array}{c}-0.147 \\
{[-2.39]}\end{array}$ & $\begin{array}{l}0.010 \\
{[0.14]}\end{array}$ & $\begin{array}{c}-0.167 \\
{[-1.71]}\end{array}$ & $\begin{array}{l}-0.230 \\
{[-2.31]}\end{array}$ & $\begin{array}{l}-0.405 \\
{[-3.87]}\end{array}$ & $\begin{array}{l}0 \\
*\end{array}$ & $\begin{array}{l}0 \\
*\end{array}$ & $\begin{array}{c}-1.124 \\
{[-4.09]}\end{array}$ & 0 \\
\hline
\end{tabular}

Table 8 Parameter Estimates, Export Relation

\footnotetext{
${ }^{16}$ In macro-econometric models, it is often difficult to explain shifts in export when there is major changes in the export market, e.g., the Danish macro-econometric models use a dummy to explain changes in export following the German reunion.
} 
In the long-run equation, the parameter to the relative export price $\left(\alpha_{2}\right)$ is negative indicating a monopolistic competition on the export market. ${ }^{17}$ In the dynamic equation, only changes in the export price changes the export $\left(\beta_{3}<0, \beta_{2}=0, \beta_{4}=0\right)$. If the World GDP increases by $1 \%$, the export increases in the long-run by $1.6 \%\left(\alpha_{1}=1.571\right)$, but there is no effect on the first quarter $\left(\beta_{1}=0\right)$.

\section{Figure 12 Export, Fit of Estimated Equation}
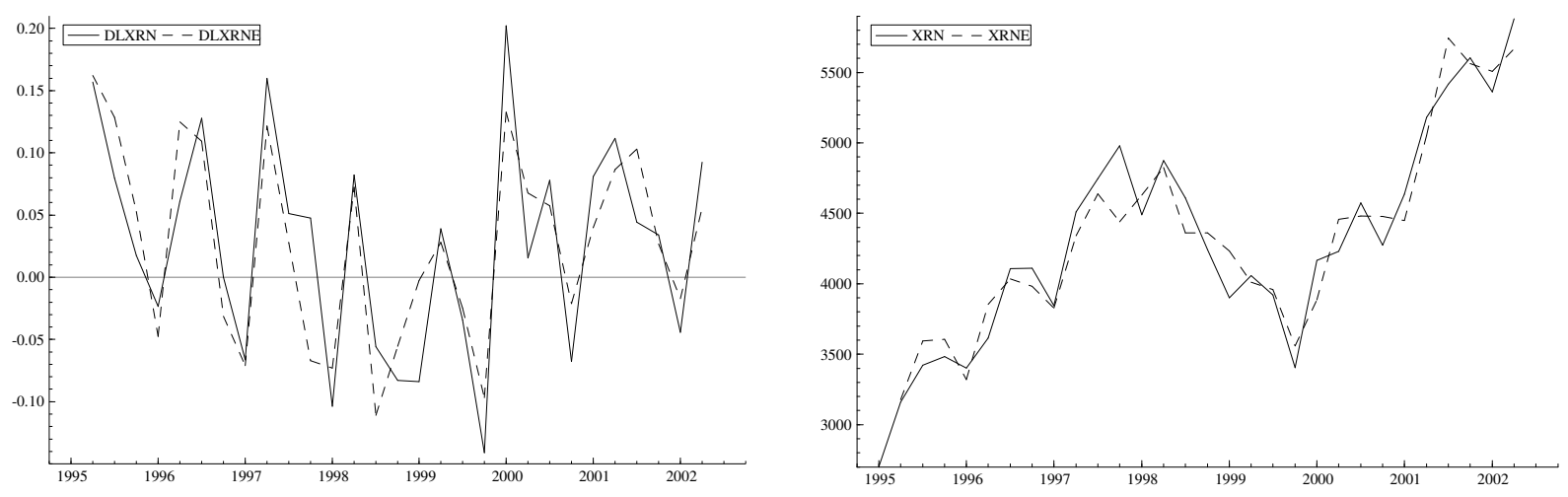

\section{Import}

Based on the Armington-model, we established the same basic demand equation for import as we did for export.

The domestic demand for import could be calculated as the demand components weighted by their import contents - unfortunately, deliveries in the Input-Output table are not distinguished between import and domestic production. We choose to use private consumption as proxy for the domestic demand for import and the consumer price as the relative price.

$$
\begin{gathered}
\log \left(M^{*}\right)=\alpha_{0}+\alpha_{1} \log \left(Y_{\text {import }}\right)+\alpha_{2} \log \left(p_{M} / p_{C}\right)+\alpha_{3} D_{R C}+\lambda_{2} \cdot Q_{2}+\lambda_{3} \cdot Q_{3}+\lambda_{4} \cdot Q_{4} \\
\operatorname{Dlog}(M)=\beta_{1} \operatorname{Dlog}\left(Y_{\text {import }}\right)+\beta_{2} \operatorname{Dlog}\left(p_{M} / p_{Q}\right)+\alpha_{3} \mathrm{D}\left(D_{R C}\right)+\beta_{0}\left[\log \left(M_{-1}\right)-\log \left(M_{-1}^{*}\right)\right]
\end{gathered}
$$

Where

$M \quad$ Import total (MRN, mill. Litas constant prices)

$M^{*} \quad$ Import equilibrium level

$Y_{\text {import }}$ Domestic demand for import (private consumption $C R N$, mill. Litas constant prices)

$p_{M} \quad$ Price on import $(1995=1)$

$p_{C} \quad$ Price on private consumption $(1995=1)$

$D_{R C} \quad$ Dummy for the Russian Crisis (= 1 1998q3-)

\footnotetext{
${ }^{17}$ In the former LITMOD sector model, a monopolistic competition was also estimated, and there was a larger coefficient to the relative export price in the export of manufacturing than in the export of service.
} 
We see in Figure 13 (left) that import grows faster than the domestic demand (MRN1 and CRN1 is equal to one in 1995q1) - except for the drop in import after 1998 (we use a dummy in the estimation to explain the change due to the Russian crisis). In the figure to the right, we see that the import price relative to the domestic consumer price (PM_PC) was decreasing until the beginning of 2000 whereafter it remained mostly constant.

\section{Figure 13 Import, Domestic Demand, and Relative Price}
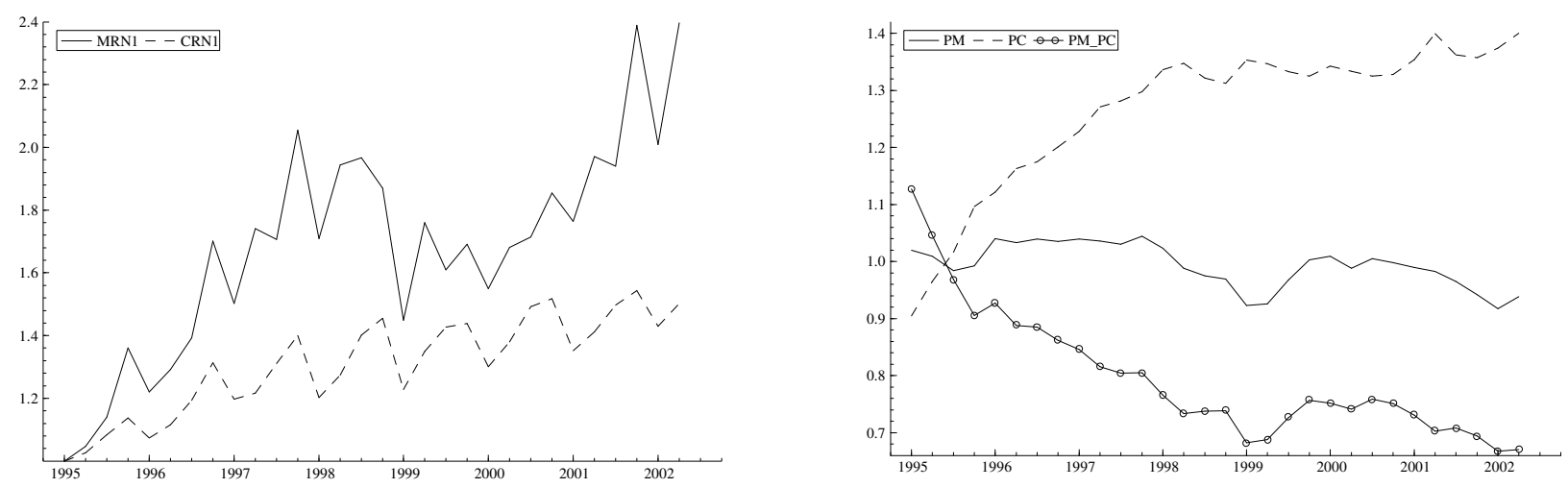

The chosen estimation is presented in Table 9. The estimated short-run demand elasticity $\left(\beta_{1}\right)$ is larger than the long-run demand elasticity $\left(\alpha_{1}\right)$. This indicates that domestic production cannot in the short-run fulfil increased demand. The import is largely influenced by the import price relative to the consumer price - the long-term price elasticity is $-0.8\left(\alpha_{2}\right)$ and the short-run elasticity is $-1.4\left(\beta_{2}\right)$. The adjustment towards the long-run equilibrium is quick ( $\beta_{0}$ $=-0.879)$.

Table 9 Parameter Estimates, Import Relation

\begin{tabular}{|c|c|c|c|c|c|c|c|c|c|c|}
\hline Param & $\alpha_{0}$ & $\alpha_{1}$ & $\alpha_{2}$ & $\alpha_{3}$ & $\lambda_{2}$ & $\lambda_{3}$ & $\lambda_{4}$ & $\beta_{0}$ & $\beta_{1}$ & $\beta_{2}$ \\
\hline & $\begin{array}{l}-5.991 \\
{[-1.90]}\end{array}$ & $\begin{array}{l}1.709 \\
{[4.51]}\end{array}$ & $\begin{array}{l}-0.807 \\
{[-2.54]}\end{array}$ & $\begin{array}{l}-0.212 \\
{[-4.69]}\end{array}$ & $\begin{array}{l}-0.093 \\
{[-1.82]}\end{array}$ & $\begin{array}{l}-0.031 \\
{[-0.64]}\end{array}$ & $\begin{array}{l}0.059 \\
{[0.66]}\end{array}$ & $\begin{array}{l}-0.879 \\
{[-3.72]}\end{array}$ & $\begin{array}{l}2.175 \\
{[4.03]}\end{array}$ & $\begin{array}{l}-1.364 \\
{[-2.64]}\end{array}$ \\
\hline
\end{tabular}

The historical fit of the relation is shown in Figure 14 (changes in the left figure and level in the right figure). The relation catches almost all changes in the import.

\section{Figure 14 Import, Fit of Equation}
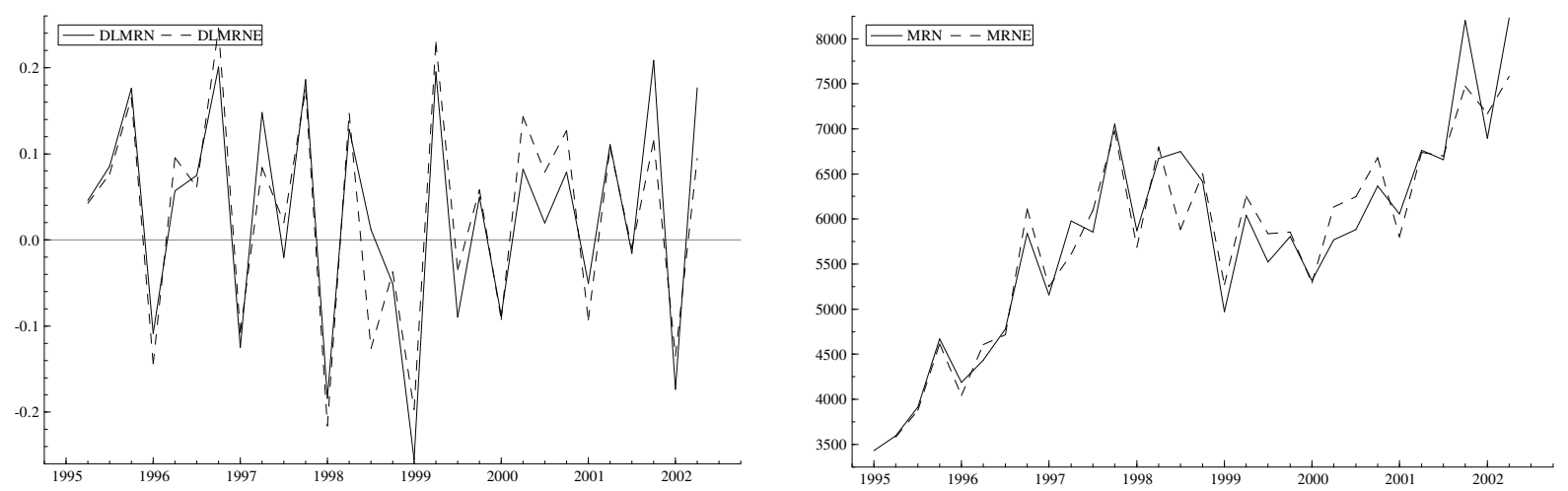


\section{Domestic Production, Intermediate, and GDP}

\subsection{Domestic Production}

We determine the domestic production in the 12 sectors by using the Input-Output coefficients. The problem is that only one set of Input-Output coefficients is available, and they are based on yearly data from 1997. Therefore, we need some corrections, which are described in the following sections.

\subsubsection{Import Correction}

Using equation (5) to determine production in the model causes problems when the model is simulated. Production may become negative in some sectors when import is subtracted from the total supply. Instead, we use the formulation (36) used in the first LITMOD. Using the Input-Output table, the import share coefficients $a m_{j}$ are calculated as $M_{j} / Q_{j}$. This ensures that the calculated production is always positive.

$$
\begin{aligned}
& \text { Supply }_{j}=Q_{j}+M_{j}=Q_{j}+a m_{j} \cdot Q_{j}=\left(1+a m_{j}\right) \cdot Q_{j}=\sum_{i} a_{j i} \cdot Q_{i}+\sum_{k} a_{j k} \cdot X_{k} \\
& \Leftrightarrow Q_{j}=\frac{1}{\left(1+a m_{j}\right)} \cdot\left(\sum_{i} a_{j i} \cdot Q_{i}+\sum_{k} a_{j k} \cdot X_{k}\right)
\end{aligned}
$$

Import $(M)$ is then indirectly determined as (37), but we will also have a demand equation for import in the model (see Section 7).

$$
M=\sum_{j=A, \ldots, S 4} a m_{j} \cdot Q_{j}
$$

The solution is to determine the import share coefficients $\left(a m_{j}\right)$ endogenously so that they depend on the import that is determined in the import demand equation. From (36) and (5), we obtain relation (38), which is used in the model. The time series for the import share coefficients are calculated in the same way.

$$
m_{j} \cdot M=a m_{j} \cdot Q_{j} \Leftrightarrow a m_{j}=\left(m_{j} \cdot M\right) / Q_{j}
$$

\begin{tabular}{|c|c|c|c|c|c|c|c|c|c|c|c|c|}
\hline ect & A & $\mathrm{MN}$ & E & M1 & M2 & 13 & M4 & C & S1 & 52 & S3 & S4 \\
\hline & 16 & 00 & 822 & 88 & & & 6 & 5 & 5 & & 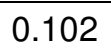 & 00 \\
\hline & 053 & .000 & 0.151 & .224 & 0.237 & .162 & 0.015 & 0.012 & 0.060 & 0.066 & 0.019 & 0.000 \\
\hline
\end{tabular}

The import coefficients are shown in Table 10. The $a m_{j}$ 's are calculated here by using the 1997 Input-Output table. However, they are not constant in the model.

Table 10 Import Coefficients in Equations for Domestic Production

\subsubsection{Corrections between Sectors and Quarters}

The input-output coefficients are calculated on the basis of yearly data. However, there are different seasonal variations in production and demand (change of stocks), especially in the agricultural sector (A). Therefore, we need to model some seasonal adjustment in these equations. Furthermore, we only have input-output coefficients for one year (1997), and there has clearly been structural changes between the sectors. We, therefore, estimate changes in the production level between the sectors. The estimated adjustments ensure that the total 
yearly production is determined by the aggregated demand by using the input-output coefficients. The different parts of the equation and restrictions are explained below:

$$
\begin{aligned}
\left(1+a m_{j}\right) \cdot Q_{j} & =\left[\sum_{i} a_{j i} \cdot Q_{i}+\sum_{k} a_{j k} \cdot X_{k}\right] \\
& +\left[\lambda_{j 1} \cdot Q_{1}+\lambda_{j 2} \cdot Q_{2}+\lambda_{j 3} \cdot Q_{3}+\lambda_{j 4} \cdot Q_{4}\right] \\
& +\left[\alpha_{j 0}+\alpha_{j 1} \cdot t+\alpha_{j 2} \cdot D_{R C}\right]
\end{aligned}
$$

Where

$\begin{array}{ll}a m_{j} & \text { Import share coefficients }\left(a_{j} i m p=a_{j} I m \cdot M R N / Q R_{j}\right) \\ Q_{j} & \text { Production in sector } j\left(Q R_{j}, \text { mill. Litas constant prices }\right) \\ X_{k} & \begin{array}{l}\text { Final consumption component } k\left(X_{k}=C R N, C G R N, I R N 1, X R N ; \text { mill. Litas }\right. \\ \text { constant prices })\end{array} \\ a_{j i} & \begin{array}{l}\text { Input-Output coefficient for deliveries from sector } j \text { to sector } i\left(a_{j i}, j, i=\mathrm{A}, \ldots, \mathrm{S} 4\right) \\ a_{j k}\end{array} \\ & \begin{array}{l}\text { Input-Output coefficient for deliveries from sector } j \text { to final consumption } \\ \text { component } k\left(a_{j k}, k=c p, c g, i r, e x\right)\end{array} \\ D_{R C} & \begin{array}{l}\text { Dummy for the Russian crisis }\left(D_{R C}=11998 \mathrm{q} 3-\right) \\ t\end{array} \\ Q_{2}-Q_{4} & \text { Time }\end{array}$

- $\quad$ The first square bracket is the Input-Output determination for supply of type $j$ based on a set of I-O coefficients from 1997. Total supply equals total demand.

- $\quad$ The second square bracket is quarterly dummies, i.e., a dummy for each quarter in each sector. The adjustment during the year adds to zero with restriction (40). This can be seen as a (simple) modelling of changes in stocks during the year for each sector (e.g., agricultural production). Yearly production in each sector remains unchanged.

$$
\lambda_{j 1}+\lambda_{j 2}+\lambda_{j 3}+\lambda_{j 4}=0, j=A, \ldots, S 4
$$

- $\quad$ The third square bracket is shifts between sectors (level (41) and trend (42)). $\alpha_{j 1}$ is additional million Litas of production in sector $j$ in each quarter. Total production remains unchanged.

$$
\begin{aligned}
& \sum_{j=A, \ldots, S 4} \alpha_{j 0}=0 \\
& \sum_{j=A, \ldots, S 4} \alpha_{j 1}=0
\end{aligned}
$$

- Changes in production structure due to the Russian crisis (43). Total production remains unchanged.

$$
\sum_{j=A, \ldots, S 4} \alpha_{j 2}=0
$$

In the estimation, we impose the three last restrictions in sector S4 (same results if imposed upon in any other sector). 
Furthermore, we allow an AR1 process in the residuals in sectors $\mathrm{C}$ and $\mathrm{S} 3$. This improves the explanation significantly, but if we do not include this process, the estimated value of the aggregated production is less than the actual production. We can explain the use of the ARprocess as stock changes, not only in the year between quarters, but also between years.

As seen in Figure 15, the estimated value of the aggregated production is quite close to the actual production. The remaining error in the aggregated production is (probably) due to the fact that actual values for total supply and total demand is not exactly equal in the entire estimation period.

\section{Figure 15 Aggregated Domestic Production, Fit and Residuals}
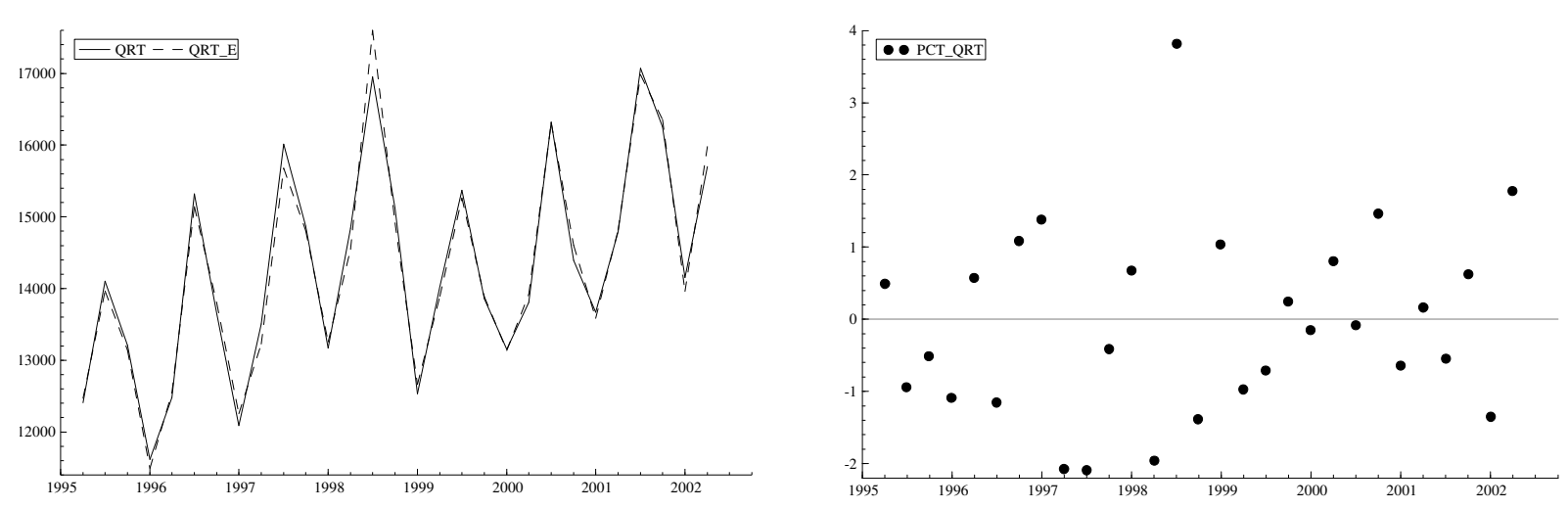

\subsection{Intermediate}

We have from the Input-Output table the following relations that determine intermediate (deliveries) between sectors (44). Intermediate used in sector $j\left(C_{j}\right.$, 'consumption' in sector $\left.j\right)$ is then a constant share of production in sector $j$ where the share is given by the sum of I-O coefficients $a_{i j}$ (deliveries from sector $i$ to sector $j$ ). The sum of the I-O coefficients in each sector is shown in Table 11; about half of the production in the sectors is based on deliveries from other sectors.

$$
C_{j}=Q_{j} \cdot \sum_{i} a_{i j}
$$

Table 11 Intermediate as Share of Production

\begin{tabular}{rrrrrrrrrrrrr}
\hline Sector & $\mathrm{A}$ & $\mathrm{MN}$ & $\mathrm{E}$ & $\mathrm{M} 1$ & $\mathrm{M} 2$ & $\mathrm{M} 3$ & $\mathrm{M} 4$ & $\mathrm{C}$ & $\mathrm{S} 1$ & $\mathrm{~S} 2$ & $\mathrm{~S} 3$ & $\mathrm{~S} 4$ \\
\hline$\sum_{i} a_{i j}$ & 0.501 & 0.546 & 0.546 & 0.642 & 0.664 & 0.655 & 0.602 & 0.511 & 0.347 & 0.472 & 0.277 & 0.370 \\
\hline
\end{tabular}

Intermediate is delivered from other sectors or imported. Using the I-O coefficients (44) we calculate the intermediate delivered from other sectors, and this is lower than the actual intermediate as seen in Figure 16 (left). We assume that import is a constant share of the intermediate and hence formulate the demand for intermediate proportional with the I-Ocalculated intermediate. 
Therefore, we extend the equation with proportionality of the I-O-calculated intermediate $\left(\alpha_{1}\right)$, a constant term $\left(\alpha_{0}\right)$, a time trend $\left(\alpha_{2}\right)$, quarterly dummies $\left(\lambda_{2}-\lambda_{4}\right)$, and a dummy for the Russian crisis $\left(\alpha_{3}\right)$ - as used in the production equations. As seen in Figure 16 (right), there is an almost perfect fit of the total intermediate, and there are only some deviations in the service sectors.

$$
C_{j}=\alpha_{0 j}+\alpha_{1 j} \cdot Q_{j} \cdot \sum_{i} a_{i j}+\alpha_{2 j} \cdot t+\alpha_{3 j} \cdot D_{R C}+\lambda_{2} \cdot Q_{2}+\lambda_{3} \cdot Q_{3}+\lambda_{4} \cdot Q_{4}
$$

Where

$C_{j} \quad$ Intermediate in sector $j\left(I N R_{j}\right.$, mill. Litas constant prices)

$Q_{j} \quad$ Production in sector $j\left(Q R_{j}\right.$, mill. Litas constant prices)

$a_{i j} \quad$ Input-Output coefficient for deliveries from sector $i$ to sector $j$

$D_{R C} \quad$ Dummy for the Russian crisis $\left(D_{R C}=11998 \mathrm{q} 3\right)$

$t \quad$ Time

$Q_{2}-Q_{4} \quad$ Quarterly dummies; $Q_{2}$ is equal to one in second quarter and else zero

The dummy $\left(\alpha_{3}\right)$ is only needed in sector $S 1$, and the quarterly dummies are only needed in sectors $\mathrm{E}, \mathrm{MN}, \mathrm{S} 1$, and $\mathrm{S} 4$. The estimated time trend $\left(\alpha_{2}<0\right)$ is negative indicating that the production has become more labour and capital intensive during the estimation period.

Figure 16 Intermediate (left: I-O-based, right: estimated)
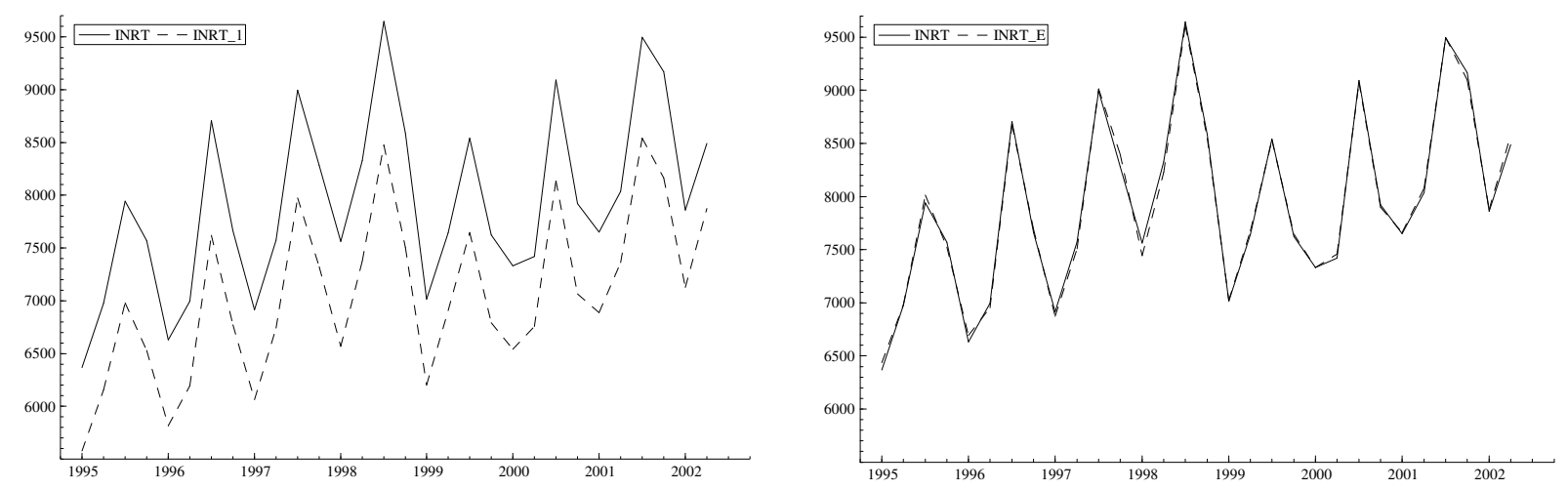

We could later extend the model and add (estimated) demand equations for energy use and other intermediates.

\subsection{Gross Value Added and GDP}

Production consists of intermediate and gross value added (capital and labour), and we will, therefore, determine gross value added in the model for each sector $\left(Y_{j}\right)$ as (46).

$$
Y_{j}=Q_{j}-C_{j}
$$

We use the national accounts ideology in the model for the calculation of GDP. We estimate GDP by using the production and expenditure approaches. By first approach, GDP is the net value of the goods and services produced within the country during the reference period. In other words, the gross value added is firstly estimated as a sum of value added by every 
activity, i.e., gross output less intermediate consumption as stated in (46). Then, the gross value added by all types of activity at basic prices plus taxes on products minus subsidies on products forms GDP at market prices:

$$
Y=P_{Y} \cdot \sum_{j} Y_{j}+R_{v}
$$

Where

$Y \quad$ GDP (GDPV, mill. Litas in current prices)

$Y_{j} \quad$ Gross value added in sector $j$ (GDPj, mill. Litas constant prices)

$P_{Y} \quad$ GDP price index ( $\left.p g d p, 1995=1\right)$

$R_{v} \quad$ Revenue from VAT paid by households (CGREVV, mill. Litas current prices)

Calculating GDP by expenditure approach (constant prices) is (48), and this is almost equal to GDP calculated by using production in sectors (47).

$$
Y^{*}=X-M+I_{D}+C_{P}+C_{G}
$$

Where

$\begin{array}{ll}Y^{*} & \text { GDP }(G D P, \text { mill. Litas constant prices }) \\ X & \text { Export }(X R N, \text { mill. Litas constant prices }) \\ M & \text { Import }(M R N, \text { mill. Litas constant prices }) \\ I_{D} & \text { Domestic investments (IRN1, mill. Litas constant prices) } \\ C p & \text { Private consumption }(C R N, \text { mill. Litas constant prices }) \\ C g & \text { Public consumption }(C G R N, \text { mill. Litas constant prices })\end{array}$

\subsection{Current Account and Balance of Payment}

The balance of payments is an important measure in relation to the formulation of economic policy. It expresses the economical transactions of the country with the rest of the World in terms of value over a specific period of time. The balance of payment consists of the following components:

- $\quad$ Current account, which shows bilateral transactions of trade and services, interest and dividends collected and paid, as well as transfers;

- Capital and financial account, which records transactions with non-residents in non-production, non-financial assets, as well as capital transfers;

- $\quad$ Reserve assets.

We should notice that, in principal, balances of the three main balance of payment parts are interlinked by the equation: the current account balance (with the opposite sign) equals the sum of the capital and financial account balance and changes in net official reserves. However, in practice, due to accounting errors and non-recorded transactions, accounts do 
frequently not balance. Differences are shown in a separate entry of the balance of payments called errors and omissions.

We concentrate in this model on the current account only (other parts and the identity for balance of payment are linked with the monetary block excluded from the present version of the model).

$$
C A=P_{X} \cdot X+I_{B A L}+N T-P_{M} \cdot M
$$

Where

$C A \quad$ Current account balance ( $C A$, mill. Litas, current prices)

$P_{X} \quad$ Export price $(P X, 1995=1)$

$P_{M} \quad$ Import price $(P M, 1995=1)$

$X \quad$ Export of goods and services ( $X R N$, mill. Litas, current prices)

$M \quad$ Import of goods and services ( $M R N$, mill. Litas, current prices)

$I_{B A L} \quad$ Income balance (INBAL, mill. Litas, current prices)

NT Net transfers (NT, mill. Litas, current prices)

\section{Factor Demand}

In order to produce, companies use three production factors: commodities (intermediate from other sectors and import), labour, and capital. The demand for commodities is described in Section 8.2. The demand for labour in the 12 sectors is described in Section 9.2, and the demand for capital in the sectors is formulated as a demand for investments in Section 9.3.

We start out by formally stating a production function. The problem, at this moment, is that there is no official data on the capital stock (see Section 5), so 'capital demand' has to be formulated as an investment relation. Therefore, we end up estimating separate demand equations for labour and investments in sectors as an approximation to theoretical more correct demand equations.

\subsection{Production Function and Factor Demand Equations}

Production is described by a nested production function with three production factors (intermediate $C$, labour $L$, and capital $K$ ) shown in (50) and illustrated in Figure 17. We assume weak separability between intermediate and the aggregation of labour and capital.

$$
\begin{aligned}
& Q=g(C, K, L)=h(C, Y) \\
& Y=f(K, L)
\end{aligned}
$$

The optimisation problem for companies is to minimise production costs subject to a fixed level of production.

$$
\begin{array}{lrl}
\operatorname{Min}_{\{C, L, K\}} \text { Costs } & =P_{C} \cdot C+P_{L} \cdot L+P_{K} \cdot K \\
\text { s.t. } & Q=g(C, K, L)=h(C, Y)=h(C, f(K, L))
\end{array}
$$

Where 


$\begin{array}{ll}Q & \text { Production in sector } j \\ Y & \text { GDP in sector } j \\ C & \text { Intermediate in sector } j \\ L & \text { Labour (hours) in sector } j \\ K & \text { Capital stock in sector } j \\ P_{C} & \text { Price on intermediate in sector } j \\ P_{L} & \text { 'Price' on labour } \\ P_{K} & \text { 'Price' on capital - user cost } \\ f, g, h & \text { Production functions }\end{array}$

\section{Figure 17 Factor Demand}

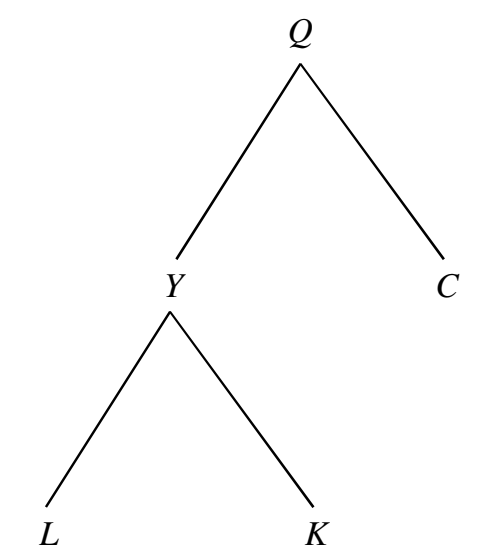

We assume that intermediate is a constant share of production (this is a standard assumption in macro-economic models). With this assumption, the outer production function $(h)$ is a Leontief function and the demand for intermediate (and GVA) is given by (52). As described in Section 8.2, we model the demand for intermediate using the input-output coefficients (45) and GVA $(Y)$ as (46).

$$
\begin{aligned}
& C=\kappa \cdot Q \\
& Y=(1-\kappa) \cdot Q=Q-C
\end{aligned}
$$

Looking at the demand for labour and capital, GVA is given from the above equation and companies should minimise costs to labour and capital. Using Lagrange optimisation solves this.

$$
\begin{array}{ll}
\operatorname{Min}_{\{K, L\}} & P_{K} \cdot K+P_{L} \cdot L \\
\text { s.t. } & Y=f(K, L)
\end{array}
$$

Depending on the choice of inner production function $f$, we will have different long-term demand equations for $L$ and $K$. In the following, we describe the three most commonly used production functions.

The simplest choice of a production function is the Leontief function assuming no substitution between the two production factors shown in (54). Contrary to no substitution, the Cobb- 
Douglas production function assumes full substitution. The Cobb-Douglas function is formulated in (55) where the parameter $\beta$ is the capital output elasticity. The CES function (Constant Elasticity of Substitution) is between the two extreme cases of substitution and assumes a constant elasticity of substitution (probably below one) between labour and capital. The CES function is formulated in (56) where the parameter $\sigma$ is the elasticity of substitution between capital and labour.

$$
\begin{gathered}
Y=f_{\text {Leontief }}(K, L)=\min \{K, L\} \\
Y=f_{C-D}(K, L)=K^{\beta} L^{1-\beta} \\
Y=f_{C E S}(K, L)=\left[\delta_{1} K^{\frac{\sigma-1}{\sigma}}+\delta_{2} L^{\frac{\sigma-1}{\sigma}}\right]^{\frac{\sigma}{\sigma-1}}
\end{gathered}
$$

We may from these production functions obtain the following demand equations for labour and capital, respectively: (57) assumes a Leontief function where demand is a constant share of GDP, (58) assumes a Cobb-Douglas function, and (59) assumes a CES function with $P_{K L}$ being the CES price index. We assume throughout constant return to scale so that the parameter to $\log (Y)$ is one in the demand equations.

$$
\begin{gathered}
\log \left(L_{L}^{*}\right)=\kappa_{L}+\log (Y) \\
\log \left(K_{L}^{*}\right)=\kappa_{K}+\log (Y) \\
\log \left(L_{C-D}^{*}\right)=\alpha_{L}+\log (Y)-\beta \log \left(\frac{P_{L}}{P_{K}}\right) \\
\log \left(K_{C-D}^{*}\right)=\alpha_{K}+\log (Y)-(1-\beta) \log \left(\frac{P_{K}}{P_{L}}\right) \\
\log \left(L_{C E S}^{*}\right)=\log (Y)+\sigma \log \left(\delta_{2}\right)-\sigma \log \left(\frac{P_{L}}{P_{K L}}\right) \\
\log \left(K_{C E S}^{*}\right)=\log (Y)+\sigma \log \left(\delta_{1}\right)-\sigma \log \left(\frac{P_{K}}{P_{K L}}\right) \\
P_{K L}=\left[\delta_{1}^{\sigma} P_{K}^{1-\sigma}+\delta_{2}^{\sigma} P_{L}^{1-\sigma}\right]^{\frac{1}{1-\sigma}}
\end{gathered}
$$

Substitution between labour and capital implies that the effect of the factor price ratio or the relative factor price has to be negative.

Since we do not have data for the capital stock within sectors, we cannot directly use equations (57) to (59). Instead, we will formulate an equation for investment demands. As a starting point, we use a CES production function, but we make some simplifying assumptions. We use the producer price $\left(P_{Q j}\right)$ instead of the CES price index $\left(P_{K L}\right)$, and estimate separate price elasticities $(\sigma$ 's) in the demand equation for labour and investments. If the elasticity is equal to zero, we will have a Leontief production function. 
As seen in Table 12, the most labour-consuming sectors are public sector (S4), manufacturing of non-durable (M3), and trade, etc. (S1). The most investment-consuming sectors are transport and communication (S2), the public sector (S4), and trade, etc. (S1).

Table 12 Average Size of Sectors 1995-2001

\begin{tabular}{lrrrrrrrrrrrr}
\hline Sector & & & & & & & & & & & \\
Share in \% & M & E & M1 & M2 & M3 & M4 & C & S1 & S2 & S3 & S4 \\
Output & 13 & 1 & 9 & 4 & 5 & 19 & 1 & 7 & 14 & 9 & 7 & 12 \\
Investment & 3 & 1 & 12 & 3 & 3 & 12 & 1 & 2 & 13 & 29 & 7 & 14 \\
Labour & 7 & 0 & 4 & 3 & 4 & 14 & 1 & 7 & 12 & 8 & 6 & 34 \\
Intermediate & 14 & 0 & 13 & 5 & 6 & 24 & 2 & 8 & 9 & 8 & 4 & 9 \\
\hline
\end{tabular}

\subsection{Labour Demand}

A log linear long-term demand equation for fulltime workers is formulated for each sector in (60) with an error correction model to describe the dynamic adjustment (61). $L$ is the number of hours worked per week divided by 40 (fulltime), so $L$ is the number of employees who have worked full days.

In the long-run, we assume constant return to scale $\left(\alpha_{2}=1\right)$, meaning that a $1 \%$ increase in GVA increases labour demand by $1 \%$. The labour demand depends negatively on the relative wage $\left(\alpha_{3}<0\right)$. We could estimate a significant long-term effect of relative wage in three sectors only (the three sectors are A, M3, and C and accounts for approximately $25 \%$ of total employment) and no short-term wage effect $\left(\beta_{3}=0\right)$. We include a time-trend as a proxy for labour productivity $\left(\alpha_{1}\right)$.

The population census, which took place in 2000q1, initiated some rapid corrections in the level of labour within sectors, i.e., data before and after this census became incomparable. However, if the re-calculated data for population has been backdated, the time series for labour demand were not. Therefore, we include a dummy for the population census $\left(D_{P C}\right)$, (in sectors $\mathrm{MN}, \mathrm{S} 3$ and $\mathrm{S} 4$, the dummy variable is lagged one year).

$$
\begin{gathered}
\log \left(L^{*}\right)=\alpha_{0}+\alpha_{1} t+\alpha_{2} \log (Y)+\alpha_{3} \log \left(w / P_{Q}\right)+\alpha_{4} D_{P C}+\lambda_{2} \cdot Q_{2}+\lambda_{3} \cdot Q_{3}+\lambda_{4} \cdot Q_{4} \\
\operatorname{Dlog}(L)=-\beta_{0}\left[\log \left(L_{-1}\right)-\log \left(L_{-1}^{*}\right)\right]+\beta_{2} \operatorname{Dlog}(Y)+\beta_{3} \operatorname{Dlog}\left(w / P_{Q}\right)+\alpha_{4} \mathrm{D}\left(D_{P C}\right)
\end{gathered}
$$

Where

$L \quad$ Labour demand in sector $j(L N j, 1000$ fulltime employed workers)

$L^{*} \quad$ Labour demand in sector $j$, equilibrium level

$Y \quad$ GVA in sector $j(G D P j$, mill. Litas constant prices)

w "Wage" (average monthly gross earnings for fulltime employed), (wpri and wpub, Litas)

$P_{Q} \quad$ Producer price in sector $j(P Q j, 1995=1)$ 
$D_{P C} \quad$ Dummy due to Population Census ${ }^{18}$ (dumPCen, $=1$ from $\left.2000 \mathrm{q} 1\right)$

$t \quad$ Time

$Q_{2}-Q_{4} \quad$ Quarterly dummies; $Q_{2}$ is equal to one in second quarter and else zero

Some of the parameters are restricted in the estimations; they were either insignificant or had the wrong sign. The chosen estimations are summarised in Table 13. The parameter to the time index $\left(\alpha_{1}\right)$ is negative (or zero) implying increasing labour productivity, or that less labour is needed over time to produce the same amount. Labour productivity increases up to $3 \%$ each quarter, which is extremely high and it should be modified in the medium to longterm forecasts. However, over the estimation period, the average labour productivity increased by approximately $0.9 \%$ each quarter. ${ }^{19}$ The average long-term price elasticity is 0.1 . The adjustment towards the long-term relation $\left(\beta_{0}\right)$ is rather slow in agriculture and manufacturing sectors and quick in construction and the private service sectors.

Table 13 Labour Demand, Parameter Estimates

\begin{tabular}{|c|c|c|c|c|c|c|c|c|c|c|c|c|}
\hline Parameter & A & $\mathrm{MN}^{1}$ & $E$ & M1 & M2 & M3 & M4 & C & S1 & S2 & $\mathrm{S} 3^{1}$ & $\mathrm{~S} 4^{1}$ \\
\hline$\overline{\alpha_{0}}$ & $\begin{array}{l}0.855 \\
{[0.44]}\end{array}$ & $\begin{array}{l}-1.971 \\
{[-3.37]}\end{array}$ & $\begin{array}{l}-1.757 \\
{[-13.5]}\end{array}$ & $\begin{array}{l}-1.931 \\
{[-13.8]}\end{array}$ & $\begin{array}{l}-1.433 \\
{[-7.24]}\end{array}$ & $\begin{array}{l}1.468 \\
{[1.02]}\end{array}$ & $\begin{array}{l}-1.425 \\
{[-5.18]}\end{array}$ & $\begin{array}{l}3.522 \\
{[2.49]}\end{array}$ & $\begin{array}{l}-2.263 \\
{[-26.0]}\end{array}$ & $\begin{array}{l}-1.858 \\
{[-27.0]}\end{array}$ & $\begin{array}{l}-2.419 \\
{[-54.5]}\end{array}$ & $\begin{array}{l}-0.878 \\
{[-17.1]}\end{array}$ \\
\hline$\alpha_{1}$ & $\begin{array}{l}-0.024 \\
{[-1.71]}\end{array}$ & * & * & $\begin{array}{l}-0.012 \\
{[-2.16]}\end{array}$ & $\begin{array}{l}-0.027 \\
{[-4.23]}\end{array}$ & $\begin{array}{l}-0.012 \\
{[-1.34]}\end{array}$ & $\begin{array}{l}-0.030 \\
{[-2.24]}\end{array}$ & 0 & 0 & $\begin{array}{l}-0.016 \\
{[-4.40]}\end{array}$ & $\begin{array}{l}-0.007 \\
{[-2.54]}\end{array}$ & $\begin{array}{l}-0.007 \\
{[-2.24]}\end{array}$ \\
\hline$\alpha_{2}$ & 1 & 1 & 1 & 1 & 1 & 1 & 1 & 1 & 1 & 1 & 1 & 1 \\
\hline$\alpha_{3}$ & $\begin{array}{l}-0.326 \\
{[-1.09]}\end{array}$ & $\begin{array}{l}0 \\
*\end{array}$ & 0 & $\begin{array}{l}0 \\
*\end{array}$ & $\begin{array}{l}0 \\
*\end{array}$ & $\begin{array}{l}-0.446 \\
{[-2.01]}\end{array}$ & 0 & $\begin{array}{l}-0.761 \\
{[-3.59]}\end{array}$ & 0 & $\begin{array}{l}0 \\
*\end{array}$ & $\begin{array}{l}0 \\
*\end{array}$ & 0 \\
\hline$\alpha_{4}$ & $\begin{array}{l}-0.339 \\
{[-4.41]}\end{array}$ & $\begin{array}{l}-0.368 \\
{[-2.95]}\end{array}$ & $\begin{array}{l}-0.031 \\
{[-1.19]}\end{array}$ & $\begin{array}{l}-0.108 \\
{[-2.07]}\end{array}$ & $\begin{array}{l}-0.089 \\
{[-1.79]}\end{array}$ & $\begin{array}{l}-0.104 \\
{[-2.07]}\end{array}$ & $\begin{array}{l}-0.118 \\
{[-2.33]}\end{array}$ & $\begin{array}{l}-0.122 \\
{[-1.89]}\end{array}$ & $\begin{array}{l}-0.252 \\
{[-5.64]}\end{array}$ & $\begin{array}{l}-0.142 \\
{[-2.51]}\end{array}$ & $\begin{array}{l}-0.070 \\
{[-1.29]}\end{array}$ & $\begin{array}{l}-0.064 \\
{[-4.42]}\end{array}$ \\
\hline$\lambda_{2}$ & $\begin{array}{l}-0.431 \\
{[-3.28]}\end{array}$ & $\begin{array}{l}-1.390 \\
{[-2.03]}\end{array}$ & $\begin{array}{l}-0.142 \\
{[-0.94]}\end{array}$ & $\begin{array}{l}0.172 \\
{[1.31]}\end{array}$ & $\begin{array}{l}0.274 \\
{[1.86]}\end{array}$ & 0 & 0 & $\begin{array}{l}-0.300 \\
{[-2.52]}\end{array}$ & $\begin{array}{l}-0.011 \\
{[-0.12]}\end{array}$ & $\begin{array}{l}-0.085 \\
{[-1.48]}\end{array}$ & $\begin{array}{l}0.065 \\
{[1.44]}\end{array}$ & 0 \\
\hline$\lambda_{3}$ & $\begin{array}{l}-1.551 \\
{[-5.95]}\end{array}$ & $\begin{array}{l}-2.009 \\
{[-2.54]}\end{array}$ & $\begin{array}{l}-0.302 \\
{[-1.27]}\end{array}$ & $\begin{array}{l}0.003 \\
{[0.04]}\end{array}$ & $\begin{array}{l}0.265 \\
{[1.61]}\end{array}$ & 0 & 0 & $\begin{array}{l}-0.222 \\
{[-1.18]}\end{array}$ & $\begin{array}{l}-0.133 \\
{[-1.56]}\end{array}$ & $\begin{array}{l}0.012 \\
{[0.17]}\end{array}$ & $\begin{array}{l}0.009 \\
{[0.20]}\end{array}$ & 0 \\
\hline$\lambda_{4}$ & $\begin{array}{l}-0.528 \\
{[-2.97]}\end{array}$ & $\begin{array}{l}1.061 \\
{[1.11]}\end{array}$ & $\begin{array}{l}-0.361 \\
{[-2.21]}\end{array}$ & $\begin{array}{l}0.209 \\
{[1.72]}\end{array}$ & $\begin{array}{l}0.325 \\
{[1.62]}\end{array}$ & 0 & 0 & $\begin{array}{l}0.363 \\
{[1.13]}\end{array}$ & $\begin{array}{c}0.214 \\
{[1.11]}\end{array}$ & $\begin{array}{l}0.078 \\
{[1.01]}\end{array}$ & $\begin{array}{l}0.142 \\
{[2.54]}\end{array}$ & 0 \\
\hline$\beta_{0}$ & $\begin{array}{l}0.284 \\
{[2.90]}\end{array}$ & 0.1 & 0.1 & $\begin{array}{l}0.256 \\
{[2.82]}\end{array}$ & $\begin{array}{l}0.191 \\
{[3.32]}\end{array}$ & $\begin{array}{l}0.302 \\
{[2.89]}\end{array}$ & $\begin{array}{l}0.110 \\
{[1.78]}\end{array}$ & $\begin{array}{l}0.509 \\
{[2.41]}\end{array}$ & $\begin{array}{l}0.447 \\
{[3.43]}\end{array}$ & $\begin{array}{l}0.529 \\
{[2.98}\end{array}$ & 0.8 & 0.1 \\
\hline$\beta_{2}$ & 0 & $\begin{array}{l}0.147 \\
{[1.65]}\end{array}$ & $\begin{array}{l}0.067 \\
{[2.37]}\end{array}$ & $\begin{array}{l}0.152 \\
{[2.60]}\end{array}$ & 0 & $\begin{array}{l}0.108 \\
{[1.23]}\end{array}$ & $\begin{array}{l}0.103 \\
{[2.21]}\end{array}$ & $\begin{array}{l}0.621 \\
{[3.28]}\end{array}$ & $\begin{array}{l}0.247 \\
{[1.22]}\end{array}$ & $\begin{array}{l}0.490 \\
{[2.78]}\end{array}$ & $\begin{array}{l}1.289 \\
{[2.71]}\end{array}$ & $\begin{array}{l}0.065 \\
{[4.07]}\end{array}$ \\
\hline$\beta_{3}$ & 0 & 0 & 0 & 0 & 0 & 0 & 0 & 0 & 0 & 0 & 0 & 0 \\
\hline $\mathrm{R}^{2}$ & 0.786 & 0.563 & 0.246 & 0.592 & 0.659 & 0.489 & 0.369 & 0.731 & 0.685 & 0.467 & 0.653 & 0.581 \\
\hline
\end{tabular}

Estimation period 1995q2-2002q2; t-values in [ ]; " restricted parameter; ' dummy lagged one year

\footnotetext{
${ }^{18}$ Though Population Census in Lithuania took place in 2001q1, we use one dummy for either the effect of this census or for other factors, which influenced labour demand and other endogenous variables during this period. According to R. Rudzkis, in the case of labour demand, one of these factors could be compulsory Health Insurance law, by which an unemployed person not registered at the Lithuanian labour exchange has to pay for any medical treatment and service. This reason caused an increase in unemployment and hence a decrease in the number of employed.
}

${ }^{19}$ Average labour productivity is calculated as $-100 \cdot \alpha_{1}$, where $\alpha_{1}$ is calculated as $\alpha_{1}=\sum_{j} \alpha_{1 j} \cdot L_{j} / \sum_{j} L_{j}$. 
The overall fit aggregated over the 12 sectors is shown in Figure 18. We see a large decrease in aggregated labour prior to year 2000, which we account for with the dummy. The residuals are less than 5\% (except in 1996q1). The fit is not as good in all sectors, but the overall picture is acceptable.

\section{Figure 18 Aggregated Labour Demand, Fit and Residuals}
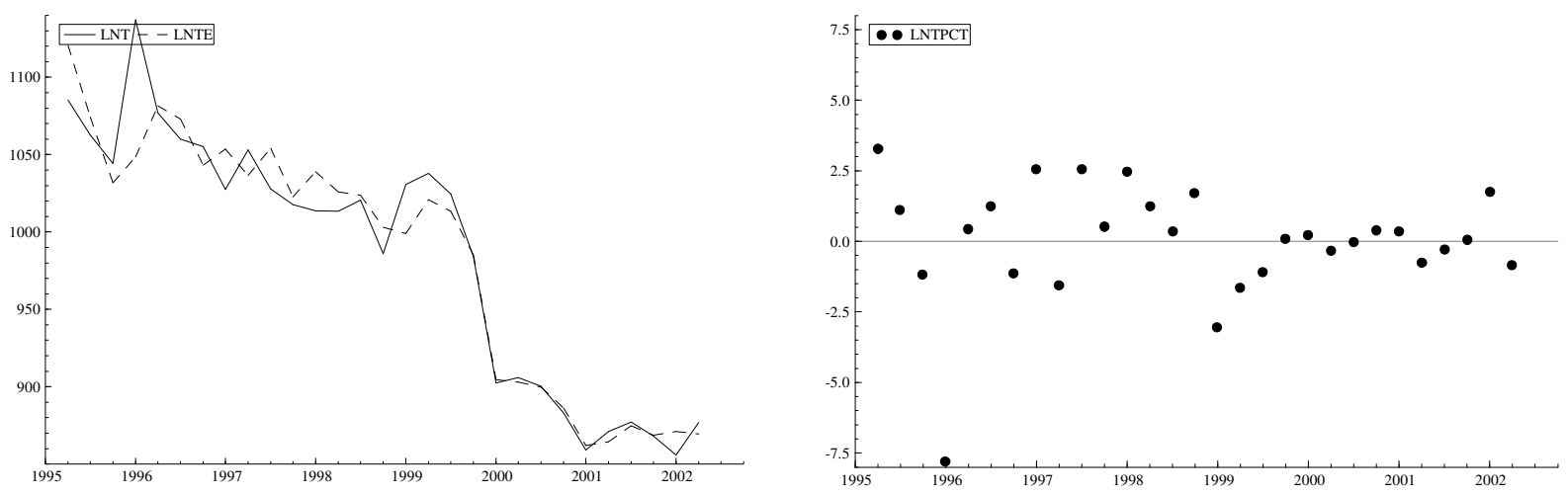

\subsection{Investments}

We formulate a log linear long-term demand equation for investments in each sector (62) with an error correction model to describe the dynamic adjustment (63). We assume constant return to scale in the long run $\left(\alpha_{2}=1\right)$, meaning that a $1 \%$ increase in GVA increases investments with $1 \%$ and thereby also capital with $1 \%$.

User-cost on capital depends on the investment price, interest rate, depreciation rate, and expected inflation. When estimating the demand for investment, we use the investment price relative to the producer price and the interest rate. If the interest rate increases, it will be more expensive to finance investment and investments will decrease $\left(\alpha_{4}<0\right){ }^{20}$

$$
\begin{aligned}
& \log \left(I^{*}\right)=\alpha_{0}+\alpha_{1} t+\alpha_{2} \log (Y)+\alpha_{3} \log \left(P_{I} / P_{Q}\right)+\alpha_{4} i+\lambda_{2} \cdot Q_{2}+\lambda_{3} \cdot Q_{3}+\lambda_{4} \cdot Q_{4} \\
& D \log (I)=-\beta_{0}\left[\log \left(I_{-1}\right)-\log \left(I_{-1}^{*}\right)\right]+\beta_{2} \operatorname{Dlog}(Y)+\beta_{3} \operatorname{Dlog}\left(P_{I} / P_{Q}\right)+\beta_{4} \mathrm{D}(i)
\end{aligned}
$$

Where

$\begin{array}{ll}I & \text { Investments in sector } j(I R j, \text { mill. Litas }) \\ I^{*} & \text { Investments in sector } j, \text { equilibrium level } \\ Y & \text { GDP in sector } j(G D P j, \text { mill. Litas constant prices }) \\ P_{I} & \text { Investment price }(p i, 1995=1) \\ i & \text { Interest rate }(\mathrm{ra}, \%) \\ P_{Q} & \text { Producer price in sector } j(P Q j, 1995=1) \\ t & \text { Time }\end{array}$

$Q_{2}-Q_{4} \quad$ Quarterly dummies; $Q_{2}$ is equal to one in second quarter and otherwise zero

\footnotetext{
${ }^{20}$ Since the interest rate is measured in percentage, we use interest rate and not log of interest rate as explanatory variable. This way, if interest rate increases from, e.g., $5 \%$ to $6 \%$, investments will in the long-run decrease by $\alpha_{4} \%$. Whereas a $1 \%$ increase in the wage will in the long-run decrease investment with $\alpha_{3} \%$.
} 
Many of the parameters are restricted in the chosen estimation shown in Table 14. There is a positive time-trend $\left(\alpha_{1}\right)$ in most sectors, meaning that in order to produce the same amount, more investments are needed. ${ }^{21}$ The average capital productivity is $-1 \%$ every quarter in the beginning of the estimation period and is increased to $0.8 \%$ at the end of the estimation period.

We are only able to estimate a long-run effect of the relative investment price $\left(\alpha_{3}<0\right)$ in three sectors, and there is a short-run negative effect of changes in relative investment price $\left(\beta_{3}<0\right)$ in four sectors. The estimated price elasticities are huge and so the average long-term price elasticity is -0.7 .

There is a negative effect in most sectors from the interest rate $\left(\alpha_{4}<0, \beta_{4}<0\right)$. An increase in production has a large positive short-run effect on the investments $\left(\beta_{2}>0\right)$. The adjustment towards the long-term relationship is quite quick $\left(\beta_{0}\right)$.

Table 14 Investments in Sectors, Parameter Estimates

\begin{tabular}{|c|c|c|c|c|c|c|c|c|c|c|c|c|}
\hline Para & A & MN & $E$ & M1 & M2 & M3 & M4 & C & S1 & S2 & S3 & S4 \\
\hline$\alpha_{0}$ & $\begin{array}{l}-1.386 \\
{[-0.79]}\end{array}$ & $\begin{array}{l}0.073 \\
{[0.08]}\end{array}$ & $\begin{array}{l}0.907 \\
{[1.96]}\end{array}$ & $\begin{array}{l}-0.959 \\
{[-2.33]}\end{array}$ & $\begin{array}{l}-2.705 \\
{[-10.9]}\end{array}$ & $\begin{array}{l}-2.206 \\
{[-16.4]}\end{array}$ & $\begin{array}{l}-3.508 \\
{[-10.8]}\end{array}$ & $\begin{array}{l}-3.172 \\
{[-4.48]}\end{array}$ & $\begin{array}{l}-3.081 \\
{[-17.6]}\end{array}$ & $\begin{array}{l}0.975 \\
{[2.94]}\end{array}$ & $\begin{array}{l}-2.961 \\
{[-12.7]}\end{array}$ & $\begin{array}{l}-1.046 \\
{[-4.10]}\end{array}$ \\
\hline$\alpha_{1}$ & 0 & $\begin{array}{l}-0.081 \\
{[-2.00]}\end{array}$ & 0 & 0 & $\begin{array}{l}0.033 \\
{[3.42]}\end{array}$ & $\begin{array}{l}0.022 \\
{[4.70]}\end{array}$ & $\begin{array}{l}0.070 \\
{[3.70]}\end{array}$ & $\begin{array}{l}0.052 \\
{[3.37]}\end{array}$ & $\begin{array}{l}0.041 \\
{[3.04]}\end{array}$ & $\begin{array}{l}-0.060 \\
{[-4.35]}\end{array}$ & $\begin{array}{l}0.064 \\
{[7.94]}\end{array}$ & 0 \\
\hline$\alpha_{2}$ & 1 & $\begin{array}{l}1 \\
*\end{array}$ & 1 & 1 & 1 & 1 & 1 & 1 & 1 & 1 & 1 & 1 \\
\hline$\alpha_{3}$ & 0 & $\begin{array}{l}-2.036 \\
{[-1.62]}\end{array}$ & $\begin{array}{l}0 \\
*\end{array}$ & $\begin{array}{l}0 \\
*\end{array}$ & 0 & 0 & 0 & 0 & $\begin{array}{l}-1.724 \\
{[-1.11]}\end{array}$ & $\begin{array}{l}-1.453 \\
{[-2.06]}\end{array}$ & $\begin{array}{l}0 \\
*\end{array}$ & 0 \\
\hline$\alpha_{4}$ & $\begin{array}{l}0 \\
*\end{array}$ & 0 & $\begin{array}{l}-0.065 \\
{[-5.94]}\end{array}$ & $\begin{array}{l}-0.034 \\
{[-1.64]}\end{array}$ & 0 & 0 & 0 & $\begin{array}{l}-0.028 \\
{[-1.27]}\end{array}$ & 1 & $\begin{array}{l}-0.059 \\
{[-4.48}\end{array}$ & $\begin{array}{l}0 \\
*\end{array}$ & $\begin{array}{l}-0.033 \\
{[-3.52]}\end{array}$ \\
\hline$\lambda_{2}$ & $\begin{array}{l}-2.369 \\
{[-1.16]}\end{array}$ & $\begin{array}{l}-0.766 \\
{[-0.90]}\end{array}$ & $\begin{array}{l}-0.157 \\
{[-0.53]}\end{array}$ & $\begin{array}{l}0.180 \\
{[0.53]}\end{array}$ & $\begin{array}{l}0.420 \\
{[1.62]}\end{array}$ & $\begin{array}{l}-0.081 \\
{[-0.64]}\end{array}$ & $\begin{array}{l}0 \\
*\end{array}$ & $\begin{array}{l}-0.507 \\
{[-2.29]}\end{array}$ & $\begin{array}{l}-0.075 \\
{[-0.51]}\end{array}$ & $\begin{array}{l}-0.022 \\
{[-0.22]}\end{array}$ & $\begin{array}{l}-0.157 \\
{[-0.66]}\end{array}$ & $\begin{array}{l}-0.114 \\
{[-0.60]}\end{array}$ \\
\hline$\lambda_{3}$ & $\begin{array}{l}-0.185 \\
{[-0.11]}\end{array}$ & $\begin{array}{l}-0.206 \\
{[-0.23]}\end{array}$ & $\begin{array}{l}0.442 \\
{[1.29]}\end{array}$ & $\begin{array}{l}0.132 \\
{[0.38]}\end{array}$ & $\begin{array}{l}0.575 \\
{[2.34]}\end{array}$ & $\begin{array}{l}0.458 \\
{[2.81]}\end{array}$ & 0 & $\begin{array}{l}0.489 \\
{[0.84]}\end{array}$ & $\begin{array}{l}0.419 \\
{[2.42]}\end{array}$ & $\begin{array}{l}0.195 \\
{[2.11]}\end{array}$ & $\begin{array}{l}-0.091 \\
{[-0.40]}\end{array}$ & $\begin{array}{l}0.289 \\
{[1.64]}\end{array}$ \\
\hline$\lambda_{4}$ & $\begin{array}{l}-4.256 \\
{[-1.04]}\end{array}$ & $\begin{array}{l}-1.690 \\
{[-1.18]}\end{array}$ & $\begin{array}{l}-2.725 \\
{[-2.34]}\end{array}$ & $\begin{array}{l}-0.947 \\
{[-1.55]}\end{array}$ & $\begin{array}{l}0.019 \\
{[0.08]}\end{array}$ & $\begin{array}{l}-0.148 \\
{[-0.70]}\end{array}$ & 0 & $\begin{array}{l}0.269 \\
{[0.39]}\end{array}$ & $\begin{array}{l}-0.379 \\
{[-1.26]}\end{array}$ & $\begin{array}{l}-0.648 \\
{[-6.85]}\end{array}$ & $\begin{array}{l}-0.793 \\
{[-2.18]}\end{array}$ & $\begin{array}{l}-1.289 \\
{[-2.37]}\end{array}$ \\
\hline$\beta_{0}$ & $\begin{array}{l}0.251 \\
{[1.27]}\end{array}$ & $\begin{array}{l}0.586 \\
{[2.88}\end{array}$ & $\begin{array}{l}0.373 \\
{[2.91]}\end{array}$ & $\begin{array}{l}0.513 \\
{[3.03]}\end{array}$ & $\begin{array}{l}0.758 \\
{[3.91]}\end{array}$ & $\begin{array}{l}0.862 \\
{[4.12]}\end{array}$ & 0.9 & $\begin{array}{l}0.821 \\
{[3.62]}\end{array}$ & 0.9 & 0.9 & $\begin{array}{l}0.796 \\
{[3.99]}\end{array}$ & $\begin{array}{l}0.680 \\
{[3.97]}\end{array}$ \\
\hline$\beta_{2}$ & $\begin{array}{l}0.621 \\
{[1.72]}\end{array}$ & $\begin{array}{l}0.662 \\
{[1.23]}\end{array}$ & $\begin{array}{l}0.270 \\
{[1.58]}\end{array}$ & 0 & $\begin{array}{l}0.813 \\
{[1.88]}\end{array}$ & $\begin{array}{l}1.240 \\
{[2.34]}\end{array}$ & 0 & $\begin{array}{l}1.187 \\
{[2.13]}\end{array}$ & $\begin{array}{l}0.826 \\
{[1.08]}\end{array}$ & 0 & 0 & 0 \\
\hline$\beta_{3}$ & $\begin{array}{l}-0.661 \\
{[-2.00]}\end{array}$ & $\begin{array}{l}-0.931 \\
{[-1.56]}\end{array}$ & 0 & $\begin{array}{l}0 \\
*\end{array}$ & 0 & $\begin{array}{l}-0.315 \\
{[-1.10]}\end{array}$ & 0 & $\begin{array}{l}-1.904 \\
{[-1.31]}\end{array}$ & 0 & 0 & 0 & 0 \\
\hline$\beta_{4}$ & 0 & 0 & 0 & 0 & $\begin{array}{l}-0.116 \\
{[-2.12]}\end{array}$ & $\begin{array}{l}-0.037 \\
{[-1.19]}\end{array}$ & 0 & 0 & & $\begin{array}{l}-0.031 \\
{[-1.05]}\end{array}$ & 0 & 0 \\
\hline $\mathrm{R}^{2}$ & 0.893 & 0.693 & 0.956 & 0.618 & 0.716 & 0.880 & 0.711 & 0.857 & 0.881 & 0.926 & 0.726 & 0.906 \\
\hline
\end{tabular}

Estimation period 1995q2-2002q2; t-values in [ ]; * restricted parameter

The estimated relations explain the major part of aggregated investments. Figure 19 (right) shows that the percentage residuals increase over the estimation period (probably because quarterly changes in investments also increase).

\footnotetext{
${ }^{21}$ One explanation can be that production becomes more capital intensive over time as well as less labourintensive.
} 

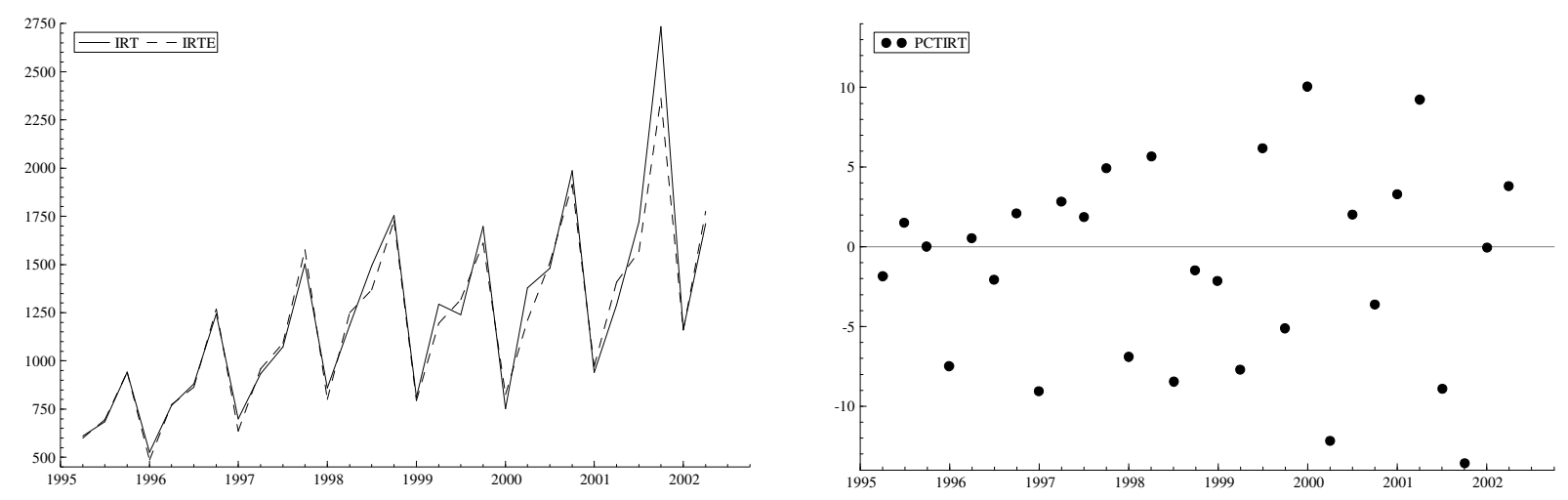

\subsection{Capital Formation}

The capital stock is estimated by applying the Perpetual Inventory Method (PIM): The capital stock is equal to past investment (net of depreciation) plus the initial capital stock. We use total capital investments in sectors for the flow of past investments, $I_{T}=\Sigma_{j} I_{j}$, i.e., our capital stock only includes capital (material and buildings) investments. The capital accumulation identity for the calculation of the implicit stock of capital $(K)$ will be

$$
K=I_{T}+(1-\delta) K_{-1}
$$

Here $\delta$ is the - assumed - depreciation rate, $(1 / \delta) / 4$ is the average lifetime in years of the capital equipment. We assume that the depreciation rate is equal to $2.5 \%$ each quarter (or, equivalently, that the average lifetime of capital is 10 years). To use equation (64) for the calculation of a capital stock, we lack an initial capital stock. Some aspects concerning the calculation of capital stock is found in Vetlov (2003), Appendix 2. ${ }^{22}$ According to this paper, we assume that the initial capital stock in $1994 q 4$ is equal to 23495.99 mill. Litas.

\section{Figure 20 Capital Stock (Constant Prices)}

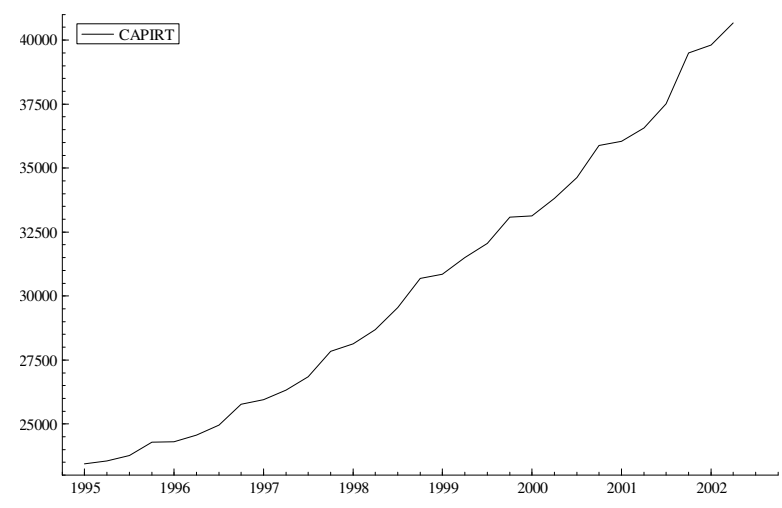

Calculating the stock of capital is the first step in introducing supply effects in the model. Capacity effects (utilisation rate of capital) should at least affect prices, import, and export.

\footnotetext{
${ }^{22}$ Igor Vetlov: "Monetary Transmission Mechanism in Lithuania". MFD Working Paper 2003 no. 2, Bank of Lithuania.
} 
An estimation of significant supply effects on macro-economic data is, however, difficult and is not included in the current version of the model.

\subsection{Profit}

We define profit used in the household disposal income as (65); payment from selling the produced goods minus expenses to production factors (commodities (intermediate), labour, and investments). ${ }^{23}$

$$
\text { Prof }=P_{Q} \cdot Q_{T}-P_{C T} \cdot C_{T} \cdot\left(1+t_{p}\right)-W \cdot t_{s s f}-P_{I} \cdot I_{T}
$$

Where

$\begin{array}{ll}\text { Prof } & \text { Profit }(P R O F, \text { mill. Litas current prices) } \\ Q_{T} & \text { Production }(Q R T, \text { mill. Litas constant prices) } \\ P_{Q} & \text { Producer price }(p q, 1995=1) \\ C_{T} & \text { Input in sectors }(I N R T, \text { mill. Litas constant prices) } \\ P_{C T} & \text { Price on input (pint, 1995=1) } \\ t_{p} & \text { Net tax rate on products }(t p) \\ W & \text { Wage sum }(W s u m, \text { mill. Litas current prices }) \\ t_{s s f} & \text { SSF rate }(s s c) \\ I_{T} & \text { Investments in sectors }(I R T, \text { mill. Litas constant prices) } \\ P_{I} & \text { Price on investments }(p i, 1995=1)\end{array}$

\subsection{Labour Supply}

Labour supply (or the labour force) could be defined as the difference between total population and the inactive population, where the inactive population covers daytime pupils and students, housewives, retired non-working population, the disabled, persons in prisons, and other inactive inhabitants.

On the other hand, it is clear that the labourforce is influenced by the same factors as the population. These factors are a natural increase in population, net-migration and administrative-territorial changes. The main factor influencing net-migration and labour market participation is the real average wage in private sectors $(w)$. As in the section for labour demand, we include a dummy for the population census effect (lagged two years).

Besides net wage for private sectors, we have tested the inclusion of other influencing factors, namely, the ratio of gross value added to the World GDP growth index and the unemployment rate, but estimations were not statistically significant. We include population in the left-handside of the equations, which means that we estimate the ratio of labour supply to the total population rather than the labour supply itself. The specified long and short-run equations for labour supply are respectively:

\footnotetext{
${ }^{23}$ We could choose to include profit from private sectors only, and that profit from the public sector (S4) is governmental income.
} 


$$
\begin{aligned}
\log \left(L_{S}^{*}\right)=\alpha_{0} & +\log (P O P)+\alpha_{1} \log \left(w / P_{C}\right)+\alpha_{2} D_{P C,-8}+\alpha_{3} \log \left(Y / Y_{\text {World }}\right)+\alpha_{4} U \\
\operatorname{Dlog}\left(L_{S}\right)= & \operatorname{Dlog}(P O P)-\beta_{0}\left(\log \left(L_{S,-1}^{*}\right)-\log \left(L_{S,-1}\right)\right) \\
& +\beta_{1} \operatorname{Dlog}\left(w / P_{C}\right)+\alpha_{3} D\left(D_{P C,-8}\right)+\beta_{3} \operatorname{Dlog}\left(Y / Y_{\text {World }}\right)+\beta_{4} D(U)
\end{aligned}
$$

Where

$L_{S} \quad$ Labour force $(L S, 1000$ persons $)$

$L_{S}{ }^{*} \quad$ Labour force equilibrium level

POP Population (POP, 1000 persons)

$W \quad$ After tax wage in private sector ${ }^{24}$

$P_{C} \quad$ Consumer price $(p c, 1995=1)$

$Y \quad$ Total gross value added (GDPT, mill. Litas in constant prices)

$Y_{\text {World }} \quad$ World GDP index (GDPwr, 1995=1)

$U \quad$ Unemployment rate

$D_{P C} \quad$ Dummy for population census (1 from 2000q1)

Table 15 Labour Supply, Parameter Estimates

\begin{tabular}{rrrrrrrrrr}
\hline Param & $\alpha_{0}$ & $\alpha_{1}$ & $\alpha_{2}$ & $\alpha_{3}$ & $\alpha_{4}$ & $\beta_{0}$ & $\beta_{1}$ & $\beta_{3}$ & $\beta_{4}$ \\
\hline & -1.138 & 0.070 & -0.081 & 0 & 0 & 0.439 & 0 & 0 & 0 \\
& {$[-7.44]$} & {$[2.93]$} & {$[-10.7]$} & $*$ & $*^{*}$ & {$[3.13]$} & $*$ & & $*$ \\
\hline
\end{tabular}

Estimation period 1995q2-2002q2. t-values in [ ]. * Restricted parameter. $\mathrm{R}^{2}=0.800235$

As seen from Table 15 in the chosen estimation, parameters to the additional variables are restricted to zero. There is a small positive effect of the real wage, implying that increasing wages increases the labour market participation rate of the population.

Figure 21 Labour Supply, Fit and Residuals
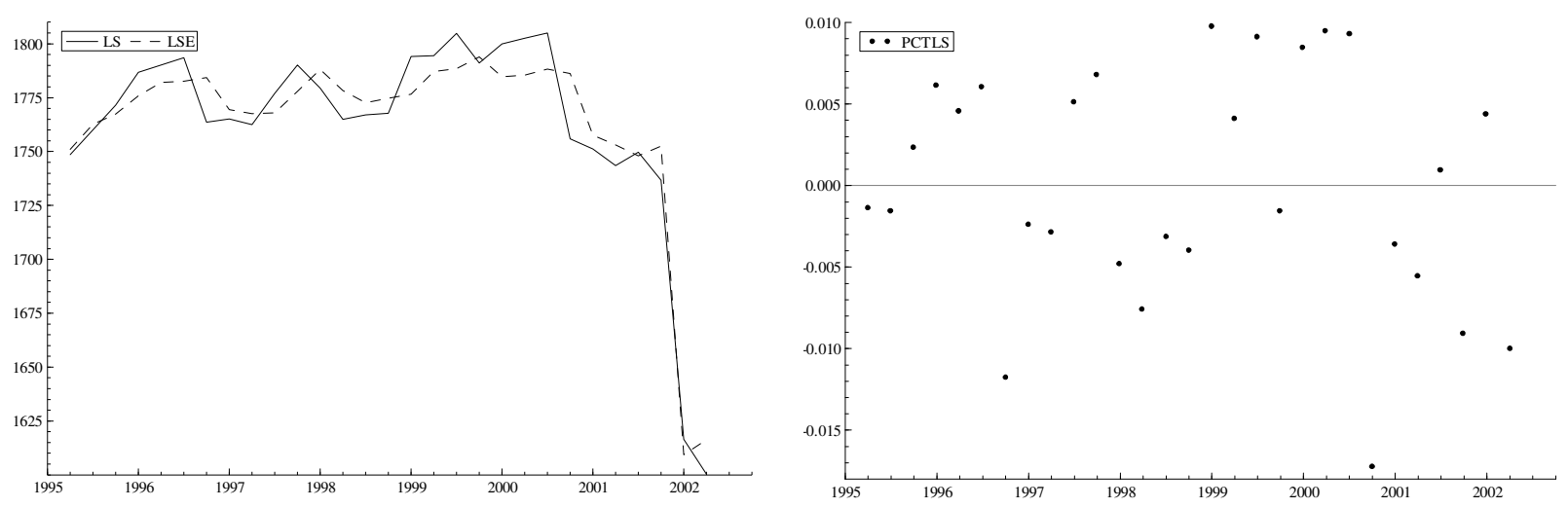

${ }^{24}$ After tax wage is calculated as $w=n t_{\min }+\left(w_{P R I}-n t_{\min }\right) \cdot\left(1-t_{L}\right)$, see Section 3.2. 


\section{Prices and Wages}

The general idea in the price equations is that producer prices in the different sectors are determined (mainly) by the production costs, and prices on final consumption (private and public consumption, investments, and export) are determined by weighting the prices on deliveries from the different sectors and abroad by using input-output coefficients (or estimated weights).

\subsection{Producer Prices}

We assume that producers maximise profit. In the long-run (in equilibrium), the output price in sectors $\left(P_{Q}\right)$ equals the marginal costs with a mark-up, and since we assume constant return to scale, the marginal costs are equal to the equilibrium unit costs to commodities, labour, and investments. $^{25}$ The unit cost $(\bar{P})$ can be calculated as (68). The variables are explained below (71).

$$
\bar{P}_{Q_{j}}=\left[\left(1+t_{p}\right) \cdot P_{C_{j}} \cdot C_{j}+(1+s s c) \cdot w \cdot L_{j}+P_{I} \cdot I_{j}\right] / Q_{j}
$$

Furthermore, we estimate a constant (positive) mark-up $\left(\mu_{j}\right)$; if competition is perfect, there will be no mark-up. With a constant mark-up on unit costs, we have the following equilibrium output price $\left(P^{*}\right)$ :

$$
P_{Q_{j}}^{*}=\left(1+\mu_{j}\right) \cdot \bar{P}_{Q_{j}} \Leftrightarrow \log \left(P_{Q_{j}}^{*}\right)=\alpha_{0 j}+\log \left(\bar{P}_{Q_{j}}\right)
$$

Besides unit cost, the producer price could also depend on the import price $\left(P_{M}\right)$. A reason for including the import price could be to model the degree of price-taking in markets where domestic producers compete with foreign companies. This is done in the first version of LITMOD for some sectors. The export price (or World Market Price) could be included as an explanatory variable in sectors with a large amount of export.

Allowing dependence on import price, time-varying mark-up, and quarterly dummies (because the seasonal fluctuation can be different in the explanatory variables and the dependent variable), we extend (69) to (70):

$$
\begin{aligned}
\log \left(P_{Q_{j}}^{*}\right) & =\alpha_{0 j}+\alpha_{2 j} \cdot t+\lambda_{2 j} \cdot Q_{2}+\lambda_{3 j} \cdot Q_{3}+\lambda_{4 j} \cdot Q_{4} \\
& +\alpha_{1 j} \cdot \log \left(\bar{P}_{Q_{j}}\right)+\left(1-\alpha_{1 j}\right) \cdot \log \left(P_{M}\right)
\end{aligned}
$$

The price equations are homogenous in prices, i.e., output prices are in the long-run increased by $1 \%$ if the import price and all the factor prices $\left(P C_{j}, w\right.$, and $\left.P_{I}\right)$ are increased by $1 \%$.

We estimate an error correction to the equilibrium price and explain changes in the output price with changes in the unit costs $\left(\bar{P}_{Q}\right)$ and changes in import price $\left(P_{M}\right)$. In the short-run, we do not impose price homogeneity.

\footnotetext{
${ }^{25}$ In this equation, we use the investment costs each quarter, but the companies' cost of having capital should be calculated as user-cost on the capital stock. Capital is financed by loans and the interest rate would affect the companies' cost of having the capital stock.
} 


$$
\begin{aligned}
\mathrm{D} \log \left(P_{Q_{j}}\right) & =\beta_{0 j}\left[\log \left(P_{Q_{j}}^{*}\right)_{-1}-\log \left(P_{Q_{j}}\right)_{-1}\right] \\
& +\beta_{1 j} \cdot \mathrm{D} \log \left(\bar{P}_{Q_{j}}\right)+\beta_{4 j} \cdot \mathrm{D} \log \left(P_{M}\right)
\end{aligned}
$$

Where

$\begin{array}{ll}P_{Q j} & \text { Producer price in sector } j(P Q j, 1995=1) \\ P_{Q_{j}}^{*} & \text { Producer price in sector } j, \text { equilibrium level } \\ \bar{P}_{Q_{j}} & \text { Unit costs in sector } j,(P Q U C j) \\ Q_{j} & \text { Production in sector } j(Q R j, \text { mill. Litas constant prices) } \\ C_{j} & \text { Intermediate in sector } j(I N R j, \text { mill. Litas constant prices) } \\ P_{C j} & \text { Price on intermediate in sector } j(P I N j, 1995=1) \\ t_{p} & \text { Average net tax rate on products }(t p=0.025) \\ L_{j} & \text { Labour in sector } j(L N j) \\ W & \text { Wage (WPRI in private sectors and } W P U B \text { in public sector, monthly wage in } \\ & \text { Litas) } \\ s S C & \text { Social Security Fund contribution rate }(s S C=0.33) \\ I_{j} & \text { Investments in sector } j(I R j, \text { mill. Litas constant prices) } \\ P_{I} & \text { Price on investments }(P I, 1995=1)\end{array}$

Figure 22 shows the average producer price and the average unit cost $(P Q U C)$. The figure indicates that the producer price depends on the calculated unit cost with an additional markup. The estimated equation has, in most sectors, a high degree of explanation and, as seen in the figure, the estimated producer price (label E) is close to the actual producer price. In general, there is a speedy adjustment towards the long-run producer price, and the average error correction parameter $\left(\beta_{0}\right)$ is 0.7 . The average estimated weight to the import price is in the long-run $0.3\left(1-\alpha_{1}\right)$ and only 0.04 in the short-run $\left(\beta_{4}\right)$.

\section{Figure 22 Aggregated Price on Production: Actual, Estimated and Residuals}
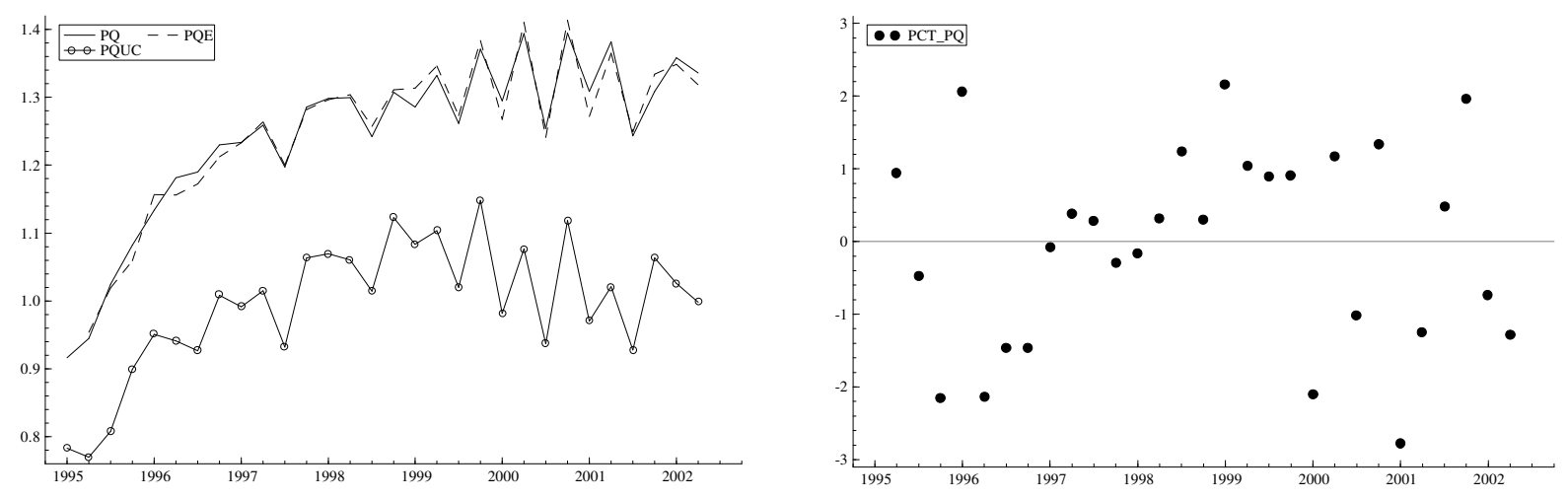


\subsection{Price on Intermediate}

In a standard Input-Output modelling framework, the intermediate used in sector $j\left(C_{j}\right)$ is a constant share of production in sector $j$ where the share is given by the sum of I-O coefficients $a_{i j}$ (deliveries from sector $i$ to sector $j$ ).

$$
C_{j}=Q_{j} \cdot \sum_{i} a_{i j}
$$

The prices on intermediate $\left(P C_{j}\right)$ should then be calculated as a weighted sum of the prices on deliveries, i.e., the producer prices in the delivering sectors $\left(P Q_{i}\right)(73)$. The weights are the share of intermediate in sector $j$ that comes from sector $i$; this is the input-output coefficient of deliveries from sector $i$ to sector $j$ divided by the sum of the input-output coefficients of deliveries from all sectors to sector $j$.

$$
P_{C_{j}}^{*}=\sum_{i}\left(\frac{a_{i j}}{\sum_{l} a_{l j}}\right) \cdot P_{Q_{i}}
$$

Where

$C_{j} \quad$ Intermediate in sector $j\left(I N R_{j}\right.$, mill. Litas constant prices)

$Q_{j} \quad$ Production in sector $j\left(Q R_{j}\right.$, mill. Litas constant prices)

$P C_{j} \quad$ Price on intermediate in sector $j(P I N j, 1995=1)$

$P Q_{i} \quad$ Producer price in sector $i(P Q i, 1995=1)$

$a_{i j} \quad$ Input-output coefficient, deliveries from sector $i$ to sector $j$ (aij)

This formulation of the intermediate prices does not fit the actual prices very well. In the sectors' determination of intermediate, we had to extend the I-O equation and included a constant term, a linear trend, and quarterly dummies (see Section 8.2). Therefore, we estimate the following price equation for the use of intermediate in sectors. Since part of the intermediate is imported, we also tried to include the import price $\left(P_{M}\right)$ as an explanatory variable, but the import price was not significant.

$$
\log \left(P_{C_{j}}\right)=\alpha_{0 j}+\alpha_{1 j} \cdot \log \left(P_{C_{j}}^{*}\right)+\alpha_{2 j} \cdot t+\lambda_{2 j} \cdot Q_{2}+\lambda_{3 j} \cdot Q_{3}+\lambda_{4 j} \cdot Q_{4}
$$

We restrict the effect of the I-O determined intermediate price $\left(P_{C}^{*}\right)$ to unity $\left(\alpha_{1 j}=1\right)$, i.e., the price equations are homogenous meaning that, if all producer-prices are increased by $1 \%$, then all prices on intermediate are increased by $1 \%{ }^{26}$

As shown in Figure 23, even though some sectors have large residuals, the overall fit is acceptable.

\footnotetext{
${ }^{26}$ However, in the construction sector $(C)$, we estimate $\alpha_{1}$ below one in order to reduce the impact on the intermediate price of the huge fluctuations in the weighted producer prices.
} 
Figure 23 Aggregated Price on Intermediate: Actual, Estimated and Residuals
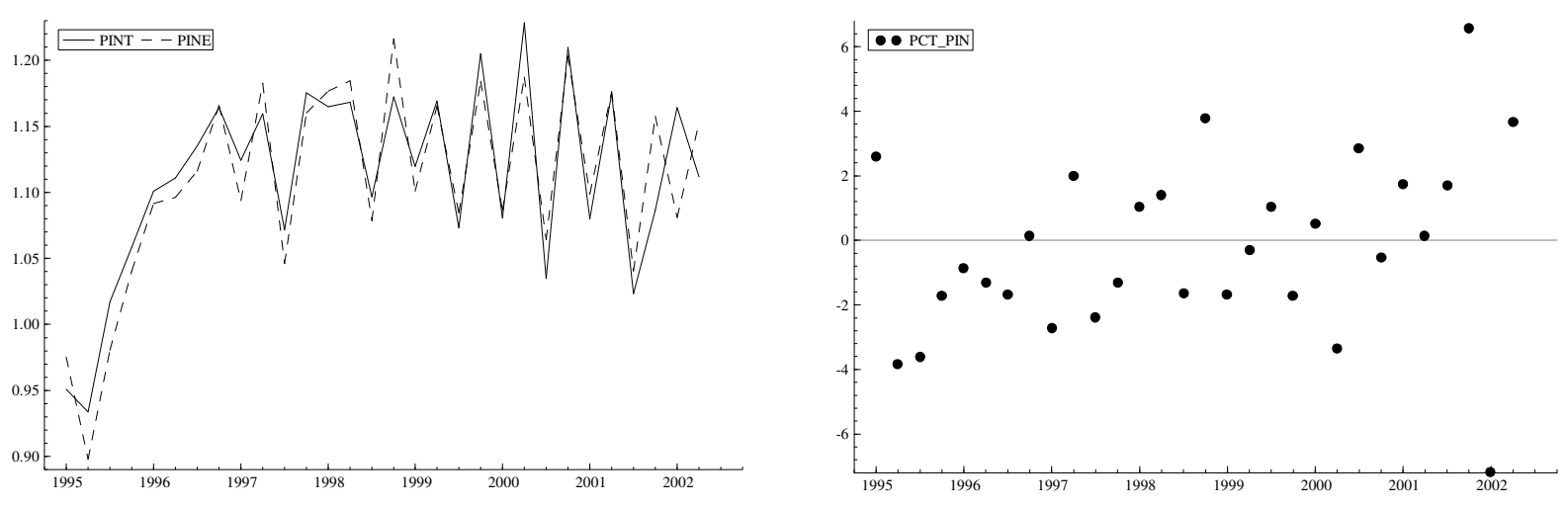

\subsection{Price on GVA}

In order to calculate GVA (Gross Value Added) in current prices, we need a price index for aggregated GVA. By definition, GVA is equal to production minus intermediate consumption in constant and current prices. This gives the definition of the GVA price index in (75).

$$
Y v=Y \cdot P_{Y}=Q v-C v \Leftrightarrow P_{Y}=(Q v-C v) / Y
$$

Where

$\begin{array}{ll}Y v & \text { GVA }(G D P V T, \text { mill. Litas current prices }) \\ Y & \text { GVA }(G D P T, \text { mill. Litas constant prices }) \\ P_{Y} & \text { GVA price index }(P G D P, 1995=1) \\ Q v & \text { Domestic production }(Q V T, \text { mill. Litas current prices }) \\ C v & \text { Intermediate }(I N V T, \text { mill. Litas current prices })\end{array}$

Unfortunately, as shown in Figure 24, this calculated price index is for most of the estimation period somewhat smaller than the actual price index. We, therefore, introduce the simple estimation in (76).

$$
P_{Y}=\alpha_{1} \cdot(Q v-C v) / Y
$$

The parameter $\alpha_{1}$ is estimated to 1.01368 with a standard error of 0.00243775 . 


\section{Figure 24 Price on GVA}

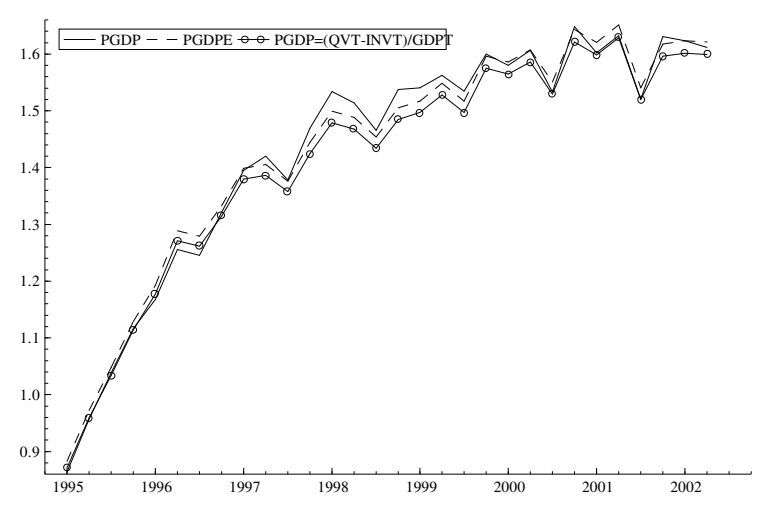

\subsection{Consumer Price}

The price on private consumption is determined by prices on the different goods and services delivered to private consumption. The goods and services are deliveries from different sectors and import, so the determining prices are the producer prices in sectors, as well as import price. The weights should be the share of private consumption delivered from the different sectors and from import. Thus, using input-output coefficients as weights, we have (77) where the $a$ 's are totalling unity. The consumer price is inclusive VAT, so we add VAT to the I-O calculated price:

$$
P_{C}^{I-O}=\left(1+t_{v a t}\right) \cdot\left[\sum_{i} a_{i, C p} \cdot P_{Q_{i}}+a_{M, C p} \cdot P_{M}\right]
$$

Where

$$
\begin{array}{ll}
P_{C} & \text { Consumer price index }(P C, 1995=1) \\
P_{M} & \text { Import price }(P M, 1995=1) \\
P_{Q i} & \text { Producer price in sector } i(P Q i, 1995=1) \\
t_{v a t} & \text { VAT rate }(v a t=0.18) \\
a_{i, C p} & \text { I-O coefficient for deliveries from sector } i \text { to private consumption (aicp) }
\end{array}
$$

Unfortunately, we do not have data in the input-output table for deliveries of import to private consumption - only total supply from domestic production and import. We, therefore, use estimated weights instead.

We tried to estimate weights to both the import price and the producer prices in four aggregated sectors (not all 12 sectors - only agriculture $(P Q A)$, energy $(P Q E)$, aggregated manufacturing $(P Q M)$ and aggregated service $(P Q S)) .{ }^{27}$ The equation is formulated in logs. The dynamic adjustment is an error correction and the short-term weights are allowed to

\footnotetext{
${ }^{27}$ We also tried to use a calculated domestic price index ( $\left.p q c p\right)$ as explanatory variable where the weights are the I-O coefficients of deliveries to private consumption. However, the chosen estimated equation gives a better explanation of the consumer price.

$p q c p=a A c p * p q A+a M N c p * p q M N+a E c p * p q E+a M 1 c p * p q M 1+a M 2 c p * p q M 2+a M 3 c p * p q M 3+a M 4 c p * p q M 4+$ $a C c p * p q C+a S 1 c p * p q S 1+a S 2 c p * p q S 2+a S 3 c p * p q S 3+a S 4 c p * p q S 4$
} 
differ from the long run weights. The weights add to one, implying that the price equation is static (and dynamic) homogeneous. Furthermore, we include an intercept and quarterly dummies. The quarterly dummies adjust for different fluctuations in the different prices.

$$
\begin{aligned}
\log \left(P_{C}^{*}\right) & =\alpha_{0}+\alpha_{1} \log \left(P_{Q_{A}}\right)+\alpha_{2} \log \left(P_{Q_{E}}\right)+\alpha_{3} \log \left(P_{Q_{M}}\right)+\alpha_{4} \log \left(P_{Q_{S}}\right) \\
& +\left(1-\alpha_{1}-\alpha_{2}-\alpha_{3}-\alpha_{4}\right) \log \left(P_{M}\right) \\
& +\lambda_{2} \cdot Q_{2}+\lambda_{3} \cdot Q_{3}+\lambda_{4} \cdot Q_{4}+\log \left(1+t_{v a t}\right) \\
\mathrm{D} \log \left(P_{C}\right)= & \beta_{1} \mathrm{D} \log \left(P_{Q_{A}}\right)+\beta_{2} \mathrm{D} \log \left(P_{Q_{E}}\right)+\beta_{3} \mathrm{D} \log \left(P_{Q_{M}}\right)+\beta_{4} \mathrm{D} \log \left(P_{Q_{S}}\right) \\
& +\left(1-\beta_{1}-\beta_{2}-\beta_{3}-\beta_{4}\right) \mathrm{D} \log \left(P_{M}\right)+\mathrm{D} \log \left(1+t_{v a t}\right) \\
& +\beta_{0}\left[\log \left(P_{C,-1}\right)-\log \left(P_{C,-1}^{*}\right)\right]
\end{aligned}
$$

where the additional variables are:

$P_{C}{ }^{*} \quad$ Consumer price index, equilibrium level

$P_{Q j} \quad$ Producer price in sector $j(P Q j, \mathrm{~A}, \mathrm{E}, \mathrm{M}=\mathrm{M} 1+\mathrm{M} 2+\mathrm{M} 3+\mathrm{M} 4, \mathrm{~S}=\mathrm{S} 1+\mathrm{S} 2+\mathrm{S} 3+\mathrm{S} 4)$

The estimated weights to the output price in sector A, E, and $\mathrm{M}$ are negative and insignificant (both in the long and short-term relation) and are, therefore, restricted to zero in the estimation in Table 16, i.e., the consumer price depends on the output price in the service sector and the price on import only.

Table 16 Parameter Estimates, Consumer Price Index

\begin{tabular}{rrrrrrrrrrrrrr}
\hline Par. & $\alpha_{0}$ & $\alpha_{1}$ & $\alpha_{2}$ & $\alpha_{3}$ & $\alpha_{4}$ & $\lambda_{2}$ & $\lambda_{3}$ & $\lambda_{4}$ & $\beta_{0}$ & $\beta_{1}$ & $\beta_{2}$ & $\beta_{3}$ & $\beta_{4}$ \\
\hline & -0.197 & 0 & 0 & 0 & 0.748 & 0.031 & -0.015 & 0.063 & -0.412 & 0 & 0 & 0 & 0.820 \\
& {$[-7.31]$} & $*$ & $*$ & $*$ & {$[16.3]$} & {$[1.20]$} & {$[-0.86]$} & {$[1.61]$} & {$[-2.30]$} & $*$ & $*$ & $*$ & {$[8.85]$} \\
\hline
\end{tabular}

The consumer price is both in the short and long-run mostly determined by the producer-price in the service sector $\left(\alpha_{4}=0.75\right.$ and $\left.\beta_{4}=0.82\right)$, and has a small effect from the import price. The estimated equation fits the actual consumer price reasonably well as seen in Figure 25.

Figure 25 Consumer Price, Actual and Fitted (label E), PC (left) and $\operatorname{Dlog}(P C)$ (right)
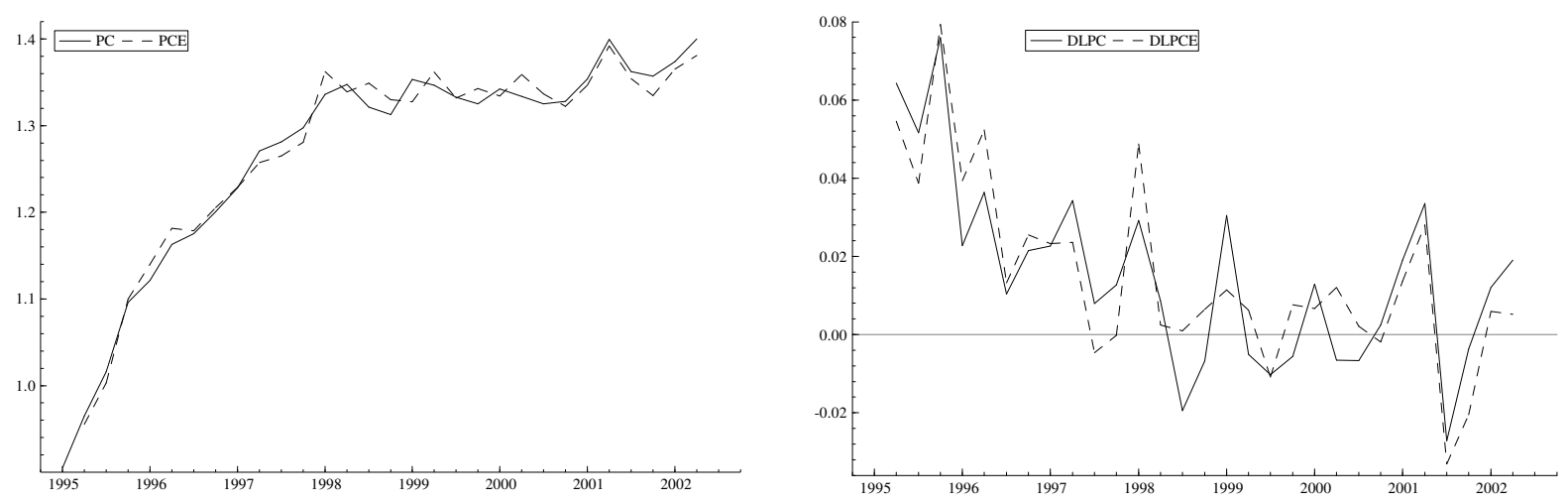


\subsection{Price of Public Consumption}

The government consumption is produced by the public sector (S4) so the price on government consumption $\left(P_{C g}\right)$ is determined by the producer-price in the public sector $\left(P Q_{S 4}\right)$. We restrict the long-run effect from the public sector producer price to be equal to one $\left(\alpha_{1}=1\right)^{28}$ so that the price equation is homogenous. As for the consumer price, we add an intercept and quarterly dummies. We formulate an error correction model (81) because there is autocorrelation in the residuals from an estimation of the long-term equation (80).

$$
\begin{gathered}
\log \left(P_{C g}^{*}\right)=\alpha_{0}+\alpha_{1} \log \left(P_{Q_{S 4}}\right)+\lambda_{2} \cdot Q_{2}+\lambda_{3} \cdot Q_{3}+\lambda_{4} \cdot Q_{4} \\
\operatorname{Dlog}\left(P_{C g}\right)=\beta_{0}\left[\log \left(P_{C g,-1}\right)-\log \left(P_{C g,-1}^{*}\right)\right]+\beta_{1} \operatorname{Dlog}\left(P_{Q_{S 4}}\right)
\end{gathered}
$$

Where

$P_{C g} \quad$ Price index on governmental consumption ( $\left.P C G\right)$

$P_{C g}{ }^{*} \quad$ Price index on governmental consumption, equilibrium level

$P_{Q S 4} \quad$ Producer price in public sector S4 (PQS4)

Table 17 Parameter Estimates, Price on Public Consumption

\begin{tabular}{rrrrrrrr}
\hline Parameter & $\alpha_{0}$ & $\alpha_{1}$ & $\lambda_{2}$ & $\lambda_{3}$ & $\lambda_{4}$ & $\beta_{0}$ & $\beta_{1}$ \\
\hline & 0.053328 & 1 & -0.034873 & -0.005643 & 0.032378 & -0.692816 & 0.572630 \\
& {$[2.94]$} & $*$ & {$[-1.31]$} & {$[-0.23]$} & {$[1.20]$} & {$[-4.74]$} & {$[5.25]$} \\
\hline
\end{tabular}

Estimation period 1995q2-2002q2. t-values in [ ] . ${ }^{*}$ Restricted parameter. $R^{2}=0.788784$

In the short-run, a $1 \%$ increase in the producer price only changes the government consumption price with $0.57 \%\left(\beta_{1}\right)$, but the adaptation towards the long-run price homogeneity is quick $\left(\beta_{0}=-0.69\right)$. As expected, the explanation is good.

Figure 26 Price on Public Consumption, Actual and Fitted
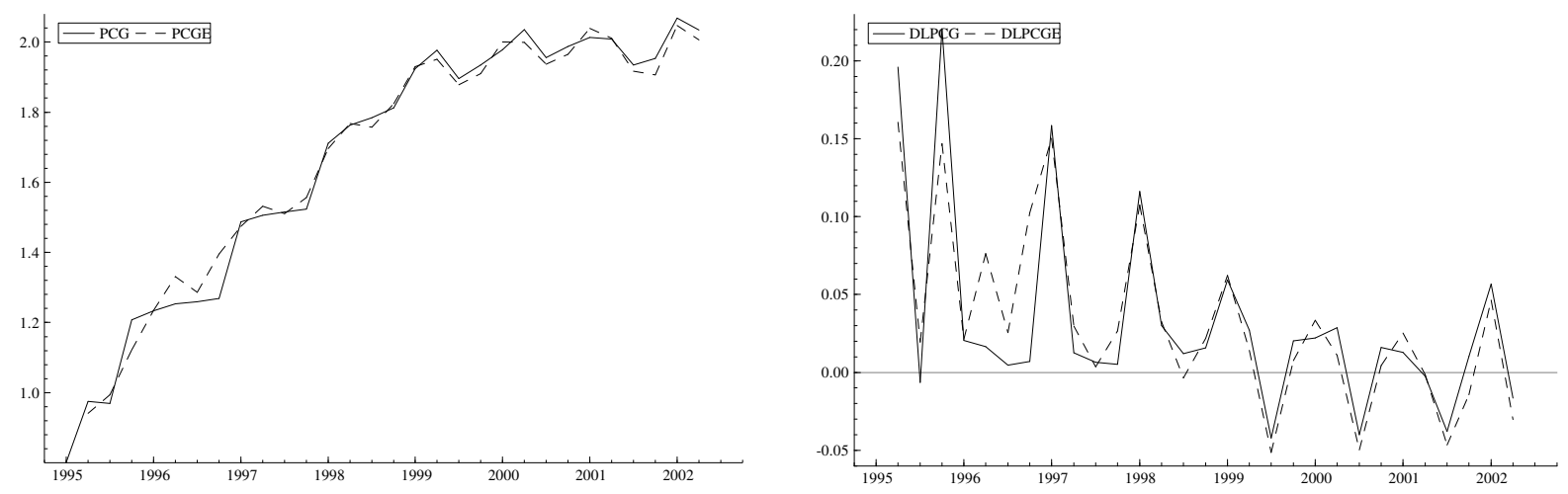

\footnotetext{
${ }^{28} \alpha_{1}$ is estimated to 1.04 .
} 


\subsection{Investment Price}

Investments are mainly composed of machinery (domestic production in sector M2 and import) and buildings (domestic production in the construction sector $\mathrm{C}$ ), so the investment price is modelled as a weighted average of the domestic producer price in the two relevant sectors $\left(P Q_{M 2}\right.$ and $\left.P Q_{C}\right)$ and the import price $\left(P_{M}\right)$. We use an error correction equation where the weights are allowed to differ from the long-run equation. The weights add to unity so the price equation is both static and dynamic homogenous. We also try to include an effect of the interest rate. ${ }^{29}$ There is no need for seasonal dummies in this equation.

$$
\begin{aligned}
\log \left(P_{I}^{*}\right) & =\alpha_{0}+\alpha_{1} \log \left(P_{Q_{M 2}}\right)+\alpha_{2} \log \left(P_{Q_{C}}\right)+\left(1-\alpha_{1}-\alpha_{2}\right) \log \left(P_{M}\right)+\alpha_{3} \cdot i \\
\mathrm{D} \log \left(P_{I}\right) & =\beta_{0}\left[\log \left(P_{I,-1}\right)-\log \left(P_{I,-1}^{*}\right)\right] \\
& +\beta_{1} \mathrm{D} \log \left(P_{Q_{M 2}}\right)+\beta_{2} \mathrm{D} \log \left(P_{Q_{C}}\right)+\left(1-\beta_{1}-\beta_{2}\right) \mathrm{D} \log \left(P_{M}\right)+\beta_{3} \mathrm{D}(i)
\end{aligned}
$$

Where

$P_{I} \quad$ Investment price $(P I)$

$P_{I}^{*} \quad$ Investment price, equilibrium level

$P_{M} \quad$ Import price $(P M)$

$P Q_{M 2, C} \quad$ Producer price in sector $\mathrm{M} 2$ and $\mathrm{C}$, respectively $(P Q j)$

I Interest rate $(\mathrm{ra}, \%)$

The estimated parameters to the producer price in the M2 sector were negative and insignificant and hence restricted to zero $\left(\alpha_{1}=0, \beta_{1}=0\right)$. The long-term estimated weight to the producer price in the construction sector was also negative and insignificant and hence restricted to zero $\left(\alpha_{2}=0\right)$. The investment price is in the short-run determined by an average of changes in the construction price and changes in the import price $\left(\beta_{2}=0.54\right)$. In the longrun, only the import price determines the investment price, and there is a small negative effect of the interest rate. However, it does not seem reasonable that the construction price does not have a long-term effect on the investment price. The adjustment is rather slow $\left(\beta_{0}=-0.25\right)$.

Table 18 Parameter Estimates, Investment Price

\begin{tabular}{cccrrrrrr}
\hline Parameter & $\alpha_{0}$ & $\alpha_{1}$ & $\alpha_{2}$ & $\alpha_{3}$ & $\beta_{0}$ & $\beta_{1}$ & $\beta_{2}$ & $\beta_{3}$ \\
\hline & 0.1885 & 0 & 0 & -0.0063 & -0.2531 & 0 & 0.5384 & 0 \\
& {$[2.51]$} & $*$ & ${ }^{*}$ & {$[-1.28]$} & {$[-2.10]$} & ${ }^{*}$ & {$[2.14]$} & ${ }^{*}$ \\
\hline Estimation period 1995q2-2002q2. t-values in [ ]. ${ }^{*}$ Restricted parameter. $\mathrm{R}^{2}=0.427083$
\end{tabular}

The problem with this estimation is that few of the changes in the investment price is explained by the equation, and as seen in Figure 27, the residuals increases in the last part of the sample period.

\footnotetext{
${ }^{29}$ Since investments are mostly financed by loans, it is more expensive to invest if there is an increase in interest rate, in which case, it is possible that the constructor is willing to lower the price in order to maintain delivery.
} 
$P_{I}$

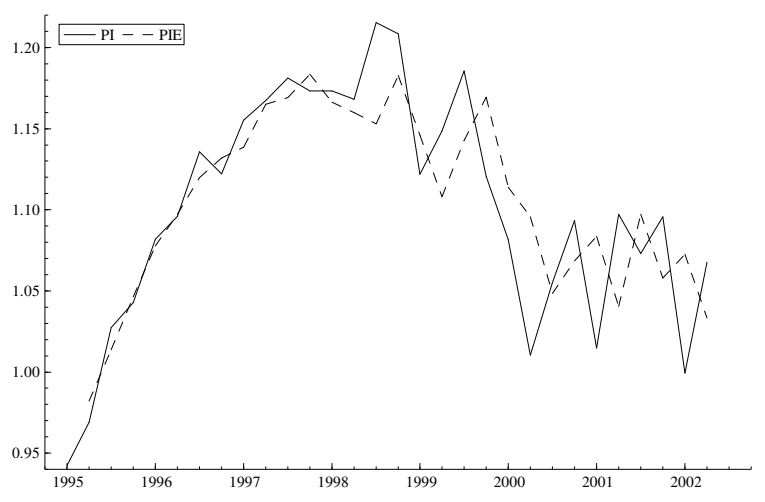

$\operatorname{Dlog}\left(P_{I}\right)$

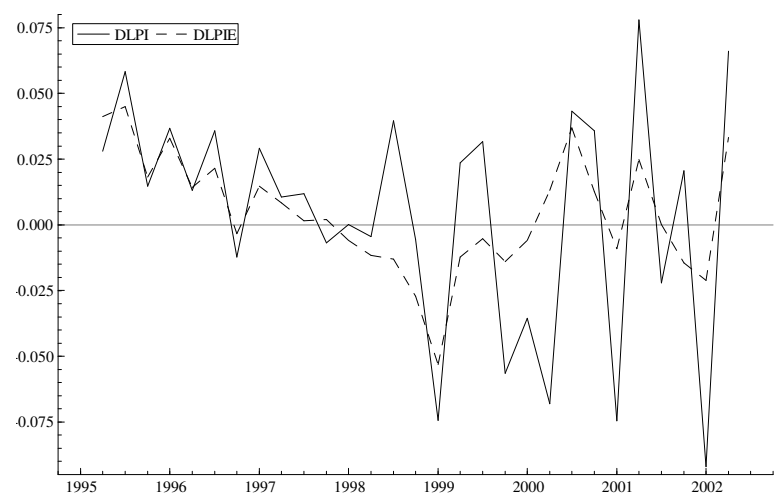

Residuals in Percentage

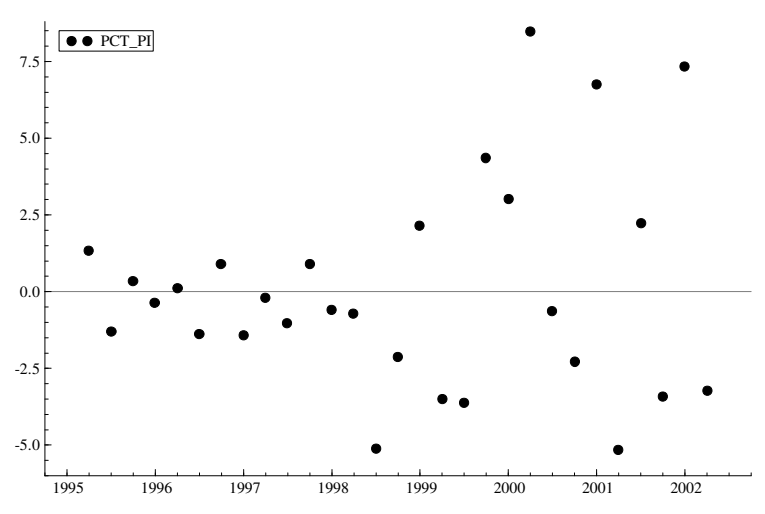

\subsection{Export Price}

The export price is modelled as a weighted average of the domestic producer price (average of exporting sectors) and the average price in three export markets (EU, CIS, and Central Europe) (84). We tried, without success, to estimate an error correction equation.

$$
\log \left(P_{X}^{*}\right)=\alpha_{0}+\alpha_{1} \log \left(P_{Q, \text { export }}\right)+\alpha_{2} \log \left(P_{E U}\right)+\alpha_{3} \log \left(P_{C I}\right)+\left(1-\alpha_{1}-\alpha_{2}-\alpha_{3}\right) \log \left(P_{C E}\right)
$$

Where

$P_{X} \quad$ Export price $(p x, 1995=1)$

$P_{X}^{*} \quad$ Export price, equilibrium level

$P_{Q \text {,export }} \quad$ Producer price on exported goods and services (pqex I-O weighted sum)

$P_{E U, C I, C E} \quad$ 'World Market Price' (in Litas) in EU, CI, and CE ( $p w r<e u, c i, c e>$ )

Figure 28 shows the export price and the prices used as explanatory variables. The EU price (corrected for exchange rate) decreases during the estimation period. There has been a steady increase in the Central Europe price, whereas there has been a huge inflation in the CIS countries (dotted line). 


\section{Figure 28 Export Price, Domestic Producer Price and Market Prices}
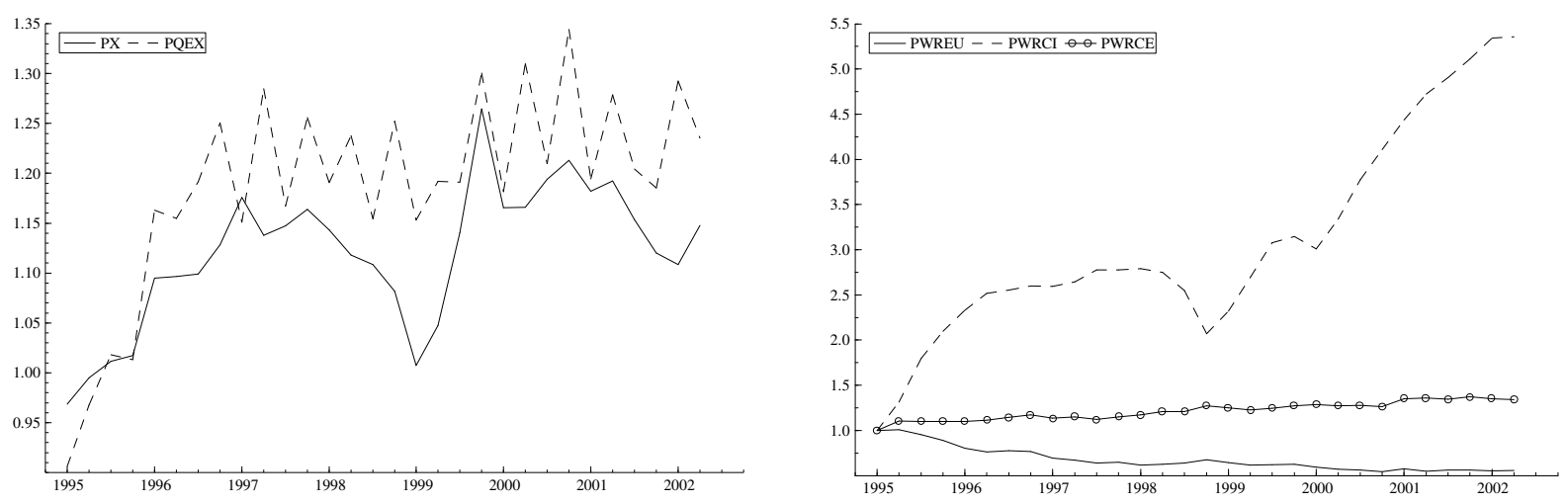

Table 19 shows the estimated coefficients. The equation is not improved by including seasonal dummies.

The export price is mostly determined by the domestic producer price $\left(\alpha_{1}=0.64\right)$. The effect of the CIS price is surprisingly small $\left(\alpha_{3}=0.05\right)$. Since the export price is not entirely determined by the World Market Price, the export market is not assumed completely competitive (as we saw in the estimation of export in Section 6).

The historical fit of the relation is shown in Figure 29. It shows that the decrease in the export price in the middle of the estimation period cannot be explained by the CIS-price, which was expected.

Table 19 Parameter Estimates, Export Price

\begin{tabular}{|c|c|c|c|c|c|}
\hline Parameter & $\alpha_{0}$ & $\alpha_{1}$ & $\alpha_{2}$ & $\alpha_{3}$ & $\left(1-\alpha_{1}-\alpha_{2}-\alpha_{3}\right)$ \\
\hline & $\begin{array}{r}-0.011933 \\
{[-0.51]}\end{array}$ & $\begin{array}{r}0.635000 \\
{[5.49]}\end{array}$ & $\begin{array}{r}0.165707 \\
{[2.69]}\end{array}$ & $\begin{array}{r}0.052584 \\
{[1.07]}\end{array}$ & 0.146709 \\
\hline
\end{tabular}

Figure 29 Export Price, Fit of Equation
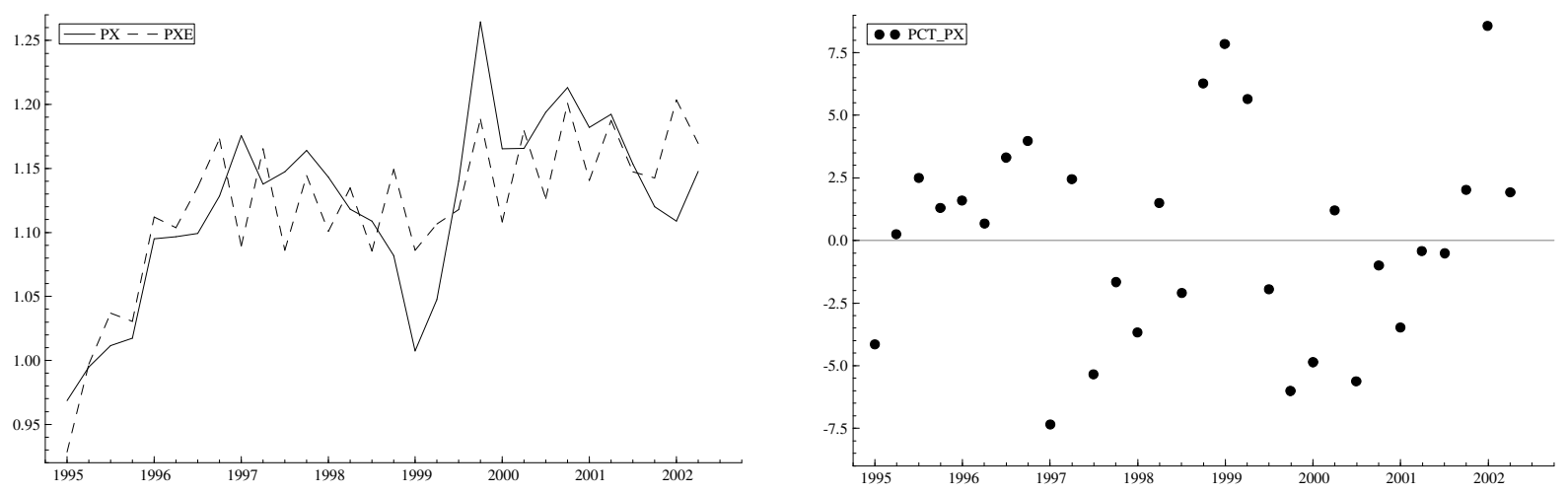

\subsection{Import Price}

The price of imported goods and services depends on the producer price (in Litas) in the countries where the goods are produced. In the former LITMOD, the import price was 
modelled as a weighted average of the prices in the three major import markets (CIS, Central Europe, and EU) and could be thought of as a World Market Price (Equation (85)):

$$
\log \left(p_{M}\right)=\alpha_{0}+\alpha_{1} \log \left(p_{C E}\right)+\alpha_{2} \log \left(p_{C I}\right)+\left(1-\alpha_{1}-\alpha_{2}\right) \log \left(p_{E U}\right)
$$

Figure 30 (left) shows the import price and the 'World Market Price' ( $w m p$ ) used in the export equation, and it is seen that while the World Market Price has grown rapidly, the import price has decreased. In the figure to the right, the three price indexes of EU, CE, and CIS corrected of exchange rate are plotted, and the growth in the World Market Price comes from the growth in the CIS price index.

\section{Figure 30 Import Price and World Market Prices}
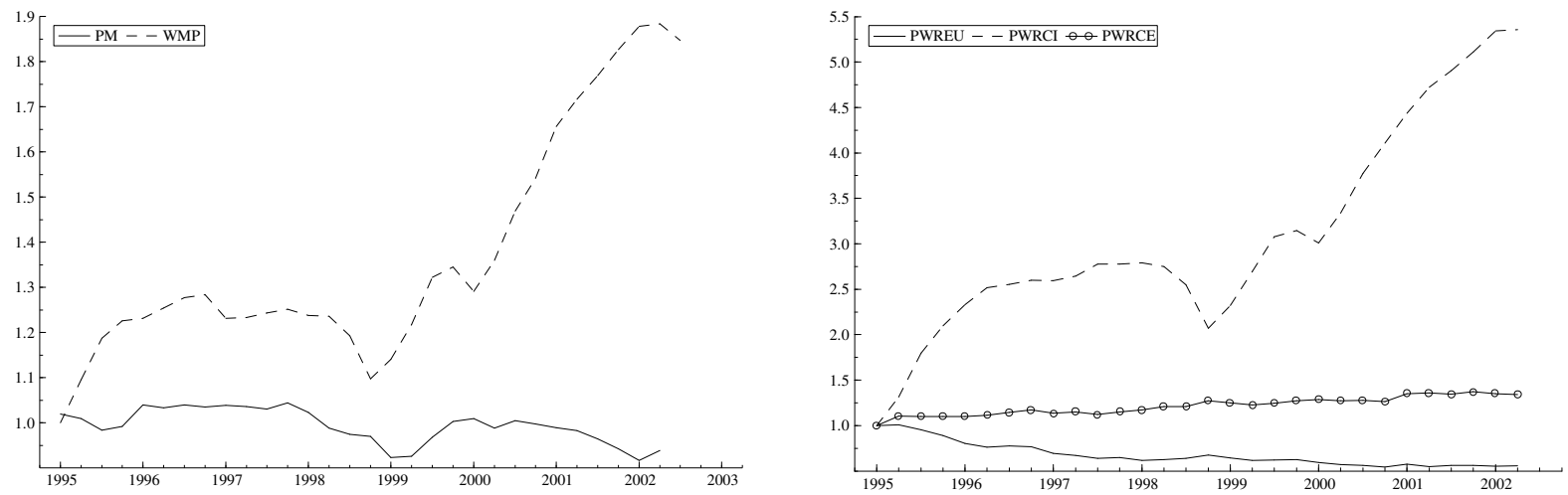

We were not able to estimate a reasonable equation. Therefore, we choose to treat the import price as an exogenous variable. It could, for instance, be updated with the same growth rate as the World Market Price.

The import price is a very important exogenous variable in the model, e.g., in the price determination.

\subsection{Wages}

Concerning wages, we have time series for the average monthly gross earnings for fulltime workers in the private and the public sector.

From the neoclassical theory, we have in the long-term, real wage changes depending on changes in labour productivity. According to the Phillip's curve theory, real wages are mainly determined by the unemployment rate or nominal wages depending on unemployment and inflation. From theories concerning wage negotiations, we also have the bargaining power of employees depending on unemployment and changes in labour productivity. This means that we have, in the long-term, a wage equation such as (86). If the neoclassical theory is dominant, the coefficients $\alpha_{1}$ and $\alpha_{2}$ should equal one and $\alpha_{3}$ should equal zero. If the Phillip's curve theory is dominant, $\alpha_{1}$ should be insignificant. Finally, if wages are not fully compensated for inflation, $\alpha_{2}$ should be between 0.0 and 1.0.

The long-run wage equation states that the private sector wage $\left(w_{P R I}\right)$ is related positively to the labour productivity $(Y / L)$, and negatively related to the unemployment rate $(U)$. We include the social security contribution rate at the right-hand side of both equations, because it forms part of the labour cost, i.e., any changes in this variable will obviously influence 
production cost and the dynamics of the private sector wage. We include quarterly dummies since wage is probably more stable during the year than the explanatory variables (consumer price and time productivity). We formulate an error correction model (87), but we were not able to estimate any short-term effect on changes in the explanatory variables, apart from a consumer price effect. The parameter estimates are shown in Table 20, and Figure 31 shows that the estimated equation (label E) catches most of the changes in the wage.

$$
\begin{gathered}
\log \left(w_{P R I}^{*}\right)=\alpha_{0}-\log (1+s c c)+\alpha_{1} \log (Y / L)+\alpha_{2} \log \left(P_{C}\right)+\alpha_{3} U+\lambda_{2} \cdot Q_{2}+\lambda_{3} \cdot Q_{3}+\lambda_{4} \cdot Q_{4} \\
\mathrm{D} \log \left(w_{P R I}\right)=\beta_{0}\left[\log \left(w_{P R I}^{*}\right)_{-1}-\log \left(w_{P R I}\right)_{-1}\right]-\log \left((1+s s c) /(1+s s c)_{-1}\right) \\
+\beta_{1} \mathrm{D} \log (Y / L)+\beta_{2} \mathrm{D} \log \left(P_{C}\right)+\beta_{3} \mathrm{D}\left(U-U_{-1}\right)
\end{gathered}
$$

Where

$\begin{array}{ll}w_{P R I} & \text { Average monthly gross earnings in the private sector (wpri, Litas) } \\ w^{*}{ }^{*} & \text { Wage, equilibrium level } \\ s S c & \text { Social security fund contribution rate } \\ Y & \text { GDP in private sector (GDPpri, mill. Litas constant prices) } \\ L & \text { Labour in private sector ( } L N p r i, 1000 \text { full time employed) } \\ P_{C} & \text { Price deflator on private consumption ( } p c, 1995=1) \\ U & \text { Unemployment rate }(U, \text { rate) } \\ Q_{2}-Q_{4} & \text { Quarterly dummies; } Q_{2} \text { is equal to one in second quarter and else zero }\end{array}$

In the long-run, a productivity increase of $1 \%$ increases the wage with $0.84 \%\left(\alpha_{1}=0.84\right)$. The effect of the unemployment rate is very high; if unemployment increases from, e.g., $8 \%$ to $9 \%$, wage decreases with $5 \%$ in the long-run. ${ }^{30}$ This large effect of unemployment is mainly determined by the last part of the estimation period where we have an increasing productivity, increasing unemployment, and an almost unchanged real wage (see Figure 32 right-hand side). The adjustment to equilibrium is rather slow $\left(\beta_{0}=0.2\right)$, but statistically significant.

Table 20 Parameter Estimates, Private Wage

\begin{tabular}{rllllllllll}
\hline Parameter $\alpha_{0}$ & $\alpha_{1}$ & $\alpha_{2}$ & $\alpha_{3}$ & $\beta_{0}$ & $\beta_{1}$ & $\beta_{2}$ & $\beta_{3}$ & $\lambda_{2}$ & $\lambda_{3}$ & $\lambda_{4}$ \\
\hline 5.899 & .8404 & 1 & -5.361 & .2091 & 0 & .3336 & 0 & -.225 & -.239 & -.383 \\
{$[16.05]$} & {$[4.636]$} & $*$ & {$[-3.810]$} & {$[4.937]$} & $*$ & {$[1.369]$} & $*$ & {$[-4.111]$} & {$[-3.347]$} & {$[-4.362]$} \\
\hline
\end{tabular}

\footnotetext{
${ }^{30}$ However, compared with other studies of wage determination, this is not unreasonable in an estimation on macro time series [Carnot 2002].
} 
Figure 31 Wage in the Private Sector, Fit of Estimated Equation (left: log, right Dlog)
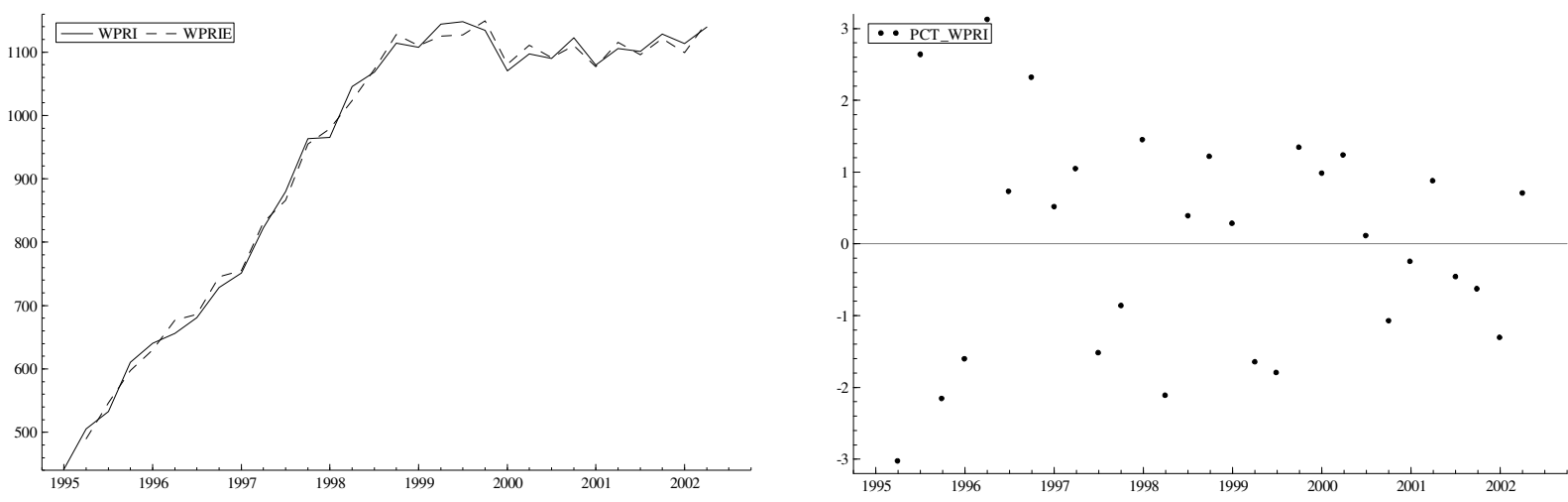

The public sector wage $\left(w_{P U B}\right)$ follows the private sector wage. Figure 32 (left) shows that the equation underestimates the public wage for the last years. There is no need to specify a dynamic adjustment, but we correct for autocorrelation in the equation.

$$
\log \left(w_{P U B}\right)=\alpha_{0}+\log \left(w_{P R I}\right)+\rho\left[\log \left(w_{P U B}\right)_{-1}-\alpha_{0}-\log \left(w_{P R I}\right)_{-1}\right]
$$

Where

$w_{P U B} \quad$ Average monthly gross earnings in the public sector (wpub, Litas)

$w_{P R I} \quad$ Average monthly gross earnings in the private sector (wpri, Litas)

Figure 32 Wage in the Public Sector, Fit Estimated Equation
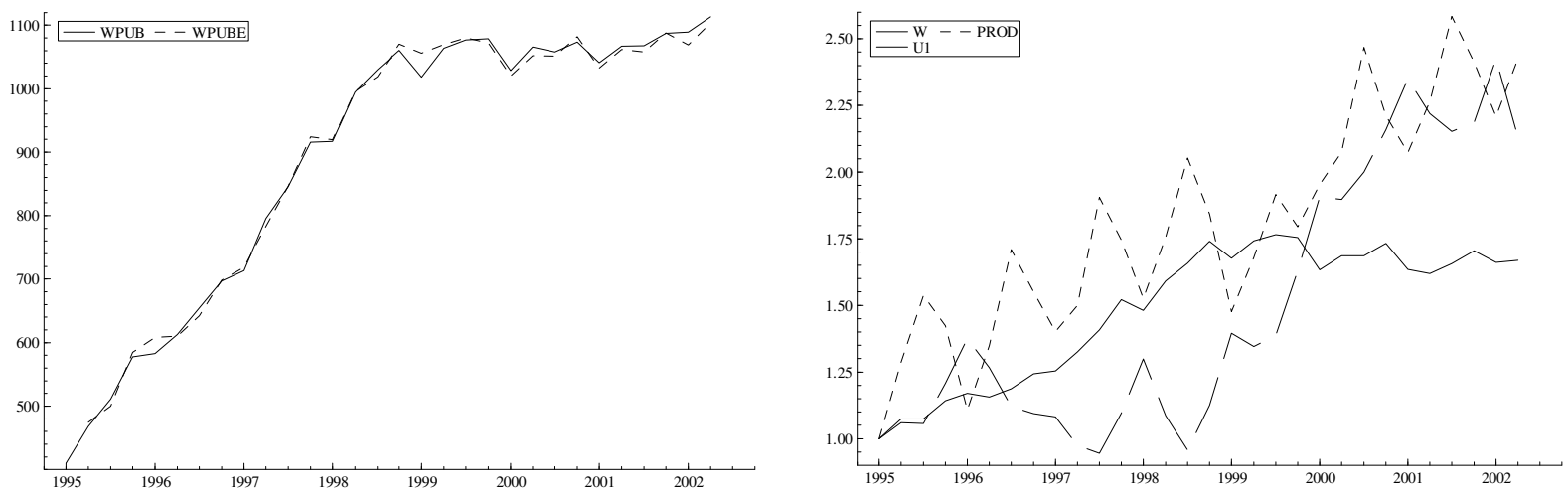

Table 21 Parameter Estimates, Public Wage

\begin{tabular}{rrr}
\hline Parameter & $\alpha_{0}$ & $\rho$ \\
\hline-.045328 & .571123 \\
{$[-6.85622]$} & {$[3.63001]$} \\
\hline Estimation period 1995q2-2002q2; t-values in [ ]; $\mathrm{R}^{2}=0.997$ \\
\hline
\end{tabular}

The wages are average monthly wages in Litas per full-time worker, and $L$ is 1000 fulltime workers, so we calculate total quarterly wage amount in mill. Litas as:

$$
W_{S U M}=0.001 \cdot 3 \cdot w_{P R I} \cdot L_{P R I}+0.001 \cdot 3 \cdot w_{P U B} \cdot L_{P U B}
$$




\section{Model and Scenarios}

We described in the previous chapter the different parts of the model, and we will in this last chapter explain how the model can be simulated as well as how a baseline scenario is constructed. We will also show some simulation experiments with the model.

All the equations in the model are estimated using the software TSP and the model is simulated in the same software.

\subsection{Solving the Model}

Large economical models currently used for forecasting and simulations are typically both highly simultaneous and non-linear. Even simple macro-economic models, where all the stochastic equations in the system may be linear in logarithms, include accounting identities that are linear in levels. As a consequence, although a model may be estimated using linear techniques, forecasts with that model (which need to take into account identities) will normally involve using non-linear solution techniques. The present Lithuanian macroeconometric model is not an exception from this rule.

In general, it is commonly agreed that non-linear models cannot be solved analytically or that the solution is quite impractical. Therefore, common practice is to resort to numerical algorithm for model solving.

Simulating models, of the two main categories of algorithms, the Newton and the GaussSeidel methods, ${ }^{31}$ the Gauss-Seidel method has been almost universally adopted for solving large models. However, a non-linear model could, in general, exhibit multiple solutions. So when the Gauss-Seidel method is used for model solution, care must be taken to ensure that the solution is either unique or that the model is converging on a 'desired' solution.

In this section, we briefly outline the Gauss-Seidel technique and discuss some possible problems caused by the method. Afterwards, we present the ex-post solutions of the model calculated by this technique and we investigate the simulation results.

\subsubsection{The Gauss-Seidel Solution Technique}

A general dynamic $n$ equation non-linear model could be written in the following implicit form:

$$
\mathrm{f}\left(y_{t}, Y_{t-1}, X_{t}, u_{t} ; \theta\right)=0
$$

where

$\mathrm{f} \quad n \times 1$ vector of valued functions

$y_{t} \quad n \times 1$ vector of endogenous variables

$Y_{t-1} \quad n \times(p-1)$ matrix of lagged endogenous variables (with a maximum lag order $\mathrm{p}$ )

$X_{t-1} \quad n \times q$ matrix of current and lagged values of exogenous variables

\footnotetext{
${ }^{31}$ In the TSP software, the Newton and the Gauss-Seidel methods correspond to the commands SIML and SOLVE, respectively.
} 
As mentioned above, it is agreed that for non-linear models, an analytic solution of (90) does not exist, i.e., the corresponding reduced form of (90), i.e. equation (91) has to be found using iterative numerical methods (Gauss-Seidel in our case).

$$
y_{t}=\mathrm{g}\left(Y_{t-1}, X_{t}, u_{t} ; \theta\right)
$$

So, as the first step, the Gauss-Seidel method requires (90) to be normalised, i.e., it should be represented in the explicit form:

$$
y_{t, i}=\mathrm{h}_{i}\left(y_{t,-i}, Y_{t-1}, X_{t}, u_{t} ; \theta\right), i=1, \ldots, n
$$

For example, if we have log-linear (long-term equation) regression, then normalisation means to take exponent on both sides of the equation. In the short-run equation, we first add the logarithm of the lagged endogenous variable to both sides and then take exponent. Each equation in (90) should be normalised on one endogenous variable, but it cannot appear twice in the left side of (92). In general, normalisation is almost always possible, but not unique. Convergence of the iteration procedure will depend on the particular normalisation that has been adopted. This is a recognised disadvantage of the Gauss-Seidel compared with the Newton method. On the other hand, the Newton method requires the inversion of the matrix of model derivatives and is hard to implement in the case of large macro models (more than 25 equations as suggested in the TSP User's Guide). The Jacobi or the Gauss-Seidel methods have no such limitation, but normalisation is the problem. ${ }^{32}$

The Gauss-Seidel method proceeds by first assigning starting values to the vector $y_{t}$ known as initial values. In practice, these are often the actual values of this vector in the previous period (last quarter in our case).

The Gauss-Seidel method solves each of the $n$ equations in the order $i, i=1, \ldots, n$. The number $s$ iteration is

$$
y_{i t}^{s}=h_{i}\left(y_{1 t}^{s}, \ldots, y_{i-1 t}^{s}, y_{i+1 t}^{s-1}, \ldots, y_{n t}^{s-1}, Y_{t-1}, X_{t}, u_{t} ; \theta\right)
$$

This method differs from the Jacobi method in that equation $i$ uses the solution from this iteration for all variables defined by equations appearing earlier in the model: i.e., $y_{j t}, \mathrm{j}<\mathrm{i}$. For this reason, the method is also known as the method of successive substitution. This variation on the Jacobi method has been found to considerably speed up convergence.

On the other hand, it makes convergence dependent on the equation ordering. Don and Gallo (1987) suggest an algorithm for the optimal ordering of a system of equations for the GaussSeidel model solution. This orders the model equations to maximise the recursivity of the system, which is equivalent to ordering the equations to make the Jacobean matrix as close as possible to being lower triangular.

\footnotetext{
${ }^{32}$ Further discussion of the problem can be found in S.G.Hall and S.G.B. Henry (1989).
} 
The Gauss-Seidel method could also be speeded up by adding relaxation parameter $\alpha$ $(0<\alpha<1)$ into (93) (Successive Over Relaxation, SOR method). The optimal value of $\alpha$ will depend on the model and can be found by experimentation.

The next step in the following discussion will be a brief theoretical analysis of predictions with non-linear models.

As with linear models, ex ante forecasts could be done by using the reduced form (92). We should notice that both static (actual values are used as explanatory variables) and dynamic (previous model solutions are used) solutions are available. In terms of forecasts, the dynamic solution is used. However, in the case of non-linear models, one disadvantage should be mentioned - the solution is not unbiased anymore, i.e.,

$$
\mathrm{E}\left\langle y_{t} \mid Y_{t-1}, X_{t}\right\rangle \neq g\left(Y_{t-1}, X_{t}, \mathrm{E} u_{t}, \theta\right)
$$

Unbiased prediction can instead be obtained by the stochastic simulation method. The basic idea of this method is, with the help of the Monte-Carlo method, to generate $R$ repeated solutions of $E\left\{y_{t}^{r} \mid Y_{t-1}, X_{t}\right\}$, where in (93): $\mathrm{E} u_{t} \rightarrow e_{t}^{r} \sim N(0, \Sigma), r=1, \ldots, R$ and $\Sigma$ is a consistent estimate of $\operatorname{Var}\left(u_{t}\right)$. Then, for sufficient large $R$, the mean of the replications will approximate the left side of (94). However, this is more difficult and time-consuming than using (92), and we will not try with this large model to perform a stochastic simulation.

\subsubsection{LITMOD}

LITMOD has approximately 150 structural equations and 50 identities. All structural equations have been normalised so that each endogenous variable appears only once at the left-hand side. Table 33 in Appendix 12.5 shows all the equations formulated in TSP code.

The TSP command MODEL is used to produce a collected model. This TSP command splits the model into 2 recursive and 1 simultaneous block:

\section{Table 22 Block Structure of LITMOD}

\begin{tabular}{|ccc|}
\hline Block & \# Recursive & \# Simultaneous \\
$\#$ & equations & equations \\
1 & 4 & \\
2 & & 141 \\
3 & 60 & \\
\hline
\end{tabular}

A quick inspection of the model confirms the following:

- We have four identities in the first recursive block, which directly influence the simultaneous block. The first three identities (real CPI in different groups of countries) only involve exogenous variables and lagged endogenous variables. The fourth equation (the World Market Price) is only dependent on the real CPI's. We can see that this block could be treated as an exogenous flow into LITMOD.

- The equations in the simultaneous block are solved with the Gauss-Seidel method as described earlier. We use a dynamic solution for this block, i.e., previously computed values are taken as the lagged endogenous variables. 
- After this block, there are a number of equations that can be solved separately by only using information on exogenous variables and previously solved endogenous variables.

- Recursive blocks are solved in one iteration.

- The convergence of the simultaneous block is rather slow (approximately 50 iterations are needed to solve each period in the simulation period).

The TSP command SOLVE will simulate the model. In the next section, we look at the expost solution where the model is simulated in the historical period, and we will afterwards simulate the model for forecast proposes.

\subsection{LITMOD Ex-Post Solution}

In this section, we verify the accuracy of point predictions produced by LITMOD. All equations are formulated according to the theoretical considerations and estimations discussed earlier in this documentation, and collected in one model (LITMOD). 'What if' types of scenarios will be analysed in the Scenarios section below and will reveal additional information about the linkage between different endogenous and exogenous variables. The aim of this section is to compare simultaneous solutions within observation period (ex-post forecasts) against actual values.

We have verified the model performance over the historical period of $1995 \mathrm{q} 42002 \mathrm{q} 2$, a shorter period than the observation period due to the inclusion of lagged variables in some of the equations.

We have chosen a number of endogenous variables (see Table 23, first column) as the most important output elements and we have used the ACTFIT TSP command, which computes and prints a variety of goodness-of-fit statistics comparing the actual (A) and predicted (P) values of time series. These statistics are: The correlation of the two series $(\mathrm{R})$, the mean square error, the root-mean-square-error (RMSPE), the mean absolute error, the mean percent error (MPE), Theil's inequality coefficient in first differences (U $\Delta$ ) and in levels (U), and a decomposition of the source of the discrepancies between the two series. Decomposition is a very important tool for the analysis of short-term predictions, as it explains the source of inequality. ${ }^{33}$ In Table 23, we show only some of these statistics.

Besides comparing the simulated and actual values, we also compare the simulated values with the estimated values obtained in the previous sections. The single equation estimation (the ECM fit) minimises the differences between the actual and estimated values. If the model only consisted of single equations with no interactions, the simulated values will equal the ECM fits. So, the differences between the simulated and estimated values show the simultaneity in the model. For example, a systematic error in the disposable income can induce errors in the simulated private consumption.

\footnotetext{
${ }^{33}$ Some theory on short-term forecasts analysis can be found in [Theil, Henri, Applied Economics, North Holland Publishing Company, 1966].
} 
One of the most important endogenous variables is private consumption. Figure 33 (left) shows the actual values of the private consumption $(C R N)$, the simulated values $\left(C R N_{-} \boldsymbol{F}\right)$, and the estimated values $(\boldsymbol{E} C R N)$.

Being impressively well determined during the separate ECM estimation (see Section 3.3), we have expected the same effect for the private consumption after the simultaneous solution. As seen in Table 23, there is a high correlation between the predicted and actual values $(\mathrm{R}=$ 0.969 ) and a small deviation from the actual series (RMSPE $=2.5 \%$ ). This shows a rather good fit for private consumption. Theil's inequality coefficient in first differences is also relatively small $(\mathrm{U} \Delta=0.3357)$, but predicted changes are slightly overestimated. This happens because of overestimation of the first differences of disposable income (DI, Figure 33 , right) and unsatisfied short-run prediction of the simultaneously estimated consumer prices ( $P C$, Theil's $U$ in differences is higher than one, see Figure 38, left). On the other hand, both disposable income and consumer prices are reasonably close to the actual series in levels (correlation is correspondingly equal to 0.965 and 0.938 ) and will due to this produce acceptable long run forecasts.

The LITMOD solution for private consumption $\left(C R N \_F\right)$ is close to the ECM solution $(E C R N)$. Disposable income $(D I)$ is influenced by the simultaneous solutions for wages and profits, but despite this, it shows a good performance both in the short and long-run.

Figure 33 LITMOD Solutions: Private Consumption (left), Disposable Income (right)
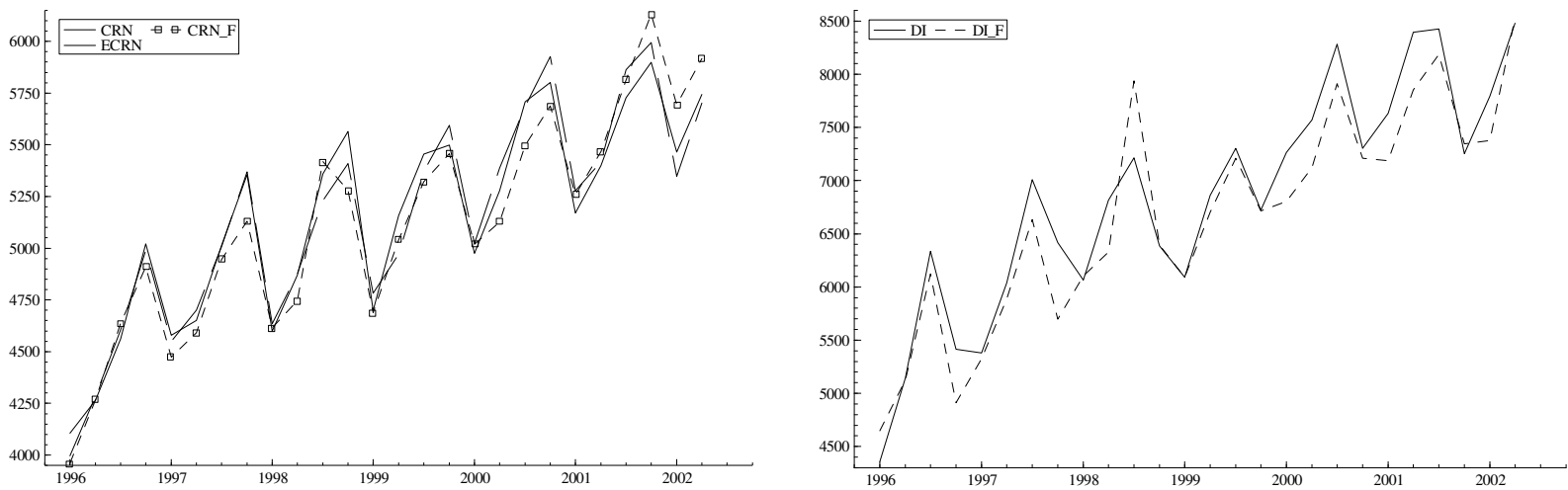

The most important determinant for the gross domestic investments (IRN1) is total capital investments in sectors (IRT). In Figure 34 (left), we see that aggregated total capital investments are reasonably close to the actual series, but percentage changes are getting larger over the estimation period, which leads to an increase in the RMSPE (0.075). However, we should notice that the RMSPE for investments in sectors sometimes approach 0.34, as it was in the ECM solutions. In fact, the simultaneous solution is very close to the ECM results. There were almost no change points in the first differences, but the changes were slightly underestimated. $U$ statistic in first differences is 0.2436 , which means that a simultaneous solution in this case provides significant short-run predictions. There is almost the same conclusion for the gross domestic investments. 
Figure 34 LITMOD Solutions: Total Capital Investment in Sectors (left), Gross Domestic Investments (right)
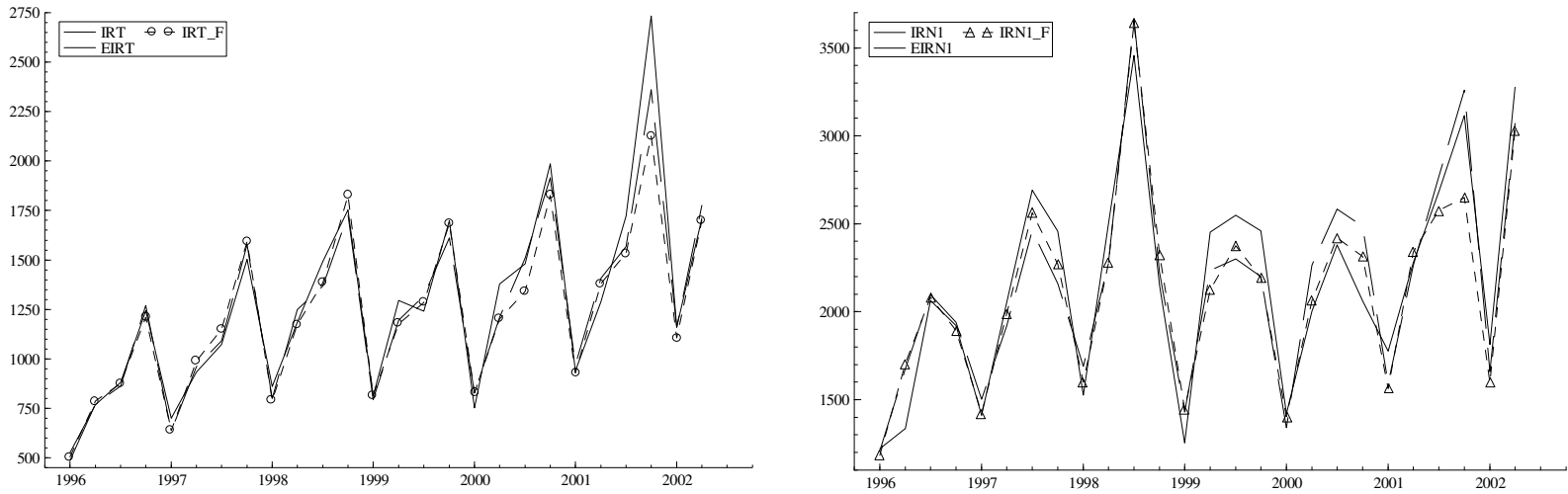

Foreign trade is represented in the model by total import $(M R N)$ and export $(X R N)$ of goods and services.

The import has a very low RMSPE of 0.053 and a high correlation with both ECM solution and actual series ensuring good long-run predictions. Short-run performances are underestimated, but significant ( $U$ is equal to 0.4107 ).

Export depends heavily on exogenous variables and hence we would expect the simulated value to be close to the estimated value. The export equation has acceptable long-run properties: small variation (RMSPE 0.08) and high correlation. However, short-run predictions are not acceptable: many turning points are not explained (wrong signs of changes compared to the actual signs of changes) leading to Theil's $U$ coefficient being equal to 0.89 , which is in the short-run close to a no-change extrapolation.

Figure 35 LITMOD Solutions: Import (left), Export (right)
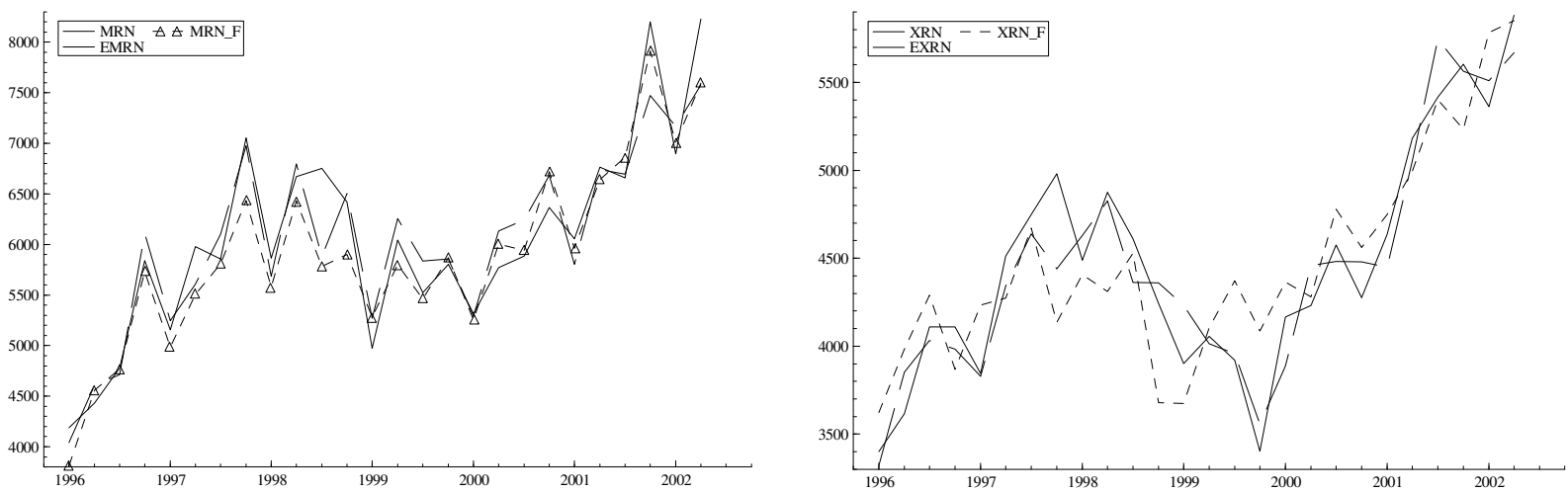

Figure 36 illustrates that total production $(Q R T)$, total intermediate (INRT), and implicitly total gross value added $(G D P T=Q R T-I N R T)$ has the same form of development over the estimation period. This is due to the fact that they are linked through the Input-Output system. The time series catch the long-run tendency (high correlation 0.83, 0.77, respectively, and small Percent Errors), and short-run changes ( $U$ in first differences close to 0.5 ) quite well, but the first differences are often overestimated. 
Figure 36 LITMOD Solutions: Total Production (left), Total Intermediate (right)
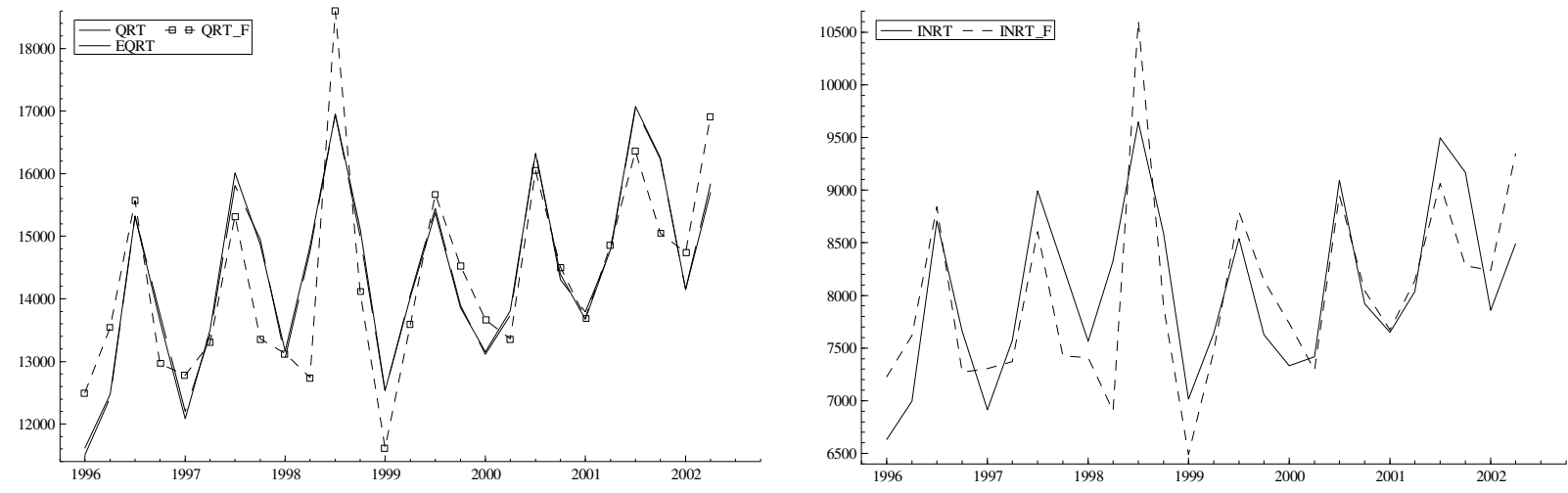

Total labour demand $(L N)$ and labour supply $(L S)$ capture the long-run tendency, but fail to explain short-run changes. Too large changes for total labour demand and a number of turning points lead to $U$ being unacceptably high. In addition, decomposition of $U$ shows that a bias in the first differences. This means that no-change extrapolation in the short-run provides better results in terms of smaller root-mean-square-error. The labour supply is mostly influenced by the exogenous number of population $(P O P)$ and is in the long-run also close to a no-change extrapolation.

Figure 37 LITMOD Solutions: Labour Demand (left), Labour Supply (right)
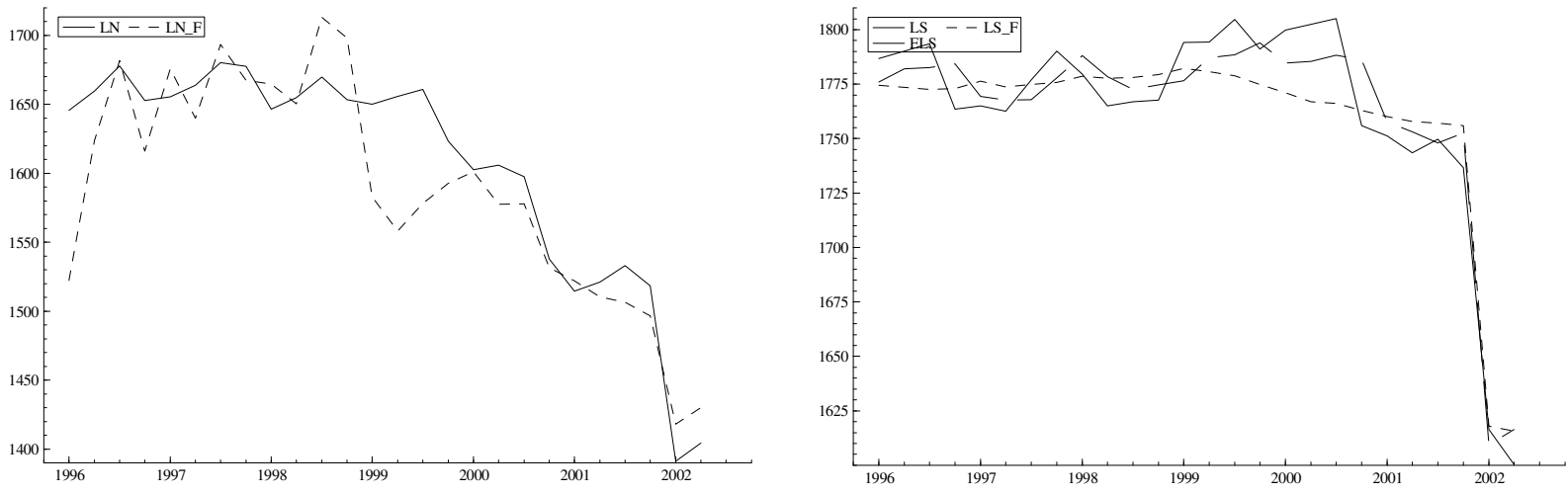

Finally, we examine some price indices. The most important are the consumer price $(P C)$ and the producer price $(P Q)$ indices. As for labour market series, the equations have consistent long-run properties, but (especially in the case of consumer prices) explain short-run changes insufficiently. 
Figure 38 LITMOD Solutions: Consumer Price Index (left), Producer Price Index (right)
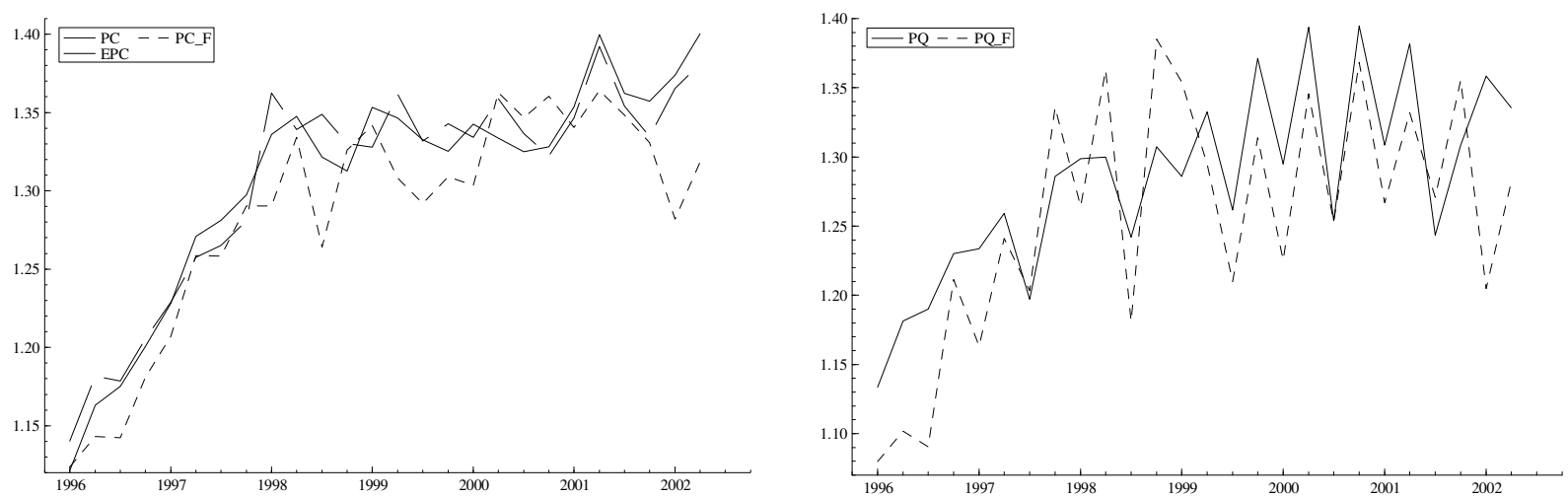

The mentioned results concerning the accuracy of ex-post simulation of LITMOD are summarised in Table 23.

Table 23 Ex-Post Forecast Verification Results

\begin{tabular}{llrrrrrr}
\hline Variable & Description & $\mathrm{R}$ & $\mathrm{RMSPE}$ & $\mathrm{MPE}$ & $\mathrm{p}$-value & $\mathrm{U} \Delta$ & $\mathrm{U}$ \\
\hline IRT & Capital investment & 0.965 & 0.076 & 0.0236 & 0.0247 & 0.2436 & 0.1070 \\
\hline WPRI & Wage & 0.980 & 0.051 & 0.0386 & 0.1659 & 0.9793 & 0.0547 \\
\hline QRT & Production & 0.831 & 0.059 & 0.0031 & 0.0556 & 0.4993 & 0.0596 \\
\hline GDPT & Value Added & 0.886 & 0.050 & 0.0042 & 0.2000 & 0.4228 & 0.0505 \\
\hline INRT & Intermediate & 0.779 & 0.067 & 0.0019 & 0.0231 & 0.5543 & 0.0685 \\
\hline Prof & Profit & 0.926 & 0.099 & 0.0078 & 0.6494 & 0.4686 & 0.0909 \\
\hline CRN & Private consumption & 0.969 & 0.025 & 0.0058 & 0.0841 & 0.3357 & 0.0260 \\
\hline DI & Disposable income & 0.965 & 0.050 & 0.0244 & 0.9661 & 0.4843 & 0.0500 \\
\hline LN & Labour demand & 0.874 & 0.026 & 0.0094 & 0.2120 & 1.3020 & 0.0265 \\
\hline LS & Labour supply & 0.943 & 0.009 & 0.0020 & 0.2232 & 0.6028 & 0.0096 \\
\hline XRN & Export & 0.857 & 0.080 & -0.0078 & 0.6856 & 0.8899 & 0.0760 \\
\hline MRN & Import & 0.950 & 0.053 & 0.0232 & 0.8157 & 0.4107 & 0.0558 \\
\hline CGREV & Gov. revenue & 0.988 & 0.038 & 0.0326 & 0.7803 & 0.5602 & 0.0385 \\
\hline PQ & Producer price & 0.828 & 0.048 & 0.0223 & 0.0005 & 0.8650 & 0.0478 \\
\hline PC & Price on consumption & 0.938 & 0.028 & 0.0174 & 0.2341 & 1.1553 & 0.0282 \\
\hline IRN1 & Domestic investments & 0.949 & 0.095 & 0.0128 & 0.5557 & 0.2751 & 0.0875 \\
\hline & & & & & & &
\end{tabular}

In this table:

$\mathrm{R} \quad$ Correlation Coefficient, $R=\frac{\frac{1}{n} \sum\left(P_{i}-\bar{P}\right)\left(A_{i}-\bar{A}\right)}{s_{P} s_{A}}$

RMSPE Root-Mean-Squared Percent Error, RMSPE $=\sqrt{\frac{1}{n} \sum\left(\frac{P_{i}-A_{i}}{A_{i}}\right)^{2}}$

MPE Mean Percentage Error, $M P E=\frac{1}{n} \sum \frac{P_{i}-A_{i}}{A_{i}}$

p-value $\quad \mathrm{p}$-value for test $\mathrm{H}_{0}: \beta=1$ in the regression $P_{i}=\beta \cdot A_{i}$

$\mathrm{U} \Delta \quad$ Theil's $U$ Inequality coefficient (in first differences), $U \Delta=\sqrt{\frac{\sum\left(\Delta P_{i}-\Delta A_{i}\right)^{2}}{\sum \Delta A_{i}{ }^{2}}}$

$\mathrm{U} \quad$ Theil's U Inequality coefficient (in levels), $U=\sqrt{\frac{\sum\left(P_{i}-A_{i}\right)^{2}}{\sum A_{i}{ }^{2}}}$ 
High correlation and small deviation of predicted values from actual series confirms that LITMOD, in most cases, produces adequate and reasonable long and medium-term forecasts. Also, most of the equations catch short-run changes reasonably well, but another part of LITMOD shows that the short-run solutions are no better than corresponding simple nochange extrapolations, i.e., one should be very cautious about the quality of short-term point predictions, but be satisfied with the long-term and medium-term performance of LITMOD, i.e. the model satisfies the general goals described in the Preface to this documentation.

\subsection{Baseline Scenario}

In this section, the aim is to produce a baseline scenario over a period of 20 years. We discuss the exogenous variables in Section 11.3.1, and the baseline scenario is presented in Section 11.3.2.

\subsubsection{Exogenous Variables}

The model includes a number of exogenous variables, and in order to forecast the endogenous variables, a forecast of the exogenous variables is required (see Appendix 12.1 for the list of variables in the model).

The advantages of using a structural econometric model for forecasting are that the equations are based on economic theory and historical data, and that forecasting of the different variables is consistent. However, in order to obtain a simulation for future periods, we will need to know the values for all the exogenous variables over the forecasted period.

In this section, we will discuss the aspects of forecasting the exogenous variables. Some of the exogenous variables are controlled by the policy-maker (policy variables), e.g., tax rates. Other exogenous variables describe the economy outside Lithuania, e.g., the World Market Price. Following a forecast of all the exogenous variables, the model is simulated whereafter we obtain a forecast of all the endogenous variables. Only changes in the exogenous variables will change the forecast. We change the value of some of the exogenous variables in Section 11.4 in order to see the effect on endogenous variables.

In practice, there is different ways to perform forecasts of exogenous variables. One way is to use official forecasts issued by different Lithuanian governmental and private institutions, for instance, Statistics Lithuania, Bank of Lithuania, Ministry of Finance, Lithuanian Free Market Institute, etc. If we do not have official forecasts, simple forecasts, expert evaluations, BoxJenkins, or ARIMA models are alternatives:

- Simple forecasts are based on the idea of the decomposition of time series into a macroscopic and a microscopic component. The model-builder will thereafter extrapolate the macroscopic component into the forecasting period.

- Expert consensus paradigm derives from the theory of rational expectations, originated from J.F. Muth in 1961 and later elaborated by R. Lucas and other economists. One of the basic assumptions behind the rational expectations theory is that if a connection has been observed between an economic variable and certain processes in the economy, individuals will use all the information available to them in forming expectations and forecasts. These expert evaluations are very useful in the case of short and medium-term forecasts. 
- $\quad$ ARIMA models could be thought of as a sophisticated extrapolation method. They are widely used in financial mathematics and as well as expert forecasts produce good predictions within the short and medium-term forecasting.

We use official forecasts whenever possible. In other cases, we tried to either estimate macroscopic components and make a simple extrapolation, or to make reasonable assumptions about the performance of exogenous time series. Naive no-change assumptions are used in some cases.

The few estimated exogenous variables are forecasted by one of the following two forms using the historical information on the seasonal pattern and a time trend. The estimation results performed over the historical data are summarised in Table 24.

$$
\begin{aligned}
X_{t} & =\alpha_{0}+\alpha_{1} T_{t}+q_{2} Q_{2}+q_{3} Q_{3}+q_{4} Q_{4}+\eta_{t} \\
\log \left(X_{t}\right) & =\alpha_{0}+\alpha_{1} T_{t}+q_{2} Q_{2}+q_{3} Q_{3}+q_{4} Q_{4}+\eta_{t}
\end{aligned}
$$

Where

$X_{t} \quad$ Dependent variable (one of the exogenous variables in the model)

$T_{t} \quad$ Trend part (linear or logarithmic trend)

$Q_{2}-Q_{4} \quad$ Seasonal dummies

$\eta_{t} \quad$ Residual

\begin{tabular}{|c|c|c|c|c|c|c|c|c|}
\hline $\begin{array}{l}\text { Exogenous } \\
\text { variable }\end{array}$ & & $\alpha_{0}$ & $\alpha_{1}$ & $\overline{T_{t}}$ & $q_{2}$ & $q_{3}$ & $\overline{q_{4}}$ & $\mathrm{R}^{2}$ \\
\hline $\begin{array}{l}\text { PENSNR } \\
\text { 1995q1-2002q4 }\end{array}$ & $\begin{array}{l}\text { Number of } \\
\text { pensioners }\end{array}$ & $\begin{array}{l}770.74 \\
{[51.75]}\end{array}$ & $\begin{array}{r}86.58 \\
{[15.60]}\end{array}$ & $\log (t)$ & $\begin{array}{l}0 \\
*\end{array}$ & $\begin{array}{l}0 \\
*\end{array}$ & $\begin{array}{l}0 \\
*\end{array}$ & 0.890 \\
\hline $\begin{array}{l}\text { CGSEOV } \\
1995 q 1-2002 q 4\end{array}$ & $\begin{array}{l}\text { Non-pension } \\
\text { SSSF transfers }\end{array}$ & $\begin{array}{l}34518 \\
{[1.13]}\end{array}$ & $\begin{array}{r}82144 \\
{[7.18]}\end{array}$ & $\log (\mathrm{t})$ & $\begin{array}{l}0 \\
*\end{array}$ & $\begin{array}{l}0 \\
*\end{array}$ & $\begin{array}{r}102337 \\
{[4.60]}\end{array}$ & 0.736 \\
\hline $\begin{array}{l}\log (\mathrm{CGRN})^{-} \\
1995 q 1-2002 q 2\end{array}$ & $\begin{array}{l}\text { Public } \\
\text { consumption }\end{array}$ & $\begin{array}{r}6.94 \\
{[215.9]}\end{array}$ & $\begin{array}{r}0.0019 \\
{[1.33]}\end{array}$ & $t$ & $\begin{array}{l}0.163 \\
{[4.88]}\end{array}$ & $\begin{array}{l}0.084 \\
{[2.44]}\end{array}$ & $\begin{array}{l}0.206 \\
{[5.91]}\end{array}$ & 0.790 \\
\hline $\begin{array}{l}\text { NT } \\
1995 q 1-2003 q 2\end{array}$ & $\begin{array}{l}\text { Current transfers } \\
\text { (bal. of payment) }\end{array}$ & $\begin{array}{l}80.27 \\
{[3.05]}\end{array}$ & $\begin{array}{l}46.53 \\
{[4.85]}\end{array}$ & $\log (t)$ & * & * & 0 & 0.424 \\
\hline $\begin{array}{l}\mathrm{FDI}^{+} \\
1995 q 1-2003 q 2\end{array}$ & $\begin{array}{l}\text { Foreign direct } \\
\text { investments }\end{array}$ & * & $\begin{array}{r}24.66 \\
{[11.49]}\end{array}$ & $\mathrm{t}$ & $\begin{array}{l}0 \\
*\end{array}$ & $\begin{array}{l}0 \\
*\end{array}$ & $\begin{array}{l}0 \\
*\end{array}$ & 0.740 \\
\hline $\begin{array}{l}\text { INBAL } \\
\text { 1995q1-2003q2 }\end{array}$ & $\begin{array}{l}\text { Income (bal. of } \\
\text { payment) }\end{array}$ & $\begin{array}{l}0 \\
*\end{array}$ & $\begin{array}{r}-89.05 \\
{[-11.45]}\end{array}$ & $\log (t)$ & $\begin{array}{l}0 \\
*\end{array}$ & $\begin{array}{l}85.63 \\
{[2.22]}\end{array}$ & $\begin{array}{r}96.172 \\
{[2.47]}\end{array}$ & 0.487 \\
\hline
\end{tabular}

Table 24 Exogenous Variables, Parameter Estimates (OLS method) 


\section{Figure 39 Exogenous Variables, Fits and Real Values (simple forecasts)}

Governmental Expenditure

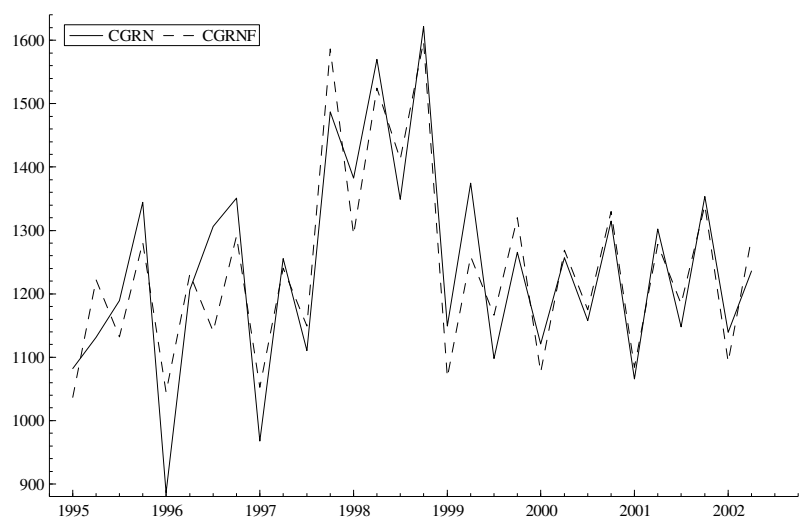

Foreign Direct Investments

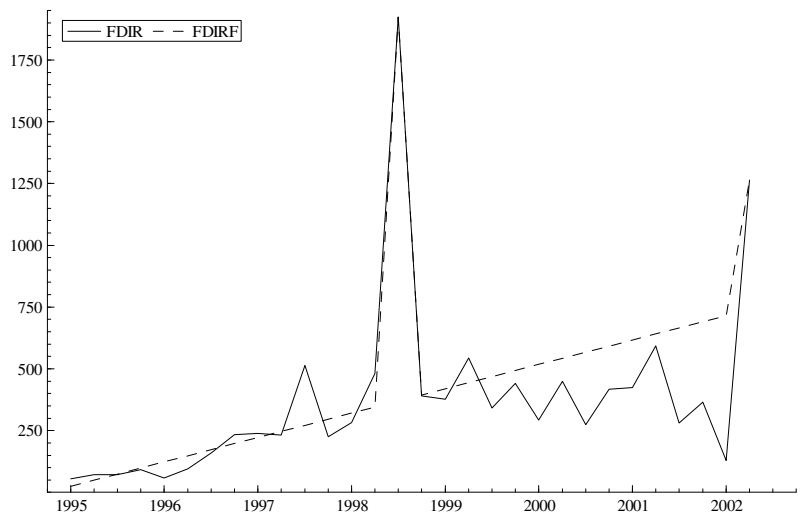

SSSF Expenditure ex. Pensions

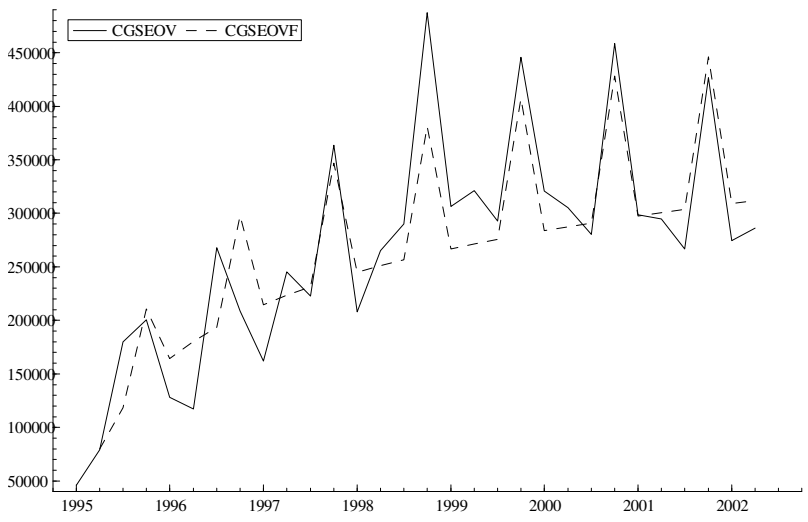

Net Transfers

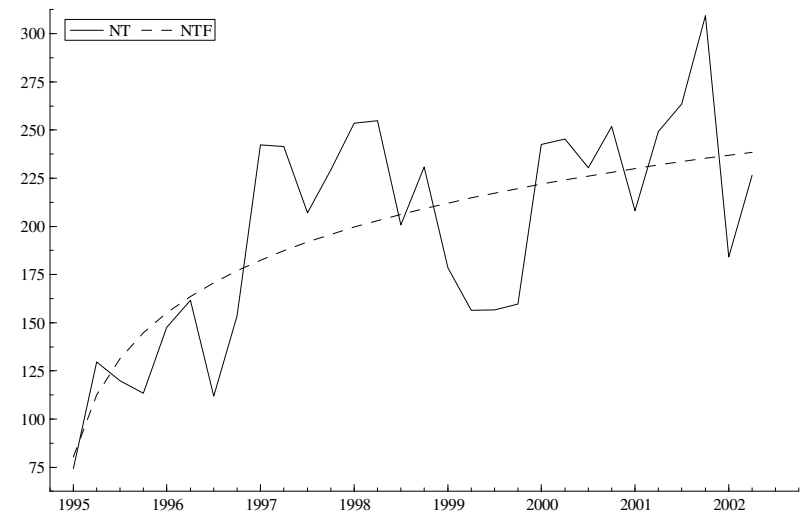

A quick analysis of Figure 39 reveals that, in most cases simple extrapolation catches the macroscopic component and seasonal changes reasonably well. However, in some cases (foreign direct investments $(F D I)$, net transfers $(N T)$ ), 'official' forecasts would be preferable. We should notice, for instance, that changes in the stock of foreign direct investments are very sensitive to privatisation of huge publically owned companies such as "Lietuvos telekomas", "Mazeikiu nafta". But we assume that fluctuations in these time series would stabilise after the Government completes the privatisation process of publically owned enterprises.

Concerning the governmental consumption, (CGRN) and SSSF's expenditure (CGSEOV), we use the seasonal components from the estimations in Table 24 and assume approximately the same growth rate as GDP within the baseline scenario (approximately $3 \%$ per year).

For the population $(P O P)$, we use the official forecast from Statistics Lithuania presented in Table 25 . We use a linear interpolation between the forecasted values.

With regard to the number of pensioners (PENSNR), the forecast in Table 25 of people over the age of 60 has almost the same growth rate as the simple forecast in Table 24. However, the number is not identical in the historical period, so we use the simple forecast in Table 24. 
Table 25 Forecasts of Population Number in 2005-2030

\begin{tabular}{|l|l|l|l|l|l|l|l|l|}
\hline \multirow{2}{*}{ Year } & \multicolumn{4}{|l|}{ Population Number, thous. } & \multicolumn{4}{l|}{ Percentage of Total } \\
\cline { 2 - 9 } & Total & $0-14$ & $15-59$ & $60+$ & Total & $0-14$ & $15-59$ & $60+$ \\
\hline 2005 & 3406.3 & 585.9 & 2127.6 & 692.8 & 100.0 & 17.2 & 62.5 & 20.3 \\
\hline 2010 & 3323.9 & 503.0 & 2119.8 & 701.1 & 100.0 & 15.1 & 63.8 & 21.1 \\
\hline 2020 & 3236.7 & 545.5 & 1932.6 & 758.6 & 100.0 & 16.9 & 59.7 & 23.4 \\
\hline 2030 & 3117.2 & 510.9 & 1755.2 & 851.1 & 100.0 & 16.4 & 56.3 & 27.3 \\
\hline
\end{tabular}

Changes in population $(P O P)$ and the number of pensioners $(P E N S N R)$ are illustrated in Figure 40 (right).

Figure 40 Yearly Growth Rates of Foreign CPI's, and $P_{M}$ (left) and the Number of Population and Pensioners (right)
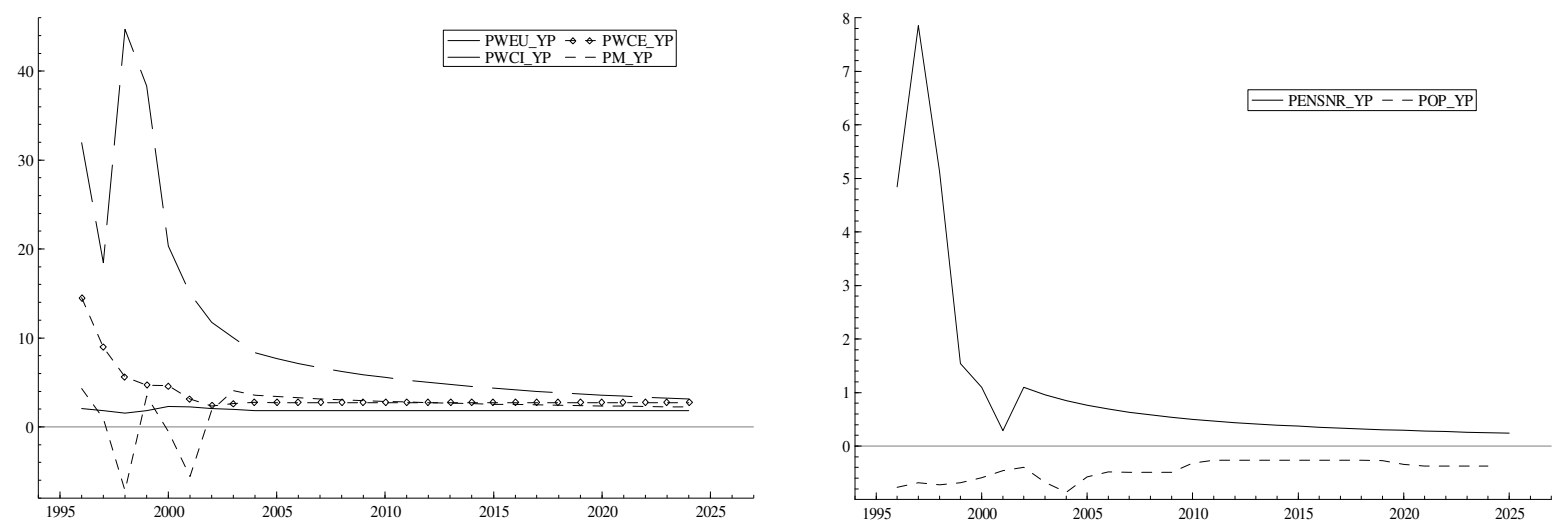

The data on foreign consumer price indices for the three groups of countries (EU, CIS, CE) and the aggregated GDP growth rate for Lithuania's export market is built on annual data. For long-term forecast, we assume that the series continue to grow at the same rate as they do in 2004 (the last year officially forecasted by IMF). However, in the case of consumer price index for CIS countries, we use a constant absolute growth rate rather than a yearly growth rate. It gives the convenient status that the annual growth rate of CPI in CIS countries decreases rather quickly from $8 \%$ annual growth to a reasonable value of $3 \%$ (see Figure 40, left). In the long-run, this ensures a moderate rate of inflation in CIS. The corresponding annual growth rates for Central Europe and EU countries are fixed at $2.7 \%$ and $1.8 \%$, respectively.

The import price index $(P M)$ is a very important determinant for most of the price indices in the model (see Section 10). It is assumed to be a weighted average of foreign CPI with the weights equal to the import shares relating to these groups in 2001.

$$
P_{M}=\left(P_{M}\right)_{-1} \cdot\left[0.64 \frac{P R_{E U}}{\left(P R_{E U}\right)_{-1}}+0.26 \frac{P R_{C I S}}{\left(P R_{C I S}\right)_{-1}}+0.10 \frac{P R_{C E}}{\left(P R_{C E}\right)_{-1}}\right]
$$

Where

$P_{M} \quad$ Import price

$P R_{j} \quad$ Real consumer price index in corresponding groups of countries (EU, CIS, CE) 
The remaining exogenous variables are assumed to follow naive no-change forecasts. The variables are: average working hours per week (workhour, equal to the mean over the estimated period 1995q1-2002q2), average annual interest rate on loans ( $R A$, the historical rapidly moving towards the zero level seemed to be unreasonable), real effective exchange rates (REEREU, REERCE, REERCI - following the EU entrance, we assume fixed exchange rates of the CIS and Central European currencies to the Euro), depreciation rate (delta, 2.5\%). In addition, a number of policy variables were fixed during the simulation of the baseline scenario: Different tax rates (on personal $(T L)$ and corporate $(T C)$ income, VAT, social security contribution rate $(s s c)$, other government receipts $(T P)$ ), and the non-taxable minimum wage (ntmin).

We included in the estimations a time trend in several equations. In the forecasting period we maintain the estimated trend in the labour demand equations only.

In conclusion, we would like to stress that a simple extrapolation may give unreasonable forecasts. Future structural changes need to be taken into account and somehow included into the model in the form of rational expectations or other alternative estimations described earlier in this section. In the case of Lithuania, a very illustrative example could be the effect of the EU entrance on Lithuanian economy in 2004, an analysis of which could be found in [EU, Vilnius 2003]. In the long-run rational expectations give crucial information about the performance of Lithuanian economy, and could considerably improve forecasting with the existing LITMOD. For instance, the effect of the EU entrance could be included through exogenous factors, e.g., influencing the balance of payment. But the analysis of this is beyond the scope of the present paper.

\subsubsection{Baseline Scenario}

This section shows a baseline scenario using the forecast of exogenous variables described in the last section. Alternative simulations used for sensitivity analysis are examined in the next section.

Three main periods of time are chosen for the examination of growth rates: The historical period (1996-2002), the short-term forecast period (2003-2005), and the long-term forecast period (2006-2020). We examine the following main LITMOD variables:

- Components of GDP calculated by expenditure approach (real private consumption $(C R N)$, total capital investments $(I R T)$, real export $(X R N)$, and import $(M R N))$ and total gross value added $(G D P T)$;

- $\quad$ Price indices (consumer price $(P C)$, aggregated producer price $(P Q)$, price on investments $(P I)$, and export price $(P X))$;

- $\quad$ Labour market's components (total labour demand (LNT) and labour supply $(L S)$ ).

In some cases, it is informative to compare the simulated growth rates with appropriate exogenous variables, e.g., GDP for the Lithuanian foreign trade market $\left(G D P_{W R}\right)$, import price index $(P M)$, and the population $(P O P)$.

The model produces quarterly forecast. However, in this section, we focus on annual growth rates in percentage. However, in Figure 43 (right) we show the simulated quarterly forecasts 
for the different price indices and we see that there is a clear seasonal pattern in the forecast as well as in the historical period. Although we find such pictures interesting, they are less informative than plots drawing the annual growth rates of the variables.

\section{Figure 41 Annual Growth Rates of GDP Components (Expenditure Approach)}
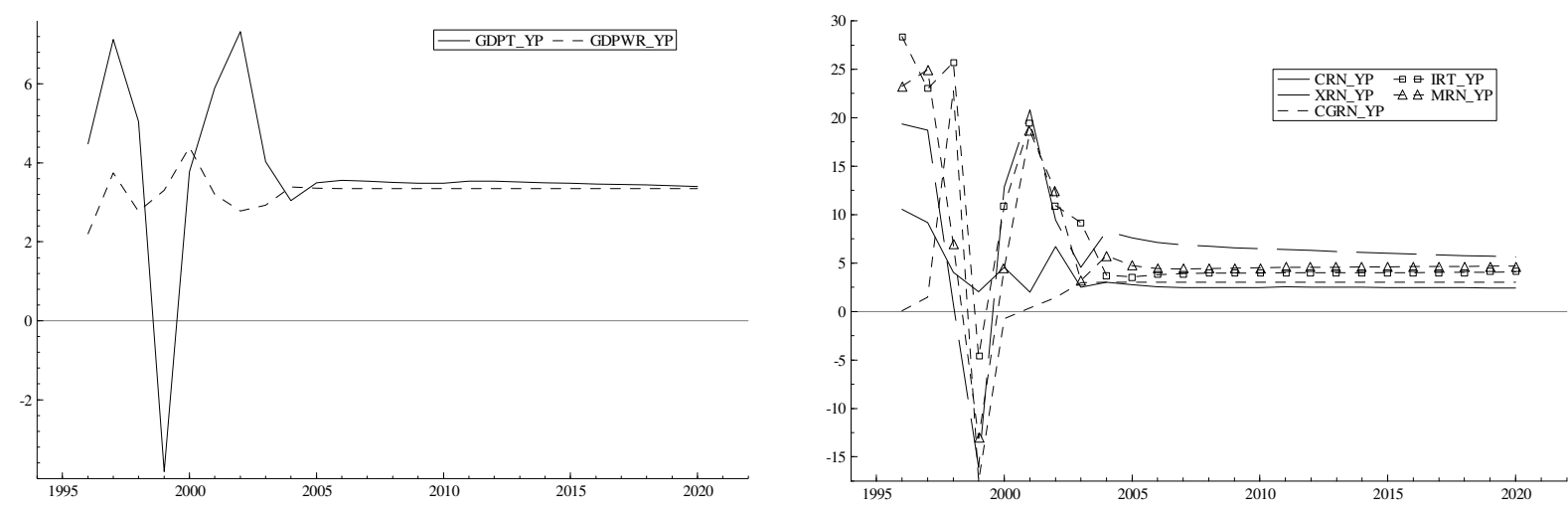

Figure 41 (left) illustrates that the GDP growth in most of the European countries (GDPWR) was not so greatly affected by the Russian crisis, as the GDP in Lithuania (GDPT) was. The right-hand side of the figure reveals that the Russian crisis had a significant lagged effect on almost all GDP components except private consumption ( $C R N$, solid line).

In the historical period, there were large and fluctuating growth rates in GDP and components of GDP, e.g., $28.4 \%$ in capital investments (IRT) and 20.8\% in export (XRN). The baseline scenario shows a much more stable economy with lower growth rates. The main reason for the stability is that we cannot predict if and when there will be major outside shocks to the economy such as the Russian crisis.

The forecasted annual GDP growth rate in Lithuania is a bit above the GDP growth rates in the Lithuanian foreign trade market (in average $3.49 \%$ and $3.35 \%$, respectively). In the longterm forecast, private consumption $(C R N)$ has the lowest annual growth rate of $2.48 \%$ of the GDP components, and export $(X R N)$ has the largest annual growth rate of $6.25 \%$.

Table 26 Annual Growth Rates of GDP Components (by Expenditure Approach) in Three Periods (all in \%)

\begin{tabular}{|c|c|c|c|c|c|c|c|c|}
\hline & & CRN & GDPT & IRT & $\mathrm{XRN}$ & MRN & CGRN & GDPWR \\
\hline & & $\begin{array}{r}\text { Private } \\
\text { consump. }\end{array}$ & GVA & $\begin{array}{l}\text { Invest- } \\
\text { ments }\end{array}$ & Export & Import & $\begin{array}{r}\text { Public } \\
\text { consump. }\end{array}$ & $\begin{array}{r}\begin{array}{r}\text { Foreign } \\
\text { GDP }\end{array} \\
\end{array}$ \\
\hline \multirow{4}{*}{$\begin{array}{l}1996- \\
2002\end{array}$} & mean & 5.58 & 4.26 & 16.25 & 9.39 & 11.07 & 1.14 & 3.20 \\
\hline & st. dev. & 3.35 & 3.80 & 11.44 & 13.25 & 13.19 & 11.72 & 0.72 \\
\hline & $\min$ & 1.20 & -3.82 & -4.63 & -16.11 & -13.08 & -17.48 & 2.20 \\
\hline & $\max$ & 10.55 & 7.33 & 28.37 & 20.81 & 24.96 & 22.86 & 4.40 \\
\hline \multirow{4}{*}{$\begin{array}{l}2002- \\
2005\end{array}$} & mean & 2.77 & 3.52 & 5.50 & 6.83 & 4.57 & 2.99 & 3.22 \\
\hline & st. dev. & 0.26 & 0.49 & 3.19 & 1.98 & 1.30 & 0.01 & 0.26 \\
\hline & $\min$ & 2.50 & 3.05 & 3.58 & 4.57 & 3.19 & 2.98 & 2.93 \\
\hline & $\max$ & 3.02 & 4.03 & 9.19 & 8.30 & 5.78 & 3.00 & 3.39 \\
\hline \multirow{4}{*}{$\begin{array}{l}2006- \\
2020\end{array}$} & mean & 2.48 & 3.49 & 3.99 & 6.25 & 4.57 & 3.00 & 3.35 \\
\hline & st. dev. & 0.04 & 0.04 & 0.07 & 0.45 & 0.10 & 0.00 & 0.00 \\
\hline & $\min$ & 2.40 & 3.41 & 3.81 & 5.64 & 4.39 & 3.00 & 3.35 \\
\hline & $\max$ & 2.55 & 3.56 & 4.09 & 7.14 & 4.68 & 3.00 & 3.35 \\
\hline
\end{tabular}


As seen in the model section, simulated labour supply $(L S)$ fluctuates like the population (the same form of path). In the forecast, the population $(P O P)$ is decreased by approximately $0.5 \%$ each year. However, the labour supply is only decreased by approximately $0.2 \%$ each year (see Figure 42, left) due to an increase in the real wage in the forecast. Total labour demand $(L N)$ (the main production factor) decreases in the short to medium-term and increases in the long-term up to $0.5 \%$ each year (but is only $0.04 \%$ per year in average). These forecasts of the labour supply and demand cause the unemployment rate to go below $9 \%$ in the long-term forecast. $^{34}$

Figure 42 Annual Growth Rates of Labour Market Components (left); Unemployment Rate (right)
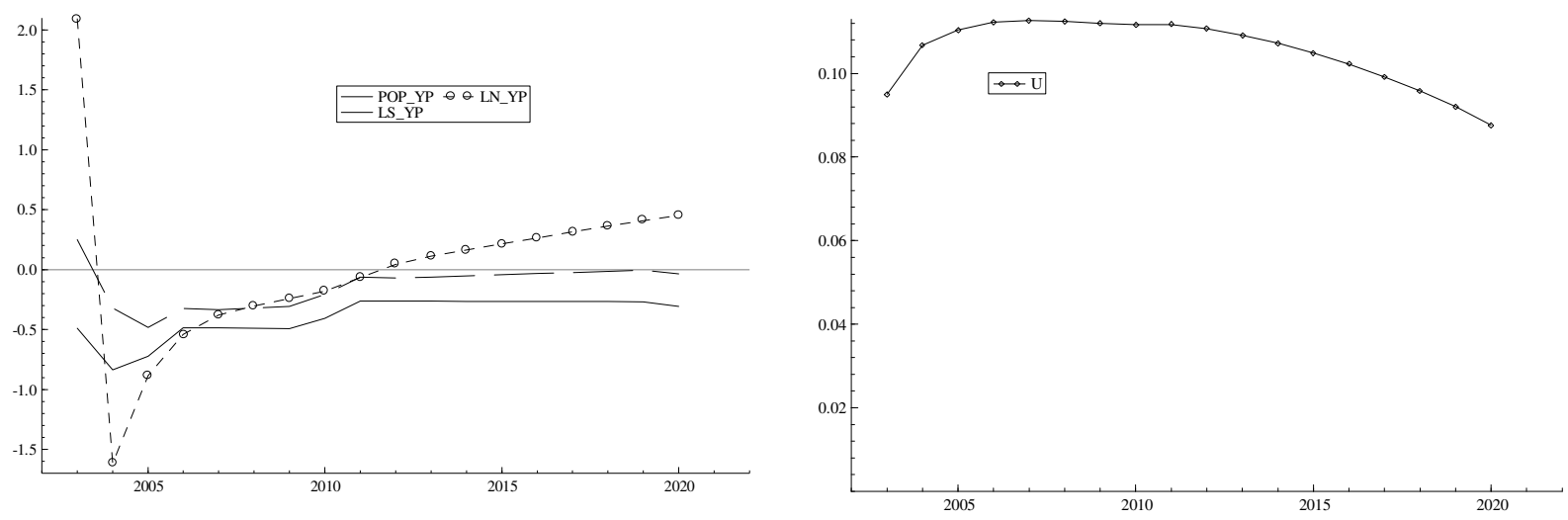

Being tightly related, all prices have the same long-term dynamics. Annual growth rates decline rather quickly and stabilise at around 3\% growth per year, except the price index on investment $(P I)$, which declines beyond this level, closely following the growth rate of the import price $(P M)$. Figure 43 (right) illustrates the quarterly development of the price indices, and Figure 43 (left) shows the more illustrative annual growth rates.

Figure 43 Annual Growth Rates of Price Indices (left); and their Quarterly Forecasts (right)
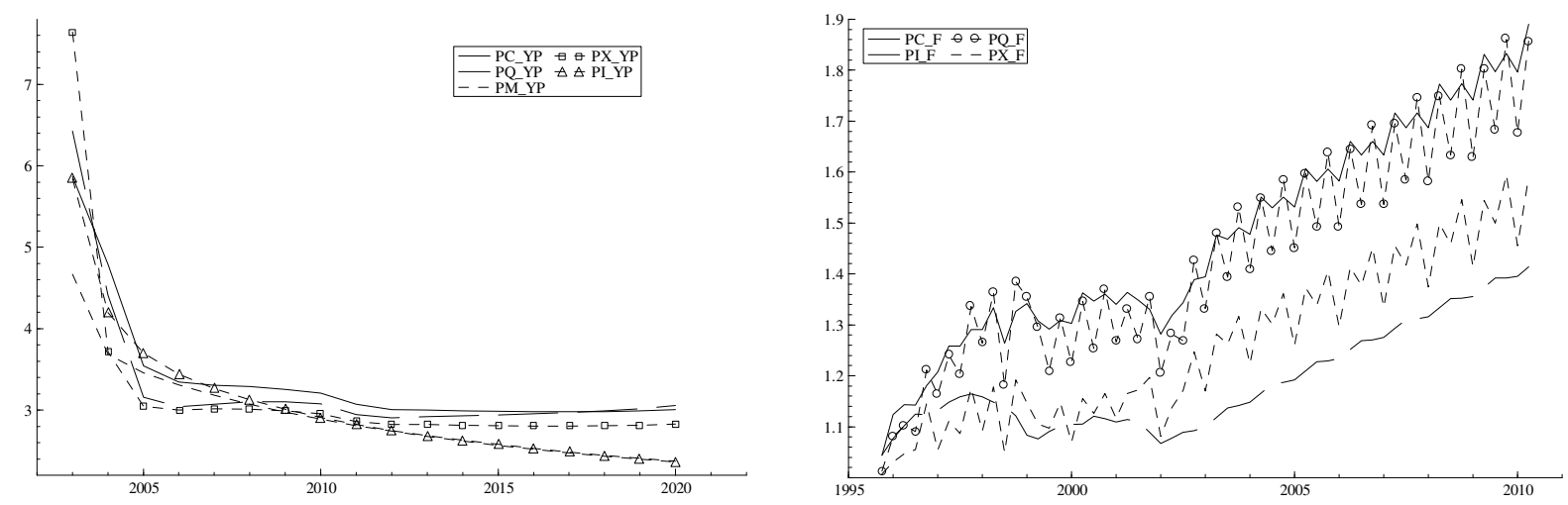

\footnotetext{
${ }^{34}$ However, it is still above the $6 \%$ of natural unemployment rate assumed in most of the developed countries.
} 
Table 27 Annual Growth Rates, Labour Market Components and Price Indices in Three Periods (all in \%)

\begin{tabular}{llrrrrrrrr}
\hline & & POP & LN & LS & PC & PX & PQ & PI & PM \\
\hline & $\begin{aligned} \text { Popula- } \\
\text { tion }\end{aligned}$ & $\begin{array}{r}\text { Labour } \\
\text { demand }\end{array}$ & $\begin{array}{r}\text { Labour } \\
\text { supply }\end{array}$ & $\begin{array}{r}\text { Price on } \\
\text { consum. }\end{array}$ & $\begin{array}{r}\text { Price on } \\
\text { export }\end{array}$ & $\begin{array}{r}\text { Producer } \\
\text { price }\end{array}$ & $\begin{array}{r}\text { Price on } \\
\text { investm. }\end{array}$ & $\begin{array}{r}\text { Price on } \\
\text { import }\end{array}$ \\
\hline $1996-$ & mean & -0.64 & -1.91 & -1.14 & 4.89 & 2.38 & 4.65 & 1.09 & -0.82 \\
\cline { 2 - 10 } 2002 & st. dev. & 0.14 & 2.62 & 3.20 & 6.24 & 5.05 & 6.81 & 6.14 & 3.69 \\
\cline { 2 - 10 } & min & -0.78 & -5.86 & -7.64 & -0.53 & -3.75 & -1.77 & -7.36 & -4.69 \\
\cline { 2 - 10 } & max & -0.37 & 0.94 & 1.76 & 17.03 & 10.68 & 19.34 & 11.40 & 4.72 \\
\hline \multirow{2}{*}{$2002-$} & mean & -0.68 & -0.14 & -0.19 & 4.73 & 4.80 & 4.66 & 4.58 & 3.94 \\
\cline { 2 - 10 } 2005 & st. dev. & 0.18 & 1.96 & 0.39 & 1.17 & 2.48 & 1.65 & 1.12 & 0.64 \\
\cline { 2 - 10 } & min & -0.84 & -1.62 & -0.48 & 3.54 & 3.05 & 3.16 & 3.70 & 3.46 \\
\cline { 2 - 10 } & max & -0.49 & 2.09 & 0.25 & 5.87 & 7.64 & 6.43 & 5.85 & 4.67 \\
\hline $2006-$ & mean & -0.34 & 0.04 & -0.13 & 3.09 & 2.88 & 3.00 & 2.76 & 2.74 \\
\cline { 2 - 9 } 2020 & st. dev. & 0.10 & 0.31 & 0.13 & 0.14 & 0.09 & 0.07 & 0.33 & 0.20 \\
\cline { 2 - 9 } & min & -0.49 & -0.54 & -0.34 & 2.98 & 2.81 & 2.90 & 2.37 & 2.36 \\
\cline { 2 - 9 } & max & -0.26 & 0.45 & -0.01 & 3.35 & 3.02 & 3.10 & 3.44 & 3.31 \\
\hline
\end{tabular}

This baseline scenario depicts a rather agreeable long-term performance of LITMOD assuming the most probable development of exogenous factors. In the long run, it shows an almost 3.5\% growth of the total gross value added (GDPT) and a higher rate of annual growth for export $(X R N, 6.2 \%)$ than import $(M R N, 4.6 \%)$. Price growth is approximately at half the rate of average wage in the private sector (WPRI, $6.6 \%$ per year). The labour market is closely related to the dynamics of the population $(P O P)$ and the gross domestic production $(Q R T)$.

\subsection{Simulations}

In this section, we change some of the exogenous variables - one at the time - simulate the model, and look at the percentage change in the endogenous variables. The simulations are based on the presented baseline scenario and are carried out in 2002q3-2008q4. In general, the model reached a new equilibrium rather quickly. We mainly focus in this section on the longterm effects.

These simulations will provide a better understanding on how the model is working and the important linkages between the variables in the model.

\subsubsection{Price on Import Increased by $1 \%$}

In the first simulation, we increase the price on import $\left(P_{M}\right)$ permanently by $1 \%$. Firstly, we look at the percentage change in the quantities and then at the prices. At the end, we simulate the whole model and discuss the overall effects of the increased price on import.

The direct effect on import is $-0.80 \%$ in the long-run and -1.35 in the first quarter (i.e., the estimated import price elasticities). Due to the large estimated error correction parameter in the import relation, the long-term adjustment is done in three quarters. This is illustrated in Figure 44 (left) showing the percentage change in import $(M R N)$.

With unchanged demand (keeping private consumption, public consumption, investments, and export fixed at the baseline level), the domestic production $(Q R T)$ is increased to fulfil the lack of decreased import as illustrated in Figure 44 (right). Intermediate (INRT) is increased slightly more than the increase in production, and hence the value added (GDPT) is increased 
less than domestic production. ${ }^{35}$ However, looking at the unexpected quarterly pattern of the changes in production, etc., in Figure 44 (right), there seems to be a minor problem with the seasonal adjustment in the simulations.

Figure 44 Direct Effect on Import (left) and Domestic Production (right)
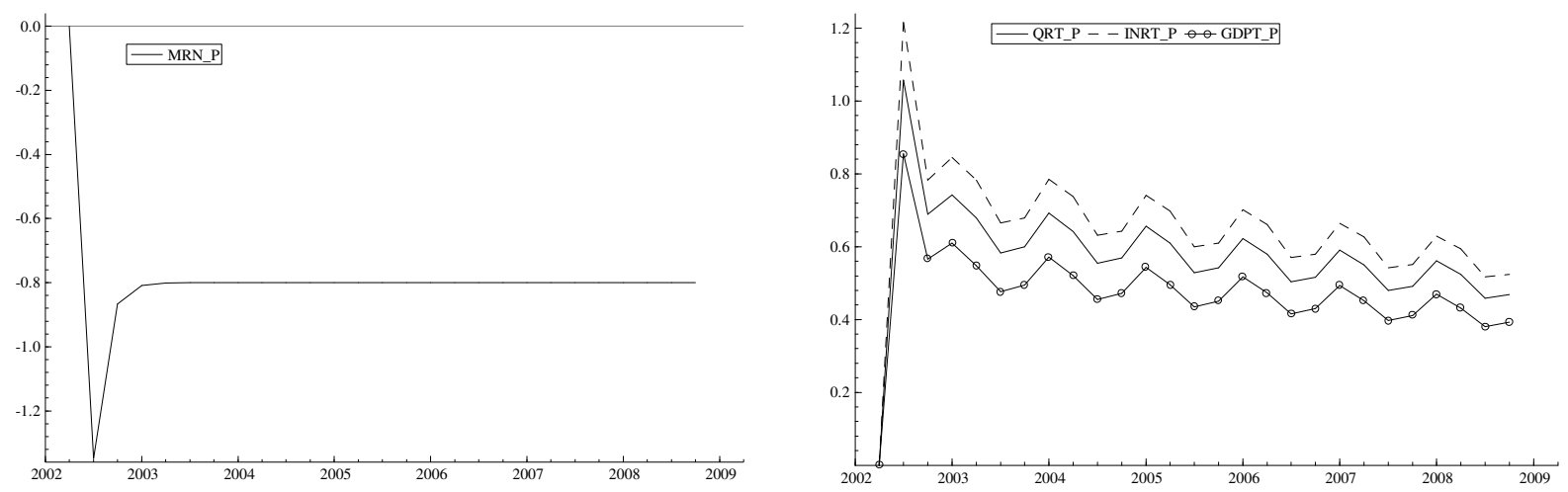

Increasing GVA increases the demand of labour and investments in sectors as illustrated in Figure 45 (left). The short-term effect is greater on investments than on labour demand due to the estimated short-term parameters. In the long-run, equilibrium labour and investments increase with approximately the same percentage as GDP (due to constant return to scale in the production). Again, the increased investments increase domestic production and investments within sectors. However, this simultaneous relationship between investments and domestic production has a limited effect.

Figure 45 Demand for Labour and Investments (left). Prices (right)
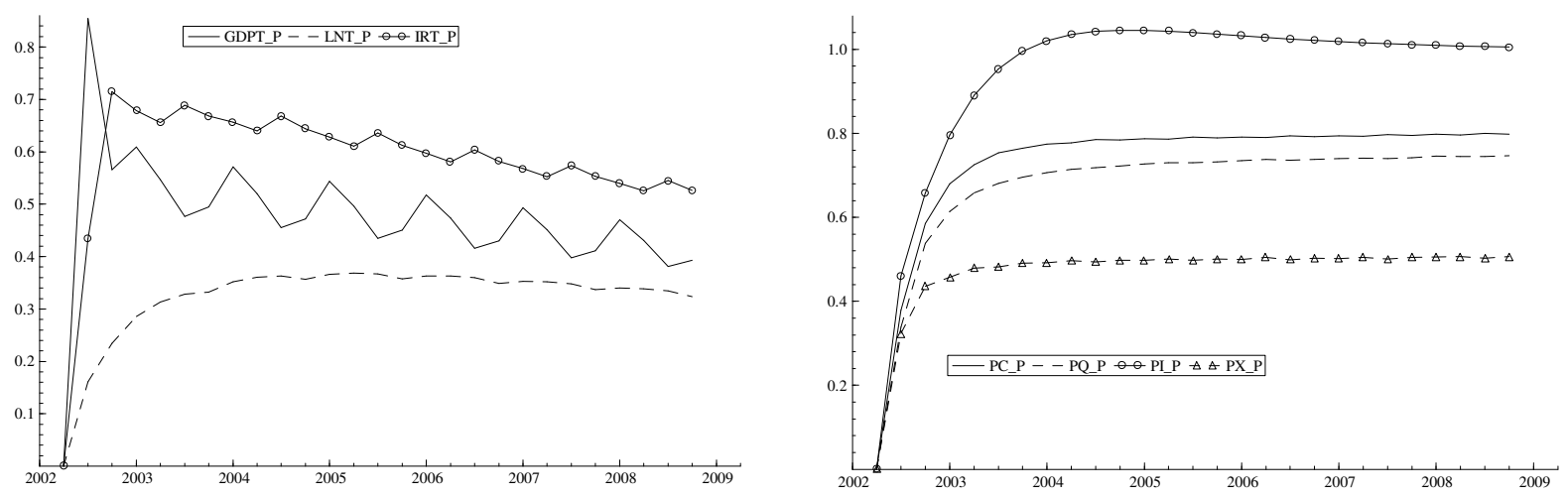

We have looked at changes in the real value variables (the quantities). We now turn to the domestic price determination due to the increased import price.

Domestic prices depend heavily on the import price as seen in Figure 45 (right). After a few quarters, when the import price has increased by $1 \%$, the price on domestic production $(P Q)$ is increased with $0.75 \%$. The average estimated weight to the import price is 0.3 , so the rest of the increase in the domestic producer price is due to increased price on investments. In the long-run, the price on investments $(P I)$ depends only on the import price and is hence increased by $1 \%$, and the price on investments is, in the medium-term, increased even more

\footnotetext{
${ }^{35}$ Aggregated intermediate is not increased with exactly the same rate as aggregated production due to structural changes between the sectors and different shares of import in the intermediate in sectors.
} 
than $1 \% .^{36}$ Increasing price on import and on domestic production increases the price on private consumption $(P C)$ by $0.8 \%$. Finally, due to the increase in the domestic producer price, the price on export $(P X)$ is increased by $0.5 \%$.

The increased price on private consumption $(P C)$ decreases the real disposable income and hence private consumption $(C R N)$ is decreased as seen in Figure 46. Due to the estimated long-run export price elasticity of -0.5 and -1.1 in the short-run, the increase in the export price of $0.5 \%$ decreases the export $(X R N)$ by $0.25 \%$ in the long-run and more in the short-run.

In the model, import $(M R N)$ depends on the private consumption and the relative import price $(P M / P C)$, and since private consumption is decreased by $0.6 \%$ and the relative import price is increased by $0.2 \%$ ( $P M$ increased by $1 \%$ and $P C$ increased by $0.8 \%$ ), the import $(M R N)$ is in the long-run decreased by $1.2 \%$ as seen in Figure 46 . This could be compared with the direct decrease of import by $0.8 \%$ in Figure 44 (left).

\section{Figure 46 Consumption, Export and Import}

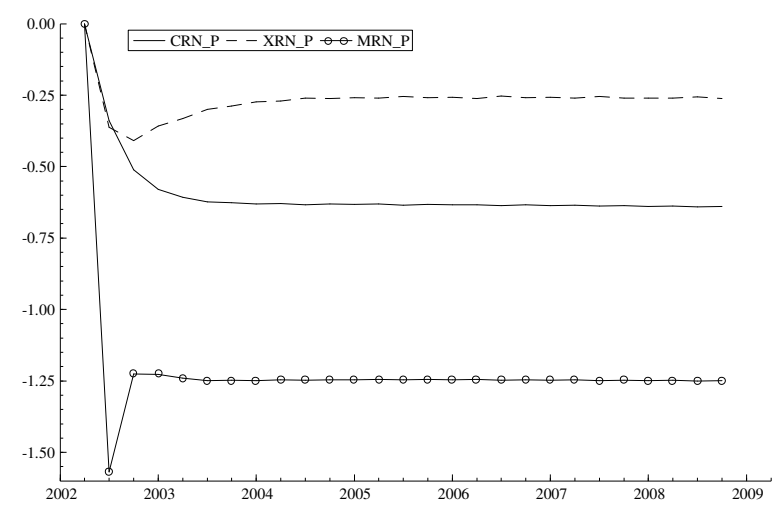

Finally, we simulate the whole model and hence look at the model interactions in terms of quantities and prices. It is not easy to explain all the effects in details, but the above comments to simulations of smaller parts of the model should give some insight on how the model works.

First of all, the domestic producer price $(P Q)$ is further increased in the simulation with the whole model since the nominal wage is in the long-run increased by $0.6 \%$, and hence the price on consumption $(P C)$ and on export $(P X)$ is increased more. The nominal wage is increased because the price on consumption is increased, but the increase in the wage is less than the increase in the consumer price due to a minor increase in the unemployment rate $(U)$ of $0.05 \%$-point - see Figure 47 (right).

\footnotetext{
${ }^{36}$ The effect on investment price $(P I)$ of a change in the import price $(P M)$ gives an unintended additional increase in the producer prices $(P Q)$. It should be considered either to let the price on investments be exogenous in the model or to fix the parameters in an estimation of the equation so the price on investments mainly depends on domestic producer prices.
} 


\section{Figure 47 Whole Model Simulated, Prices (left) and Labour Market (right)}
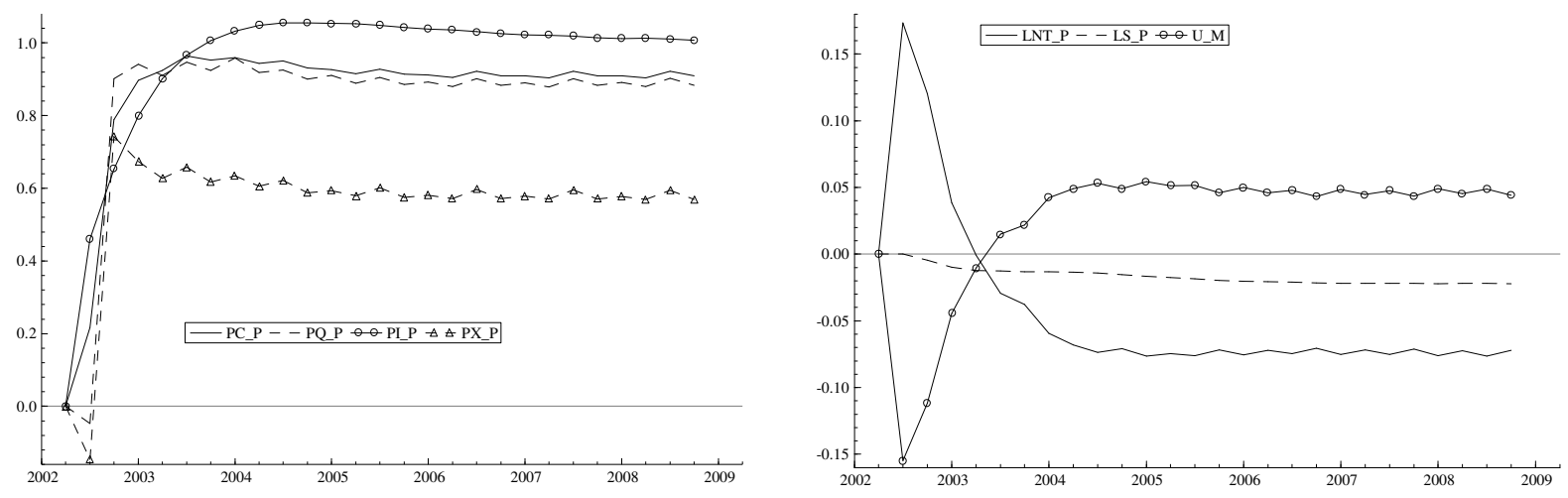

Looking at the percentage change in the quantities in Figure 48 (left), we see that the domestic production $(Q R T)$ is only increased in the first quarter due to the decrease in import. As explained above, private consumption $(C R N)$ and export $(X R N)$ is decreased due to increased prices, so total demand is decreased and hence domestic production is also decreased. In the long run, both import and export is decreased by $-0.3 \%$, and both domestic production and private consumption is decreased by $-0.1 \%$.

In Figure 47 (right), we see that the demand for labour in sectors (LNT) is increased in the first quarter and since decreased as the domestic production. There is a minor decrease in the labour supply $(L S)$ due to a decrease in the real wage (WPRI/PC).

Figure 48 Whole Model: Quantities (left) and Governmental Balance (right)
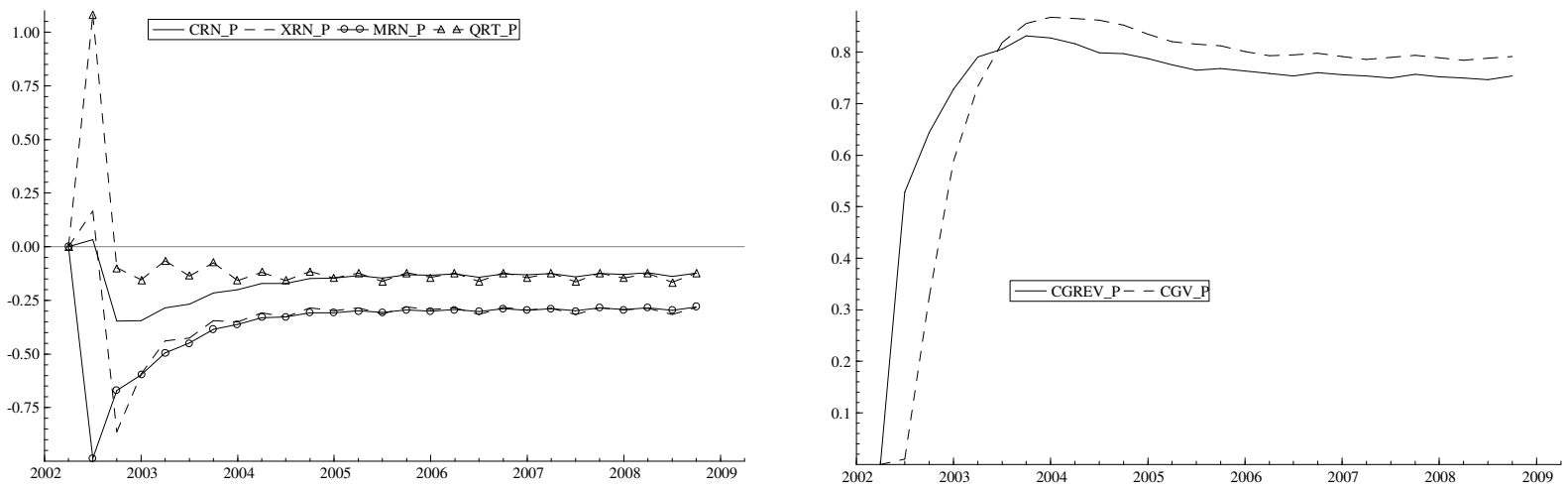

As seen in Figure 48 (right), the governmental balance has worsened (not much) since the expenditure to the public consumption $(C G V)^{37}$ has increased more than the governmental revenue $(C G R E V)$.

\subsubsection{Public Consumption Increased by $1 \%$}

We saw in the above experiment the effects of changing one of the exogenous prices. In this experiment, we change one exogenous demand component and explain the changes in the simulated endogenous variables.

\footnotetext{
37 The price on public consumption $(P C G)$ is increased due to the increase in the producer prices, and the quantity of public consumption $(C G R N)$ is exogenous.
} 
Public consumption in constant prices $(C G R N)$ is permanently increased by $1 \%$.

The direct effect is that production in the public sector (S4) is increased by $1 \%$, and the total production $(Q R T)$ is increased by $0.14 \%$. This increases the demand for labour and investments in sectors.

Keeping wages fixed at the baseline level, there are minor price changes as seen in Figure 49 (left). Therefore, the percentage change in the quantities presented in Figure 49 (right) is almost the same as with exogenous prices (except import which is very sensitive to an increase in the price on private consumption). As explained above, production and hence labour demand is increased. A higher rate of employment increases the disposable income, so private consumption is increased and thereby also import.

\section{Figure 49 Simulation with Wage Fixed, Prices (left) and Quantities (right)}
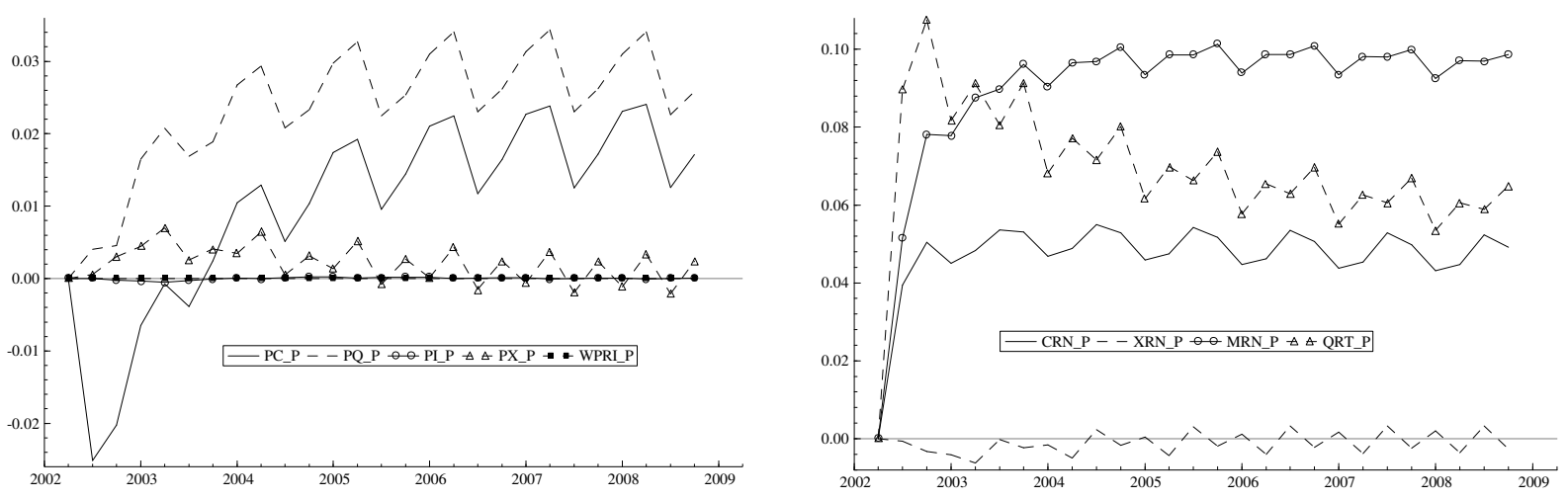

By simulating the model with wage rate endogenously, the percentage changes in prices and quantities are shown in Figure 50. Because of the decreasing unemployment rate, the nominal wage (WPRI) is increased, and the wage is very sensitive to changes in the unemployment rate. An increased wage increases production costs and hence the domestic producer price $(P Q)$ and other domestic prices $(P C$ and $P X)$. In the long-run, this results in an (almost) unchanged private consumption $(C R N)$, so an increase in the public consumption has a positive short-term effect only.

Figure 50 Percentage Change in Prices (left) and Quantities (right)
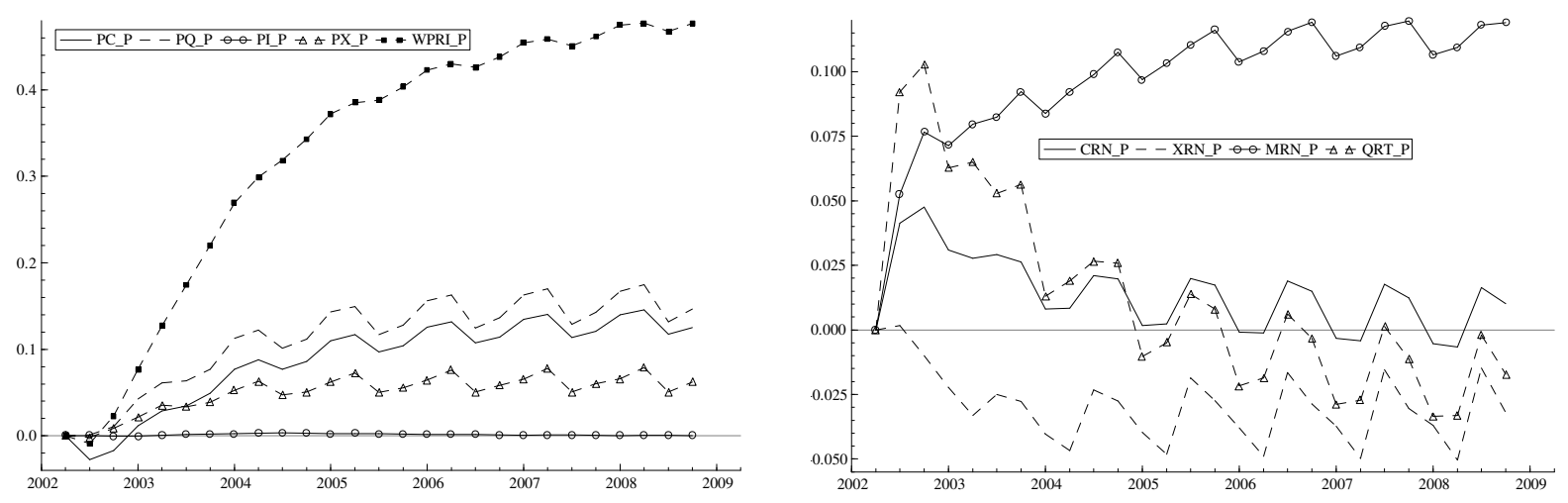

Since import increases and export decreases, the balance of the current account $(C A)$ is worsened by more than 5 mill. Litas each quarter as seen in Figure 51 (left). The 
governmental balance $(G D E F)$ is also worsened because the public consumption is increased without a similar increase in the governmental revenue.

\section{Figure 51 Balances (left) and Labour Market (right)}
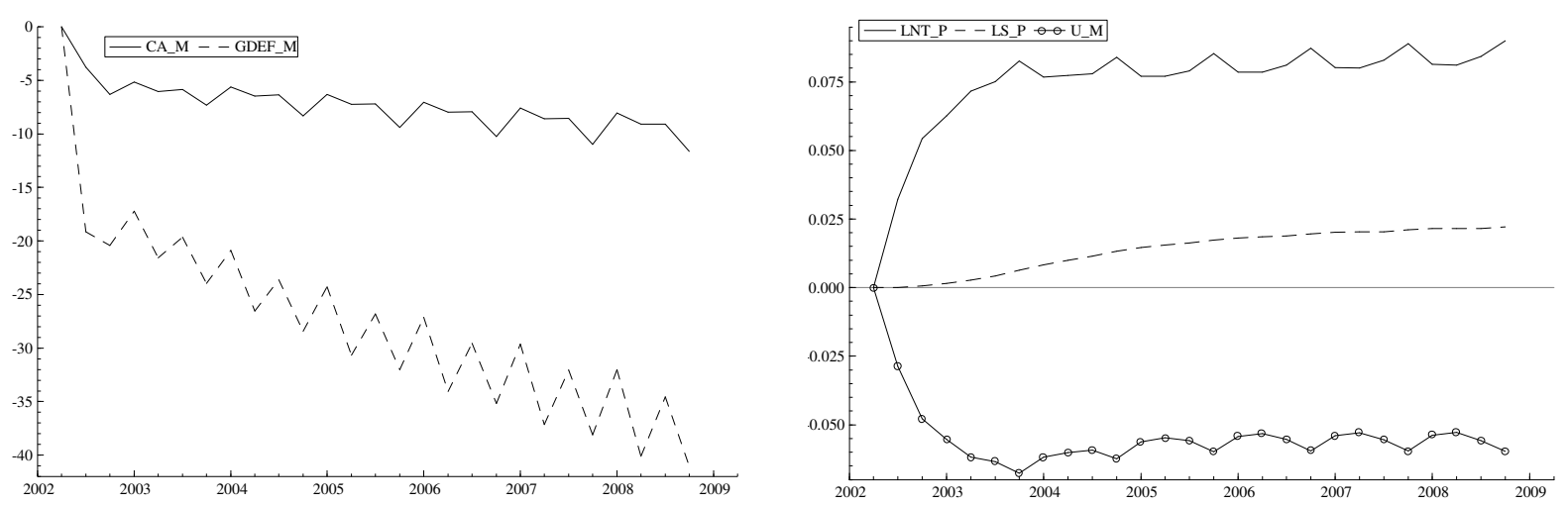

There is a minor long-term increase in the labour demand (LNT) of $0.075 \%$ as seen in Figure 51 (right). The labour supply $(L S)$ is increased due to an increase in the real wage (WPRI/PC).

\subsubsection{Export Market Increased by 1\%}

In this experiment, we examine the influence of a $1 \%$ increase in the export market, i.e. a $1 \%$ permanent increase in the GDP in the Lithuanian foreign trade market $\left(G D P_{W R}\right)$.

The foreign GDP growth $\left(G D P_{W R}\right)$ has a direct influence on the amount of export from Lithuania to the foreign countries. The direct effect is that real export $(X R N)$ is in the long-run increased by $1.6 \%$ (the estimated long-term parameter). In order to export more goods and services, the Lithuanian economy requires an increased domestic production $(Q R T)$. Consequently, this leads to increases in the demand of labour (LNT), and investments in sectors $(I R T)$.

Larger labour demand decreases the unemployment rate $(U)$, and hence increases wage (WPRI). By increasing household disposable income, and hence private consumption, $(C R N)$ is increased.

Increased wage increases production costs and, therefore, the producer price $(P Q)$ and hence the consumer price $(P C)$ and export price $(P X)$ increases. This gives a reverse effect on private consumption and export, so that the increases are lowered.

As seen in Figure 52 (right), import $(M R N)$ is increased in the long-run by approximately $1 \%$ due to the increase in private consumption and a decrease in the relative import price $(P M / P C)$. 
Figure 52 Percentage Change in Prices (left) and Quantities (right)
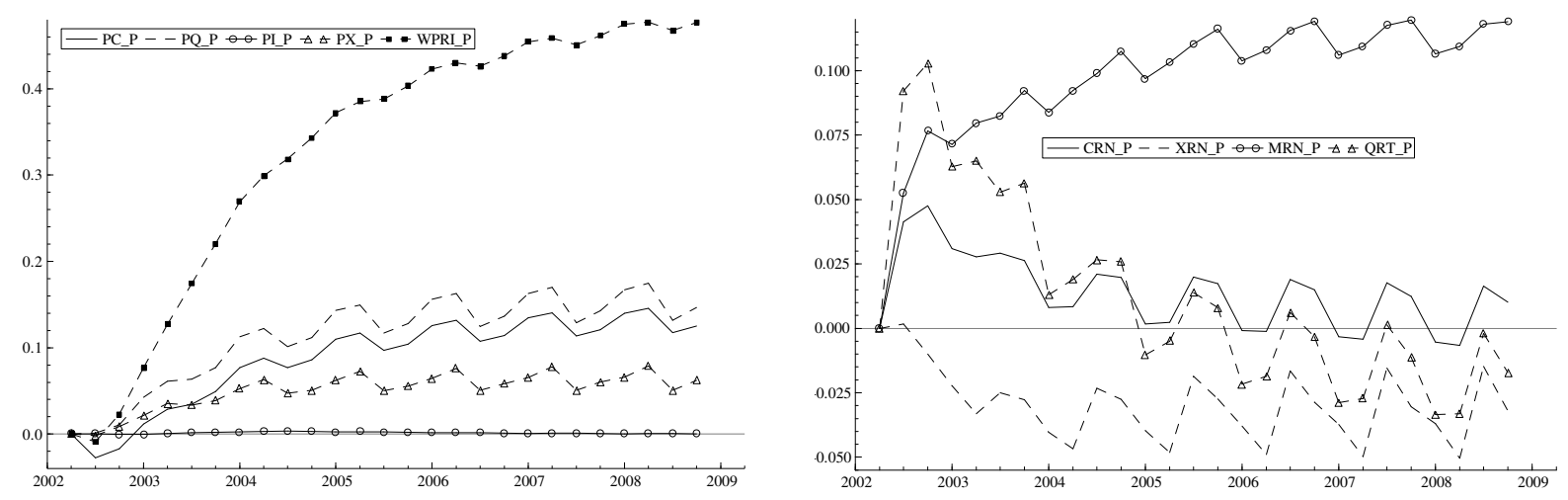

Since the increase in export is greater than the increase in import, the current account $(C A)$ is inproved in average as seen in Figure 53 (left) by 72 mill. Litas each quarter. Increased government revenue results in a 14 mill. Litas decrease in budgetary deficit each quarter.

\section{Figure 53 Balances (left) and Labour Market (right)}
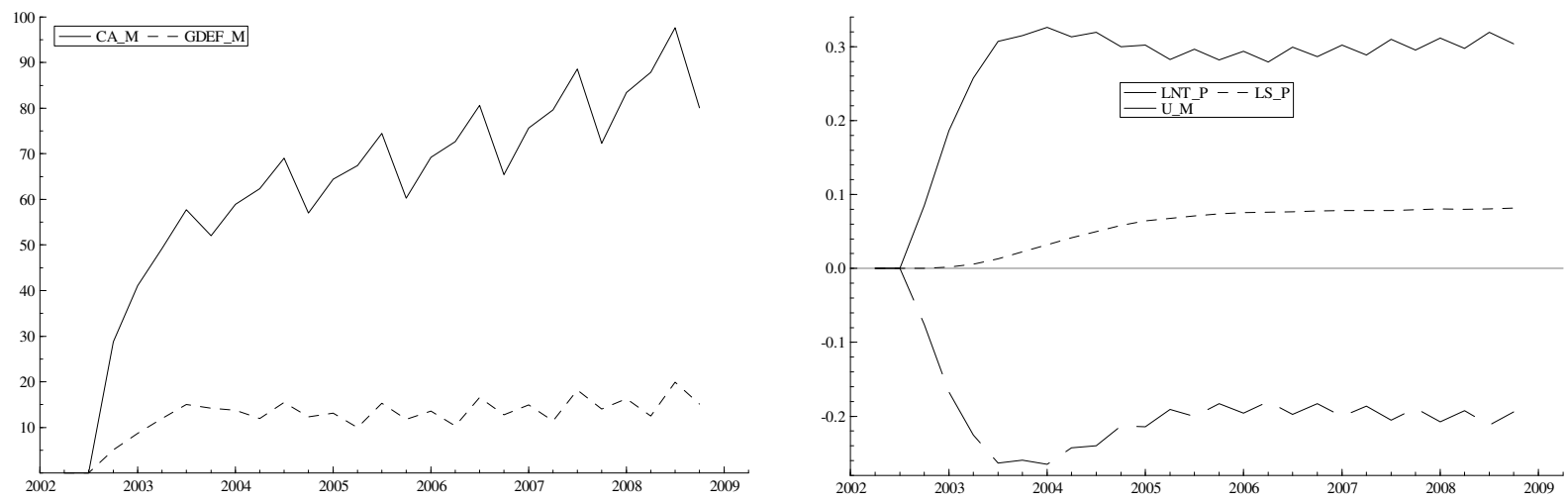

Finally, Figure 53 (right) shows the total effect on the labour market of an increase in the foreign GDP growth. Increased production requires more labour, and there is a $0.3 \%$ increase in the labour demand $(L N T)$. There is a slight increased labour supply $(L S)$ due to the increased real wage. This leads to a relatively small $0.2 \%$-point decrease in the unemployment rate $(U)$.

\subsubsection{Interest Rate Decreased by 1\%-point}

One of the most important exogenous variables in simulation experiments regarding monetary policy is the annual interest rate $(R A)$. In this experiment, we permanently decrease the interest rate by 1 percentage point.

The interest rate directly influences the price on investments $(P I)$ and the demand for investments $(I R T){ }^{38}$ The increase in the domestic investments increases the domestic production $(Q R T)$ and hence GDP and the labour demand $(L N T)$ as shown in Figure 54 (left).

\footnotetext{
${ }^{38}$ A decrease in the interest rate increases the demand for investments, but on the other hand, a lower interest rate increases the price on investments (see Section 10.6), and hence the demand for investments is decreased. The overall effect is an increase in the investments as expected. Once again, we should mention that the current equation for the price on investments should be reconsidered.
} 


\section{Figure 54 Percentage Change in Quantities (left) and Government Finance (right)}
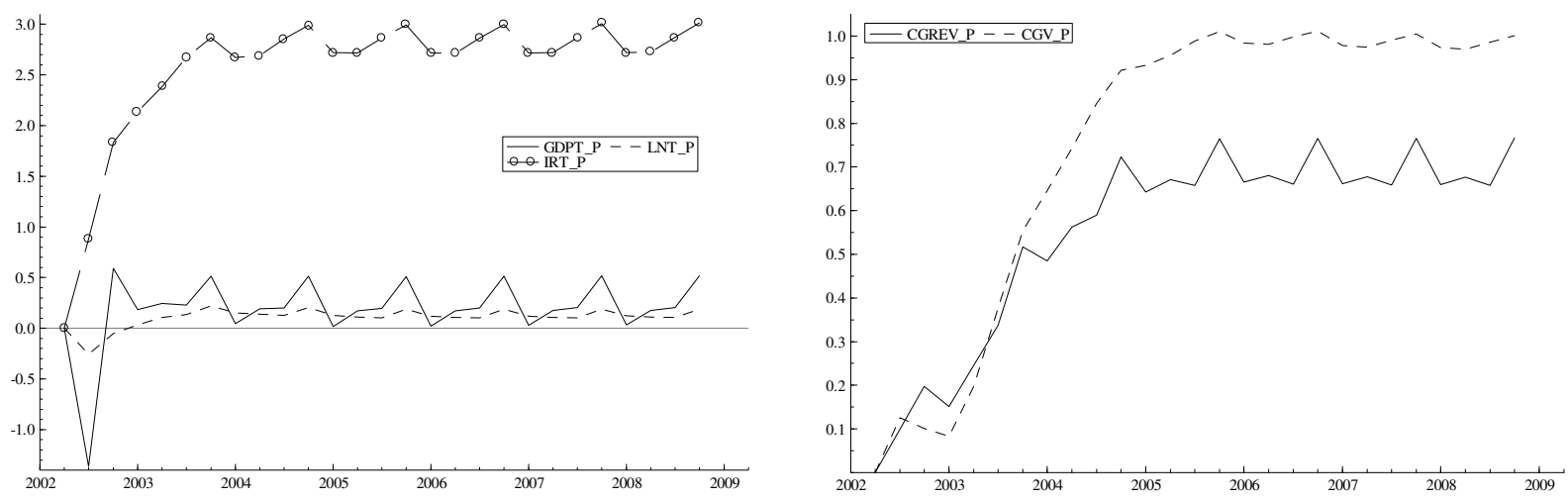

The production costs are increased due to a higher price on investments and primarily due to a higher wage (the wage is increased because of increased labour demand). So, the producer price $(P Q)$, and hence the consumer price $(P C)$ and export price $(P X)$ are increased in the long-run as seen in Figure 55 (left). Therefore, in Figure 55 (right), we see a long-run decrease in private consumption $(C R N)$ and export $(X R N)$. In the long-run, the import $(M R N)$ is almost unchanged (decreased due to the decrease in private consumption and increased due to a decrease in the relative import price, $P M / P C$ ).

Figure 55 Percentage Change in Prices (left) and Quantities (right)
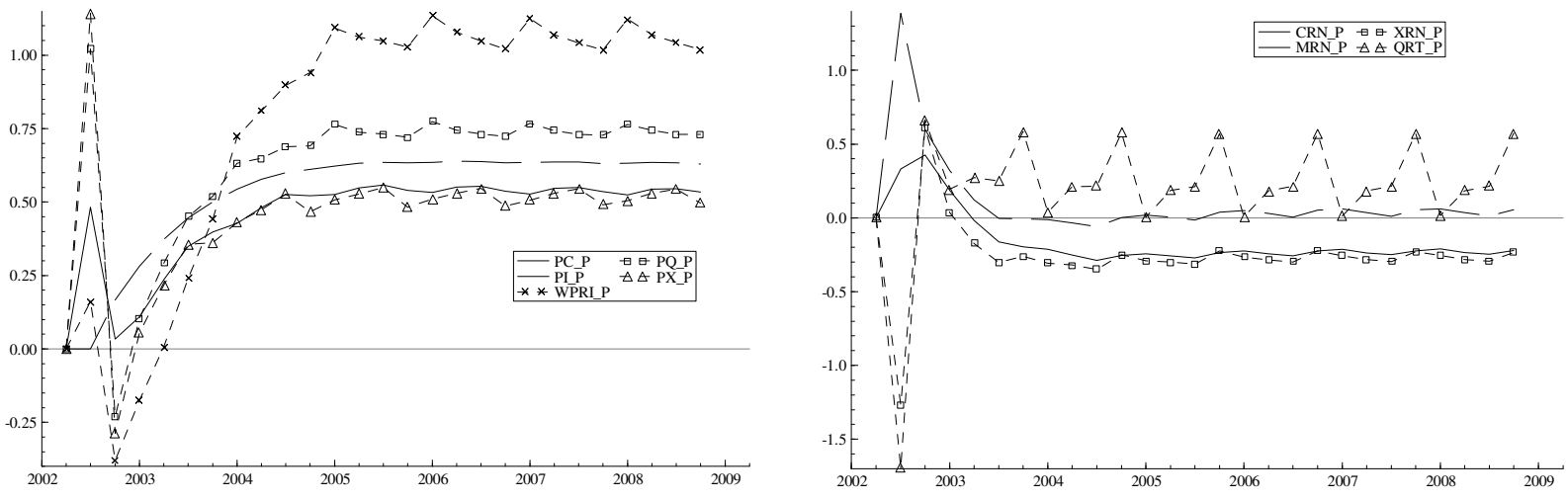

The overall long-term effect is an increase in total capital investments (IRT) by $2.82 \%$, and the price on investment $(P I)$ is increased by $0.5 \%$. There is a $0.24 \%$ decrease in private consumption $(C R N)$ and a $0.28 \%$ decrease in export $(X R N)$.

Governmental expenditure $(C G V)$ will in the long-run increase up to $1 \%$ (due to a $1 \%$ increase in the price on public consumption, $P C G$ ), which exceeds the corresponding growth of governmental revenue (CGREV) as seen in Figure 54 (right). It follows that there will be an increase of 8.3 mill. Litas in the budgetary deficit (GDEF) as shown in Figure 56 (left).

There is after one year a positive change each quarter in the current account balance $(C A)$ of 21 mill. Litas. Import is almost unchanged, and the value of export is increased because the price on export is increased more than the export is decreased. 


\section{Figure 56 Balances (left) and Labour Market (right)}
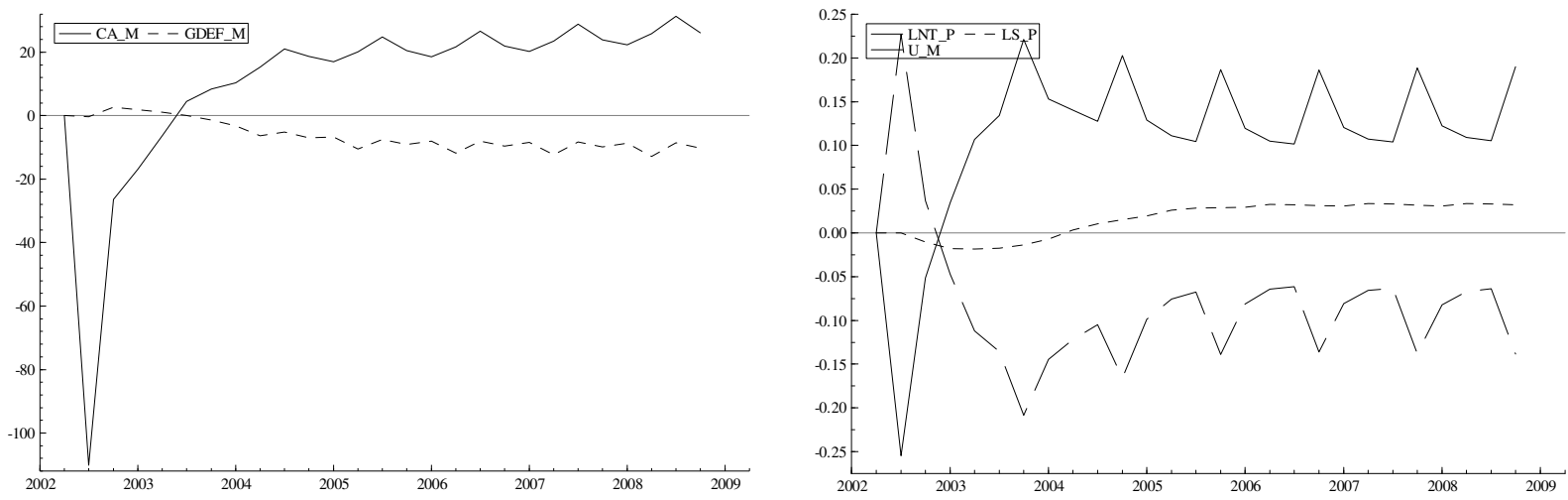

Increased average wage in the private sector (WPRI) increases labour supply. Moreover, significant capital investments lead to the creation of new working places and hence an increase in the labour demand. Since labour demand increases more than the labour supply, the unemployment rate is decreased by $0.1 \%$-point as seen in Figure 56 (right).

\subsubsection{VAT Rate Decreased by 1\%-point}

There are a number of policy variables in the model that could be used for different simulation exercises concerning fiscal policy modelling, e.g., different tax rates. In this experiment, we examine the effect of the VAT rate being permanently decreased by $1 \%$ point. $^{39}$

The VAT decrease has two direct effects in the model. The governmental VAT revenue $(C G R E V)$ is decreased by $1 \%$, and there is a decrease in the consumer price $(P C)$ of $1 \%$.

When the consumer price is decreased by $1 \%$, the private consumption $(C R N)$ is in the longrun increased by $0.8 \%$ and by $0.9 \%$ in the first quarter meaning that the consumption expenditure $(P C \cdot C)$ is almost unchanged. Increasing private consumption increases import $(M R N)$. The direct effect from the private consumption is that import is increased by a factor 1.7 , but since the relative import price $(P M / P C)$ is increased, the import is increased less than the private consumption. ${ }^{40}$

There is full compensation in the wage equation for price changes, so the wage (WPRI) is decreased as much as the consumer price $(P C)$. However, due to a minor decrease in the unemployment rate $(U)$, the wage is not decreased as much as the consumer price (see Figure 57 (left)), so the real wage (WPRI/PC) is increased in the simulation. Lower wage decreases the production costs and the labour demand is increased.

Figure 57 (right) shows that domestic production $(Q R T)$ is only increased by $0.1 \%$ since the increased private consumption is mainly covered by an increasing import.

\footnotetext{
${ }^{39}$ We should notice that the VAT rate in the model is only paid of private consumption, whereas there is a 'net tax rate on products' $(t p)$. Therefore, this experiment does not thoroughly cover a VAT rate decrease.

${ }^{40}$ Looking at a VAT rate decrease in the model, we should maybe additionally decrease the import price.
} 
Figure 57 Percentage Change in Prices (left) and Quantities (right)
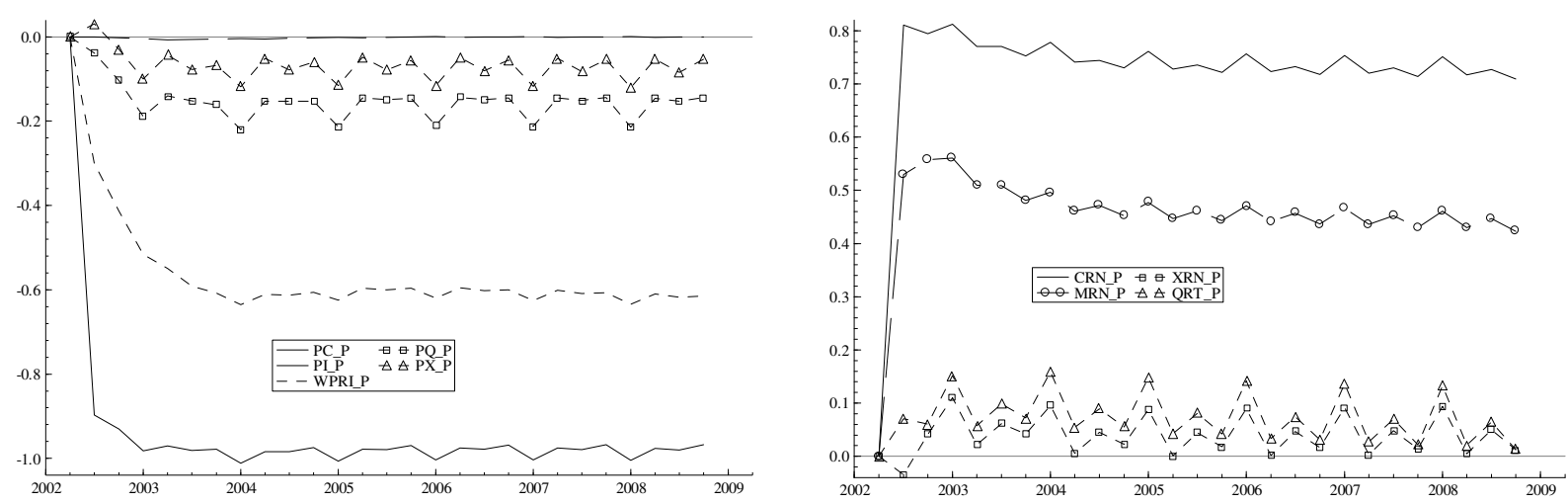

Export $(X R N)$ is almost unchanged, and import $(M R N)$ is largely increased by $0.45 \%$. Therefore, each quarter, we see in Figure 58 (left) a 49 mill. Litas decrease in the current account $(C A)$. Due to the lower VAT revenue, there is a 79 mill. Litas increase in the governmental deficit $(-G D E F)$.

There are only minor changes in the labour market as seen in Figure 58 (right). The labour supply is increased by $0.025 \%$ due to an increase in real wage (WPRI/PC), and labour demand is increased by $0.12 \%$, resulting in the unemployment rate being decreased by $0.08 \%$ point. This is a small effect of a $1 \%$ decrease in the VAT rate.

\section{Figure 58 Balances (left) and Labour Market (right)}
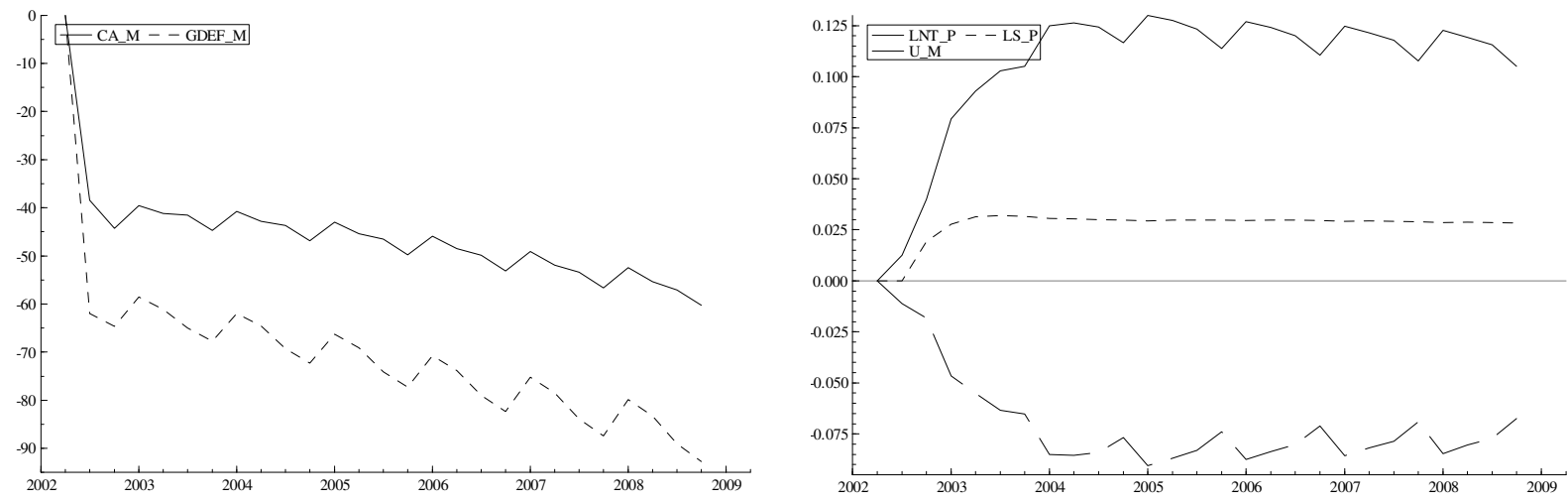

However, we should notice that the present model has only a simple block of equations representing governmental finance and hence is, in some cases able to provide approximate answers to questions of fiscal policy only.

\subsubsection{Population is Increased by $1 \%$}

We analyse in this last experiment the influence of a more optimistic point prediction of the number of population in Lithuania. This variable is crucial for the labour supply. The population $(P O P)$ is permanently increased by $1 \%$.

The direct effect is that labour supply $(L S)$ is increased by $1 \%$ both in the short and long-run. By keeping wages fixed at the baseline level, the $1 \%$ increase in labour supply is the only effect, and the unemployment rate $(U)$ is proportionally increased. 
With a fixed level of labour demand, the unemployment rate $(U)$ is proportionally increased. In the model, the wage is very sensitive to changes in the unemployment rate and the wage (WPRI) is, therefore, decreased by $2.6 \%$ as seen in Figure 59 (left). A decreasing real wage means less labour supply, and the overall effect on the labour supply is an increase by almost $1 \%$ in the short-run and by $0.87 \%$ in the long-run.

The decrease in the wage reduces production costs and there is hence a decrease in the producer price $(P Q)$. This decreases the consumer price $(P C)$ and export price $(P X)$, which leads to an increase in private consumption $(C R N)$ and export $(X R N)$. The import $(M R N)$ is decreased by $0.1 \%$ composed of an increase due to the increase in the private consumption and a decrease due to the increase in the relative import price $(P M / P C)$. This is shown in Figure 59.

\section{Figure 59 Percentage Change in Prices (left) and Quantities (right)}
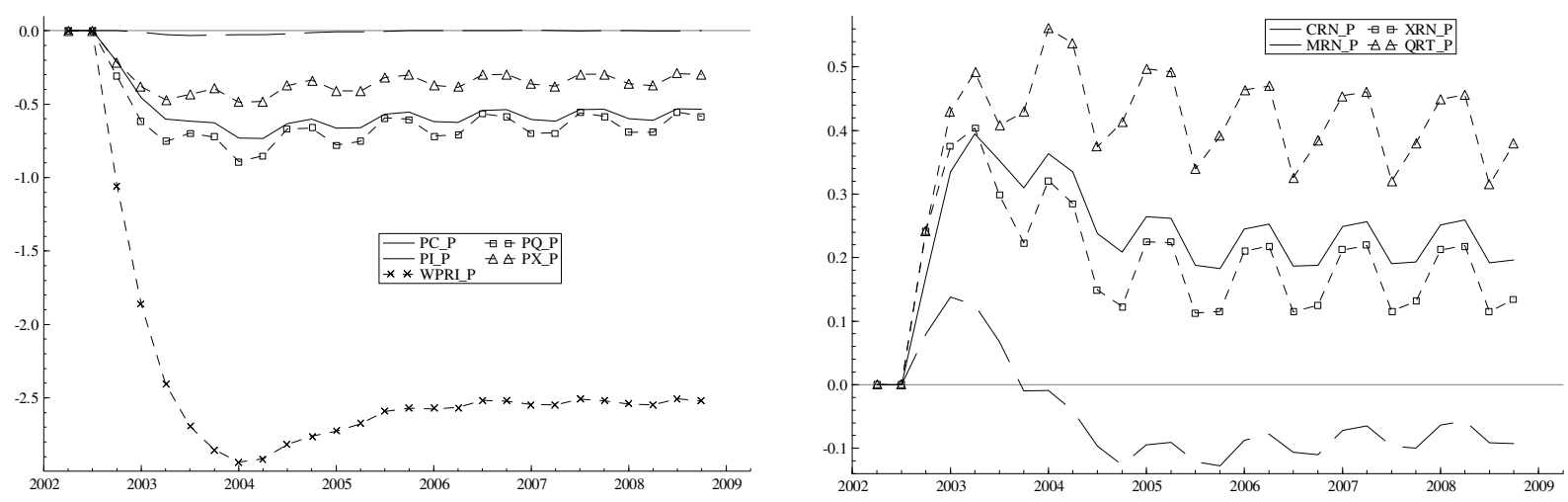

The increased demand increases the domestic production $(Q R T)$ and hence the demand for labour $(L N T)$ as well as investments. The labour demand is somewhat increased more than the domestic production due to the decreased wage. Figure 60 (right) shows that, a $1 \%$ increase in the population will, in the long-run, increase the unemployment rate $(U)$ by $0.3 \%$-point, so the main part of the additional population is transferred to employment.

\section{Figure 60 Balances (left) and Labour Market (right)}
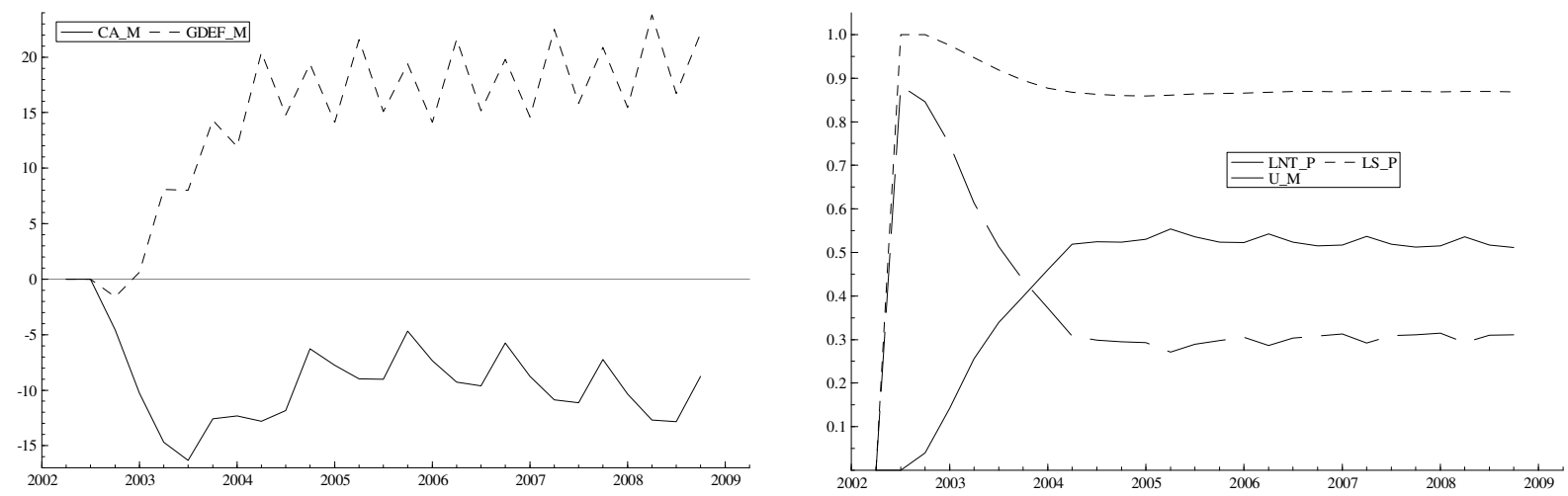

Figure 60 (left) shows that the current account (CA) is worsened by approximately 10 mill. Litas each quarter because the value of the export $(P X \cdot X)$ is decreased more than the decrease in the value of the import $(P M \cdot M),(P X$ is decreased by $0.3 \%, X$ is increased by $0.2 \%, M$ is decreased by $0.1 \%$, and $P M$ is unchanged). 
An increase in the population improves the governmental balance as seen in Figure 60 (left). This covers a decrease in the public expenditure $(C G V)$ of $1.3 \%,{ }^{41}$ and a decrease in the governmental revenue (CGREV) of $0.8 \%$. The wage is decreased so much that the increased employment does not give the households a larger wage income, and hence the tax bases are decreased.

This experiment shows that the effect on the wage (WPRI) from a change in the unemployment rate $(U)$ is too great (if the unemployment rate is increased by $1 \%$-point, the private wage is in the long-run decreased by 5\%, (see Section 10.9). It would have been expected that the governmental revenue be increased in this experiment, since the employment is increased.

\subsection{Concluding Remarks}

In general, the simulations show that the model work appropriately for medium-term forecasts and structural analyses of the Lithuanian economy. However, if the model is to be used for more detailed policy analyses, the equations describing the Governmental finance should be further developed. The simulations and sensitivity analyses also point out equations where further developments may improve the model properties, e.g.:

- Wage determination: In the equation for the wage rate in the private sector, the effect of the unemployment rate is very large. In simulations, this implies that changes in, for example,. the supply of labour and employment have a very small effect on disposable income and thereby private consumption and production.

- $\quad$ Price determination: The prices on final consumption $(P C, P I, P X)$ should be formulated as an I-O-weighted sum of producer prices allowing an effect of the import price (or other variables). This could worsen the empirical explanation, but the model would be more consistent.

- $\quad$ Export: There most be a way to estimate the effect of the Russian crisis besides a dummy, for example, divide the export (and GDP-index) in CIS and "other" and model the shift from CIS to "other". This requires a further detailing of the export data, but would improve both the historical fit and the use of the model for analyses of foreign market developments.

- Import and intermediate: Part of the intermediate is imported and hence the import should depend on the demand for intermediate (and not only on private consumption). An important improvement would be to use an input-output table with separate rows for deliveries from import.

\footnotetext{
${ }^{41}$ Public consumption $(C G R N)$ is exogenous. The price on public consumption $(P C G)$ is decreased by $1.3 \%$. This is more than the average producer price $(P Q)$ decrease because wages form a larger part of the production costs in the public service sector.
} 


\section{Appendix}

\subsection{List of Variables}

\begin{tabular}{|c|c|c|c|c|}
\hline Variable & Type & Description & Unit & Source/Computation \\
\hline$a\{i\}\{j\} \mathrm{i}=$ Set $1 ; \mathrm{j}=$ Set2; & const & Input-Output coefficient, from supply i to demand j & & IO-97, BL \\
\hline$a\{j\}$ im j=Set1 & const & Import in sector j as share of total import & & IO-97, BL \\
\hline$a\{j\}$ imp $1 \mathrm{j}=$ Set1 & endo & Import share coefficients & & $a\{j\}$ imp1 $=a\{j\}^{*} M R N / Q R\{j\}$ \\
\hline binr $\{j\}$ j=Set1 & data & Intermediate share of production & & IO-97, BL, binr $\{j\}=I N R j / Q R j$ \\
\hline $\mathrm{CA}$ & endo & Current account balance & Mill. Litas, current prices & Balance of payment, BL \\
\hline CAPRT & endo & Total capital stock & Mill. Litas, constant prices & \\
\hline CGEXV & data & National budget expenditure & 1000 Litas, current prices & Ministry of Finance \\
\hline CGREV & endo & National budget revenue & Mill. Litas, current prices & \\
\hline CGREVP & endo & National budget revenue from corporate profits & Mill. Litas, current prices & \\
\hline CGREVS & endo & National budget revenue from sectors & Mill. Litas, current prices & \\
\hline CGREVV & endo & National budget revenue from VAT & Mill. Litas, current prices & \\
\hline CGREVW & endo & National budget revenue from personal income & Mill. Litas, current prices & \\
\hline CGRN & exo & Government consumption expenditure & Mill. Litas, constant prices & National accounts, SL \\
\hline CGSEOV & exo & SSSF expenditure substracted by total pensions & 1000 Litas, current prices & CGSEOV $=$ CGSEV $-3^{*}$ pens ${ }^{*}$ pensnr \\
\hline CGSEV & endo & SSSF fund budget expenditure & 1000 Litas, current prices & SSSF \\
\hline CGV & endo & Government consumption expenditure & Mill. Litas, current prices & National accounts, SL \\
\hline CRN & endo & Household consumption & Mill. Litas, constant prices & National accounts, SL \\
\hline $\mathrm{CV}$ & endo & Household consumption expenditure & Mill. Litas, current prices & National accounts, SL \\
\hline D98q2 & exo & Dummy in the equation for investments in dwellings & & Dummy, $1998 q 2=1$, else 0 \\
\hline Delta & const & Depreciation rate & & Delta $=0.025$ \\
\hline $\mathrm{DI}$ & endo & Disposable income & Mill. Litas, current prices & See doc. \\
\hline Dmaz & data & Privatisation of "Mazeikiu nafta" and "Lietuvos dujos" & & Dummy, 2002q2=1, else 0 \\
\hline Dtel & data & Privatisation of "Lietuvos Telekomas" & & Dummy, $1998 \mathrm{q} 3=1$, else 0 \\
\hline DumPCen & exo & Population census & & Dummy, 1 after $2000 q 1$, else 0 \\
\hline DumRC & exo & Crisis in Russia & & Dummy, 1 after $1998 q 3$, else 0 \\
\hline FDI & exo & Foreign direct investment & Mill. Litas, current prices & Balance of payment, BL \\
\hline GDEBT & data & Total government debt & Mill. Litas, current prices & Ministry of Finance \\
\hline GDEF & endo & National budget deficit & 1000 Litas & Ministry of Finance \\
\hline GDP & endo & GDP & Mill. Litas, constant prices & National accounts, SL \\
\hline GDP $\{\mathrm{j}\}, \mathrm{j}=$ Set1 & endo & Gross value added & Mill. Litas, constant prices & National accounts, SL \\
\hline GDP $\{w\}, w=$ Set3 & data & GDP in country w based on yearly data from IMF & $1995=1$ & IMF \\
\hline GDPPRI & endo & Total gross value added in private sector & Mill. Litas, constant prices & GDPPRI = GDPT - GDPS4 \\
\hline GDPT & endo & Total gross value added in sectors & Mill. Litas, constant prices & GDPT $=$ SUM(GDP $\{j\})$ \\
\hline GDPV & endo & GDP & Mill. Litas, current prices & GDPexpenditure.XLS \\
\hline GDPV $\{j\} \mathrm{j}=$ Set1 & data & GVA in sectors & Mill. Litas, current prices & GDPQIN.XLS \\
\hline GDPVT & endo & Total gross value added in sectors & Mill. Litas, current prices & SL \\
\hline GDPwr & exo & GDP index for export market & $1995=1$ & Weightet average of GDP\{w\} \\
\hline INBAL & exo & Income & Mill. Litas, current prices & Balance of payment, BL \\
\hline INDT & data & Taxes on products minus subsidies on products & Mill. Litas, constant prices & National accounts, SL \\
\hline INDTV & data & Taxes on products minus subsidies on products & Mill. Litas, current prices & National accounts, SL \\
\hline INR $\{j\} \mathrm{j}=$ Set1 & endo & Input (intermediate in sector j) & Mill. Litas, constant prices & $S L$, INR=QR-GDP \\
\hline INRT & endo & Input total & Mill. Litas, constant prices & SL, INRT = SUM(INR\{j\}) \\
\hline INV $\{j\}$ j=Set1 & data & Input & Mill. Litas, current prices & $S L, I N V=Q V-G D P V$ \\
\hline INVT & endo & Input total & Mill. Litas, current prices & SL, INVT = SUM(INV\{j\}) \\
\hline$I R\{j\} \mathrm{j}=$ Set1 & endo & Capital investement in sectors & Mill. Litas, constant prices & $\mathrm{SL}, \mathrm{IR}\{\mathrm{j}\}=(\mathrm{IV}\{\mathrm{j}\} / \mathrm{PI}) / 1000$ \\
\hline IRH & endo & Capital investement in dwellings & Mill. Litas, constant prices & $\mathrm{SL}, \mathrm{IRH}=(\mathrm{IVH} / \mathrm{PI}) / 1000$ \\
\hline IRN & data & Gross fixed capital formation & Mill. Litas, constant prices & National accounts, SL \\
\hline IRN1 & endo & Gross domestic investment & Mill. Litas, constant prices & National accounts, SL \\
\hline IRT & endo & Total capital investement in sectors & Mill. Litas, constant prices & SL, IRT = SUM(IR $\{j\}) \mathrm{j}=$ Set1 \\
\hline IRTH & endo & Total capital investement & Mill. Litas, constant prices & $\mathrm{SL}, \mathrm{IRTH}=\mathrm{IRT}+\mathrm{IRH}$ \\
\hline IV & data & Gross fixed capital formation & Mill. Litas, current prices & National accounts, SL \\
\hline$I V\{j\} \mathrm{j}=$ Set1 & data & Capital investement in sectors & 1000 Litas, current prices & National accounts, SL \\
\hline IV1 & data & Gross domestic investment & Mill. Litas, current prices & National accounts, SL \\
\hline IVT & data & Capital investement & Mill. Litas, current prices & SL, IVT = SUM(IV\{j\}) j=Set1 \\
\hline LN & endo & Employed people & 1000 persons & SL \\
\hline$L N\{j\} j=$ Set 1 & endo & Employed (who work the whole work day) & 1000 persons & $\mathrm{SL}$ \\
\hline LNPRI & endo & Employed (who work the whole work day) Private sector & 1000 persons & LNPRI $=\operatorname{SUM}(\mathrm{LN}\{j\})-\mathrm{LNS4}$ \\
\hline LNT & endo & Employed (who work the whole work day) Total & 1000 persons & LNT $=\mathrm{SUM}(\mathrm{LN}\{j\})$ \\
\hline LS & endo & Labour force & 1000 persons & SL, LNWP.XLS \\
\hline MRN & endo & Imports of goods and services & Mill. Litas, constant prices & SL, GDPexpenditure.xls \\
\hline MV & data & Imports of goods and services & Mill. Litas, current prices & SL, GDPexpenditure.xls \\
\hline NT & exo & Current transfers, balance & Mill. Litas, current prices & Balance of payment, BL \\
\hline NTMIN & exo & Nontaxable minimal wage & Litas, current prices & Ministry of Finance \\
\hline
\end{tabular}




\begin{tabular}{|c|c|c|c|c|}
\hline Variable & Type & Description & Unit & Source/Computation \\
\hline PC & endo & Consumer price & $1995=1$ & $P C=C V / C R N$ \\
\hline PCG & endo & Price on public consumption & $1995=1$ & PCG $=$ CGV/CGRN \\
\hline PENS & endo & Average monthly pension & Litas, current prices & SSSF \\
\hline PENSNR & exo & Number of pensioners & 1000 persons & SSSF \\
\hline PGDP & endo & GDP price & $1995=1$ & $P G D P=G D P V / G D P$ \\
\hline PGDP $\{j\} \mathrm{j}=$ Set1 & data & GDP price in sector $j$ & $1995=1$ & $P G D P\{j\}=G D P V\{j\} / G D P\{j\}$ \\
\hline $\mathrm{PI}$ & endo & Aggregated investment price & $1995=1$ & $\mathrm{PI}=\mathrm{IV} / \mathrm{IRN}$ \\
\hline$P I N\{j\}$ j=Set1 & endo & Price on intermediate in sector $\mathrm{j}$ & $1995=1$ & $P I N\{j\}=I N V\{j\} / I N R\{j\}$ \\
\hline PINT & endo & Average price on intermediate & $1995=1$ & PINT $=$ INVT/INRT \\
\hline $\mathrm{PM}$ & exo & Import price & $1995=1$ & $\mathrm{PM}=\mathrm{MV} / \mathrm{MRN}$ \\
\hline POP & exo & Population & 1000 persons & SL \\
\hline $\mathrm{PQ}$ & endo & Output price & $1995=1$ & $P Q=Q V T / Q R T$ \\
\hline$P Q\{j\} \mathrm{j}=$ Set1 & endo & Output price & $1995=1$ & $P Q\{j\}=Q V\{j\} / Q R\{j\}$ \\
\hline PQEX & endo & Producer price used in equation for PX & $1995=1$ & See doc. \\
\hline PQM & endo & Output price in manufacturing & $1995=1$ & $P Q M=Q V M / Q R M$ \\
\hline$P Q S$ & endo & Output price in service & $1995=1$ & $P Q S=Q V S / Q R S$ \\
\hline PQUC $\{j\}, j=$ Set1 & endo & Unit cost & & See doc. \\
\hline PROF & endo & Profit & Mill. Litas, current prices & See doc. \\
\hline Pw $\{j\}, j=S e t 4$ & exo & CPI-index in country j & & IMF \\
\hline Pwr $\{j\}, j=$ Set4 & endo & World market price $\mathrm{j}$ in Litas & $1995=1$ & See doc. \\
\hline $\mathrm{PX}$ & endo & Export price & $1995=1$ & $P X=X V / X R N$ \\
\hline$Q\{j\}, j=2,3,4$ & exo & Quarterly dummies & & $\mathrm{Q} 2=1$ in 2. quarter, else zero \\
\hline Q4dirh & exo & Modified 4th quarter dummy (0 in 1998 and 1999) & & disables Q4 after Russian crisis \\
\hline$Q R\{j\} j=$ Set1 & endo & Gross domestic production in sector $j$ & Mill. Litas, constant prices & $\mathrm{SL}$ \\
\hline QRM & endo & Production in manufacturing & Mill. Litas, constant prices & $\mathrm{QRM}=\mathrm{QRM} 1+\mathrm{QRM} 2+\mathrm{QRM} 3+\mathrm{QRM} 4$ \\
\hline QRS & endo & Production in service sector & Mill. Litas, constant prices & QRS = QRS1+QRS2+QRS3+QRS4 \\
\hline QRT & endo & Gross domestic production & Mill. Litas, constant prices & $S L, Q R T=S U M(Q R\{j\})$ \\
\hline$Q V\{j\} j=$ Set1 & data & Gross domestic production in sector $j$ & Mill. Litas, current prices & SL \\
\hline QVT & endo & Gross domestic production & Mill. Litas, current prices & SL, QVT $=S U M(Q V\{j\})$ \\
\hline RA & exo & Average annual interest rates on loans in litas & $\%$ & $\mathrm{BL}$ \\
\hline REER \{\}$\}, j=$ Set 4 & exo & Real Effective Exchange Rate for $\mathrm{j}$ & Litas vs other currencies & $\mathrm{BL}$ \\
\hline SSC & exo & Social security contribution rate & rate & SSSF \\
\hline SSCIN & endo & SSSF revenue & Mill. Litas, current prices & See doc. \\
\hline $\mathrm{T}$ & exo & Time index, quarterly & & $1995 q 1=1$ \\
\hline TC & exo & Tax rate on profit & rate & Ministry of Finance \\
\hline tcbase & exo & Correction factor for tax on profit & & See doc. \\
\hline TL & exo & Wage tax rate & rate & Ministry of Finance \\
\hline TP & exo & Rate of taxes minus subsidies on products & rate & See doc. \\
\hline $\mathrm{U}$ & endo & Unemployment rate & rate & Labour Exchange \\
\hline VAT & exo & VAT rate & rate & Ministry of Finance \\
\hline VMV & data & Changes in inventories & Mill. Litas, current prices & National accounts, SL \\
\hline WMP & endo & World market price & $1995=1$ & See doc. \\
\hline workhour & exo & Average hours of working pr. week & hours & workhour $=\left(\mathrm{LNT}^{*} 40\right) / \mathrm{LN}$ \\
\hline WPRI & endo & Average monthly gross earnings in privat sector & Litas, current prices & $S L$ \\
\hline WPUB & endo & Average monthly gross earnings in public sector & Litas, current prices & SL \\
\hline WSUM & endo & Wage sum & Mill. Litas, current prices & See doc. \\
\hline XRN & endo & Exports of goods and services & Mill. Litas, constant prices & Balance of payment, BL \\
\hline $\mathrm{XV}$ & data & Exports of goods and services & Mill. Litas, current prices & Balance of payment, BL \\
\hline
\end{tabular}

Set1 $=\{A, M N, E, M 1, M 2, M 3, M 4, C, S 1, S 2, S 3, S 4\}$

Set2 $=\{A, M N, E, M 1, M 2, M 3, M 4, C, S 1, S 2, S 3, S 4, C p, I R, C g, E x\}$

Set3 $=\{$ UKI,LAT, GER,RUS, POL,DEN,BER,USA,SWE,UKR,FRA,EST,NET,ITA,BEL $\}$

Set4 $4=\{\mathrm{EU}, \mathrm{CE}, \mathrm{Cl}\}$

Type: endo (endogenous variable in the model), exo (exogenous variable in the model), const (constant coefficient), data (additional variable used in data generation)

Source: $B L=B a n k$ of Lithuania; $S L=S t a t i s t i c s$ Lithuania; SSSF=State Social Security Fund; IMF=International Monetary Fund 


\subsection{Input-Output Matrix}

Table 28 Input-Output Table 12 Sectors, Deliveries in mill. Litas (1997)

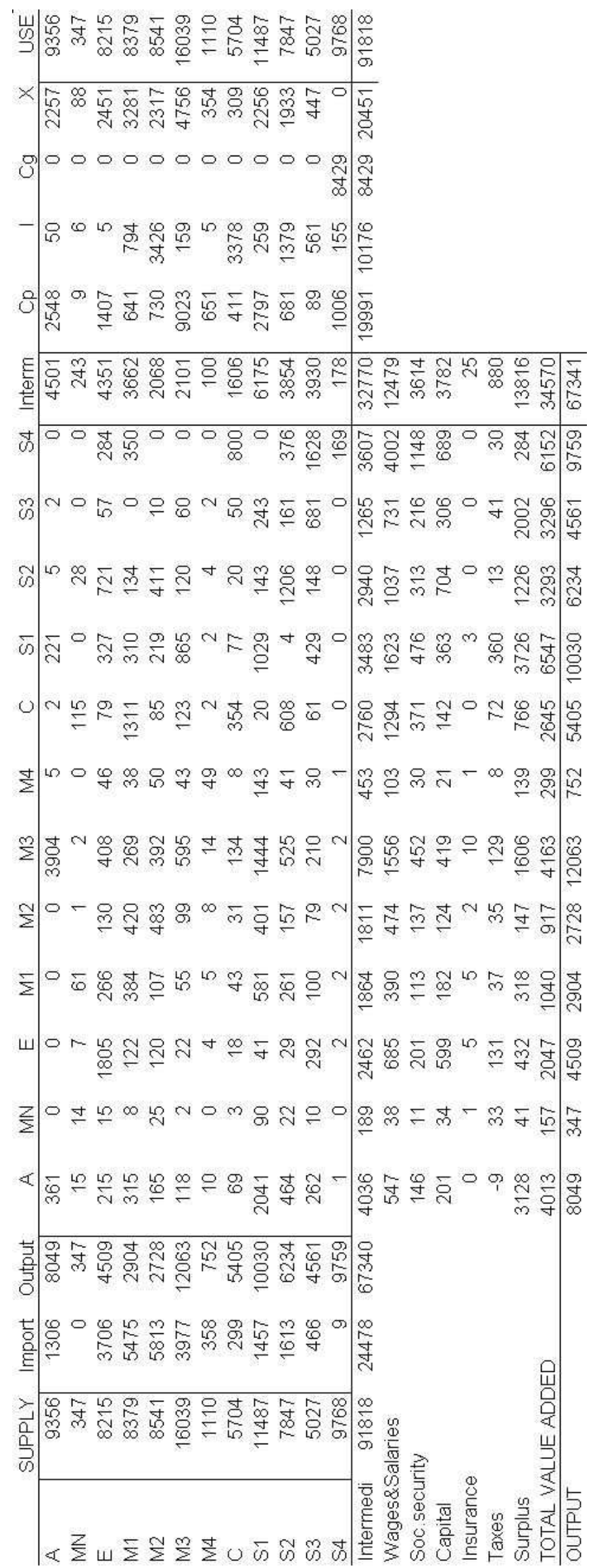


Table 29 Input-Output Coefficients 12 Sectors 1997

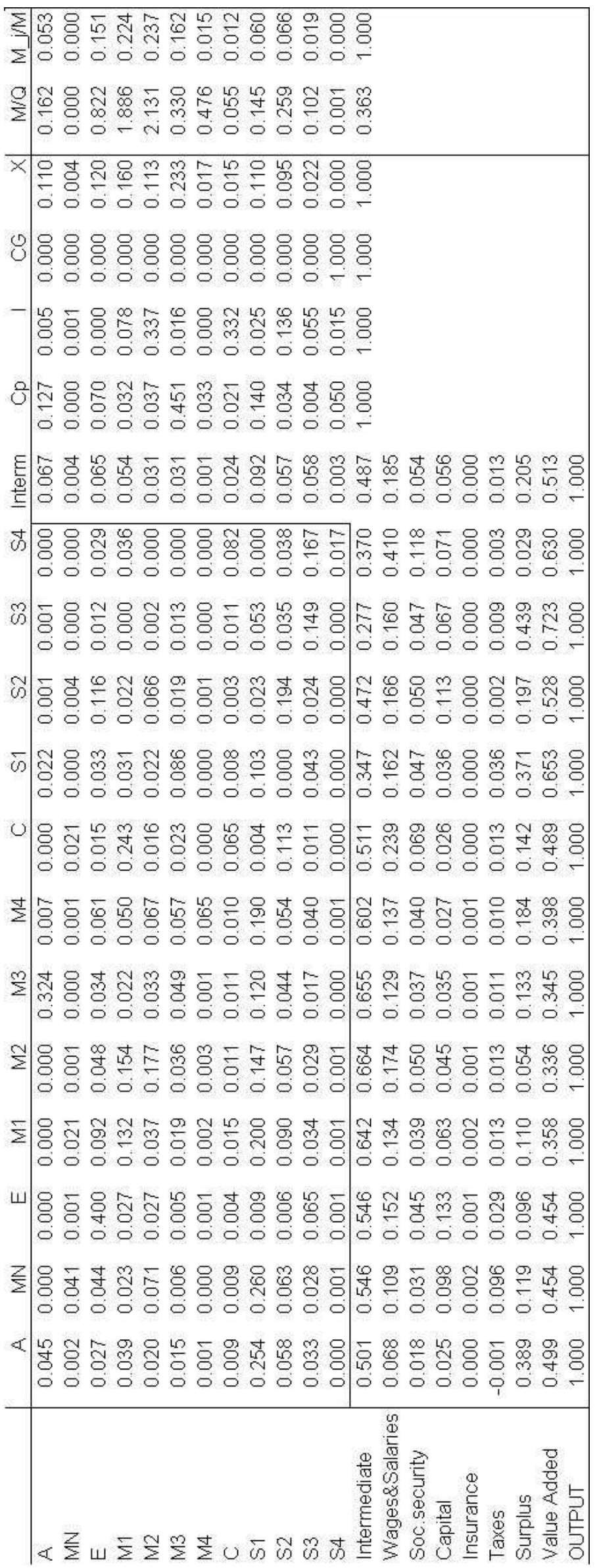




\subsection{Private Consumption, Alternative Estimations}

In this section, we present three different estimations of the equation for private consumption:

$$
\begin{gathered}
\log \left(C p^{*}\right)=\alpha_{0}+\alpha_{1} \cdot \log \left(Y / P_{C}\right)+\lambda_{2} \cdot Q_{2}+\lambda_{3} \cdot Q_{3}+\lambda_{4} \cdot Q_{4} \\
\operatorname{Dlog}(C p)=\beta_{1} \operatorname{Dlog}\left(Y / P_{C}\right)+\beta_{2} \mathrm{D}(i)+\beta_{3} \mathrm{D}(U)+\beta_{4} \operatorname{Dlog}\left(P_{C}\right) \\
+\beta_{0}\left[\log \left(C P_{-1}^{*}\right)-\log \left(C p_{-1}\right)\right]
\end{gathered}
$$

It was not possible to estimate a significant negative effect on changes in the unemployment rate $(U)$, so we restrict the parameter to zero in all the estimations $\left(\beta_{3}=0\right)$.

In the first estimation, all parameters are estimated simultaneously. In the second estimation, the long-term equation is firstly estimated and then the short-term equation is estimated contingent to the long-term coefficients (two-step estimation). In the third estimation, the long-term marginal income elasticity $\left(\alpha_{1}\right)$ is restricted to one. The three estimation results are presented in Table 30.

Table 30 Three Estimations of Private Consumption

\begin{tabular}{lrrrrrrrrrrr}
\hline No. & $\alpha_{0}$ & $\alpha_{1}$ & $\lambda_{2}$ & $\lambda_{3}$ & $\lambda_{4}$ & $\beta_{0}$ & $\beta_{1}$ & $\beta_{2}$ & $\beta_{3}$ & $\beta_{4}$ & $R^{2}$ \\
\hline 1 & 3.253 & 0.627 & -0.019 & 0.050 & -0.208 & 0.428 & 0.189 & -0.008 & 0 & -0.955 & 0.957 \\
& $[4.04]]$ & {$[6.74]$} & {$[-0.71]$} & {$[1.01]$} & {$[-2.23]$} & {$[3.57]$} & {$[2.21]$} & {$[-2.03]$} & $*$ & {$[-4.02]$} & \\
2 & 1.726 & 0.806 & -0.012 & 0.069 & -0.268 & 0.351 & 0.232 & -0.010 & 0 & -0.666 & 0.950 \\
& {$[40.20]$} & $*$ & {$[-0.36]$} & {$[1.07]$} & {$[-2.68]$} & {$[2.97]$} & {$[2.68]$} & {$[-2.58]$} & $*$ & {$[-3.55]$} & \\
3 & 0.135 & 1 & 0.141 & 0.141 & -0.600 & 0.185 & 0.219 & -0.013 & 0 & -0.469 & 0.939 \\
& {$[1.23]$} & $*$ & {$[0.30]$} & {$[0.97]$} & {$[-1.50]$} & {$[1.84]$} & {$[1.84]$} & {$[-3.24]$} & $*$ & {$[-2.37]$} & \\
\hline
\end{tabular}

Estimation period 1995q2-2002q2. t-values in [ ]. * Restricted parameter.

The long-term marginal propensity to consume out of income is in the first estimation very small $\left(\alpha_{1}=0.63\right)$, and the short-run propensity is even smaller $\left(\beta_{1}=0.19\right)$. If disposable income $(Y)$ is permanently increased with $1 \%$, private consumption $(C p)$ increases only by $0.19 \%$ in the first quarter and with $0.63 \%$ in the long-run.

Looking at the estimated price effect in the first estimation, if the price on private consumption $\left(P_{C}\right)$ is permanently increased by $1 \%$, private consumption is in the long-run decreased by $0.63 \%\left(\alpha_{1}\right)$, because real disposable income $\left(Y / P_{C}\right)$ is decreased by $1 \%$. But private consumption is in the first quarter decreased by $1.1 \%\left(-\beta_{1}+\beta_{4}\right)$. If real consumption is decreased by $1 \%$ (and hence consumption expenditure $C \cdot P_{C}$ is unchanged), this tells us that consumers in Lithuania have in the short-run a very strict budget limit. However, with this estimation, real consumption decreases by more than $1 \%$ - and consumption expenditure is decreased by $0.1 \%$; this seems unreasonable.

Therefore, in the third estimation, we estimate the consumption equations restricting the longterm marginal propensity to consume to unity, meaning that real consumption is a constant share of the real disposable income $\left(\alpha_{1}=1\right)$. The degree of explanation $\left(\mathrm{R}^{2}\right)$ is decreased slightly from 0.957 to 0.939 . The price elasticity is -0.69 in the first quarter $\left(-\beta_{1}+\beta_{4}\right)$ and 1.00 in the long-run $\left(\alpha_{1}\right)$. The problematic surrounding this estimation is that the error correction parameter $\left(\beta_{0}\right)$ is decreased from 0.43 to 0.19 , implying that adjustment towards the equilibrium relation is slow. 
In the second estimation, we commence by only estimating the long-term relation (97). The long-run marginal propensity to consume is estimated to $0.81\left(\alpha_{1}\right)$. This parameter is then fixed and the dynamic adjustment (98) is estimated. The degree of explanation is only decreased from 0.957 to 0.950 . The short-run marginal propensity to consume is about the same as in the other estimations $\left(\beta_{1}=0.2\right)$. The long-run price elasticity is -0.81 , and the short-run price elasticity is -0.89 . This means that consumers have in the short-run a stricter budget restriction, whereas there are in the longer run wider possibilities to distribute income and consumption more equally between quarters. The adjustment is a bit slower than in the first estimation $\left(\beta_{0}=0.35\right)$.

Due to the above considerations, we choose to use the second estimation in the model.

The effects of changing the exogenous variables in the three equations for private consumption are shown in the following figures.

Figure 61 shows the percentage change in private consumption where disposable income is permanently increased by $1 \%$; the straight line is the effect by using estimation 1 , the dotted line is estimation number 2 , and the circled line is estimation $3 .^{42}$ The long-term change in the private consumption differs between $0.6 \%$ (estimation 1) and $1 \%$ (estimation 3 ). We can see that the adjustment is much slower in the third estimation than the two others.

\section{Figure 61 Percentage Change in Private Consumption, Disposable Income + 1\%}

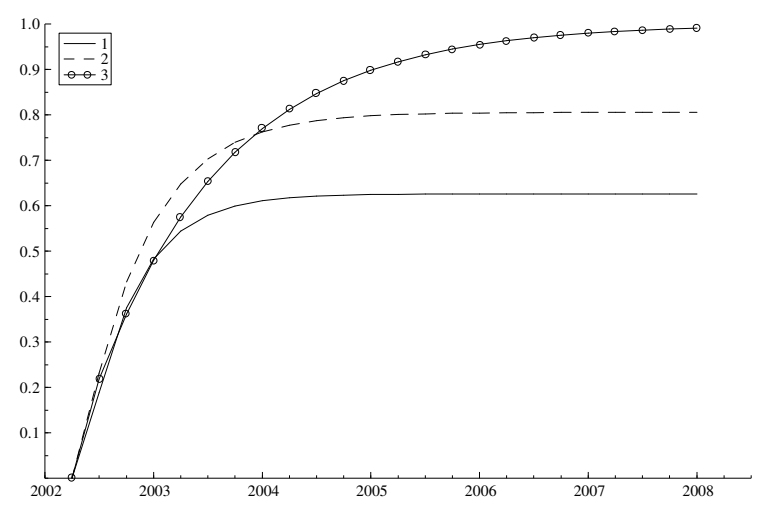

Figure 62 shows the effect on the private consumption when the consumer price is permanently increased by $1 \%$. The long-term effect differs between $-0.6 \%$ (estimation 1 ) to $1.0 \%$ (estimation 3). The greatest difference between the estimations is the short-term effect of a price increase on private consumption. There is in the first and second estimation a larger effect in the first quarters than in the long-run - and this effect is in the first estimation unacceptably high, as explained above.

\footnotetext{
${ }^{42}$ Firstly, equation (97) and (98) is simulated in the period 2002q3 to 2008q1 with an exogenous forecast of $Y d$, $P_{C}$, and $i$ to give a baseline scenario. Second, one of the exogenous variables, e.g. $Y d$, is increased by $1 \%$ in the forecast period, and the two equations are simulated again. Third, we calculate the percentage change from the baseline scenario in the real private consumption (the multiplier).
} 
Figure 62 Percentage Change in Private Consumption, Consumer Price $+1 \%$

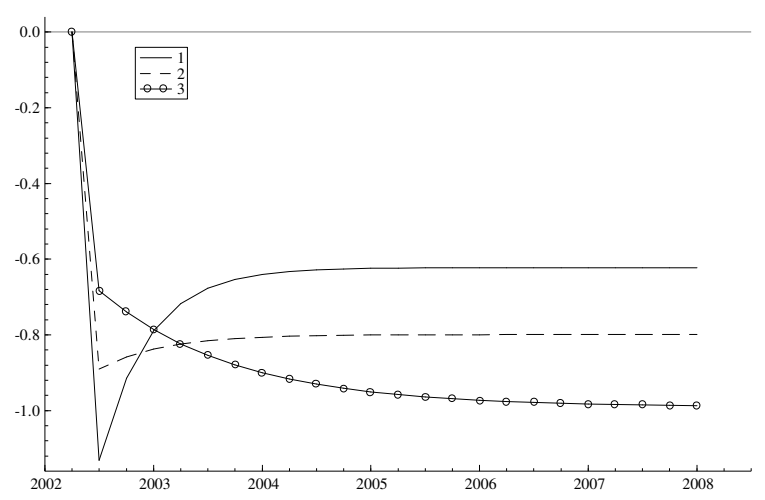

Finally, we show in Figure 63 the effect of a $1 \%$ increase in the interest rate (i), e.g., from 5\% to $6 \%$. There is in the long-run no effect on the private consumption. The first quarter, real consumption is increased by $100 \cdot \beta_{2} \%$. The effect is almost the same in the three estimations (from $-0.8 \%$ to $-1.3 \%$ ). The adjustment towards zero is determined by the error correction parameter $\left(\beta_{0}\right)$, and is quite slow in the third estimation.

Figure 63 Percentage Change in Private Consumption, Interest Rate +1

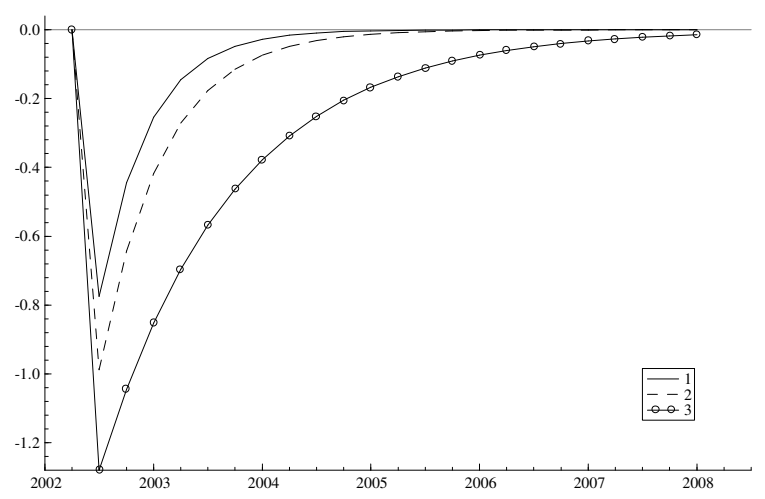




\subsection{Calculation of World Market Variables}

Lithuania's 14 main foreign trade partners are: United Kingdom (uki), Latvia (lat), Germany (ger), Russia (rus), Poland (pol), Denmark (den), Belarus (ber), USA (usa), Sweden (swe), Ukraine (ukr), France (fra), Estonia (est), Netherlands (net), Italy (ita), and Belgium (bel). In 2001, export to other countries accounts for 11.4\%. Source: Statistical Yearbook 2002 table 23.3.

\section{Table 31 Calculation of GDP World}

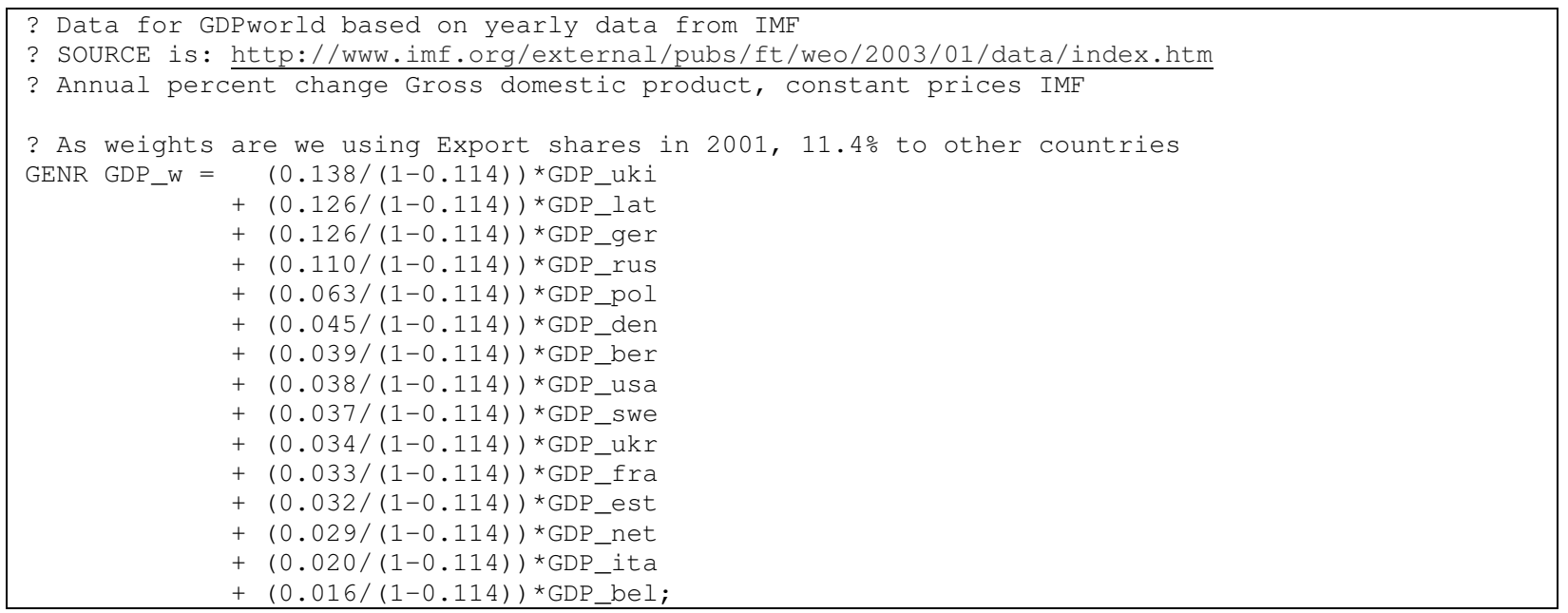

Table 32 Calculation of World Market Price

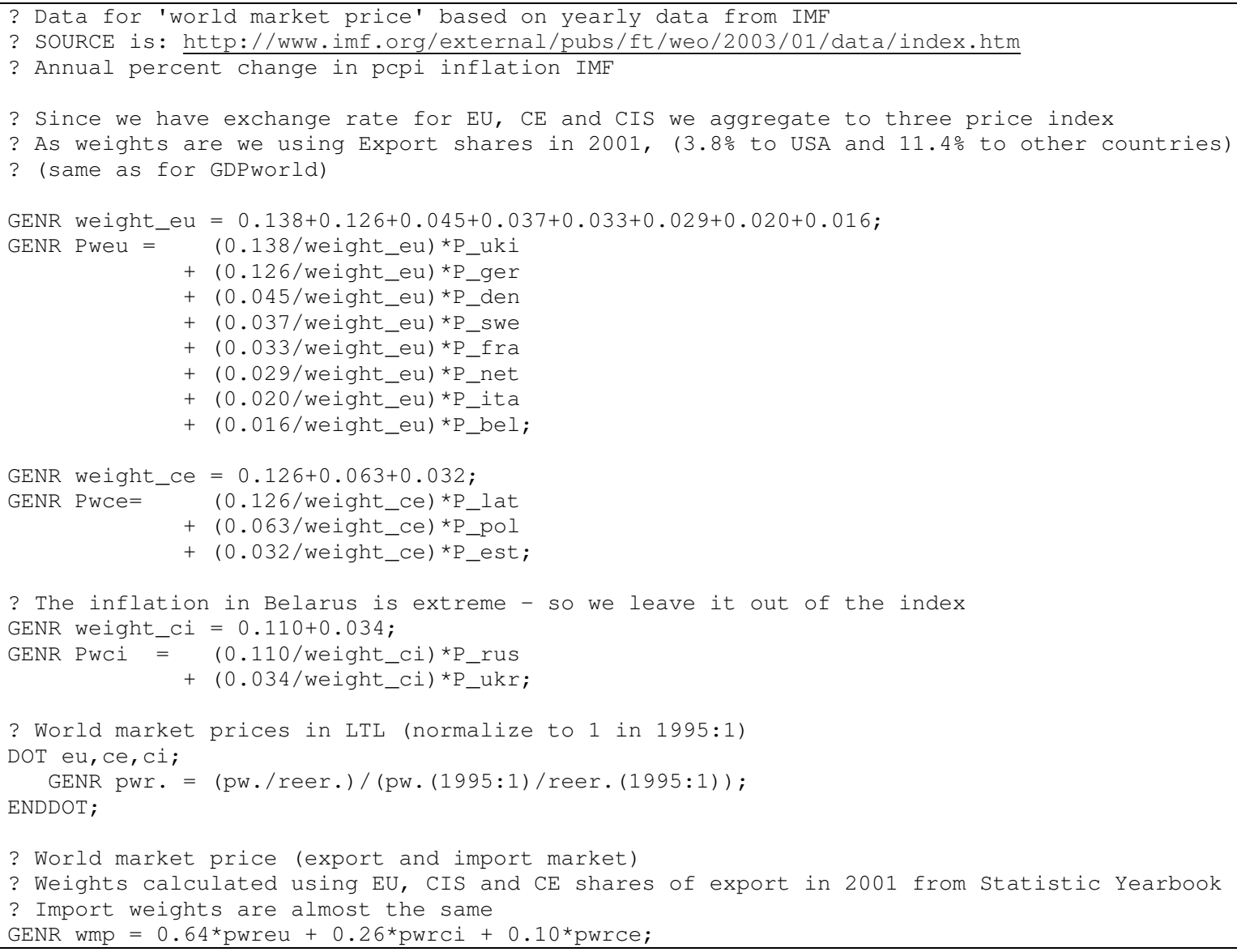




\subsection{Model Equations}

\section{Table 33 Equations Formulated in TSP}

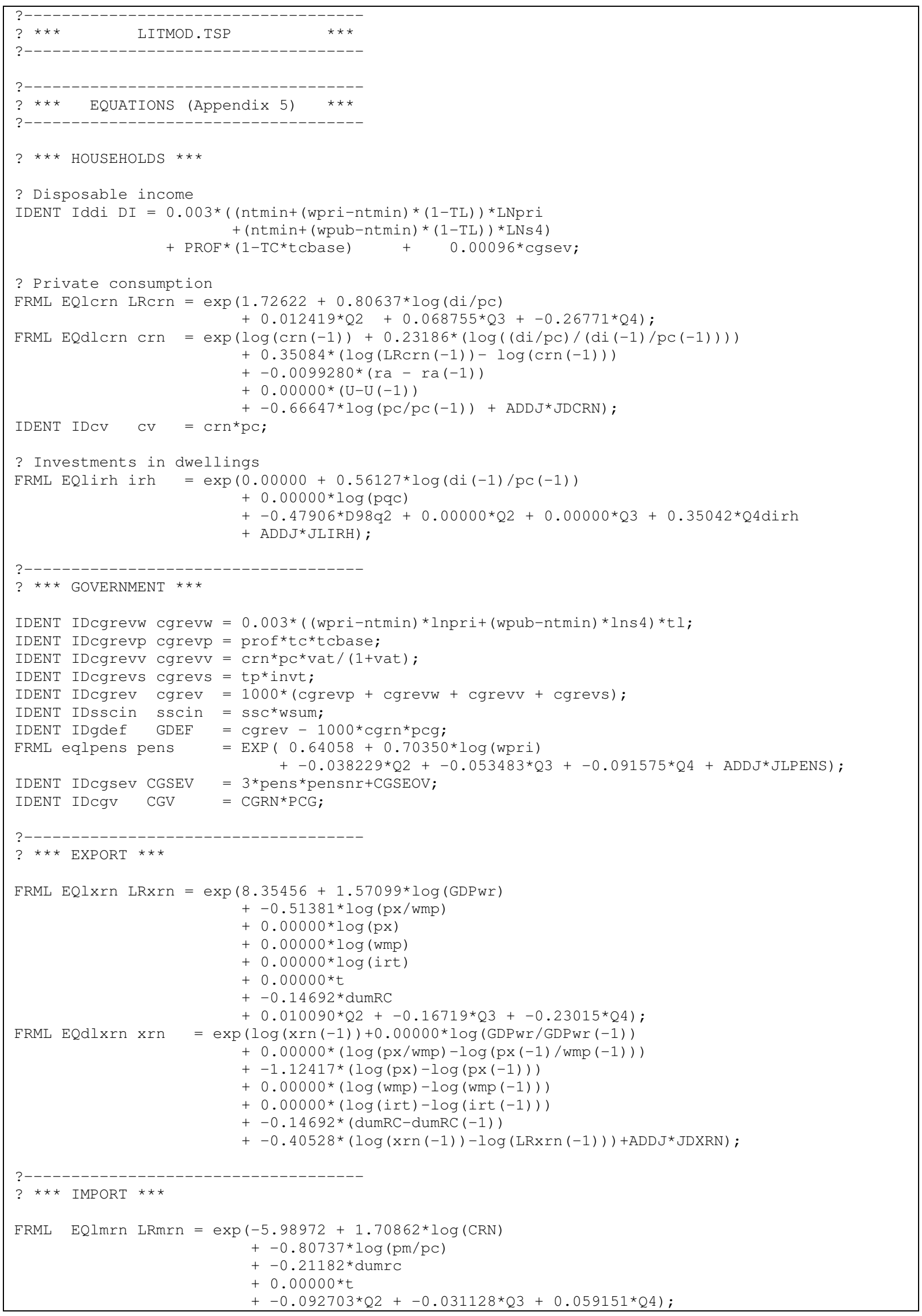




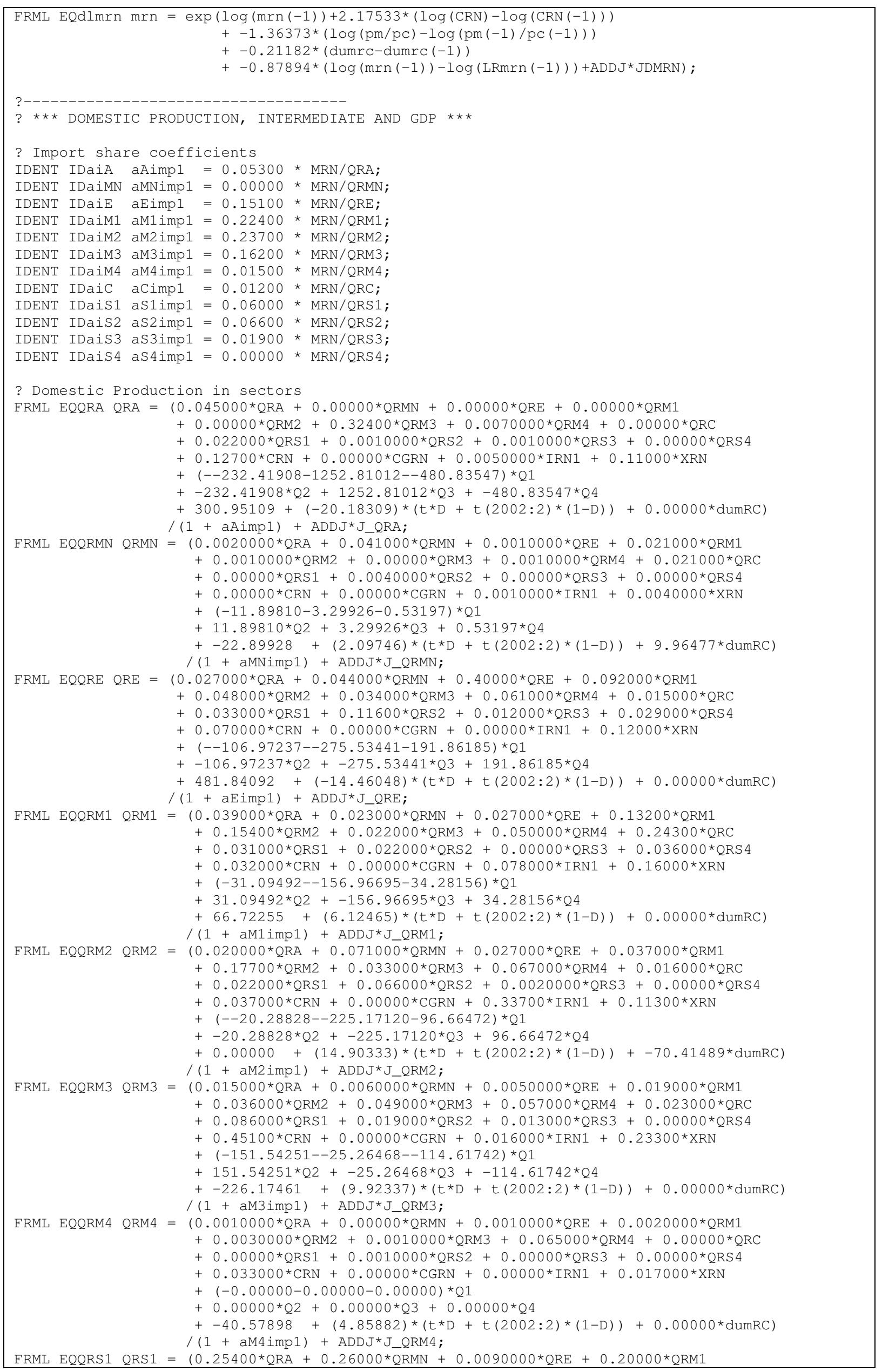




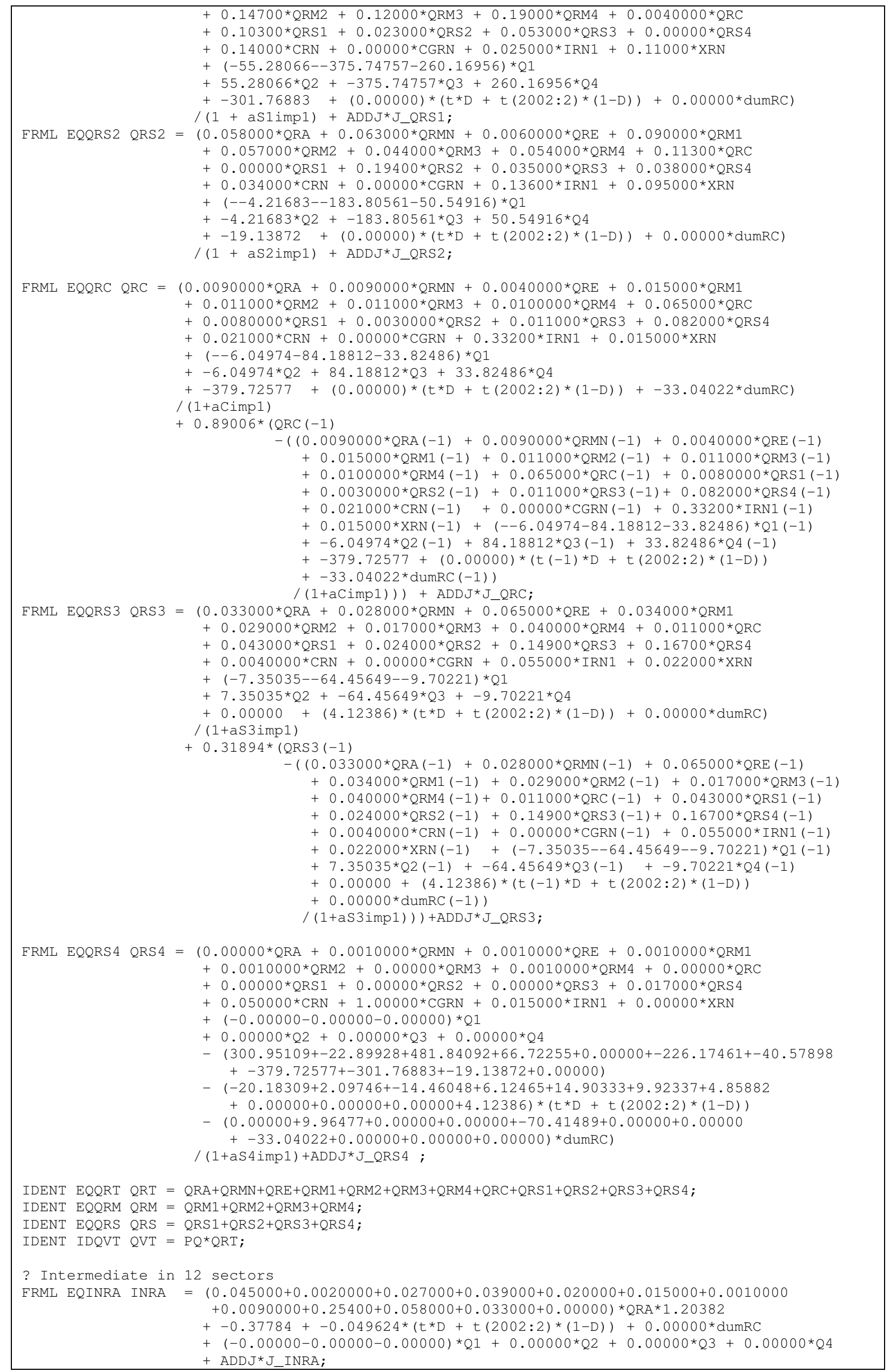




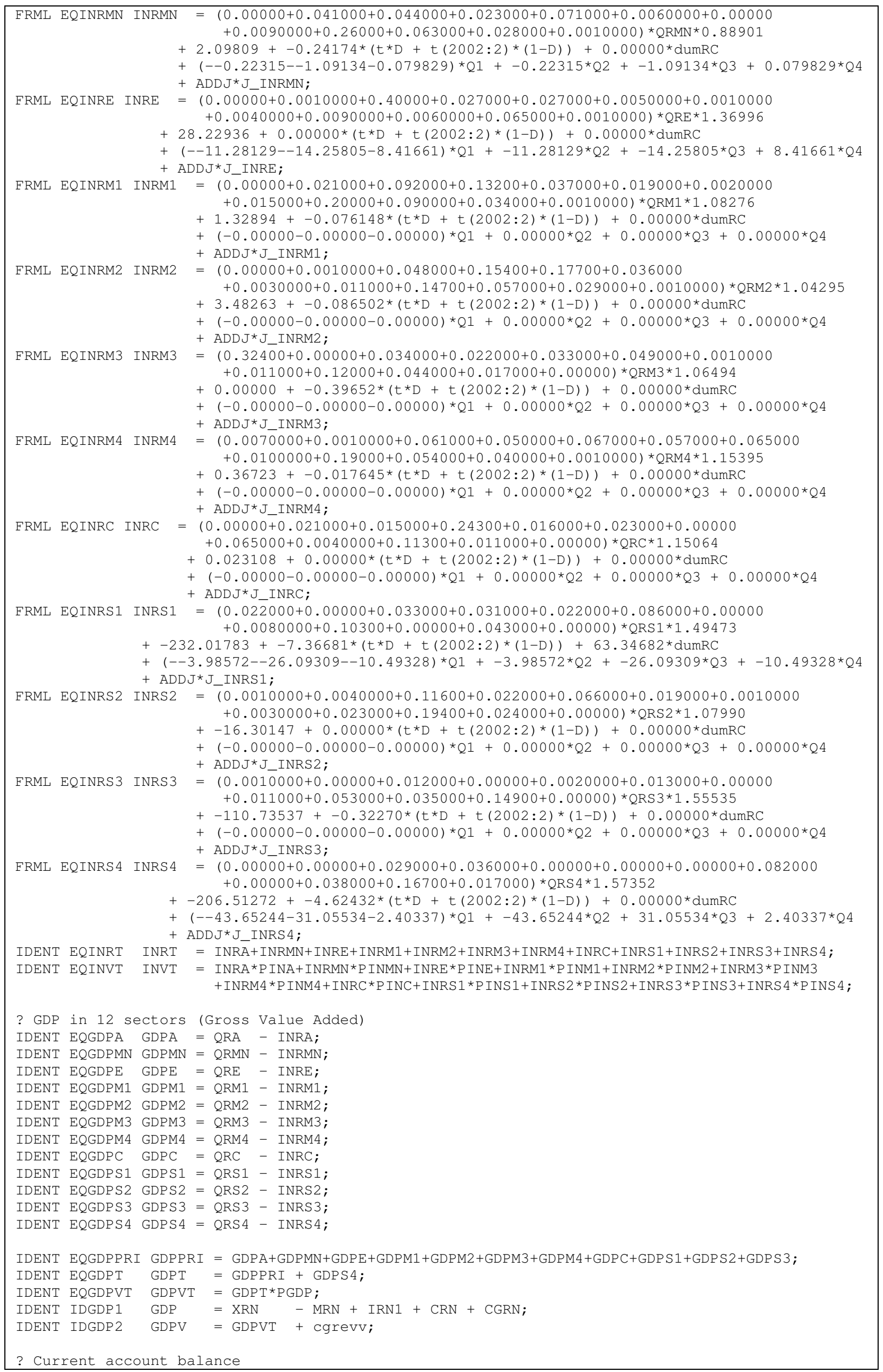




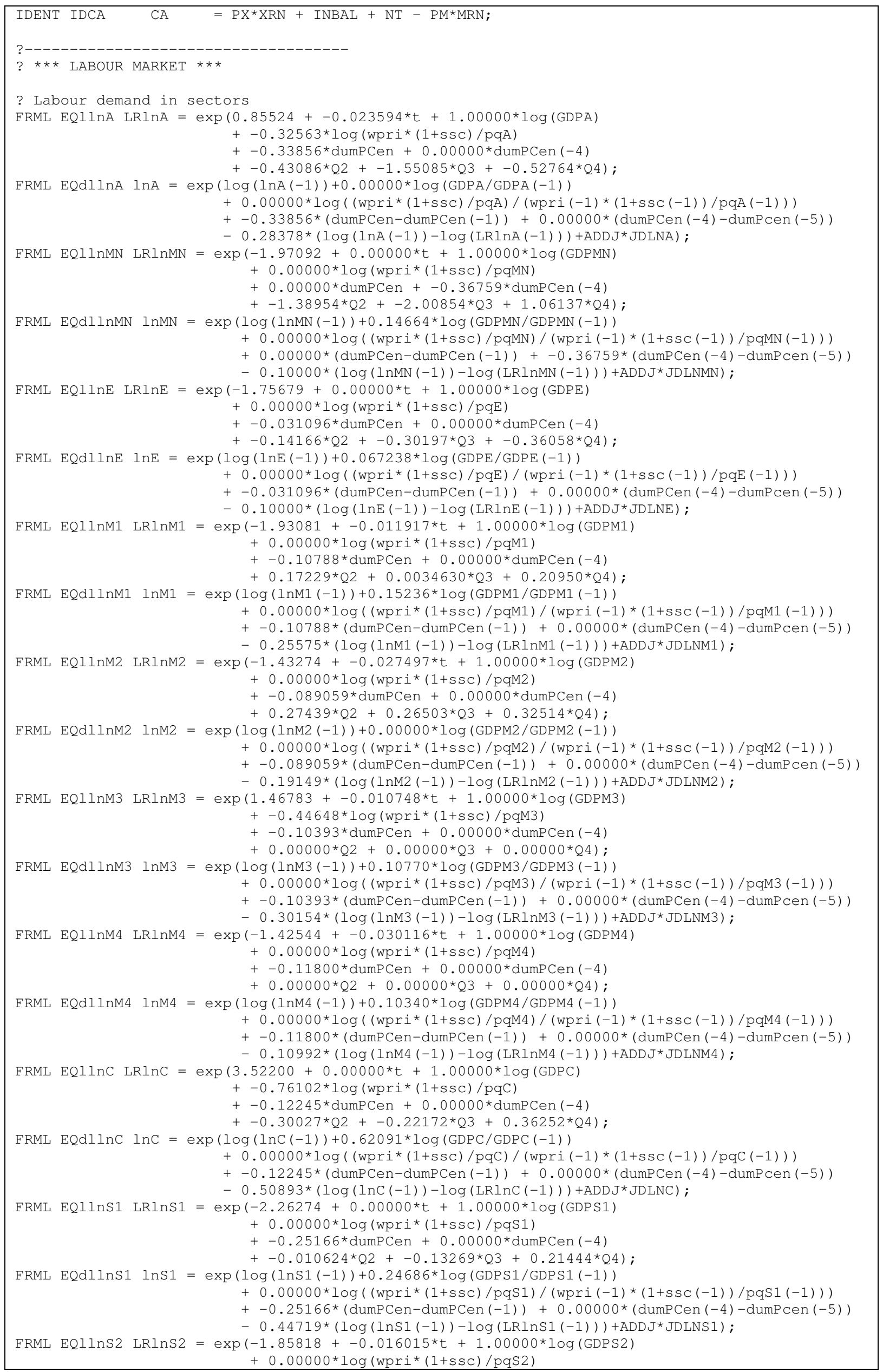




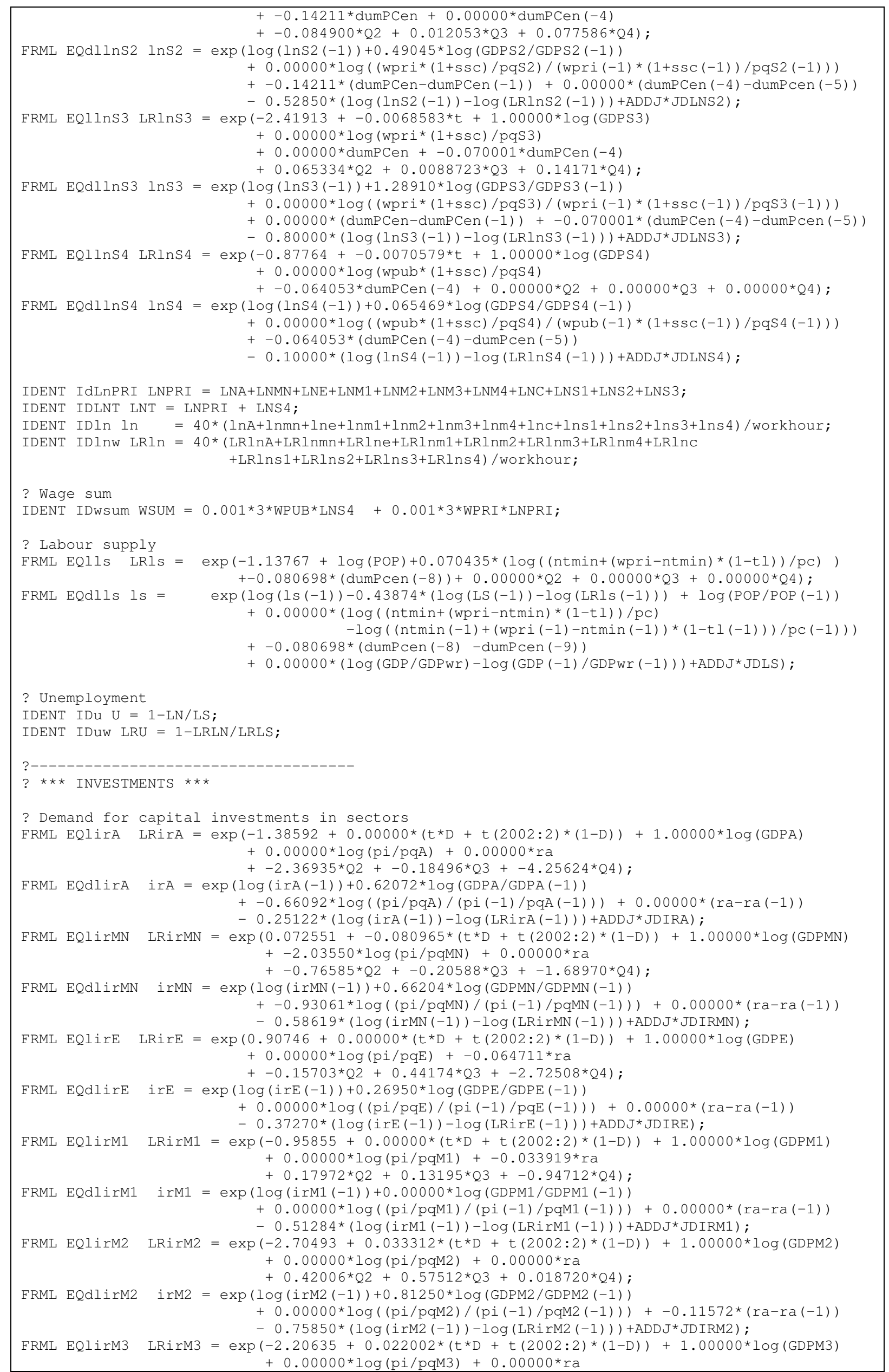




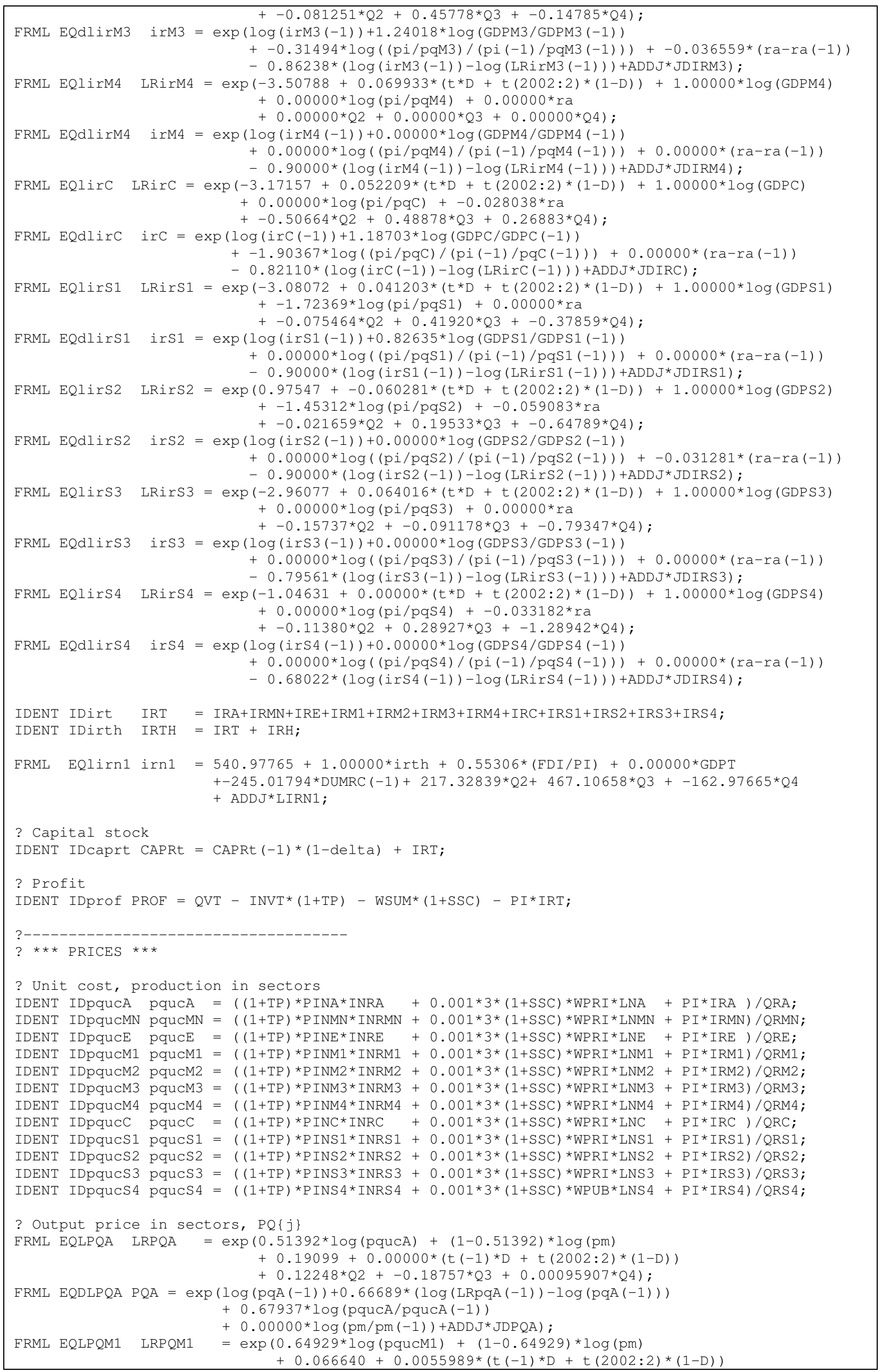




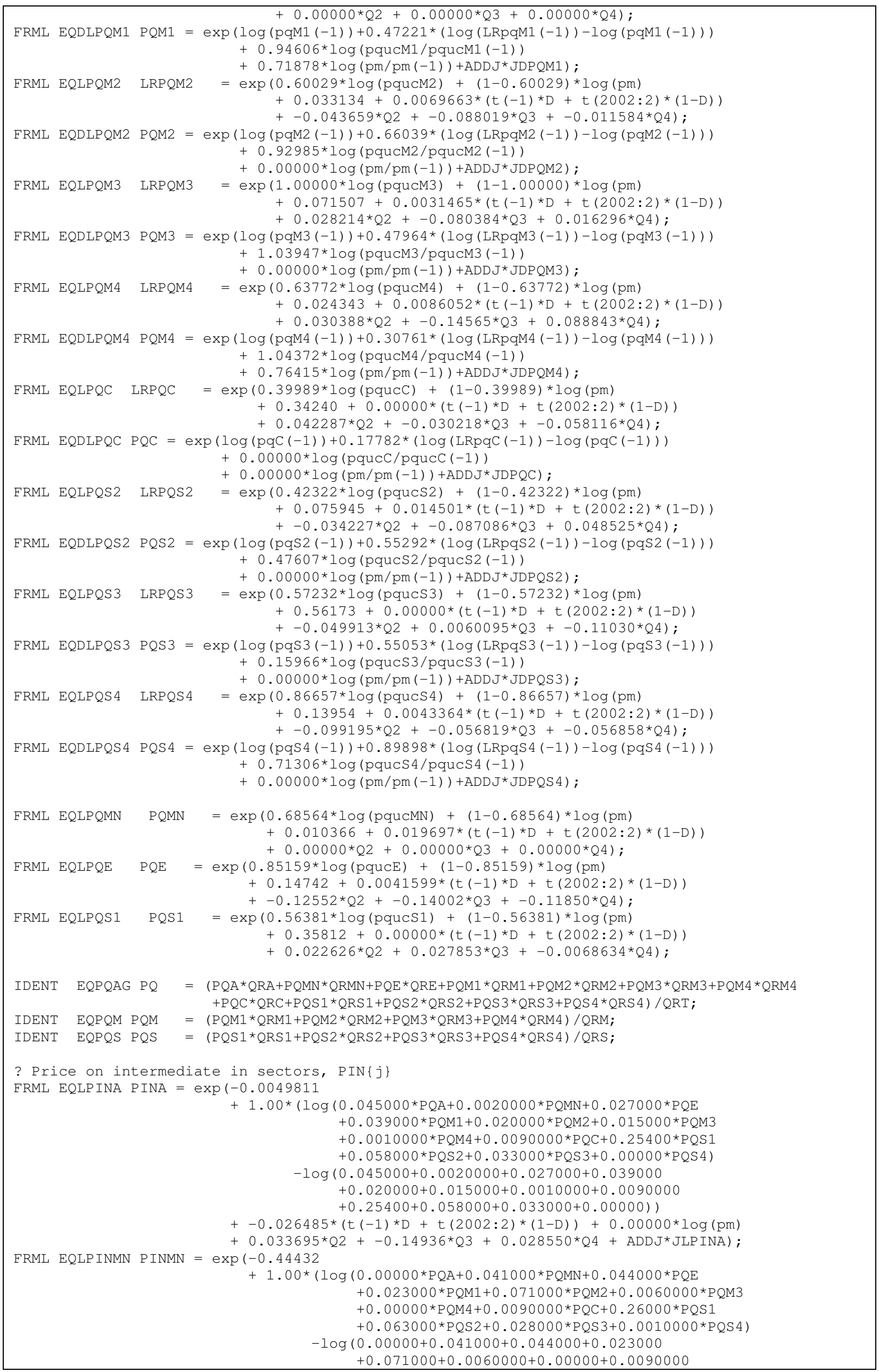




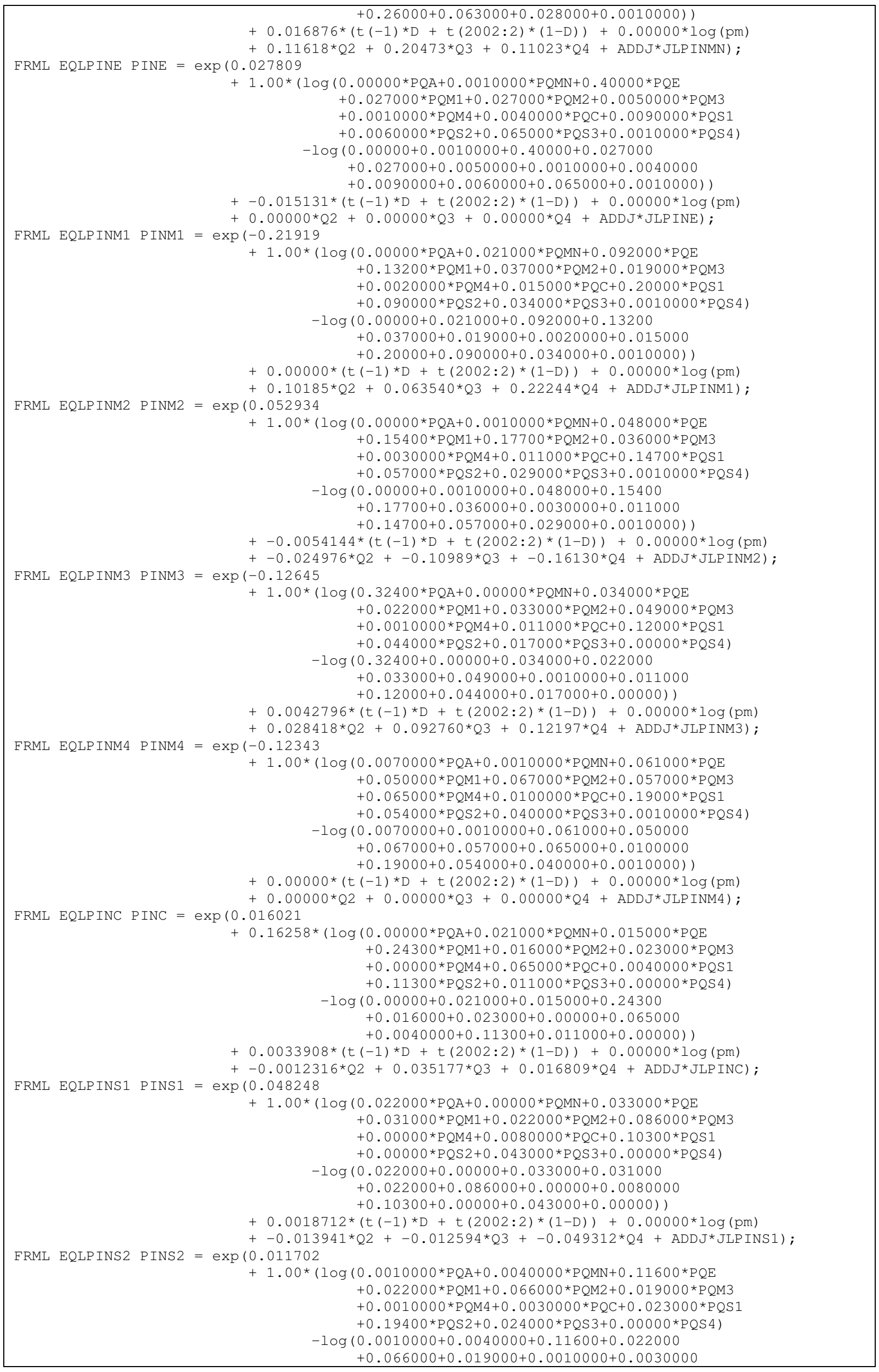




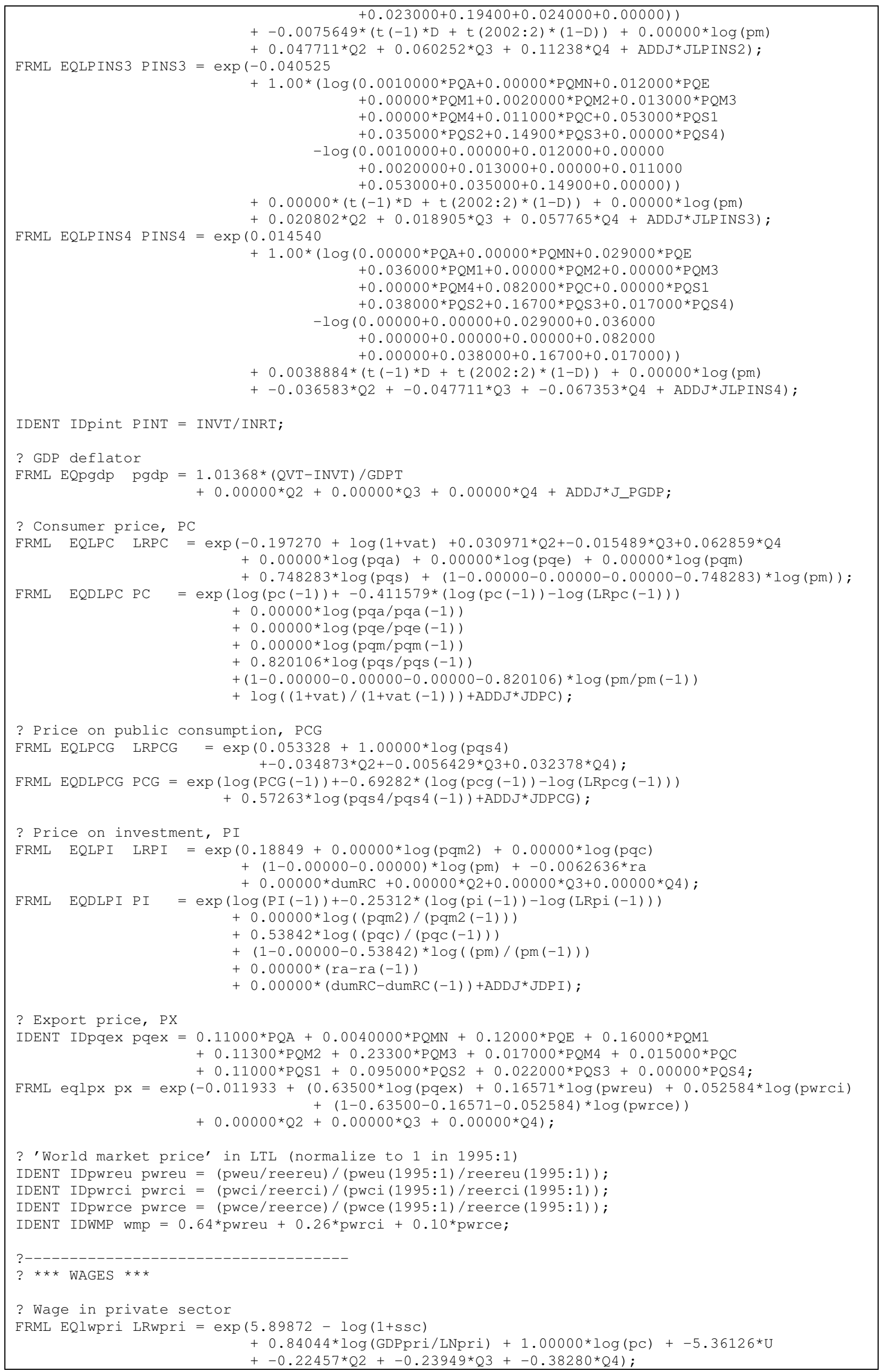




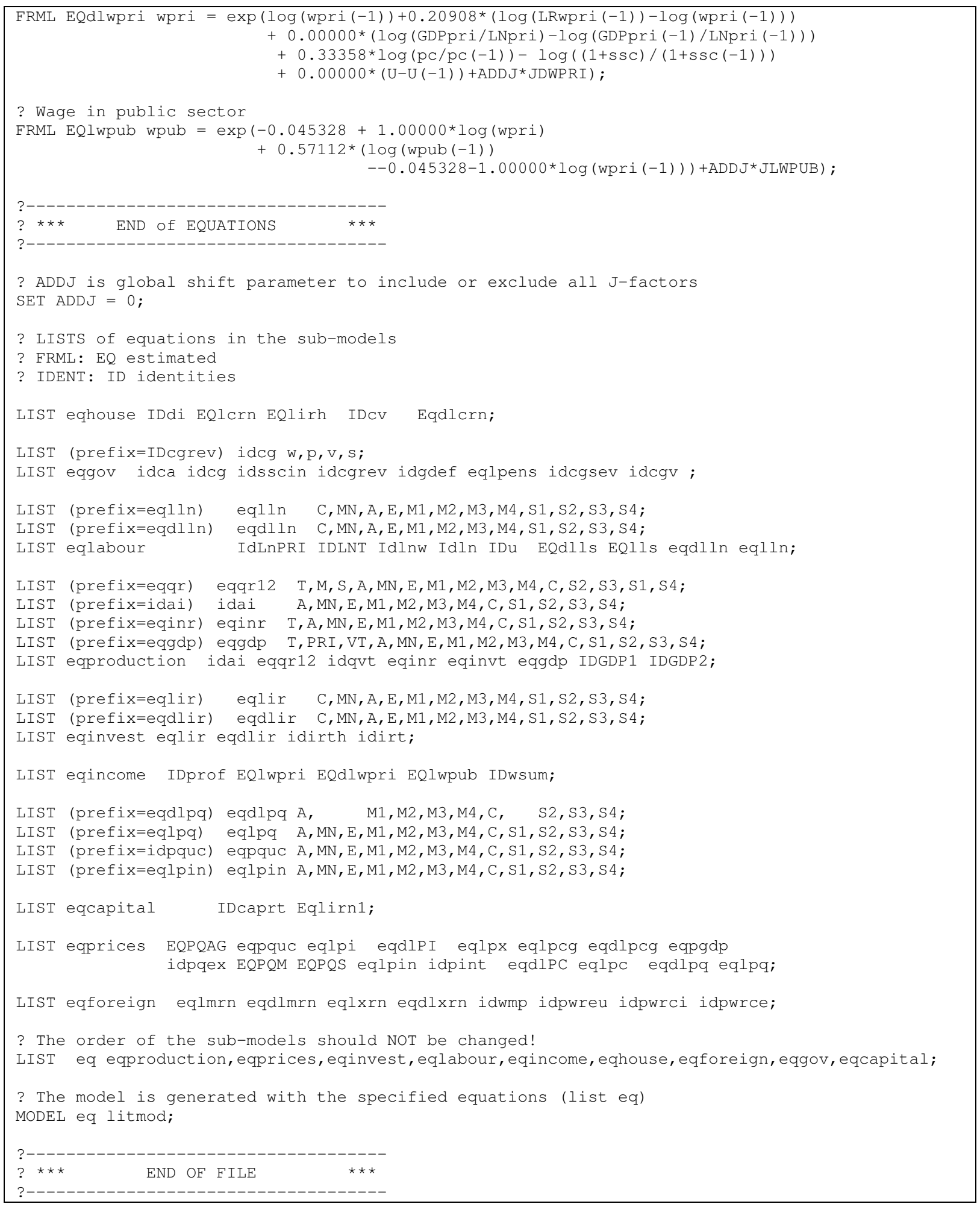




\section{List of References}

Armington, Paul (1969). A Theory of demand for Products Distinguished by Place of Production. IMF staff Papers, 26 (p. 159-178).

Carnot, Nicolas (2002). MANAGE: a small macro-econometric model of the French economy. Economic Modelling 20 (2002), 69-92.

Chan, Nagai Hang (2002). Time series: applications to finance. Willey, New York.

Don, F. J. H. and G. M. Gallo (1987). Solving large sparse systems of equations. Journal of Forecasting, 6, 167-180.

Europos komitetas prie Lietuvos respublikos vyriausybės (2003). Lietuvos integracijos i ES finansinio, ekonominio ir socialinio poveikio susisteminimas ir analizè. Vilnius, 2003.

Greene, William H. (1997). Econometric Analysis. Third edition, Prentice-Hall International.

Hall, Bronwyn H. (1999). TSP User's Guide version 4.5 Including an Introductory Guide. TSP International.

Hall, S.G., and S.G.B. Henry (1989). Macroeconomic Modelling. North Holland Publishing Company.

Kazlauskas, Arvydas, and August Leppä (2000). Two Models for the Lithuanian Economy. Lithuanian Ministry of Economy, Working Paper, 2000-10.

LEI (2003). Models for Energy Demand Forecasting in Lithuania. Lithuanian Energy Institute, Laboratory of Energy Systems Research.

Leppä, August (2000). The Lithuanian Labour Market, Some Quantitative Aspects. Lithuanian Ministry of Economy, Working Paper, 2000-10.

Parkin, Michael (1989). Macroeconomics. Addison-Wesley Publishing Company.

Pierse, Richard G. (1997). Solution Methods for Nonlinear Models. Department of Economics, University of Surey, Working Paper, November 1997.

Sliogirene, Rasa, and August Leppä (2000). The Impact of Russian Crisis in 1998 in the Lithuanian Economy. Lithuanian Ministry of Economy, Working Paper, 2000-10.

Statistics Lithuania (2002). Statistical Yearbook of Lithuania 2002. Statistics Lithuania.

Statistics Lithuania (2003). Economical and Social Development in Lithuania January-August 2003. Statistics Lithuania, 2003-8.

Theil, Henry (1966). Applied Economic Forecasting. North Holland Publishing Company.

Vetlov, Igor (2003). Monetary Transmission Mechanism in Lithuania. Bank of Lithuania, MFD Working Papers, 2003, №2. 